\title{
BLUE JUNCTION \\ IMPROVING SPATIAL EXPERIENCE THROUGH ECOLOGICAL WATER MANAGEMENT AT CARLETON UNIVERSITY
}

by

Gregory Juneau

A thesis submitted to the Faculty of Graduate and Postdoctoral Affairs in partial fulfillment of the requirements for the degree of:

\section{Master of Architecture}

Carleton University

Ottawa, Ontario

(C) 2021

Gregory Juneau 


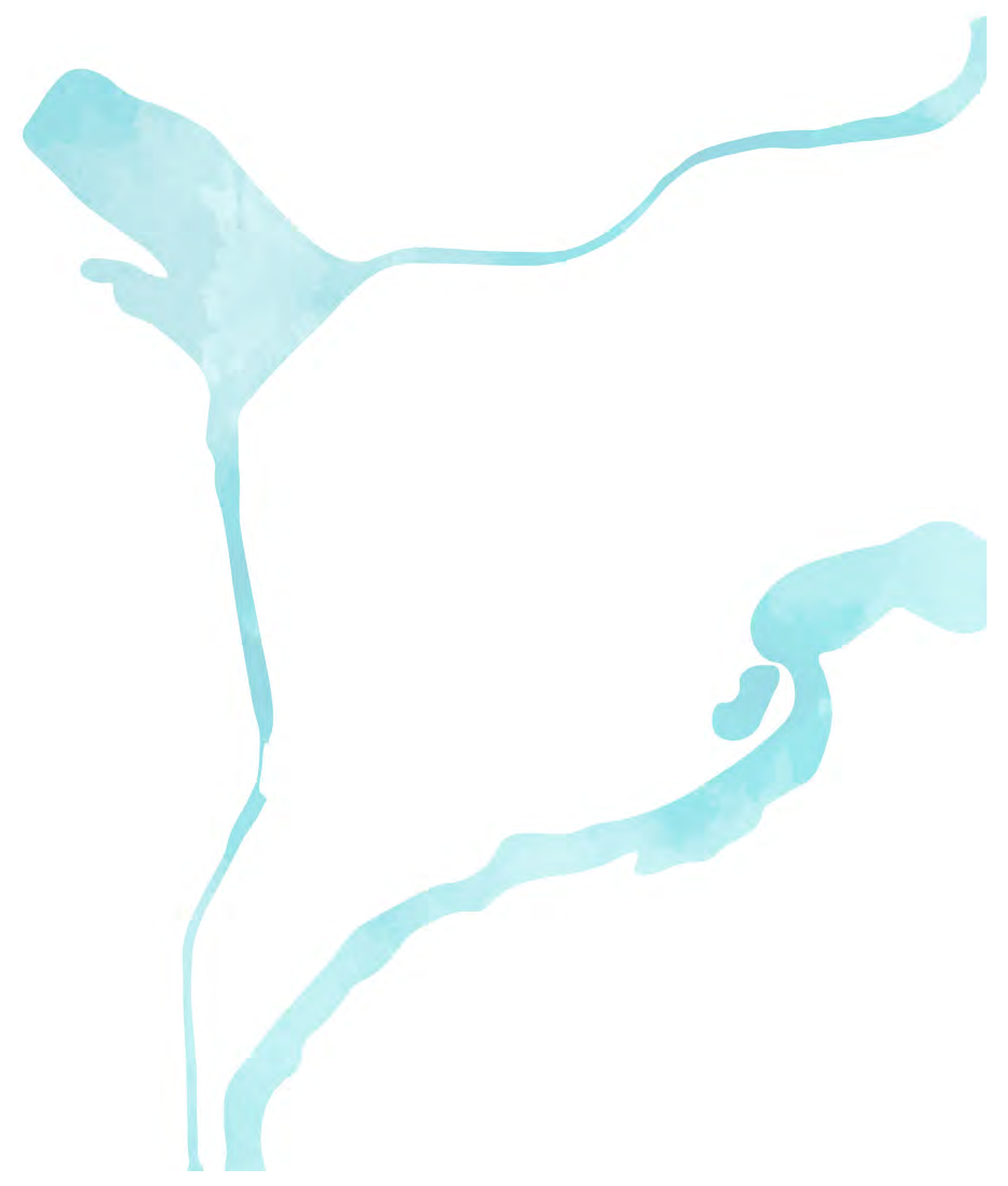




\section{ABSTRACT}

Although the earth's water supply is finite and is indispensable to the survival of all living things, it is routinely understood to be a single-use, disposable element framing a relationship which causes increasing environmental degradation. As with all things in our culture that intersect with the waste we generate, our relationship to water has resulted in strategies that largely conceal water from our daily experience. At Carleton University this camouflaging is in full effect: extensive impermeable surfaces and buried stormwater drains allow unimpeded surface runoff into the Rideau River while sewers send untreated sewage directly into Ottawa's strained sewage network. In response, this thesis explores how implementing ecological water management systems for both stormwater and wastewater at Carleton University, seen as the responsible path forward, can be entwined with architectural experience to reverse what is the secret life of wastewater and improve human relationships and attitudes towards water management. 


\section{ABSTRACT}

TABLE OF CONTENTS

LIST OF IMAGES/ILLUSTRATIONS

INTRODUCTION

1 - THE WATER PROBLEM

Water in a Global Context - Visible Stresses

Water in Canada - A Looming Crisis

Water in Ottawa - Crisis Manifest

Water and Everyday Life - Influencing a Sustainable Ideology

\section{2 - ECOLOGICAL WATER MANAGEMENT PRACTICES}

Exploring Alternatives - Natural Water Treatment Mechanisms

Wastewater Treatment - Living Machines

Stormwater Treatment - Constructed wetlands

3 - CASE STUDIES

Constructed Wetlands - Sidwell Friends School (Washington, DC)

Constructed Wetlands - Wakodahatchee Wetlands (Delray Beach, FL)

Constructed Wetlands - Shanghai Houtan Park (Shanghai, China)

Living Machine - Sechelt Water Resource Centre (Sechelt, BC)

Living Machine - Port of Portland Offices (Portland, OR)

Living Machine - Omega Centre (Rhinebeck, NY)

Living Machine - Living Machine (Burlington, VT)

4 - CARLETON UNIVERSITY SITE STUDY

Current Situation - Realities and Consequences

Opportunities for Improvements - Establishing a Proposal
5 - THE CAMPUS SPINE DESIGN PROPOSAL

New Infrastructure - Creating a Valuable Campus Landscape

Wastewater Treatment - University Centre Living Machine

Stormwater Treatment - Aqueducts

Stormwater Treatment - Wetland Canals

Stormwater Treatment - Constructed Wetland Park

Biodiverse Plantings - Selection and Dispersion

CONCLUSION

GLOSSARY

BIBLIOGRAPHY

APPENDIX 1: OTTAWA WATERSHED DATA

APPENDIX 2: ECOLOGICAL WATER TREATMENT SCIENCE

APPENDIX 3: LIVING MACHINE TECHNOLOGY

APPENDIX 4: CONSTRUCTED WETLAND TECHNOLOGY

APPENDIX 5: CARLETON UNIVERSITY SITE PHOTOS

APPENDIX 6: ADDITIONAL IMAGES
120 
Photograph showing wastewater being dumped into a waterway Photograph showing polluted water in India.

Photograph showing dead fish due to water pollution in Nigeria. Illustrated map demonstrating the drainage paths of watersheds in Canada and resulting water-stressed areas.

Photograph showing the dried out lake bed at Kluane Lake in Yukon Territory.

Photograph showing an algal bloom in Lake Erie.

lustrated map demonstrating sewer overflows located along the Ottawa sexisting main sewage networks,

Photograph of a stormwater on flooding on the Ottawa River in 2019

Pollution and advissing again

.

Photograph showing a natural wetland in Ontario.

Diagram showing ecological water treatment mechanisms.

Diagram of a conventional Living Machine

Diagram of the Organica Food Chain Reactor Living Machine

Photograph showing a Living Machine in Las Vegas, Nevada.

Photograph showing a Living Machine in Findhorn, Scotland.

Diagram of a free-water surface flow constructed wetland.

Diagram of a subsurface horizontal flow constructed wetland

Diagram of a subsurface vertical flow constructed wetland.

Photograph of a Meishe River Greenway and Fengxiang Park by

Turnescape.

Photograph of the Qinghe constructed wetland wastewater treatment

plant in Baishiyi Town, Chongqing.

Photograph of the Living Machine at Emmen Zoo in the Netherlands.

Diagram of the wastewater, stormwater, and domestic hot water heating

systems at Sidwell Friends Schoo

Photograph of the Sidwell Friends School courtyard and constructed wetlands.

Photo

Photograph of the Wakodahatchee Wetlands publci walkway.

Photon

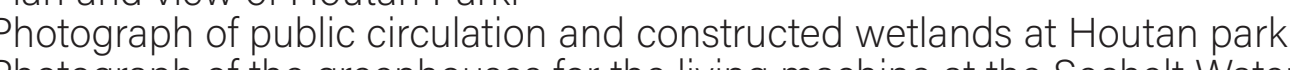
for the living machine at the Sechelt Water

Image showing the conceptual treatment processes at Sechelt Water Resource Centre.

Diagram showing the treatment processes at the Port of Portland facility Photograph of the wetland cells in the lobby at the Port of Portland facility. Diagram showing the treatment processes at the Omega Centre.

Photograph of the Living Machine at the Omega Centre.

Diagram of the Burlington Living Machine.

Photograph of the interior of the Burlington Living Machine.

Satellite Image of Carleton University.

Map of existing topographic characteristics and surface water flow at
Map of existing stormwater and wastewater networks at Carleton University.

Map of existing vehicle and transit circulation at Carleton University.

Map of existing pedestrian and bike circulation at Carleton University

Map of existing academic and public space distribution at Carleton University.

Diagram of proposed conceptual water management networks.

Map of water management opportunities at Carleton University.

Map of transportation opportunities at Carleton University.

Map of green space opportunities at Carleton Univer

Map of proposed water management interventions at Carleton University.

Map of proposed public space interventions at Carleton University.

Map of proposed new master plan for Carleton University.

Volumetric axo of the current campus.

Volumetric axo of the UC Living Machine put into the current campus.

Volumetric axo of the aqueducts put into the current campus.

Volumetric axo of the wetland canals put into the current campus.

Volumetric axo of the constructed wetland park put into the current campus.

Volumetric axo of the campus after interventions.

Volumetric axo showing the University Centre Living Machine.

Schematic diagram of proposed Living Machine system.

Plan of the University Centre Living Machine.

Transverse section of the University Centre Living Machine.

Longitudinal section of the University Centre Living Machine.

Rendering looking south at the University Centre Living Machine.

Rendering looking north at the University Centre Living Machine.

Before photograph of the University Centre Living Machine site.

After rendering of the University Centre Living Machine site.

Plan and sections of Living Machine modules.

Rendering of Living Machine modules.

Section across an aquduct where it meets a public space.

Plan and elevations of aqueduct configuration

Rendering of aqueduct configuration

Plan and elevations of aqueduct configuration 2

Rendering of aqueduct configuration 2

Plan and elevations of aqueduct configuration 3

Ren and elevations of aqueduct configur

Rendering of aqueduct configuration 4 ration 4 .

Ren and

.

After rendering of an aqueduct site.

Section along an aqueduct connecting to the wetland canal in the central spine Section along the the western canal in the central spine.

Section part 1 along the the western canal in the central spine

Section part 2 along the the western canal in the central spine.

Section part 3 along the the western canal in the central spine.

Section part 4 along the the western canal in the central spine.

Rendering looking north at the wetland cana

Rendering looking south at the wetland canal. 
Before photograph of the wetland canal site.

After rendering of the wetland canal site.

Volumetric axo showing the constructed wetland park

Plan of the constructed wetland park

Transverse section of the constructed wetland park.

Longitudinal section of the constructed wetland park.

Rendering looking southwest at the constructed wetland park.

Rendering looking southeast at the constructed wetland park.

Before photograph of the constructed wetland park site.

After rendering of the constructed wetland park site.

Rendering of the constructed wetland modules.

Table of Ontario wetland plants that can be used in the project.

Table of Ontario wetland plants that can be used in the project.

Table of Ontario wetland plants that can be used in the project.

Table of Ontario wetland plants that can be used in the project

Map of planting distribution across campus.
INTRODUCTION

Due to the perceived abundance of fresh water in Canada, our cities and institutions tend to view themselves as excluded from the looming international and global water crisis. This reflects the mentality of many Canadians who believe the myth of Canada having an endless supply of water. As a result, Canadians in fact use the second most water per capita while having the third-smallest population out of all the G7 countries! This damaging Canadian myth is leading to dire water issues arising across Canada. In recent years, rapidly expanding population, industrial development and urbanization have exerted immense environmental pressures on freshwater sources. Common practices of discharging wastewater into water bodies have created numerous negative impacts on human health and aquatic ecology. Consequently, reimagining our relationship with water is now imperative to understanding and protecting our future collective livelihood. Therefore, the pollutants must be removed/remediated in order to preserve the water environment and protect both aquatic life and health of water users downstream. ${ }^{2}$ There is a requirement for direct interventions at local scales that will hopefully influence increasing change in larger contexts around the world. However, it is only through understanding individual Canadian waterways and the ecology they support that adequate water management systems can be instilled in order to maintain these waterways for years to come.

In Ottawa, a city built on waterways, the neglectful relationship with water is also pervasive, with inhabitants rarely questioning where water comes from or where it goes after they use it. The city's limited stormwater mitigation systems, coupled with an 1 Environment and Climate Change Canada Canadian Environmental Sustainabaility Indicators: Canad's Woter Use in Globe Context (Gatineau: Environment and Climate Change Canada, 2016), 4.

2 Golda A. Edwin and G Poyyamoli M. Nandhivaman Ramaswamy Arun Prasath. Dwipen Boruah. "Constructed Wetlends for the Treatment of Grey Water in Campus Premises" in Implementing Campus Greening Intitatives: Approaches Methods and Perspectives, eds. Walter Leal Filho, Nandhivarman Muthu, Golda Edwin Mihaela Sima (Switzerland: Springer International Publishing, 2015), 338, https://doi-org. proxy.library.carleton.ca/10.1007/978-3-319-11961-8. 
antiquated water management network, lead to widespread flooding along the Rideau and Ottawa Rivers on a yearly basis. Furthermore, continued pollution from combined sewer overflows during numerous annual storm events causes additional detrimental effects. These consequences are a common occurrence and polluted waterways are mostly an accepted reality within the city.

Being upriver from downtown Ottawa, and bordered by both the Rideau River and Rideau Canal, Carleton University potentially has an important role in managing and maintaining the surrounding waterways. As an educational institution with a leadership role in the city, Carleton University has both the opportunity and responsibility to help change the current mindset that Ottawa's inhabitants have towards water use that can hopefully translate to the national and global scale. However, as it stands, Carleton engages in minimal efforts when it comes to sustainable stormwater or wastewater management principles. On the campus, limited stormwater management and extensive impermeable surfaces produce excessive runoff that contributes to downriver flooding of both the Rideau and Ottawa Rivers while its single sanitary sewage outlet adds to the strain on Ottawa's overburdened sewer system resulting in combined sewer overflows during storm events. Solving this problem will require engineered architectural solutions to improve the campus' relationship with water. Accordingly, central to the exploration of this thesis project is whether a combination of decentralized collection strategies and intensified points of treatment could offer an infrastructural and experiential solution to better manage sewage and stormwater locally on Carleton University's campus. Thus, in addition to improving the spatial experience on campus, the goal is to reduce its impact on Ottawa's already strained water system and protect Ottawa's waterways
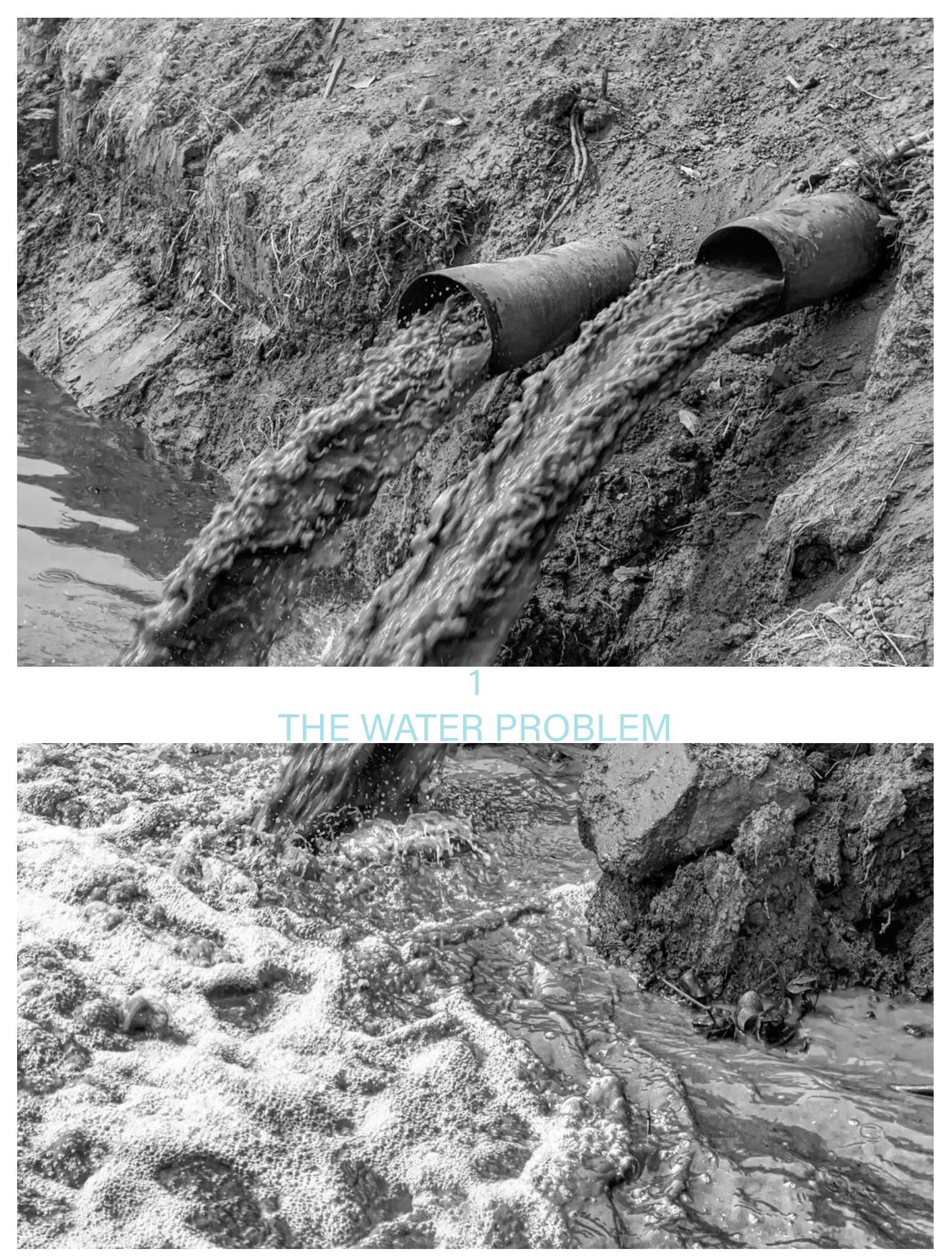

Figure 1: Photograph showing wastewater being dumped into a waterway. (The Independent from Getty Images, https: / / www.
independent.co.uk/environment/world-water-day-2019-floods-drought-pollution-plastic-waste-28833616 html) 
The earth is currently experiencing its sixth mass extinction and, while the first five had physical causes (comet impacts, abrupt climate shifts, etc.), the present one can be directly attributable to the actions of a single species: humans. ${ }^{3}$ One of the major resources contributing to this reality is water. Water is essential to life in every form; we cannot exist without it. However, although water covers about two-thirds of the earth's surface, only $3 \%$ of this volume is freshwater with two-thirds of that being locked in ice and much of the remainder being locked underground. ${ }^{4}$ Therefore, a mere $1 \%$ of earth's water is used to support all life on land. ${ }^{5}$ Because of this ratio, water is understood as one of the world's most valuable resources and has even been referred to as "blue oil." 6 The importance of water extends much further beyond the surface of our everyday lives than humans tend to think.

Freshwater ecosystems provide many services that humans rely upon including visible examples such as drinking water or hydroelectric production, and less visible examples such as erosion control and water retention. ${ }^{7}$ The effects that water quality and quantity have on these complex systems cannot be overstated. These aquatic habitats are constantly changing and gain stability from complex interactions of chemical, biological, and physical fluctuations which support all forms of life and maintain equilibrium. ${ }^{8}$ With all life on Earth depending upon these systems, their health and functionality is made even more important when considering that small alterations

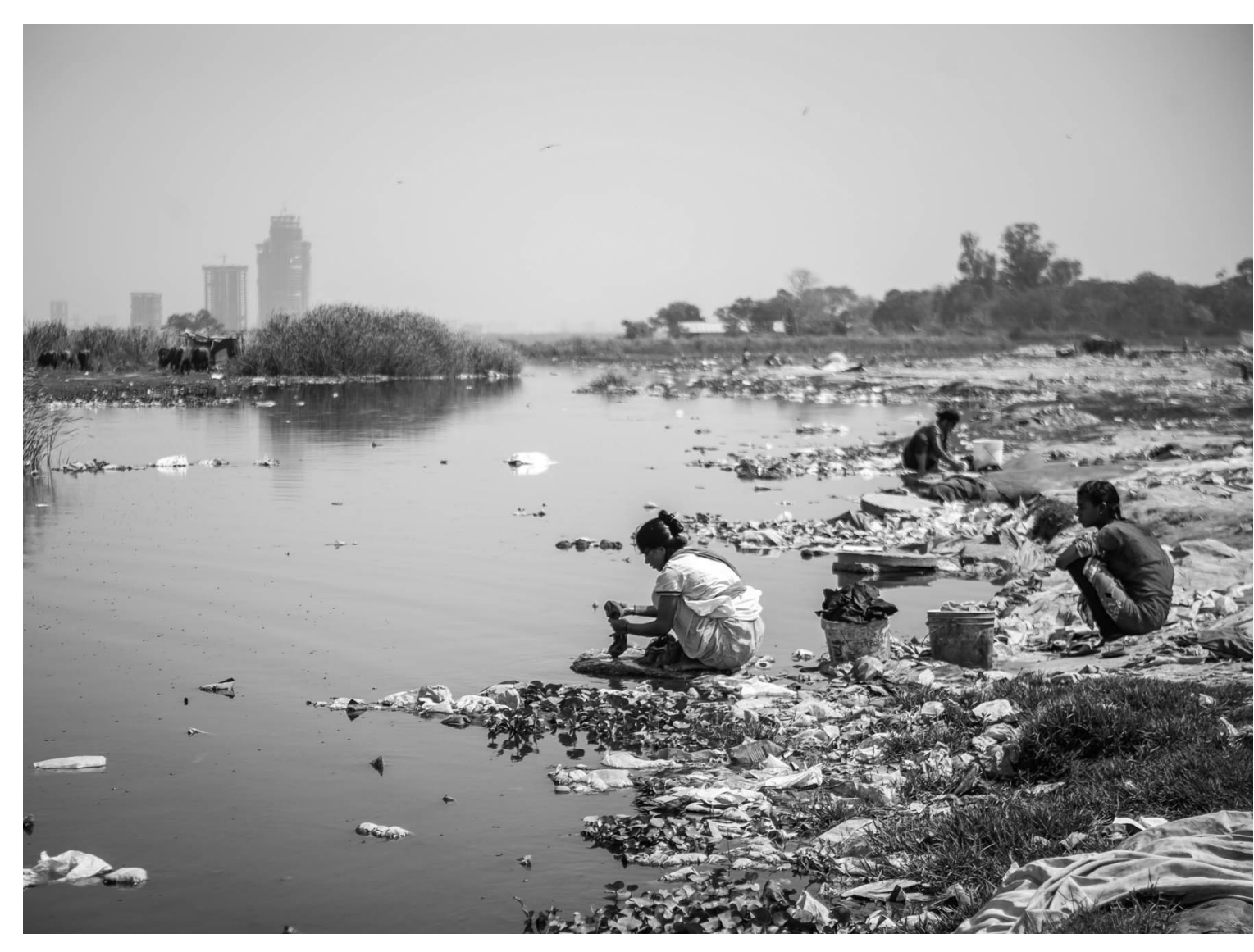

3 Ottawa Riverkeeper, "Ecology and Impacts," Ottawa Riverkeeper's River Report, no. 1 (May 2006): 62, accessed January 9, 2021 https://www.ottawariverkeeperc.ca/wp-content/uploads/2018/01/River-Report-English.pdf.pdt 4 Zoe Ryan, Building with Water: Concepts, Typology, Design (Basel: Birkhauser GmbH, 2010) 5 Zoe Ryan, Buld ding with Water: Concepts, Typology, Design, 7.

7 National, Round Table on the Environment and the Economy. Changing Currents: Water Sustainability and the Future of Canada's Natural Resource Sectors (Ottawa: National Round Table on the Environment and the Economy, 2010), 26. 8 National Round Table on the Environment and the Economy. Changing Currents: Water Sustainability and the Future of Canada's Natural Resource Sectors, 37 . 
to the timing and volumes of flow, quality, and temperature of freshwater, create incremental effects to both aquatic and terrestrial ecosystems. ${ }^{9}$ Therefore, freshwater is vital in maintaining the health of ecosystems, biodiversity, and, by extension, human beings. ${ }^{10}$ One would think that the important functions of these ecosystems would lead to them being respected by all humans but this is not the reality.

With the rapid development of both human society and the constant changes upon the natural environment, sources of water have been consistently dwindling and water quality is continuously degrading." In response, water is a resource that we are forever trying to preserve, conserve, clean and re-use, but also an element we continue to fight against, barricading ourselves against rising sea levels from melting polar ice caps and flooding.12 Thus, the relationships that humans have with freshwater are not reflective of this natural scarcity.13 Typically, humans take clean, treated water, use it once, and then flush it away without a second thought.14 As a result, water shortage has become a prominent problem that restricts the sustainable development of human society and conservation of the natural environment. ${ }^{15}$ Worldwide 1.1 billion people lack access to safe drinking water and 2.4 billion lack adequate sanitation leading to 5,400

\footnotetext{
9 National Round Table on the Environment and the Economy. Changing Currents: Water Sustainability and the Future of Canada's Natural Resource Sectors, 26 10 National Round Table on the Environnent and the Economy. Changing Currents: Water Sustainability and the Future Canada's Natural Resource Sectors, 34 II Shenying Gong, Yanting Wang and Jie Fu, "Advanced Treatment of Campus Sewage by MV/UV/O3 for Water Reclamation," In Green Engineering for Campus Sustainability, ed. Abu Zahrim Yaser (Singapore: Springer Nature Singapore Pte Ltd, 2020), 245,

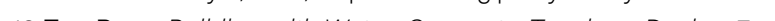

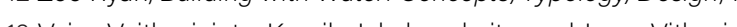

Cleaning and Reusing of Wastewater

Passing

Kamile Jakubauskaite and Jurga Vitkuviene, "Ecological Cleaning and Reusing of Wastewater: Possibilities,

15 Shenying Gong, Yanting Wang and Jie Fu, "Advanced Treatment of Campus Sewage by MV/UV/O3 for Water Reclamation,"
} 16 Pollution Probe, "A New Approach to Water Management in Canada," 5, published March 2008, accessed January 9,
2021 , https:///books-scholarsportal-info.proxylibrary.carleton.ca/en/read? ?id=/ebooks/ebookso/gibson_cppc/2009-1201/10/252172\#page $=2$.

17 Pollution Probe, ANew Approach to

(8) Sveinung Saegrov, Leif Sigura Halskjold, Axel Konig, Jon Ronstum, Ingrid Selseth, Froydis Sjovold, "Wastewater Network

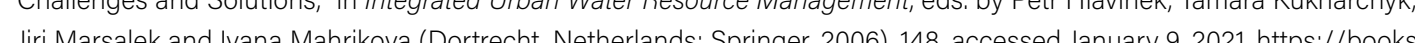

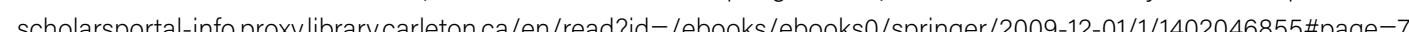
19 National Round Table on the Environment and the Economy Changing Currents, Water Sustainability and the Future of Canad's Natural Resource Sectors 17

20 Zoe Ryan, Building with Water: Concepts, Typology, Design, 7. world's known freshwater species have become extinct, threatened or endangered.7 Worldwide, sewer and stormwater systems suffer from various deficiencies such as cannot function properly or deliver ecosystem services without reliable and clean sources of freshwater. ${ }^{19}$ Given the increasing emphasis on environmental approaches to living, working and playing, water has recently become central to discussions about new architecture and urban planning. ${ }^{20}$ There is an understanding that, although there issues associated with water use, investigations of stormwater and wastewater with the impacts of our unsustainable relationship with water beginning to show. 
In Canada, rivers, lakes, snow and ice are part of our national identity. ${ }^{21}$ Both nationally and internationally, Canada is perceived as a water-rich nation having access to approximately $20 \%$ of the world's surface freshwater supply while only containing $0.5 \%$ of the world's population.22 Possessing some of the largest lakes in the world and thousands of smaller lakes scattered across its landmass, Canada has $12 \%$ of its total surface area covered by surface freshwater, 14\% by wetlands and 200,000 km2 of

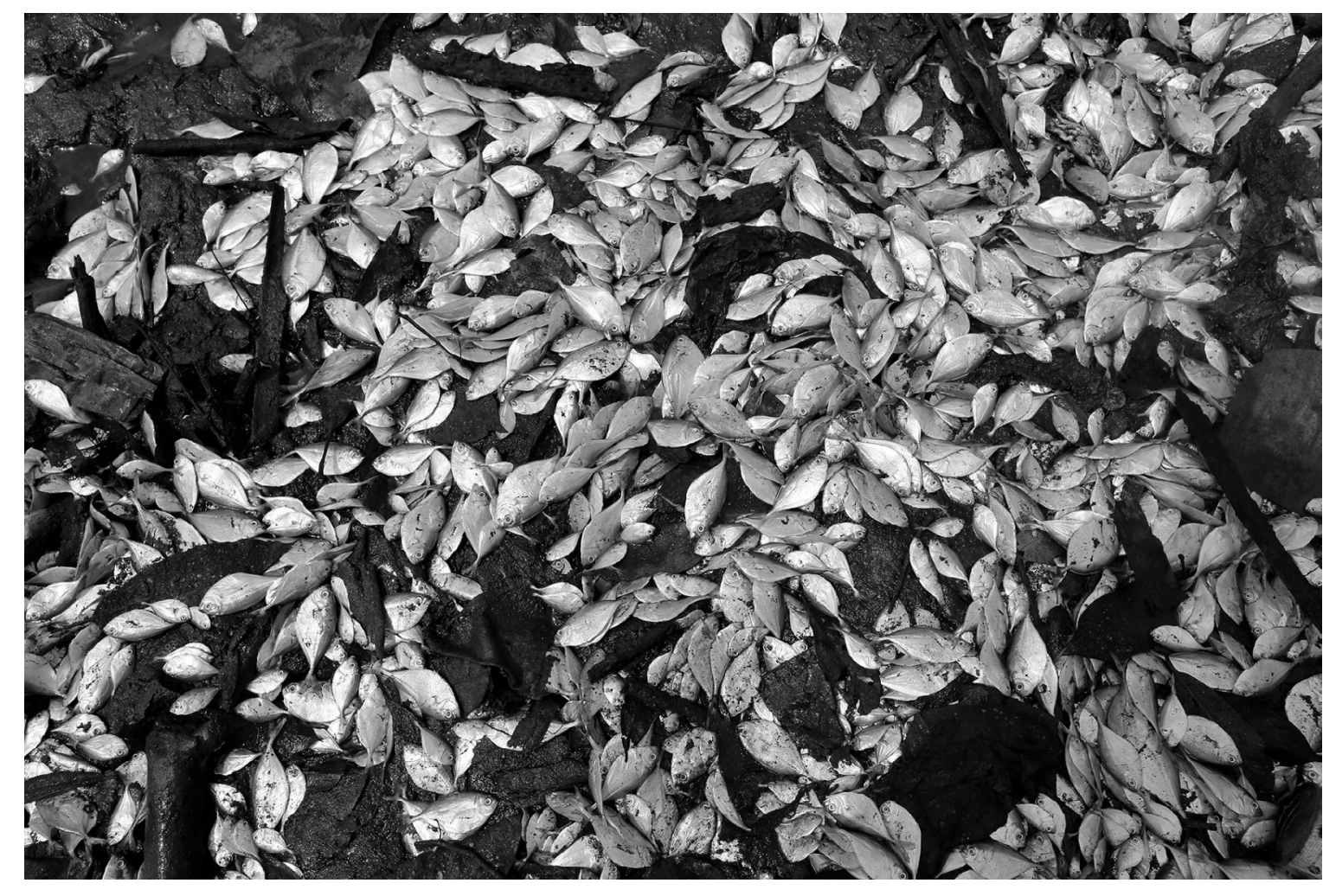

Figure 3: Photograph showing dead fish due to water pollution in Nigeria., (https://www.bloomberg.com/news/
articles/2020-05-15/heavy-metal-pollution-causes-mass-fish-deaths-in-nigeria) glacier cover. ${ }^{23}$ This amounts to an average annual renewable freshwater supply (water yield) of 3,472 km3; a total that is higher than most drier countries but is still only $36 \%$ of the water yield in Brazil and $60 \%$ of the water yield in India. ${ }^{24}$ This apparent water bounty foreshadows a larger water issue in Canada.

The main issue in Canada is that, although water is abundant on the national scale, there are strategic water problems and shortages at regional scales due to the uneven distribution of population and water supplies as well as attitudes towards water consumption. ${ }^{25}$ For example, $98 \%$ of Canadians live in the warmer southern parts of the country where the renewable freshwater supply is only $38 \%$, whereas most of Canada's freshwater flows north where the population is scarce. ${ }^{26}$ Water problems caused by population increase, urbanization, economic development, and climate change are on the rise, and have all started to pose a threat to both the quality and quantity of 21 Pollution Probe, "Towards a Vision and Strategy for Water Management in Canada," 5, published April 2007, accessed January 9, 2021, hitps://books-scholarsportal-info.proxy.library.carleton.ca/en/read? id=/ebooks/ebookso/gibson_cppc/2009-12$01 / 6 / 206684 \#$ page $=1$.

22 National Round Table on the Environment and the Economy. Changing Currents: Water Sustainability and the Future of Canada's Natural Resource Sectors, 15

23 Banu Ormeci, "An Overview of Water Supply, Use and Treatment in Canada," in Urban Water Challenges in the Americas: A Perspective from the Academies of Sciences, edited by Katherine Vammen and Adriana de la Cruz Molina (Paris, France: UNESCO, 2015), 114, a acess__book_2015.pdf.

24 Banu Ormeci "An Overview of Water Supply Use and Treatment in Canada" 114

25 Banu Ormeci, "An Overview of Water Supply, Use and Treatment in Canada," 114,

26 Banu Ormec: "An Overview of Wher Supply, Use and Treatment in Canda" 114 
surface waters and groundwater. ${ }^{27}$ As the population grows and pressure for industrial and agricultural uses of water increases, water supplies will become more and more vulnerable to contamination and overuse while climate change will continue to increase pressure and risks to water availability. ${ }^{28}$ Even though this challenges the image that Canadians have of their country, dramatic consequences of failing to prepare for this issue can already be seen in many places around the world. ${ }^{29}$ Given these precedents and evidence across the globe, Canada must begin taking pro-active measures in order to avoid these similar plights seen around the world. In order to challenge this reality, the combined human and environmental factors influencing the current circumstances must be better understood.

The primary human factors leading to the water crisis in Canada involve increased water withdrawals and water contamination that can stress water resources and pose a threat to aquatic ecosystems. ${ }^{30}$ As a result of the perceived abundance of water and its low cost to citizens, Canadians are among the highest water consumers per capita in the world. In 2009, Canadians consumed 298 litres per person per day, a figure twice as high when compared to France and slightly less than US statistics. ${ }^{31}$ In fact, Canada has the second highest consumption of water per capita in the world, more than double that of the European average. ${ }^{32}$ Furthermore, in the coming years, water demands are predicted to increase drastically with Canada's population expected to increase by $25 \%$ by 2050 and the Canadian economy predicted to grow approximately $55 \%$ by $2030 .{ }^{33}$ This will only put further pressure on our currently unsustainable water

27 Banu Ormeci, "An Overview of Water Supply, Use and Treatment in Canada," 126

28 Pollution Probe, "Towards a Vision and Strategy for Water Management in Canada," 5.

30 Bnu Oreci "An Overview of Water Supply Use and Treatment in Canad" 115-116

31 Banu Ormeci "An Overview of Water Supply Use and Treatment in Cana, "17-118

32 Pollution Probe. "Towards a Vision and Strategy for Water Management in Canade" 41

33 National Round Table on the Environment and the Economy Changing Currents: Water Sustainability and the Future of Canada's Natural Resource Sectors, 15 .

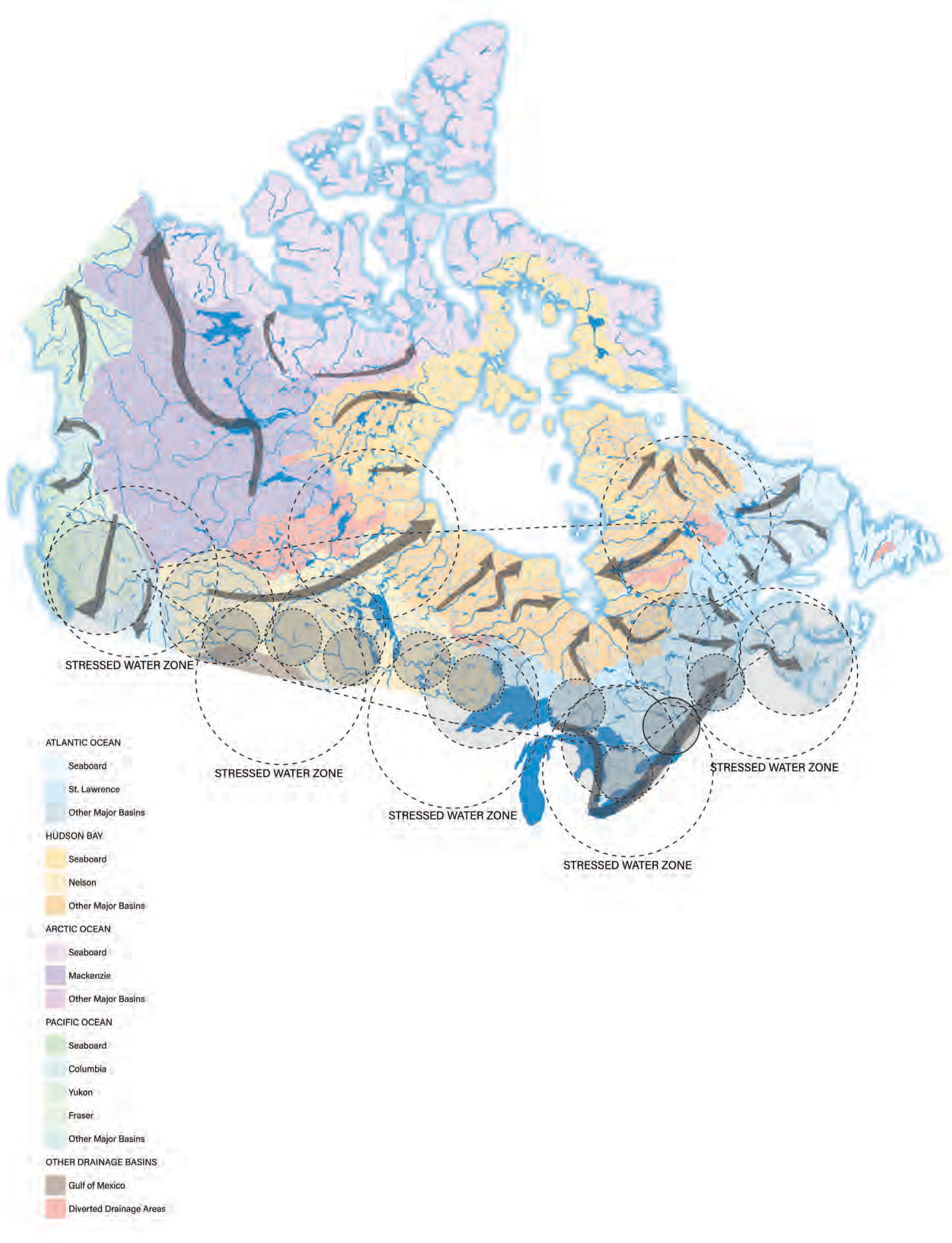

Figure 4: Illustrated map demonstrating the drainage paths of watersheds in Canada and resulting water-stressed areas. 
Canada uses a supply-oriented water model where, when more water is needed, it is either withdrawn from existing sources or new sources are located instead of sustainably managing existing sources and protecting future resources through ecological maintenance. ${ }^{34}$ This new water is usually inexpensive to access, providing a low cost to the consumer that does not reflect its true value. ${ }^{35}$ This reveals the Canadian attitude towards water reflecting the belief that no matter how much water is used, the bounty of the country will always supply more. Also, because the harvested water is all supplied by the same system, it is all treated to the same level no matter what its fina use will be. ${ }^{36}$ This means that even if the water will be used to flush toilets, it is treated to drinking water quality, which can mean using uneccessary resources and energy in the process depending on use. These factors produce little incentive to conserve water or ensure that available water is put to the best possible use when considering its quality. ${ }^{37}$ These issues can be directly attributed to the outdated water management approaches affecting both sourcing and treatment that are present throughout Canada.

Currently, inadequate water management systems across the country result in the extensive pollution of its waterways. In Canada, wastewater treatment levels vary greatly between provinces. ${ }^{38}$ Within this context, no treatment means raw sewage as is, preliminary treatment is the removal of grit and large objects, primary treatment is the removal of solids using settling tanks, secondary treatment is the biological removal of organic matter, and tertiary treatment is the removal of mainly nutrients such as nitrogen and phosphorus, ${ }^{39}$ In Newfoundland and Labrador, approximately 34 Pollution Probe, "Towards a Vision and Strategy for Water Management in Canada," 41.
35 Pollution Probe, "Towards a Vision and Strategy for Water Management in Canada," 41.
36 Pollution Probe, "Towards a Vision and Strategy for Water Management in Canada," 41.
37 Pollution Probe, "Towards a Vision and Strategy for Water Management in Canada," 41.
38 Banu Ormeci, "An Overview of Water Supply, Use and Treatment in Canada," 121.
39 Banu Ormeci, "An Overview of Water Supply, Use and Treatment in Canada," 119.
$50 \%$ of wastewater does not receive any treatment and a further $40 \%$ receives only preliminary treatment. In the territories, close to $60 \%$ of wastewater does not receive treatment while the remaining 40\% received secondary treatment. ${ }^{40}$ Even in Quebec British Columbia, New Brunswick and Nova Scotia, 40-65\% of wastewater does not receive any biological treatment and is limited to preliminary and primary treatment. ${ }^{4}$ The best results are found in Ontario, Manitoba, Saskatchewan and Alberta, where more than $90 \%$ of wastewater received biological or superior treatment before being released, although tertiary treatment was minimal in Ontario and Manitoba. ${ }^{42}$ This means that, due to inadequate water management approaches, large amounts of undertreated water are being released into waterways on an annual basis affecting water quality and availability, as well as impacting ecosystems. In fact, in terms of urban runoff, in the Canadian Great Lakes region alone, annual discharges amount to 105 tonnes of suspended solids, 104 tonnes of chloride, 103 tonnes of oil and grease, and 102 to 103 tonnes of trace metals released into waterways. ${ }^{43}$ Additionally, on average, over 150 billion litres of untreated or undertreated sewage are dumped into waterways every year in Canada. ${ }^{44}$ Therefore, water management occupies an important role for the maintenance of Canadian ecosystems and helps to create a reliable water supply meaning it must be considered within the sustainability discourse in order to achieve broader goals.

As mentioned, in tandem with human factors impacting water availability, environmental factors influenced by climate change also play an important role in water quality and availability in Canada. Water resources are already overused due to 40 Banu Ormeci, "An Overview of Water Supply, Use and Treatment in Canada," 121 4i Banu O mimeci, "An Overvew of Water Supply, Use and Treatment in Canada," 21

43 Environment Canada, "Threats to Sources of Drinking Water and Aquatic Ecosystem Health in Canada," NWRI Scientific Assessment Report Series, no. 1 (Burlington, Ontario: National Water Research Institute, 2001): 47, accessed January 9, 2021, http:// publications.gc.ca/collections/Collection/En40-237-1-2001E.ppd.

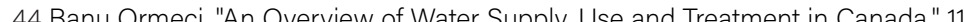




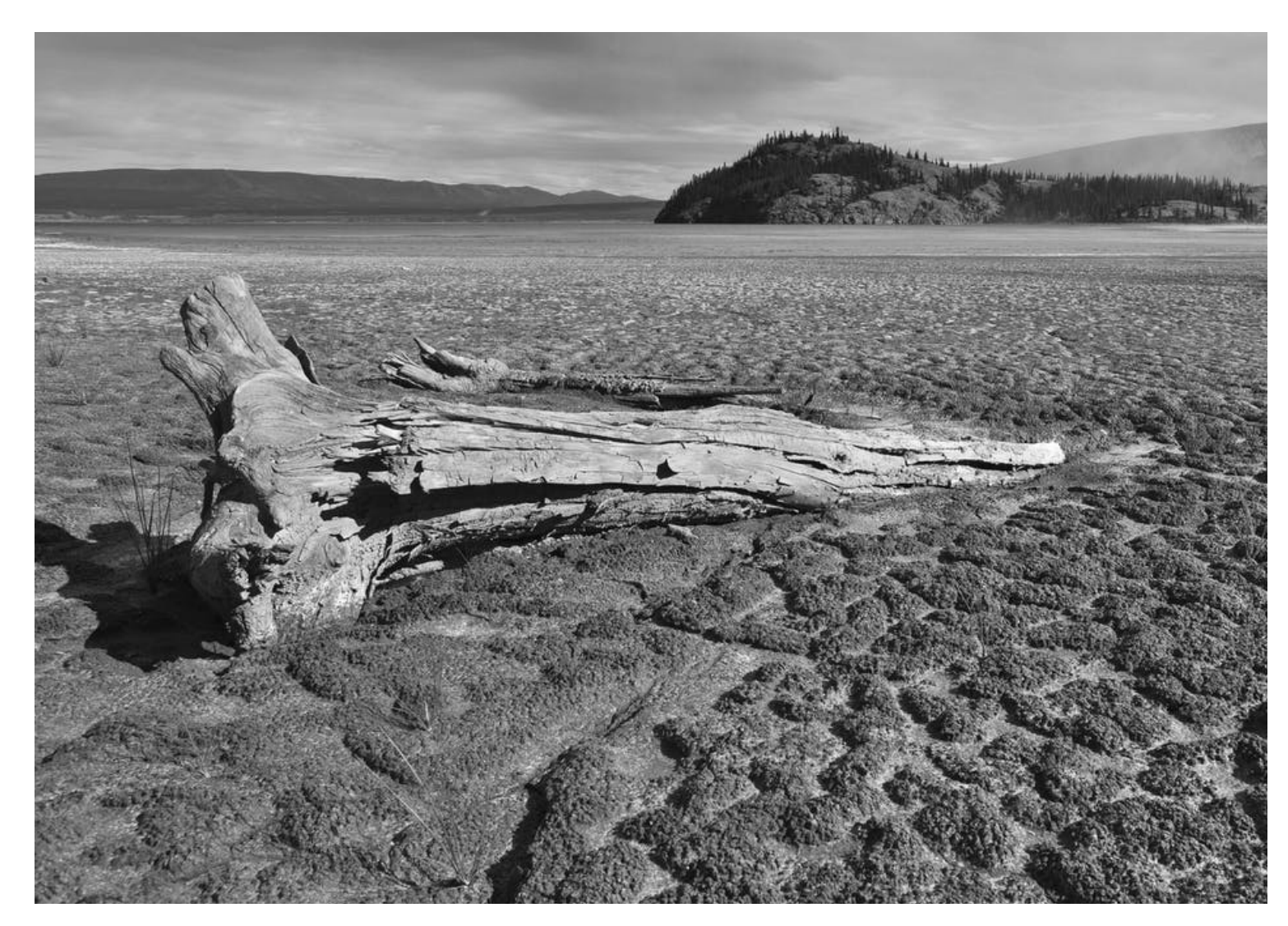

Figure 5: Photograph showing the dried out lake bed at Kluane Lake in Yukon Territory. (https://theconversation.com/how-cana-
da-can-solve-its-emerging-water-crisis-114046) rapid economic and population growth in Southern Canada, and climate change will only exert additional water stress. ${ }^{45}$ Based on 2014 global climate models, precipitation was predicted to increase between 3 and 15 percent when $\mathrm{CO} 2$ is doubled in the atmosphere, ${ }^{46}$ This will lead to an increase in severe weather events such as majo storms, hurricanes, floods, droughts, and ice melts that will increase the carriage of sediments, nutrients and a wide range of pollutants including fertilizers, pesticides and endocrine disrupting compounds into surface waters and aquifers. ${ }^{47}$ In addition, the increased frequency and strength of rain and storm events is expected to increase sewer overflows and the discharge of untreated sewage to surface waters, which is already a grave problem in most Canadian cities ${ }^{48}$ Therefore, climate change will lead to a shift in the seasonal availability and distribution of water, effects of which are already being noticed in many regions in Canada, and will further increase the competition among municipal, industrial and agricultural use of water in Canada in the near future. ${ }^{49}$ Overal precipitation is expected to increase slightly in the north and decrease slightly in the south and west, with less in the summer and more during intense events resulting in declines in annual streamflow, declines in groundwater recharge, increased evapotranspiration, and lower summer water supplies. ${ }^{50}$ In Ontario and Quebec alone, nutrient-enriched lakes and warmer temperatures have already resulted in toxic blue-green algae blooms making the water unsuitable for human consumption. ${ }^{51}$ Further pressures exerted by climate change on water resources are also expected to be felt across the country and will continue affecting run-off and evaporation patterns, the amount of water stored in

45 Banu Ormeci, "An Overview of Water Supply Use and Treatment in Canada," 124

45 Banu Ormeci, "An Overview or Water Supply, Use and Trealmentin Canada," 124.

46 Banu Ormeci," An Overview or Water Supply, Use and Treatment in Canada," 244-125.

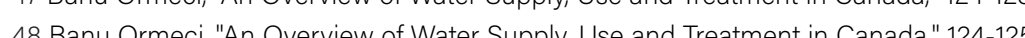

498 Banu Ormeci "An Overview of Water Supply, Use and Treatment in Canade" 124.

50 National Round Table on the Environment and the Economy Changing Currents: Water Sustainability and the Future of Canada's Natural Resource Sectors, 131-132.

51 Banu Ormeci, "An Overview of Water Supply Use and Treatment in Canada" 124-125. 
glaciers, snowpack, lakes, wetlands, soil moisture, and groundwater. ${ }^{52}$ These extensive consequences will result in declines in water quality and quantity that are already being noticed in certain areas and will continue to increase in amplitude if positive human interventions continue to be avoided.

These examples demonstrate that Canada's waterways and drinking water sources are threatened by various environmental and human factors that include, but are not limited to: waterborne pathogens, algal toxins and taste and odour, pesticides, persistent organic pollutants and mercury, endocrine disrupting substances, nutrients (nitrogen and phosphorous), aquatic acidification, ecosystem effects of genetically modified organisms, municipal wastewater effluents, industrial point source discharges, urban runoff, landfills and waste disposal, agricultural and forestry land use impacts, natural sources of trace elements contaminants, impacts of dams, diversions and climate change. ${ }^{53}$ These various detriments can all be attributed to the mismanagement of water resources and inadequate water management systems. The solution will not be found with our current water allocation methods. Most of the water allocation approaches in Canada are based on historical policies that promoted settlement and development throughout the country when water was plentiful and there were limited competing uses for water sources. ${ }^{54}$ Nowadays, there are several competing uses for water and, with the certainty of an increased demand due to human factors coupled with a reduction in supply due to environmental factos, water management approaches need to be rethought in Canada to protect our water supply. ${ }^{55}$

Due to the availability of cheap and plentiful water from municipal services, 52 National Round Table on the Environment and the Economy. Changing Currents: Water Sustainability and the Future of Canada's Natural Resource Sectors, 16.

53 Environment Canada. "Threats to Sources of Drinking Water and Aquatic Ecosystem Health in Canada," 47

54 National Round Table on the Environment and the Economy. Changing Currents: Water Sustainability and the Future of

Canada's Natural Resource Sectors, 142

W Canada's Natural Resource Sectors, 142
Canadians do not perceive a water supply problem. ${ }^{56}$ However, there has been a decreasing trend in residential water use since 2006 indicating a slowly shifting ideology towards a more sustainable approach to water use. ${ }^{57}$ Furthermore, as of 2010, more than eight in 10 Canadians believed that Canada would have a shortage of freshwate if sustainable water management programs were not put in place. ${ }^{58}$ But, while many Canadians are concerned about water, due to a lack of awareness, an unavailability of alternatives, and an unequal sharing of the burden, there is a disconnect between what people say is important and the actions they are prepared to take..$^{59}$ The hope remains that, if awareness and management principles can be widely promoted, change can be made. This will certainly take time and this slow shift may not be enough to tip the scales and improve the outlook on water in Canada. In the meantime, the human and environmental factors continue to stress the ecosystem.

One way that the relationship with water can be improved is in the domain of water management and water reuse. Due to current stresses on the water supply, there is a growing incentive to explore possibilities for water and wastewater reclamation and reuse. ${ }^{60}$ If water is being reused, an incentive is created for its treatment that can be extended towards general water management principles. In order to develop a holistic approach to integrated water management, water reuse provides the opportunity to ease the current stresses on the water supply by simultaneously promoting environmental sustainability through conservation of water resources and reduced

\footnotetext{
56 Pollution Probe, "Towards a Vision and Strategy for Water Management in Canada," 41. 57 Banu Ormeci, "An Overview of Water Supply, Use and Treats 58 National Round Table on the Environment and the Economy. Changing Currents: Water Sustainability and the Future of ural Resource Sectors, 134

Whand Strategy for Water Management in Canada" 41.
} 
wastewater discharges to receiving waters. ${ }^{61}$ However, compared to other countries, water reuse in Canada has been practiced infrequently and only on a small-scale or experimental basis using decentralized wastewater reclamation and water reuse in individual homes and clusters of homes or isolated industries, service operations and institutional facilities.62 The main applications of wastewater reclamation and water reuse in Canada have been for agricultural and landscape irrigation, with these practices being well established in Western Canada and tested for over 30 years. ${ }^{63}$ Alternatively, industrial water recycling is fairly common in Canada and, while industry accounts for over $80 \%$ of total water intake, approximately $40 \%$ of this intake water is typically recycled for separate purposes. ${ }^{64}$ The extent to which water reuse is adopted depends on water availability, economic incentives, regulatory feasibility, and public acceptance. ${ }^{65}$ With this in mind and in the face of climate change and human impacts on water, the response of water users to climate change, including the implementation of adaptive water management and reuse approaches, will be critically important part of an integrated approach to sustainability in order to ensure the future sustainability of water across Canada. ${ }^{66}$ The proliferation of sustainable water management systems in Canada will require more local and site-specific examples to draw from in order to encourage regional and national community engagement for the purposes of change.

61 Kirsten Exall, Jiri Marsalek and Karl Schaefer, "Water Reuse in Canada: Opportunities and Challenges," in Integrated Urba Water Resource Management, edited by Petr Hlavinek, Tamara Kukharchyk, Jiri Marsalek and Ivana Mahrikova (Dortrechi, Netherlands. Springer, 2006), 254, accessed January 9 , 2021, hitps.///books-scholarsportal-info.proxy.library.carleton.ca/en/ (2)

(2) Dportunities and Challenges," 25

64 Kirsten Exall

65 Kirsten Exall Jiri Marsalek and Karl Schaefer "Water Reuse in Canada. Opportunities and Challenges", 250

66 National Round Table on the Environment and the Economy Changing Currents: Water Sustainability and the Future of Canada's Natural Resource Sectors, 16

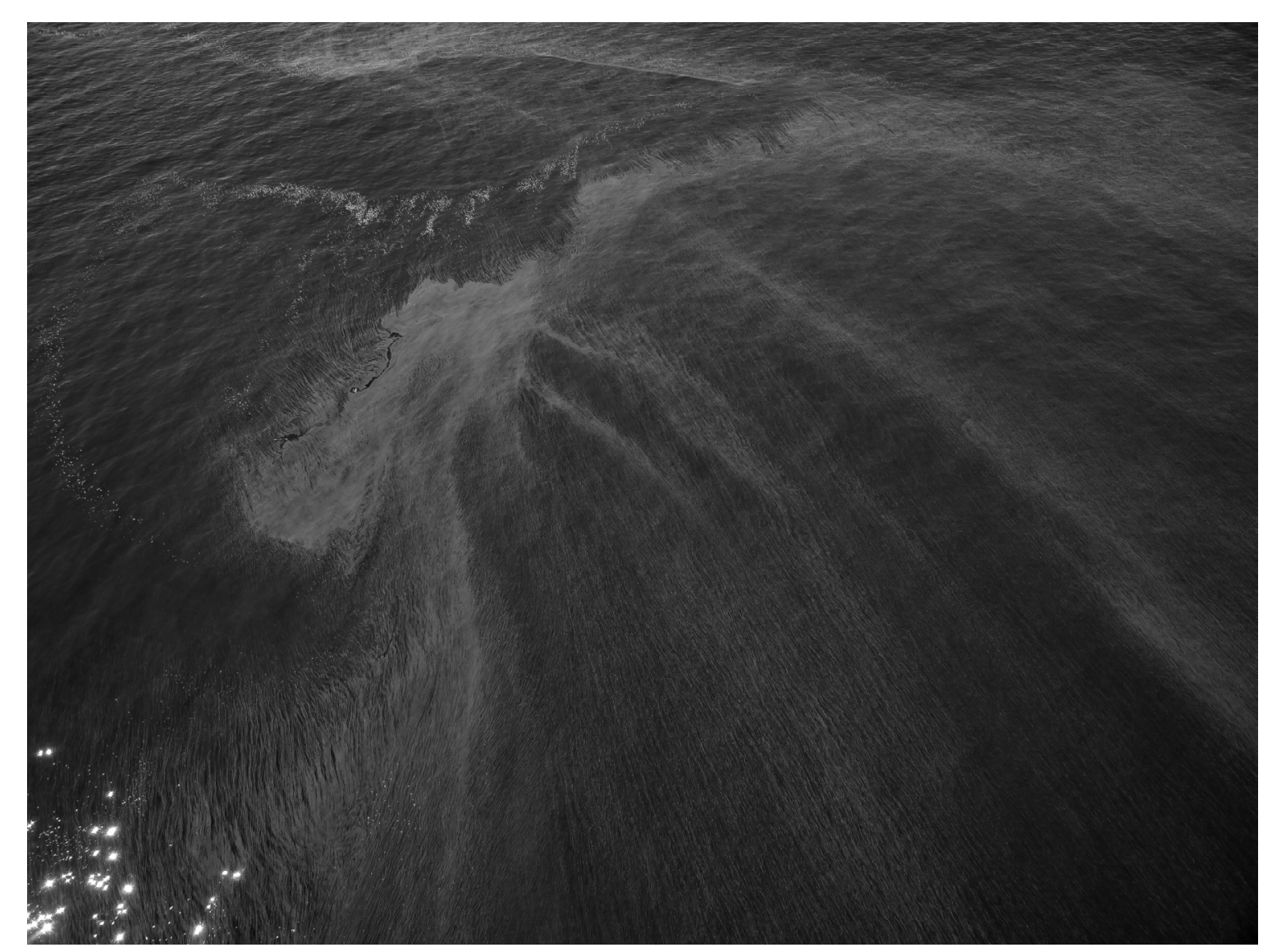


The Canada-wide issues with regards to watershed deterioration and wate management can also be observed within the context of Ottawa's waterways. By examining these local conditions, strategies may be identified to begin addressing the various crises identified. Bordered by the Ottawa River and bisected by both the Rideau River and Rideau Canal, Ottawa is a city dominated by waterways that are integral to its identity. However, even though water is ingrained within the city's identity, the relationship that the city has with its waterways reflects the norm throughout Canada and demonstrates a clear lack of sustainable regulation or consideration for the conservation and protection of the environment

A review of the literature covering the Ottawa River watershed, including the Ottawa River and Rideau River and Canal, concluded that there are several issues present within the watershed caused by natural and human-made impacts including physical-chemical conditions, elevated nutrients (specifically phosphorus), cyanobacteria (specifically blue-green algae) and eutrophication, higher bacteria counts (specifically E. coli), the presence of heavy metals and toxic substances, turbidity and an increase of suspended matter that indicated an increasing trend of water quality decline and ecosystem health deterioration. ${ }^{67}$ From this review, concerns were also raised with regards to flooding and changing water levels in the region caused by an increase in extreme precipitation events and land use changes. ${ }^{68}$ Besides affecting the overall water levels and quality, these issues were also found to be putting stress on the biodiversity of the region caused by loss or degradation of habitat, deterioration or loss

67 Environment and Climate Change Canada, Examination of Governance, Existing Data, Potential Indicators and Values in the Ottawa River Watershed (Gatineau: Environment and Climate Change Canada, 2019), 90, accessed January 9, 2021, http:// publications.gc.ca/collections/collection_2019/eccc/En4-373-2019-eng.pdt'

68 Environment and Climate Change Canada, Examination of Governance, Existing Data, Potential Indicators and Values in the Ottawa River Watershed, 90 fragmentation. ${ }^{69}$ The issues present within the watershed can be attributed to severa factors resulting primarily from human influences that are well documented across the watershed and outline that improvements need to be made in order to begin to resolve the situation.

Within the watershed several overflows of municipal wastewater are released into the Ottawa River and its tributaries on a weekly basis. ${ }^{70}$ According to the City of Ottawa, in 2019 alone, 26 overflow events across the 13 combined sewer overflow locations in the Ottawa and Rideau Rivers released 810,000 m3 of wastewater, whereas in 2020, overflows combined for 344,020 m3 of wastewater released from 24 events. ${ }^{7}$ The municipal wastewater released during these overflows combines sanitary sewage from household, business and industrial waste and stormwater from rain or snow melt runoff making it contain both human excrement as well as hundreds of chemicals and toxic pollutants depending on the products being consumed by residents or the waste being generated by the commercial, institutional or industrial sectors. ${ }^{72}$ It is common for this water to contain pathogens, nutrients, metals, oils, grease, pharmaceuticals, persistent organic pollutants such as pesticides and solvents, among others, which can lead to changes in aquatic habitats and composition, decrease biodiversity, impair the use of recreational waters and shellfish harvesting areas, and contaminate drinking water. ${ }^{73}$ These characteristics have led to municipal wastewater being identified as one of the most significant sources of pollution to surface waters in Canada. ${ }^{74}$ It is 69 Environment and Climate Change Canada, Examination of Governance, Existing Data, Potential Indicators and Values in the Ottawa River Watershed, 92

70 Ottawa Riverkeeper, "Ecology and Impacts," 3 71 City of OOttawa, "Wastewater Collection and Treatment", City of Ottawa, accessed January 9, 2021, hittps://ottawa.ca/en/living
ottawa 72 Ottawa Riverkeener "Ecology and Impacts" 36

73 Ottawa Riverkeeper, "Ecology and Impacts" 36

74 Ottawa Rivereenes "Ecology and impacts" 36 


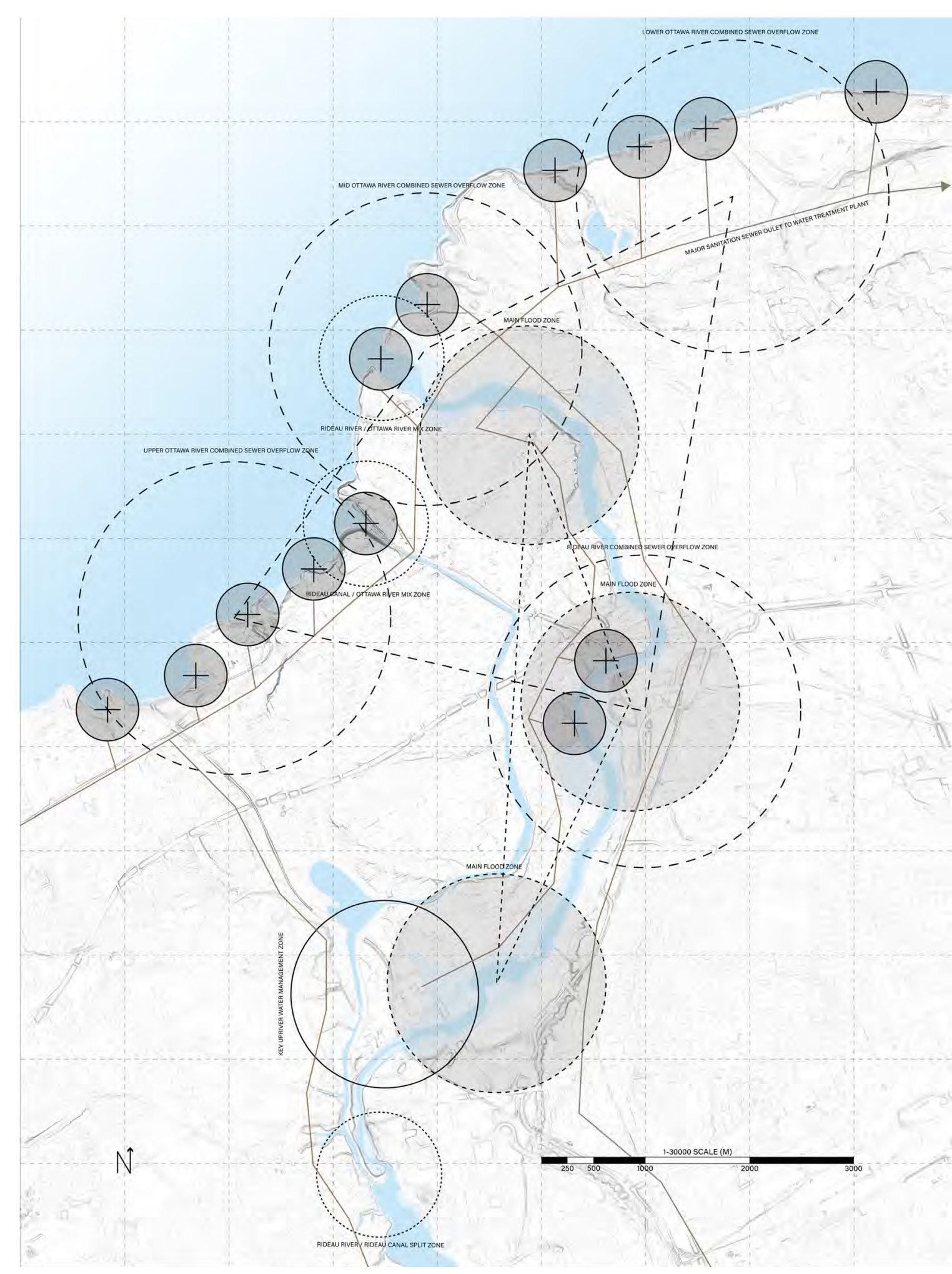

Figure 7: Illustrated map demonstrating sewer overflows located along the Ottawa and Rideau Rivers as well as existing main
sewage networks. obvious that in Ottawa this reality is coming to fruition and is only becoming worse as urbanization intensifies

Given what is known about the detrimental effects that municipal wastewater has on the environment, one would assume that changes are being made with regards to how water is treated. However, because of the large quantity of water resources present in Ottawa, an attitude of, " dilution is the solution to pollution," still remains, suggesting that the large volumes of water in Ottawa can accommodate any quantity of pollution. ${ }^{75}$ The problem is that this outlook is simply not true. In fact, organic chemicals and metals do not have to be discharged in large quantities to result in environmental degradation and, regardless of their concentrations, many of these chemicals can be toxic at low levels and can remain in the environment for extensive periods while travelling long distances. ${ }^{76}$ In order to deal with this issue, each municipality in the watershed employs various pollution prevention techniques for their particular sewage needs ranging from simple screening, to settling (primary treatment), to biological treatment (secondary treatment) to advanced processes (tertiary treatment) that remove a diverse range of contaminants. ${ }^{77}$ Not only do these processes result in varying levels of polluted effluent wastewater but they also produce polluting emissions and contaminated biosolids such as sludge which are rich in nutrients and other pollutants and must be carefully disposed or instead processed for use as agricultural fertilizers. ${ }^{78}$

Ottawa's municipal wastewater treatment plant, the Robert O. Pickard Water Environmental Centre, was built in 1960 as a primary treatment facility then upgraded in 1992 for secondary biological processing with enhancement to remove phosphorus

75 Ottawa Riverkeeper, "Ecology and Impacts," 37.

76 Ottawa Riverkeeper, "Ecology and Impacts," 37.

77 Ottawa Riverkeeper, "Ecology and Impacts," 38.

78 Ottawa Riverkeeper, "Ecology and Impacts," 41-42. 


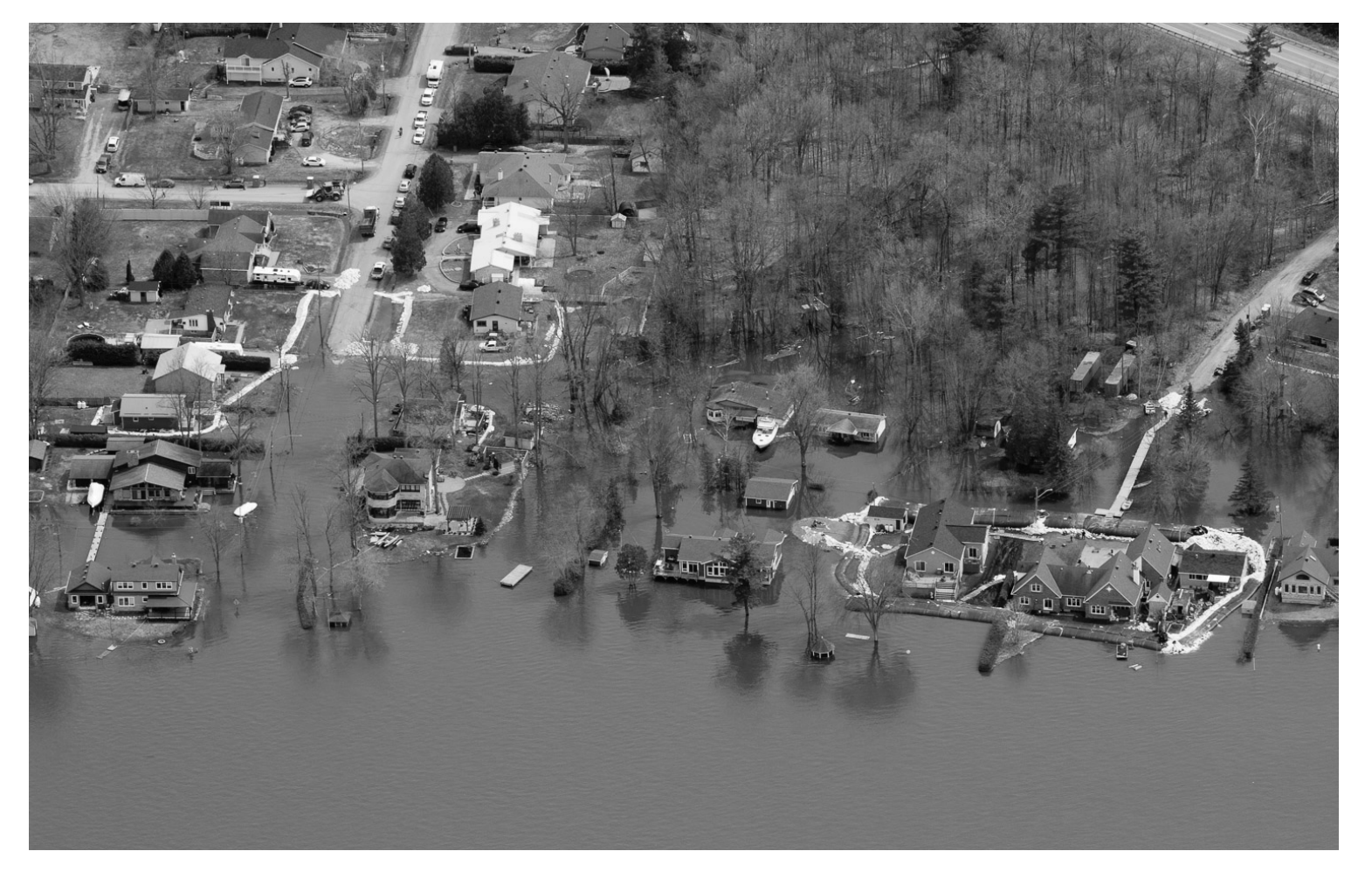

Figure 8: Photograph showing extent on flooding on the Ottawa River in 2019. (http://aerialphotographs.ca/fllood2019/content/
IMG_1669__arge.html) and finally received a sludge treatment upgrade in the last few years. ${ }^{79}$ On average, this water treatment plant in east Ottawa treats $545,000 \mathrm{~m} 3$ of wastewater daily before releasing the effluent into the Ottawa River. ${ }^{80}$ The facility uses ultraviolet radiation for disinfection all year except in the swimming season when chlorine is used as a disinfectant, commonly causing acute toxicity in the local fish population. ${ }^{81}$ This current system serves as the end of line for an ageing sewer infrastructure that is currently nearing full treatment capacity and will require large investments in order to deal with predicted population growth and the effects of climate change generating more untreated sewage overflows into Ottawa's waterways in the near future. ${ }^{82}$ The described factors indicate that wastewater management is a major issue in Ottawa that requires immediate attention

Even though wastewater is posing a significant threat to Ottawa's water ecosystems, stormwater runoff in Ottawa is actually an even larger issue when it comes to quantifying environmental impact. In terms of discharge volume and contaminant loads, stormwater runoff significantly exceeds municipal wastewater in water quality contamination. ${ }^{83}$ In fact, urban stormwater runoff is one of the leading sources of water quality impairment to surface waters. ${ }^{84}$ Stormwater and snowmelt are transported by sewers, drainage channels and streams, collecting various pollutants, materials and thermal energy from the environment along their path to receiving waters. ${ }^{85}$ These collected substances are transported to water sources directly by runoff without any treatment causing more detrimental effects than point source pollutants such as 79 Ottawa Riverkeeper, "Ecology and Impacts," 41 80 City of Ottawa, "Wastewater Collection and Treatment," City of Ottawa, accessed January 9, 2021, hitps:///ottawa.ca/en/living 81 Ottawa Riverkeeper, "Ecology and Impacts," 41 82 Ottawa Riverkeeper, "Ecology and

83 Environment Canads "Threats to Sources of Drinking Water and Aquatic Ecosystem Health in Canada" 47. 84 Ottawa Riverkeeper, "Ecology and Impacts", 52.

85 Environment Canada, "Threats to Sources of Drinking Water and Aquatic Ecosystem Health in Canada," 47. 
municipal wastewater. ${ }^{86}$

These contaminants are also becoming more important to consider due to land use changes including urbanization, agriculture, and industrial activities that bring a hardening of the surface of the watershed from homes, streets, soil compaction and destruction of natural vegetation. ${ }^{87}$ These changes lead to a reduced capacity for water absorption in the watershed and an increase in direct runoff where the water previously infiltrated and results in less groundwater recharge, more flooding and stream erosion. ${ }^{88}$ In tandem with urbanization, wetland destruction is particularly detrimental to the ecological health of the watershed because wetlands support more life than any other ecosystem, reduce the effects of flooding and act as natural water purification systems removing sediment, nutrients, and toxins from the rest of the watershed. ${ }^{89}$ In Ottawa, competing interests are putting pressure on wetland conservation and, while many wetlands have been preserved as Provincially Significant Wetlands by the Ontario Ministry of Natural Resources, other wetlands are vulnerable to future development in the City's official plan. ${ }^{90}$ Due to these various factors, implementing considerate development regulations that include stormwater management infrastructures as part of their intervention strategies are important for the protection of these ecosystems.

Apart from municipal wastewater and stormwater runoff, climate change is also a factor influencing watershed health. According to Environment Canada, surface air temperatures in the Ottawa watershed have already increased by about $0.5 \mathrm{C}$ since 1950 and the prediction is that mean temperatures will increase by $3-4 \mathrm{C}$ by $2100 .{ }^{91} \mathrm{As}$ stated earlier, these seemingly small changes can have huge impacts on the frequency

$$
\begin{aligned}
& 86 \text { Ottawa Riverkeeper, "Ecology and Impacts," } 51 . \\
& 88 \text { Ottawa Riverkeeper, "Ecology and Imacts" } \\
& 89 \text { Ottawa Riverkeener, "Ecology and Impects" } 53 \\
& 90 \text { Ottawa Riverkeeper "Ecology and Impacts" } 53 \\
& \text { 91 Ottawa Riverkeen "Ecology a dimpects" } 50
\end{aligned}
$$

and magnitude of large flow flood events, leading to more intense storm events generating more runoff and producing large flows that can cause channel widening and erosion and can also overwhelm the ageing stormwater infrastructures leading to more combined sewer overflows. ${ }^{92}$ These impacts of climate change will only amplify the human impacts already present within the Ottawa watershed, resulting in further deterioration of vulnerable ecosystems and reduced water quantity and quality.

With an understanding of the various threats to drinking water present within the Ottawa River watershed Ottawa has established two water quality indicators in order to monitor the situation: fish consumption advisories and beach closures. ${ }^{93}$ Both of these indicators have been common in recent years indicating issues with wate quality due to the various human and environmental factors described

The various factors influencing Ottawa's waterways explained in this section demonstrate that, while Ottawa has a bounty of water resources, there is little being done to protect them. Ottawa's sewer network clearly has weaknesses and there is a need for serious mitigation upstream in order to help alleviate pressure on the system. There is also minimal stormwater management present throughout the watershed that needs an overhaul to improve water quality. Furthermore, Ottawa also has extensive flood risk zones, influenced by stormwater runoff, which extend along the Rideau River after it divides into the Canal and threaten the development and well-being of many species and neighbourhoods.
92 Ottawa Riverkeeper, "Ecology and Impacts," 56.

93 Ottawa Riverkeeper, "Ecology and Impacts," 59-60. 


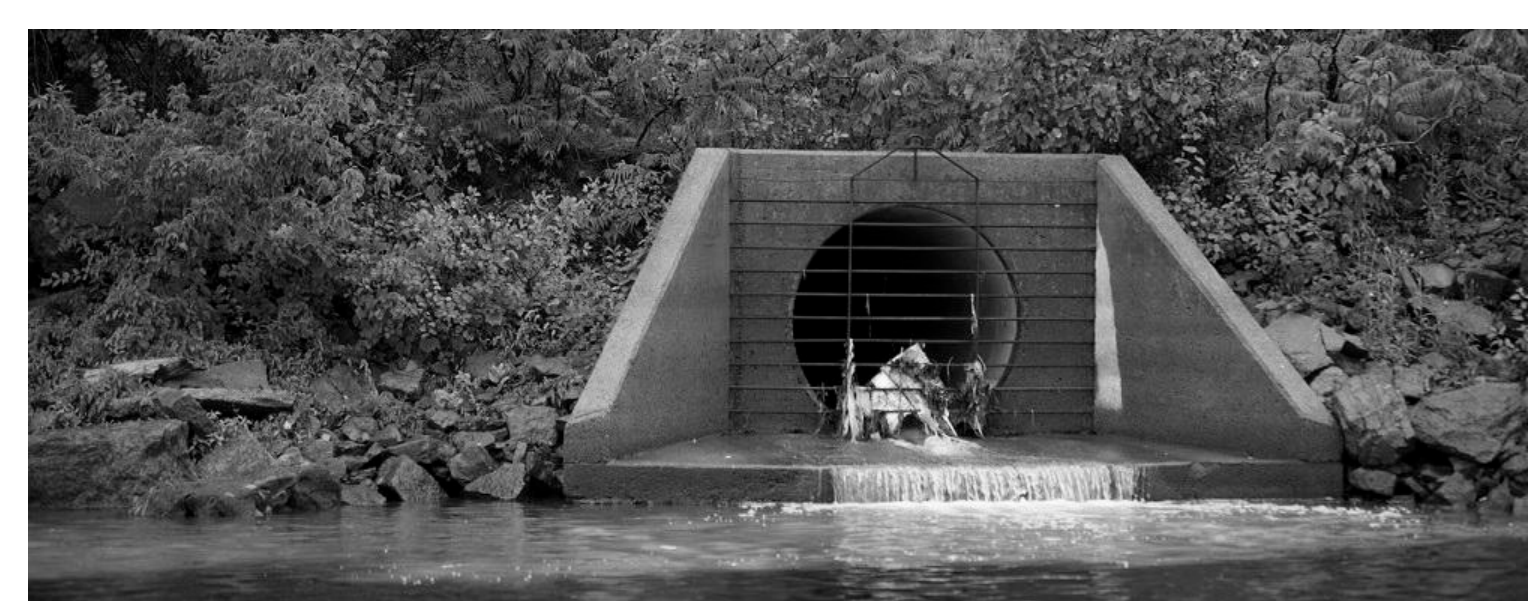

Figure 9: Photograph of a stormwater sewer outlet in Ottawa. (https://www.ottawariverkeeperca/urban-stormwater/)

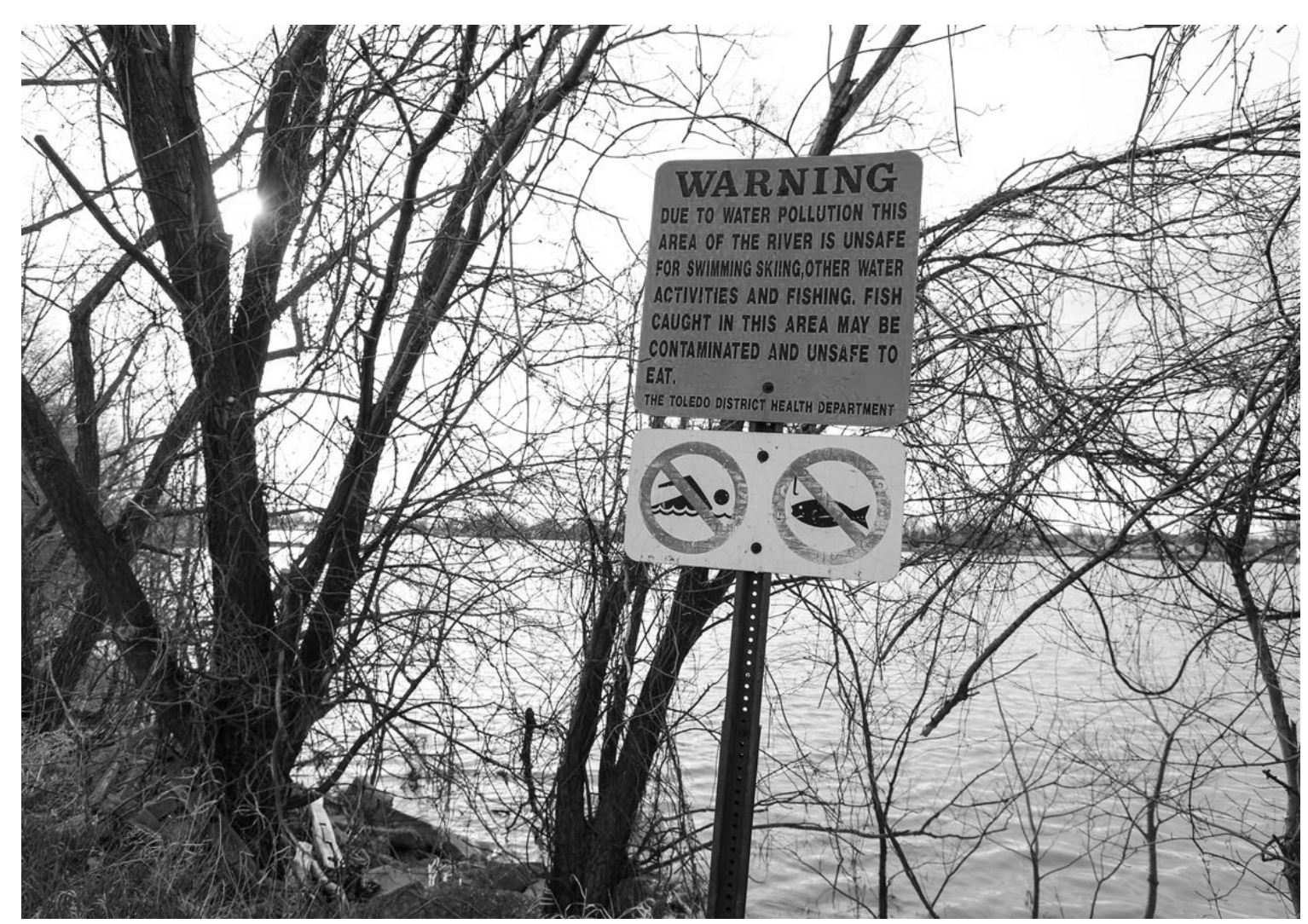

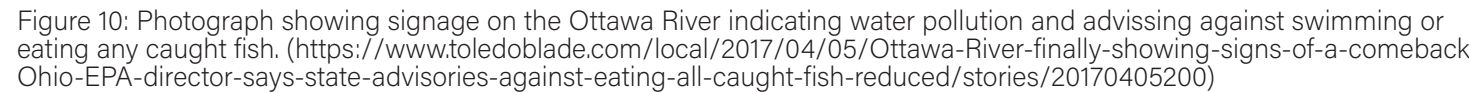

Due to the increasing negative impacts of the human relationship with water some good news is that the attitude towards water is slowly shifting. However, this shift may not be fast enough. Few Canadians can identify the watershed within which they live, or even their source of drinking water, making it difficult for them to understand the interconnectedness of these systems and their daily activities. ${ }^{94}$ In particular, the link between people upstream and people downstream, as well as between urban and rural dwellers, needs to be strengthened, since, the further people are removed from the initial source of an issue, their incentive to participate in resolving it diminishes. ${ }^{95}$ Therefore, a new approach to water management needs to foster a strong identity and sense of place in order to create a stewardship ethic that motivates Canadians in all walks of life to contribute to sustainable watershed management through shared responsibility. ${ }^{96}$ Attention must be directed to the local scale in order to manifest change.

In response to this situation, water issues are increasingly being viewed from a watershed perspective in Canada. ${ }^{97}$ As pressure on Canada's water supplies increases, greater attention is being paid to managing demand, with some water experts and officials arguing that water should be provided as a service, rather than a good ${ }^{98}$ The issues and solutions are evolving from traditional engineering solutions to community engagement enabling the incorporation of societal values and social and economic considerations that were formerly unconsidered. ${ }^{99}$ Public education and engagement are becoming important factors that can help instill the environmental value of water in order to recognize the importance of maintaining and protecting it instead of degrading 94 Pollution Probe, "Towards a Vision and Strategy for Water Management in Canada," 14. 95 Pollution Probe, "Towards a Vision and Strategy for Water Management in Canada," 15 96 Pollution Probe, "A New Approach to Water Management in Canada," 7.

98 Pollution Probe, "Towards a Vision and Strategy for Water Management in Canads" 41 99 Pollution Probe, "Towards V Vision and Strategy for Water Management in Canada" 21. 
or depleting iti.100 Also, instead of managing all water quality and quantity problems at the delivery end, greater attention is being paid to protecting water at its source.10 However, source water protection is only the first barrier in a multi-barrier approach to protecting drinking water that includes a watershed-based, locally driven program that uses scientific methods for assessing risks to drinking water and an approach to decision making that emphasizes information sharing, consultation and involvement by interested members in the watershed communities ${ }^{102}$ These approaches are helping to generate an effective watershed outlook that also fosters life cycle thinking about water by attempting to integrate and address all factors that affect water quality and quantity throughout the watershed.103 The result is an integrated water resource management which promotes, "the coordinated development and management of water, land and related resources in order to maximize the resultant economic and social welfare in an equitable manner without compromising the sustainability of vital ecosystems."104 In order to achieve these goals, individuals and organizations at all levels have a role to play in generating widespread awareness and support to achieve sustainable watershed based relationships with water.105 Therefore, there is an imperative to create local water management solutions that, when adopted on the national scale, could help change the paradigm of the national and global water crisis,

100 Pollution Probe, "A New Approach to Water Management in Canada," 9

101 Pollution Probe, "Towards a Vision and Strategy for Water Management in Canada," 11

102 Pollution Probe, "Towards a Vision and Strategy for Water Management in Canada," 34

104 National Round Table on the Environment and the Economy. Changing Currents: Water Sustainability and the Future of

da's Natural Resource Sectors, 36

05 Pollution Probe, "A New Approach to Water Management in Canada," 13
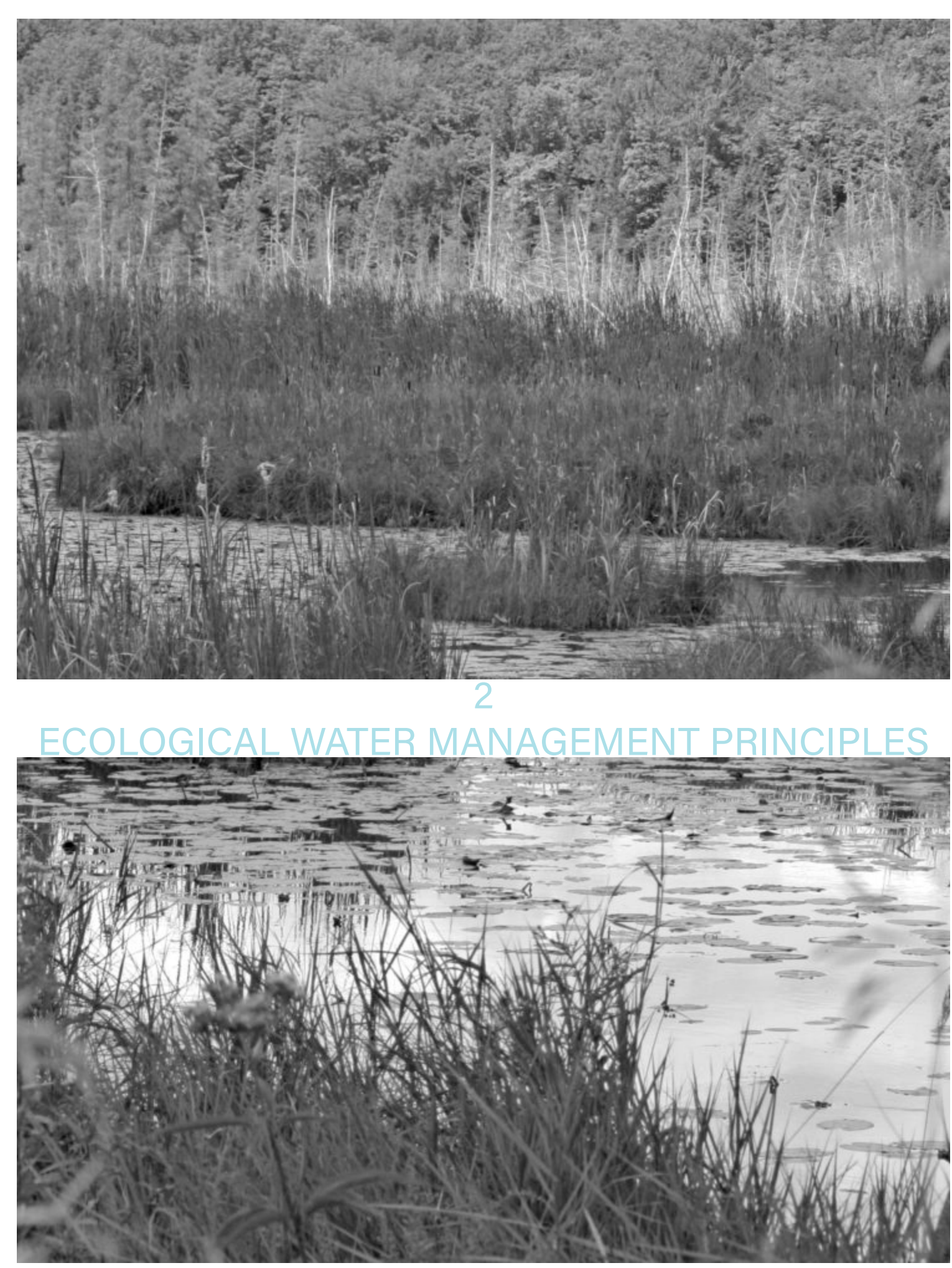

Figure 11: Photograph showing a natural wetland in Ontario. (https://www:watercanada.net/ontario-government-provides-fund- 
With an increasing discourse on sustainability, the paradigm for water treatmen is beginning to shift towards systems that reclaim water, energy, and nutrients instead of the conventional approach of removing them before discharging treated effluent into receiving waters ${ }^{106}$ Conventional wastewater treatment systems, including centralized treatment plants or septic systems, are currently the standard approaches for dealing with wastewater but both have associated issues and communities are now looking at alternative methods for treating and managing wastewater. ${ }^{107}$ Centralized wastewater treatment plants collect and treat water through grey infrastructure mechanical processes using pipes to convey water and chemicals to treat it, causing them to be separated from the natural environment while fragmenting the hydrological system. ${ }^{108}$ These systems are typically designed to handle large volumes of wastewater but have high costs, negative environmental effects and are not always able to treat water to sufficient standards due to insufficient capacity. ${ }^{109} \mathrm{Dr}$. John Todd, the pioneer of Living Machine technology, believed that the conventional waste treatment industry was, "one of the major environmental destroyers."110 When the industry was tasked with solving the problem of regulating pollutants, they created numerous other problems by using unregulated compounds to achieve their goals."11 For example, Todd explained that, for the treatment of phosphorus, the industry decided to pour large amounts of highly toxic aluminum salts into the water which achieved their goals of removing the 106 Mathew E. Verbyla, Ponds, Lagoons and Wettands for Wastewater Management (New York: Momentum Press, 2017), 1. 107 Kellie Fenton, "Innovative Waste Water Strategies in the Landscape: The Application of Green Infrastructure Principles in Cape Cod, Massachusetts," Landscape Architecture \& Regional Planning Masters Projects (2017): 7, accessed January 9, 2021,

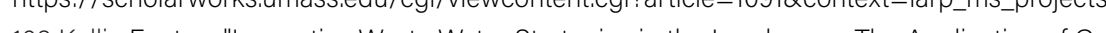
(108 Kellie Fenton, Innovative Waste Water Strategies in the Landscape. The Application of Green Infrastructure Principles in

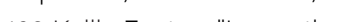

Whater Strategies in the Landscape: The Application of Green Infrastructure Principles in

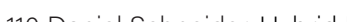

Sewage Treatments and the Contradictions of the Industrial Ecosystem (Cambridge

Daniel Schneider. Hybrid Nature Sewage Treatments and the Contradictions of the Industrial Ecosystem, 194-195 of Alzheimer's disease.12 $\mathrm{He}$ also noted that, when the industry chose to add chlorine to their treatment processes, chloramines were produced, "making every sewage plant, in effect, a carcinogen factory."113 These consequences are forcing communities to begin to move away from the one-size-fits-all approach towards a context-based approach that considers the link between wastewater management and environmental health.114 This leads to more ecological approaches that, instead of trying to counter nature and separate technology from natural systems, are more harmonious with the environment.

Therefore, as alternatives to mechanical and chemical mechanisms, there has been a growing trend in understanding the value of ecosystems and their ecological processes. Ecosystems provide valuable services for the environment including carbon sequestration, air and water pollutant filtration, stabilization of soil to reduce erosion, wildlife habitat, reduction of the heat island effect, reduction of the public cost of water infrastructure and reduction of energy usage through passive heating and cooling.115 Using careful consideration of these benefits, green wastewater management is an approach that serves to protect, restore or mimic the natural water cycle to create an effective and economical infrastructure that enhances quality of life while also contributing to social, economic and environmental health. ${ }^{116}$ These systems offer the possibility for water recycling that allow communities to address water infrastructure vulnerabilities resulting from population growth, drought, diminishing supplies, scarcity,

112 Daniel Schneider, Hybrid Nature: Sewage Treatments and the Contradictions of the Industrial Ecosystem, 194-195 113 Daniel Schneider, Hybrid Nature: Sewage Treatments and the Contradictions of the Industrial Ecosystem, 194-195. 114 Kellie Fenton, "Innovalive Waste Water Strategies in the Landscape: The Application of Green Infrastructure Principles in 115 Kellie Fenton "Innovative Wast

Water Strategies in the Landscape: The Application of Green Infrastructure Principles in 110 Kellie Fenton "IInovative "Wast

Water Strategies in the Landscape: The Application of Green Infrastructure Principles in Cape Cod, Massachusetts," 15. 
and reliance on a single water source.17

In order to treat wastewater ecologically, several options exist. But before these options can be explored, water treatment mechanisms must first be established. Water treatment can be completed to achieve various levels of filtering that typically fall within four categories: preliminary treatment removes only debris (paper, plastic, rags, etc), primary treatment partially removes suspended solids and organic materials by physical screening and sedimentation, secondary treatment removes organic solid materials using bacterial decomposition, and tertiary treatment removes inorganic components."18 Because of its hazardous characteristics, in order for sewage water to be recycled, it must meet strict guidelines that can be achieved through ecological treatment processes. ${ }^{119}$ To meet these guidelines, organic material, nitrogen, phosphorus and sulphur must be removed and biochemical oxygen demand (BOD) must be reduced. ${ }^{120}$ By using ecological mechanisms that replace the conventional treatment systems, these goals can be met with lessened environmental effects and imrpoved ecosystem health.

The various elements within an ecological system work to treat water through several removal mechanisms that can be physical and chemical (abiotic) or microbial and biological (biotic) and are typically cyclic in nature involving plant roots, stems, leaves, sediments, substrate, water and organisms. ${ }^{121}$ These various removal mechanisms

117 Nasuha Safie, Nurliyana and Abu Zahrim Yaser, "Sewage Treatment in Campus for Recycling Purpose," in Green Engineering for Campus Sustainability, edited by Abu Zahrim Yaser (Singapore: Springer Nature Singapore Pte Ltd, 2020), 233, accessed January 9, 2021, https://doi-org.proxy.library.carleton.ca/101007/978-981-13-7260-5. 118 Vaiva Vaitkeviciute, Kamile Jakubauskaite and Jurga Vitkuviene, "Ecological Cleaning and Reusing of Wastewate: Possibilies, Advantages and Proposals," 60 .

.

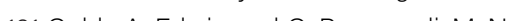

for the Tree.tant of Gre. Woyyatmoli, M. Nandhivarman, hamaswarmy Arun Prasath, Dwipen Boruah, "Constructed Wetlands Perspectives eds by Walter Leal Filho Nandhiverman Muthu, Golda Edwin Mihala Sima (Switzerland: Springer Interational Publishing, 2015.), 341, accessed January 9, 2021. https://doi-org.proxy.library.carleton.ca/10.1007/978-3-319-11961-8. are naturally occurring and use plant matter as primary agents in their processes The types of vegetation that thrive in these systems include emergent, floating and submerged macrophytes, metaphyton, periphyton, epiphytes, and phytoplankton.122 Emergent macrophytes are often the visually dominant species in the system and usually include bulrushes, reeds and cattails.123 Floating macrophytes include plants such as water hyacinth, duckweed, or water lettuce. ${ }^{124}$ Submerged macrophytes include plants such as eelgrass, widgeon grass, and turtle grass. ${ }^{125}$ Metaphyton are unattached algae that form a visible floating mat:26 Periphyton are a diverse group of organisms including algae, cyanobacteria, and other bacteria that form a mat at the bottom of the structure.127 Epiphytes are plants and algae that grow on the surfaces of other organisms.128 Phytoplankton are microalgae such as diatoms and green algae that remain suspended in the sunlit upper layer of the water profile. ${ }^{129}$ Overall, the presence of these plants helps to create an environment that promotes biodiversity and supports a healthy ecosystem

In addition to the plant functions within the ecosystems, small organisms also play important roles in the water treatment processes. In addition to bacteria, numerous macroinvertebrates such as scrapers, shredders, collectors, filterers, and predators can also be found within the system. The most common of these organisms in natural treatment systems are flies, beetles, fleas, mites, snails, and worms, among others. ${ }^{130}$ Some of these organisms, such as mosquitoes, can become a nuisance, whereas others

$$
\begin{aligned}
& 122 \text { Mathew E. Verbyla, Ponds, Lagoons and Wettands for Wastewater Management, } 13 . \\
& 123 \text { Mathew E. Verbyla, Ponds, Lagoons and Wettands for Wastewater Management, } 13 \\
& 124 \text { Mathew. Verbyla, Ponds, Lagoons and Weilands for Wastewater Management, } 33 \\
& 126 \text { Mathew E Verbyla Ponds Laoons and Wettonds for Wastewater Management } 13 . \\
& 127 \text { Mathew E Verbyla Ponds Lagoons and Wettands for Wastewater Magenent, } 13 \\
& 128 \text { Mathew E Verbyla Ponds Laoons and Wettends for Wastewater Magogenent } 13 \\
& 129 \text { Mathew E Verbyla, Ponds, Lagoons and Wettands for Wastewater Management, } 13 \\
& 130 \text { Mathew E Verbyla Ponds Lagoons and Wettands for Wasteweter Menogement } 15
\end{aligned}
$$


are harmless and can even be beneficial to the operation of the system. ${ }^{131}$ However, together these organisms all account for various processes that help to create a robust food chain and self-sufficient ecosystem.

Based upon these natural processes, the solution to conventional wastewater treatment systems seemed to be biological treatment facilities which are not only engineered solutions for wastewater management, but are in fact ecosystems in and of themselves that employ organisms including fungi, bacteria, plants and animals that consume food, energy, and nutrients to transform raw sewage into a pure effluent. ${ }^{132} \mathrm{As}$ such, they can provide ecosystem services that can improve biodiversity, provide habitat for endangered or threatened species, and serve as community green spaces that can enhance the overall well-being of the local population. ${ }^{133}$ By achieving their initial goals to remove pathogens and organic matter, and subsequently dealing with removing other pollutants such as phosphorus and nitrogen, biological sewage treatment plants have shown their adaptability and flexibility of their treatment capabilities.134 Another benefit of natural water treatment systems is that, because they are driven by sunlight, gravity, and natural biological processes, they are synergistic with sustainable development. ${ }^{135}$ Lastly, the effluent wastewater can be recycled for many applications such as agricultural land irrigation, aquaculture, landscape irrigation, urban and industrial applications, artificial recharging of groundwater, and even potable water. ${ }^{136}$ This establishes the baseline for ecological wastewater treatment systems that can achieve tertiary treatment through natural processes that improve the environment.

131 Mathew E. Verbyla, Ponds, Lagoons and Wetlands for Wastewater Management, 15.

132 Daniel Schneider, Hybrid Nature: Sewage Treatments and the Contradictions of the Industrial Ecosystem, XV.

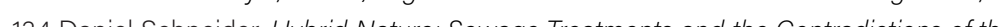

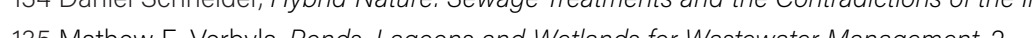

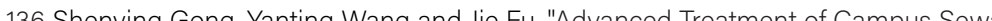

in

246 acessed lanuary 9, 2021, https://doi-org. proxylibrary.carleton.ca/101007/978-981-13-7260-5.

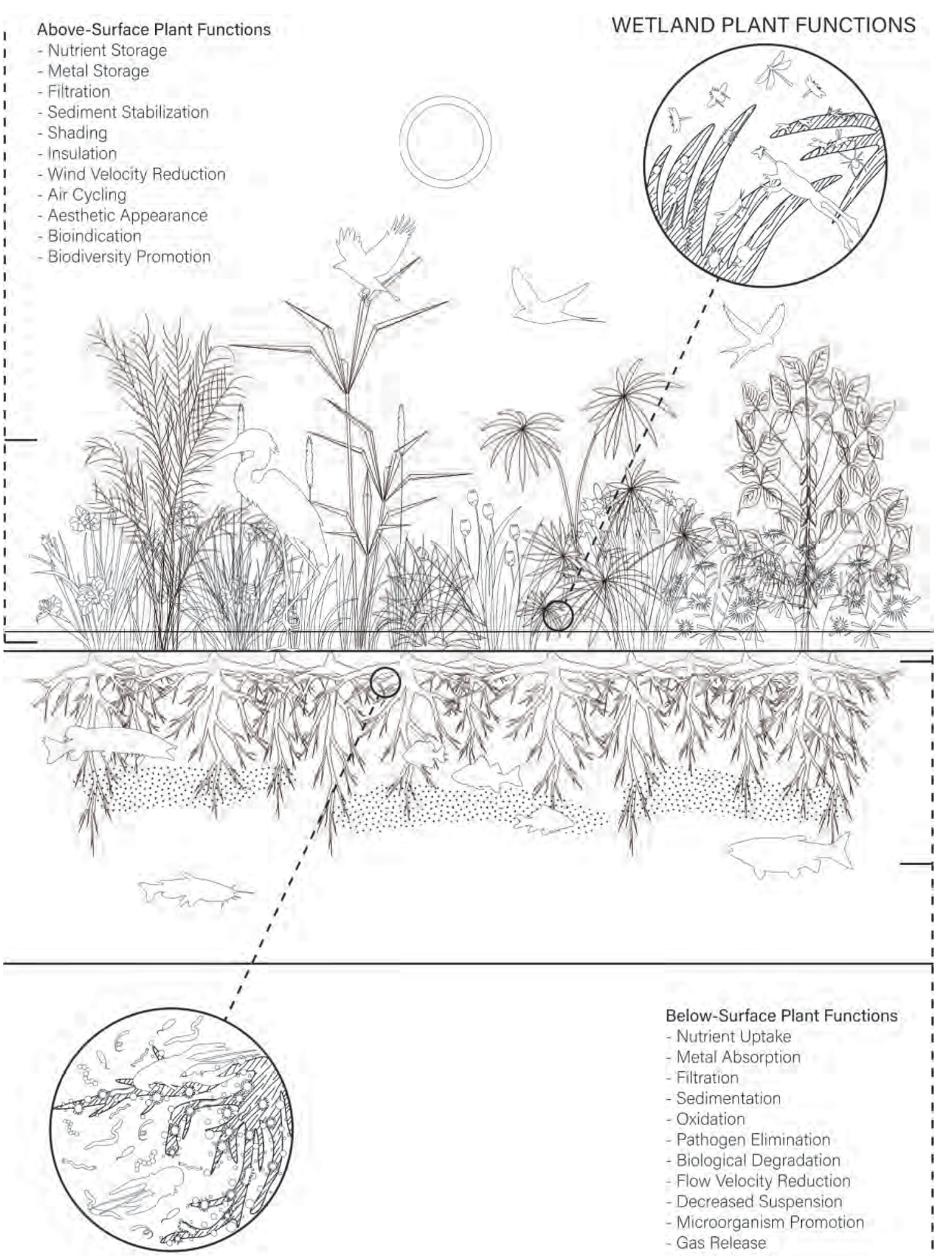

Figure 12: Diagram showing ecological water treatment mechanisms. 
Building upon lessons learned from the biological treatment facilities, and realizing that natural processes could be concentrated into smaller areas to improve efficiency in treating wastewater, Dr. John Todd used these natural water treatment principles to realize designs for the first Living Machine. ${ }^{137}$ The Living Machine system uses a series of tanks supporting vegetation and a variety of other organisms that perform many of the basic processes, such as sedimentation, filtration, clarification, absorption, nitrification and denitrification, volatilization, and anaerobic and aerobic decomposition, used in conventional biological sewage treatment plants. ${ }^{138}$ The difference between Living Machines and conventional systems is their use of plants and animals in the treatment process producing a unique aesthetic appearance.139 Without the addition of harmful chemicals, the system takes wastewater and produces clean water using an ecological system where plants and animals process the nutrients and chemicals with the resulting plant residuals can be composted ${ }^{140}$ They are wastewater treatment systems that can achieve tertiary treatment, cost less to operate than conventional systems and don't require chemicals that are harmful to the environment ${ }^{141}$ Thus, building upon established principles, Living Machines are able to achieve advanced treatment through a condensed system of several modules working together to achieve treatment goals.

The typical Living Machine consists of six principal treatment components after initial influent screening that are an anaerobic reactor, an anoxic tank, a closed aerobic

137 Daniel Schneider, Hybrid Nature: Sewage Treatments and the Contradictions of the Industrial Ecosystem, 223. 138 United States Environmental Protection Agency, Wastewater Technology Fact Sheet: The Living Machine (Washington, DC Municipal Technology Branch, 2002), 1, accessed January 9, 2021, https://www3.epa.gov/npdes/pubs//ving_machine.p nmental Protection Agency, Wastewater Technology Foct Cape Cod Mnnovative Waste Water Strategies in the Landscape: The Application of

(2) Wastewater Technology Fact Sheet: The Living Machine, 2 a series. ${ }^{142}$ These components can be arranged and replaced in various configurations depending on treatment goals and influent characteristics. One benefit of anaerobic digestion has the possibility of resource recovery through the production of biogas and nutrient-rich digested liquor that can be turned into fertilizer. ${ }^{143}$ The biogas can be manufactured into a fuel resource for mechanical combustion in heating and cooling or for electrical generation. Water cycles through each component, getting polished further as it goes through the system. After completing the circuit, the wastewater should be suitable for discharge to surface waters or can be recycled to replace the clean water typically used for a variety of applications including cooling water for power plants, boiler feed water, industrial process water, irrigation, or indoor residential and commercial end uses. ${ }^{144}$ The overall assortment of reactors creates a logical and organized series for the efficient treatment of wastewater to industry standards.

A fairly new alternative to the typical Living Machine is The Organica Food Chain Reactor. It builds upon the principles of the Living Machine to allow the treatment of more wastewater in a smaller area. To produce a clean effluent, the system is typically composed of influent pre-treatment leading to a series of two anoxic reactors and four aerobic reactors, each containing roots from plants suspended above and an engineered biofiber media throughout the reactor, followed by phase separation and disinfection if required ${ }^{145}$ These characteristics provide numerous benefits that include a footprint that is up to $60 \%$ smaller than conventional systems, a reduction in operating costs of $30 \%$ or more, an optimized sludge production resulting in a $20 \%$ reduction

142 United States Environmental Protection Agency, Wastewater Technology Fact Sheet: The Living Machine, 2. 143 Lucita Felicity Ayut and Newati Wid, "Anaerobic Digestion of Organic Waste in UMS Campus for Resource Recovery and Waste Reduction." In Green Engineering for Campus Sustainability, ed. by Abu Zahrim Yaser (Singapore: Springer Nature Singapore Pte Ltd, 2020), 140, accessed January 9, 2021. https://doi-org.proxy.library.carleton.ca/10.1007/978-981-13-7260-5. 144 Nasuha Safie, Nurliyana and Abu Zahrim Yaser, "Sewage Treatment in Campus for Recycling Purpose," 233. 145 Organica. "Facility." Organica Water. Accessed January 9, 2021. https://www.organicawater.com/facility. 


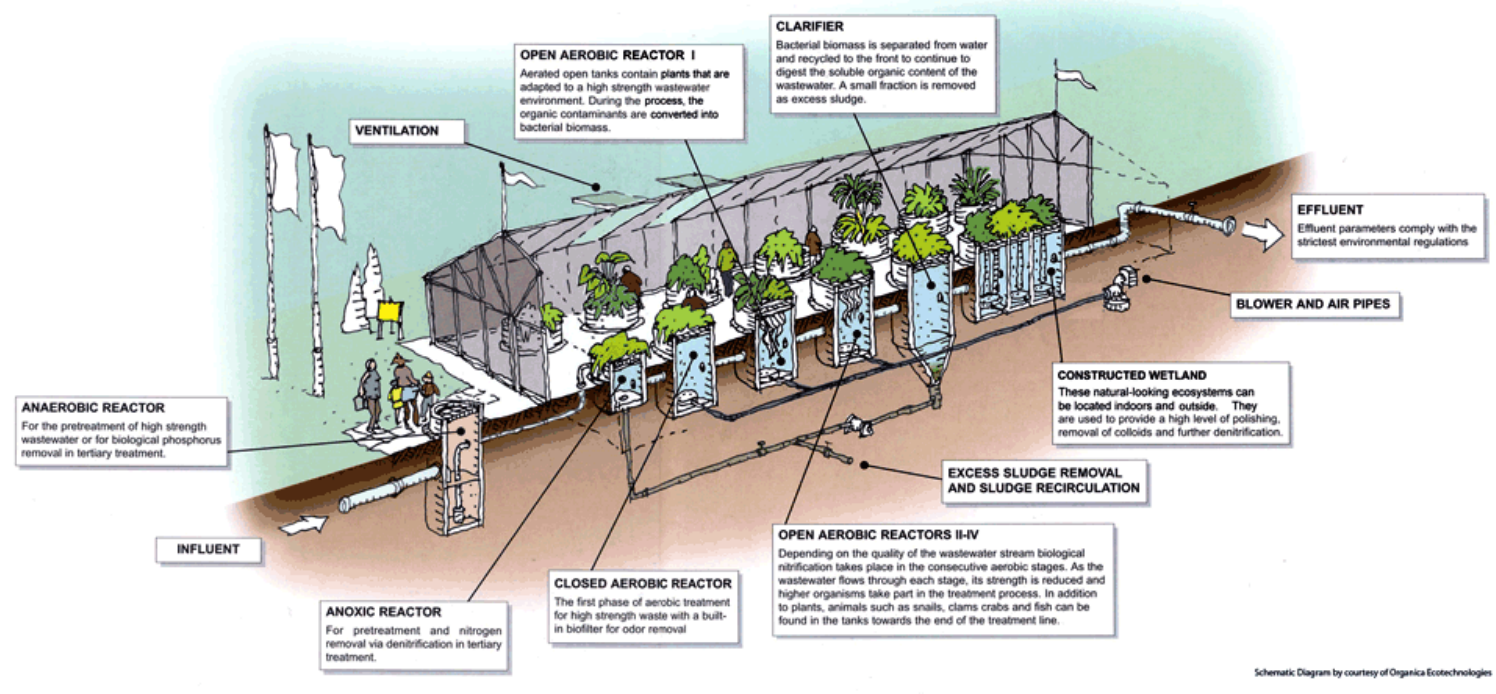

Figure 13: Diagram of a conventional Living Machine. (https://theecologist.org/2010/jun/08/living-machine-ecological-ap-
proach-poo)

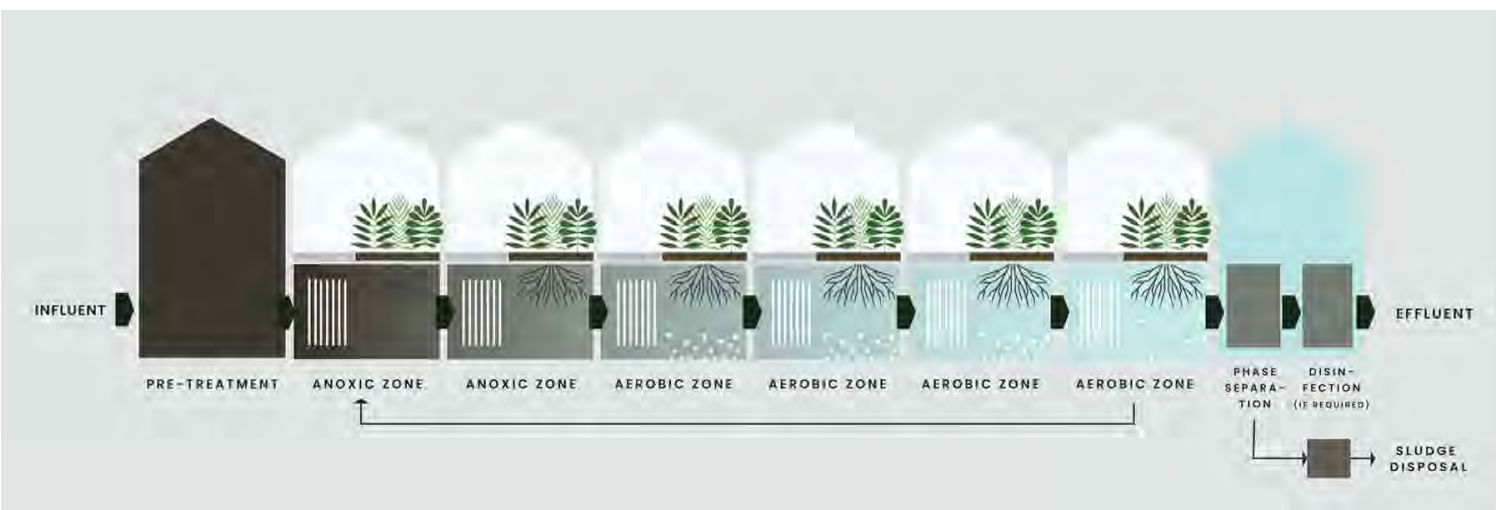

Figure 14: Diagram of the Organica Food Chain Reactor Living Machine. (https://www.organicawatercom/facility/) in excess sludge, and a resilient and stable system that can withstand fluctuations in influent quality and quantity while producing an effluent with TSS as low as $5 \mathrm{mg} / \mathrm{L}^{146}$ These benefits make the Organica system an attractive and efficient evolution of the typical Living Machine model with concepts and principles that can be adapted to a diverse set of requirements.

Overall, Living Machines are well-suited to treat both municipal and industrial wastewater and have both advantages and disadvantages that should be considered prior to construction. ${ }^{147}$ They are capable of treating wastewater to BOD, TSS and Tota Nitrogen $<10 \mathrm{mg} / \mathrm{L}$, Nitrate $<5 \mathrm{mg} / \mathrm{L}$, and Ammonia $<1 \mathrm{mg} / \mathrm{L}$, and they achieve this within an aesthetically pleasing and environmentally positive environment. ${ }^{148}$ However, they can require a larger footprint than conventional systems including greenhouses in temperate climates and have been shown to remove only about $50 \%$ of influent phosphorus depending upon influent levels. ${ }^{149}$ Also, while the primary and secondary treatment can typically process the water to specified guidelines, sometimes tertiary processes such as disinfection are required to meet higher standards. These benefits and disadvantages are put into perspective when compared to conventional wastewater treatment facilities.

Compared to conventional systems, Living Machines can cost approximately $20 \%$ less while producing less sludge and can achieve on-site treatment while simultaneously integrating with the ecosystem to provide an aesthetically pleasing environment for educational and recreational ecosystem services. ${ }^{150}$ However, they also require monitoring and balancing of elements through seasonal variations in order 146 Organica. "Facility." Organica Water. Accessed January 9, 2021. https://www.organicawater.com/facility. 147 United States Environmental Protection Agency, Wastewater Technology Fact Sheet: The Living Machine, 3. 149 United States Environmental Protection Agency, Wastewater Technology Fact Sheet. The Lastewater Technology Fact Sheet: The Living Machine, 4 150 Kellie Fenton. "Innovative Waste Water Strategies in the Landscape: The Application of Green Infrastructure Principles in Cape Cod, Massachusetts," 19 , 
to maintain the complex biological processes involved in operation.151 By focusing on conserving and processing water at a local level, Living Machines are exemplary in the integration of natural systems in wastewater treatment and have the ability to work on various scales where at the smaller scale they can provide and treat the water for a neighbourhood of 25-50 homes and at a larger scale they can be retrofitted into existing infrastructures to increase capacity or reduce costs, ${ }^{152}$ Overall, a Living Machine can function simultaneously within several realms as a utility because the system functions to clean wastewater, as an amenity for the public and environment because they use plants and natural processes, and as a habitat for fish, insects and birds..$^{153}$ These factors outline the efficiency and treatment capabilities of Living Machines that, in tandem with additional tertiary treatment modules, can produce potable water from wastewater while also providing an aesthetic and biodiverse environment.

11 Kellie Fenton, "Innovative Waste Water Strategies in the Landscape: The Application of Green Infrastructure Principles in Cape Cod, Massachusetts," 19

152 Kellie Fenton, "Innovative Waste Water Strategies in the Landscape: The Application of Green Infrastructure Principles in Cape Cod, Massachusetts," 20.

"nnovative Waste Water Strategies in the Landscape: The Application of Green Infrastructure Principles in 42

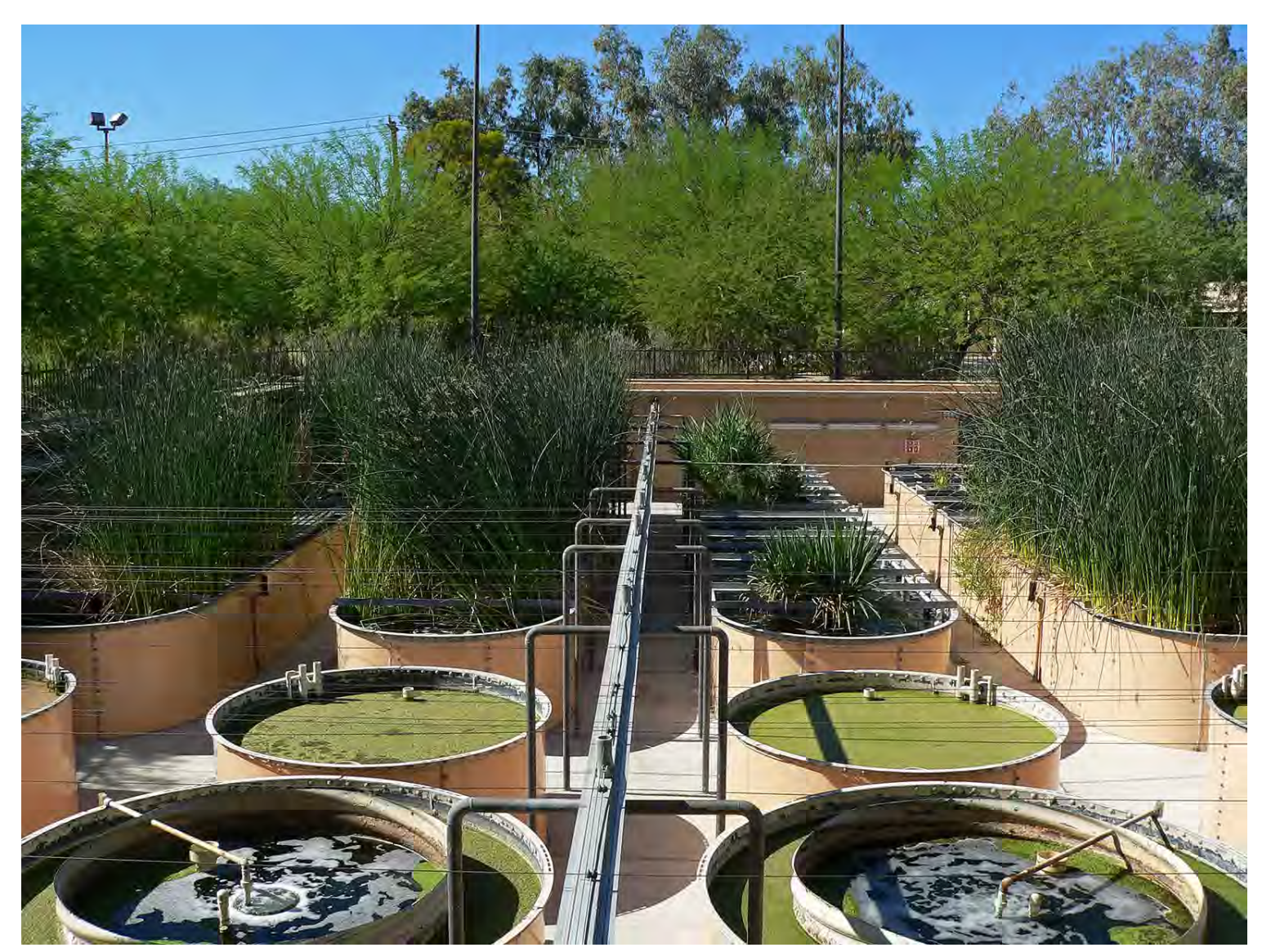

Figure 15: Photogra
ing_Machine_1.jpg)

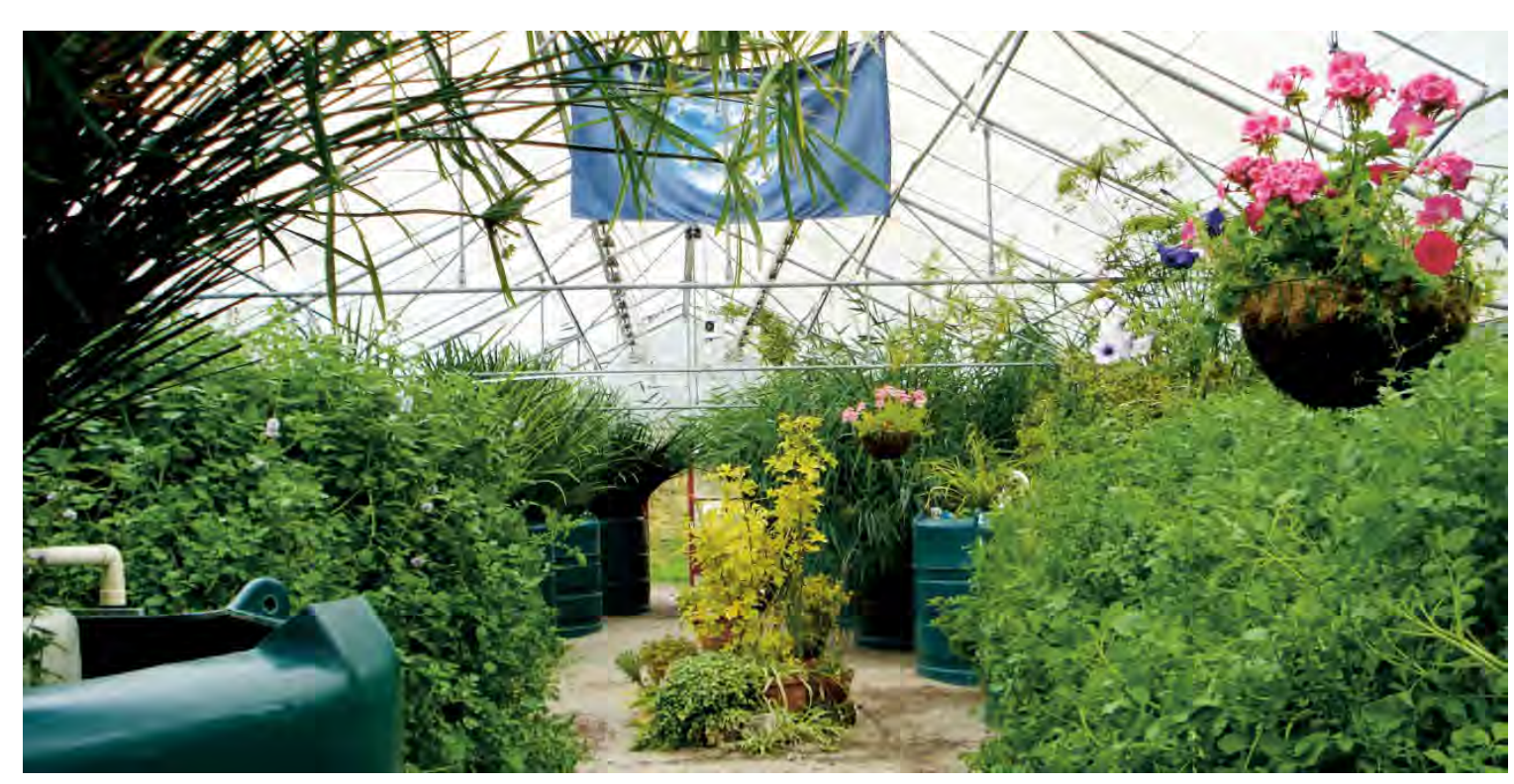

Figure 16: Photograph showing a Living Machine in Findhorn, Scotland. (https://www.urbangreenbluegrids.com/measures/ 
As a simplified process, constructed stormwater wetlands temporarily store

Constructed wetlands (CW) are defined as water treatment systems that have at least $25 \%$ of their surface area covered by vegetation and use natural processes involving wetland vegetation, soils, and their associated microbial populations to improve water quality. ${ }^{154}$ Constructed wetlands systems mimic natural wetlands such as swamps, bogs and marshes that pre-treat wastewater by filtration, settling and bacterial decomposition before its release into larger water bodies..$^{155}$ Furthermore, they can provide many of the ecological functions of natural wetlands including providing habitat for wildlife while increasing biodiversity, water retention, peak flow attenuation, and groundwater recharge, but are primarily designed to improve stormwater runoff quality. ${ }^{156}$ Constructed wetlands treat water through several physical, chemical, and biological processes using wetland plants as the main treatment medium supporting processes similar to those in Living Machines. Depending on desired results, there are numerous configurations for constructed wetland design including free wate systems, surface flow systems of sub-surface flow systems. ${ }^{157}$ This variety of wetland cell configurations can be operated in single stage or multi stage series to accomplish the primary, secondary or tertiary treatment of different types of influent water depending on system desires, ${ }^{158}$ Each of these configurations has both advantages and disadvantages that influence their effectiveness in achieving adequate water treatment depending on desired results.

154 Okanagan Basin Water Board, Constructed Wettands for Stormwater Manegement: An Okanagan Guidebook (Associated Environmental Consultants Inc, 2018), 1-1, accessed January 9, 2021, https://www.obwb.ca/newsite/wp-content/uploads/2018_ constructed_wetlands_guidebook.pat.

. Constructed Wetlands for 150 Orana

(Constock 1-1

Wh Golda A. Edwh Poyyamoli, M. Nandhivarman, Ramaswamy Arun Prasath, Dwipen Boruah, "Constructed Wetlands for

150 Golda A. Edwin and G Poyjamoli M Nandhis for the Treatment of Grey Woter in Campus Premises" 340 stormwater runoff in shallow pools that support the growth of wetland plants and maximize the removal of pollutants from the water through plant uptake, retention and settling. ${ }^{159}$ Primarily due to the evolution of wetland plants, constructed wetlands possess attributes that promote higher contaminant removal compared to conventional stormwater ponds. ${ }^{160}$ The selection of plant species can have a huge impact on the performance of the constructed wetland. ${ }^{161}$ Plant selection should be directed to native plants that have the ability to process nitrogen and other excess nutrients and will help to recharge the ground aquifer and reduce pollution in the area while also being able to provide food and habitat for nesting birds, bees and other pollinators. ${ }^{162}$ With this in mind, it is important to consider specific moisture and site conditions for plant survival, removal capabilities, and to select native, non-invasive plants that are perennial, establish quickly, and can achieve other objectives for the ecosystem.163

The plants used in constructed wetlands are generally macrophytes (aquatic plants), although various grasses may also be used, and usually consist of reeds, bulrushes and cattails, among others. ${ }^{164}$ Rooted-emergent plants are preferred in temperate climates due to their ability to insulate, however, floating macrophytes can also be employed to improve performance ${ }^{165}$ Also, increasing the diversity of plant life in the system can help to improve nitrogen removal.166 Water temperature also plays

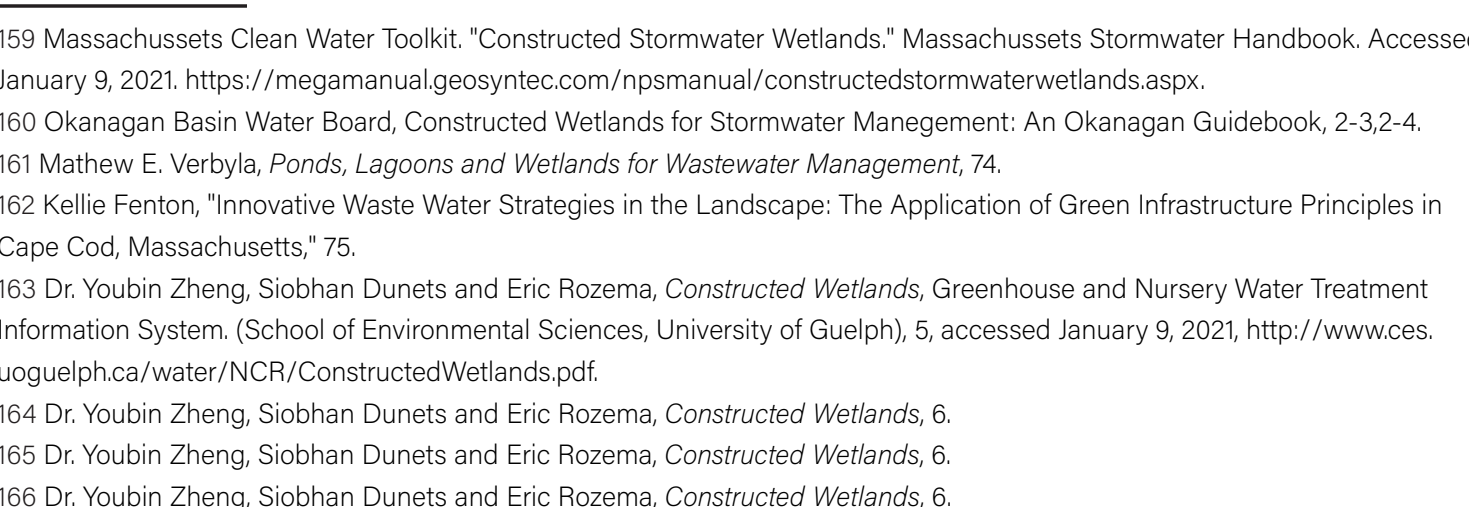




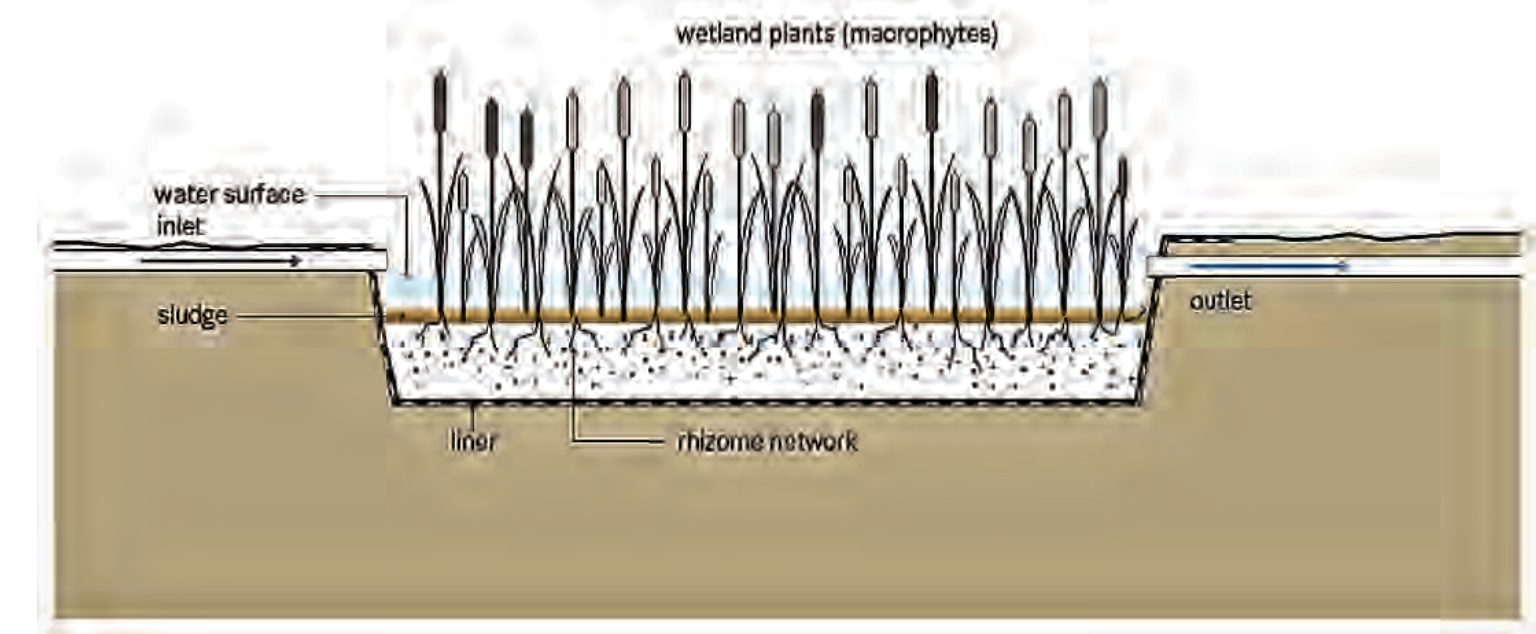

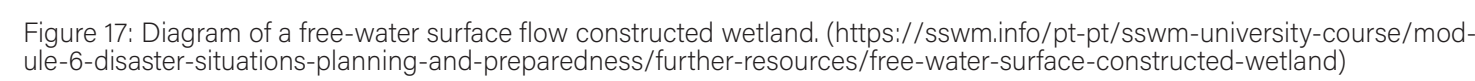

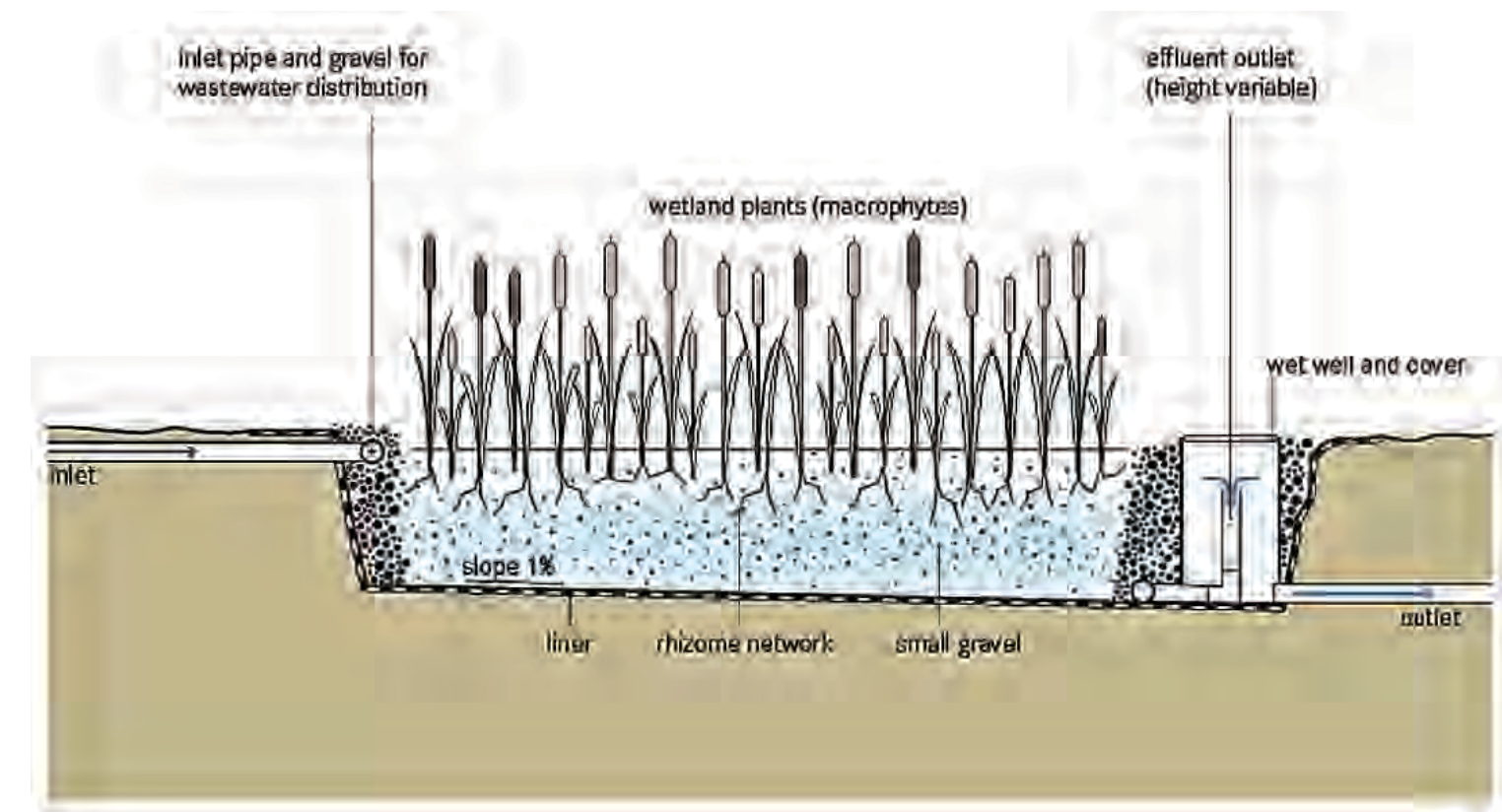

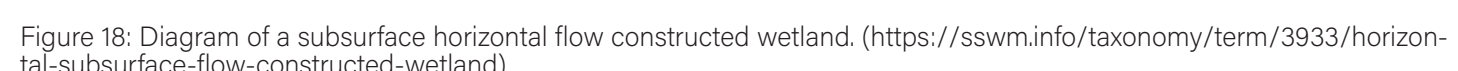

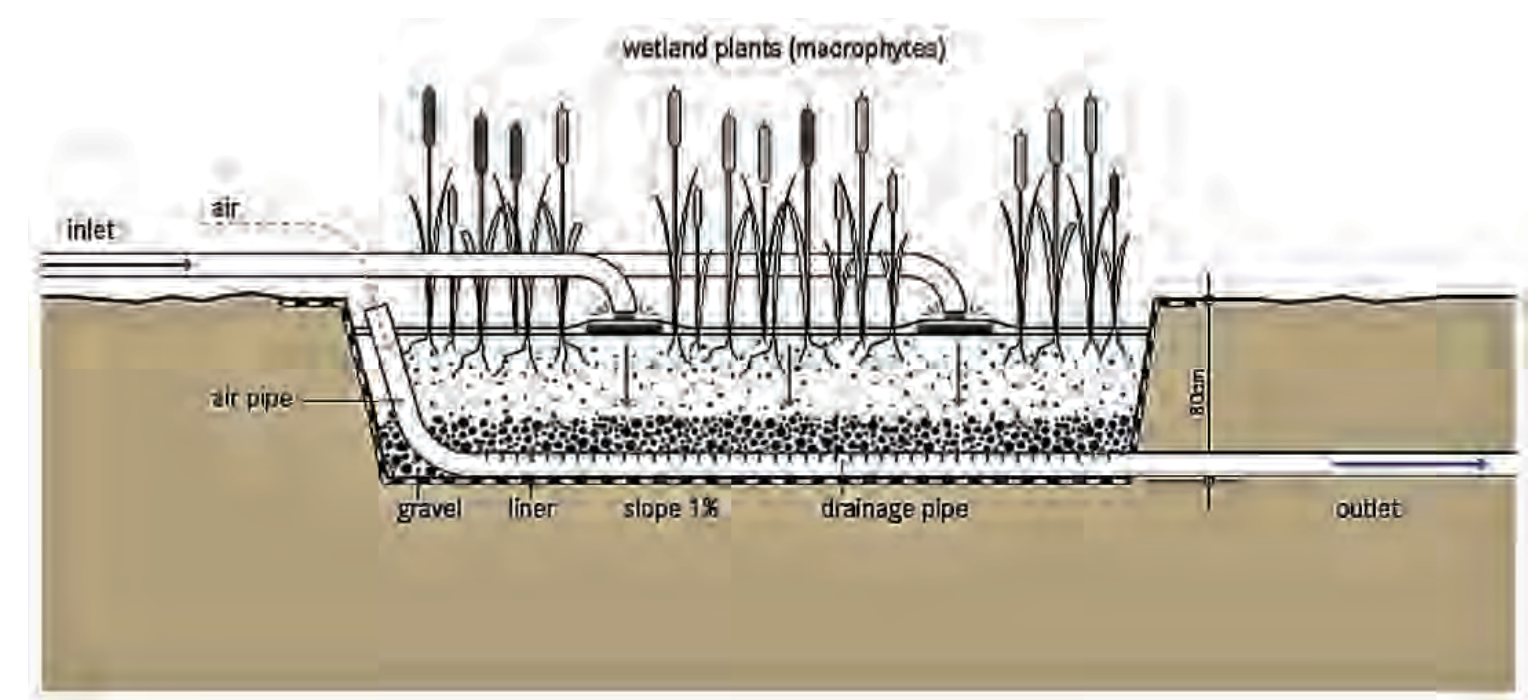


an important role in affecting the activity of microbes and plants and determines the rate of important chemical reactions. ${ }^{167}$ In the winter months, when pollutant removal efficiency is typically lowered, certain decisions can be made to maintain the system such as employing a subsurface flow system can prevent freezing, lowering the wate levels and allowing the accumulation of snow and dead vegetation on the surface can help to insulate ${ }^{168}$

With regards to maintaining the system, because constructed wetlands are natural systems, their maintenance is mostly passive and requires little operator intervention besides observation and taking action when problems develop. ${ }^{169}$ For the most part, wetland plant communities are self-maintaining and will grow, die, and regrow each year so the primary objective in vegetation management is to maintain the desired plant communities within the system. ${ }^{170}$ Therefore, constructed wetlands can provide an ecological, low-impact and low-maintenance solution for improved stormwater management.

Overall, constructed wetlands are used as a standard strategy for on-site treatment of stormwater and utilize natural planting to leverage biological processes to treat water in an open environment to create a landscape feature. ${ }^{171}$ They can be employed for numerous benefits including: recycling nutrients, purifying water, maintaining stream flow, restoring groundwater levels, attenuating floods, providing potable water, fish, fodder, fuel, wildlife habitat, buffer shorelines, leisure, recreation and

167 Dr. Youbin Zheng, Siobhan Dunets and Eric Rozema, Constructed Wettends 6 168 Dr. Youbin Zheng, Siobhan Dunets and Eric Rozema, Constructed Wettands, 6.

169 UN-HABITAT, Constructed Wetlands Manual, 47-48,

171 Kellie Fenton, "Innovative Waste Water Strategies in the Landscape: The Application of Green Infrastructure Principles in Cape Cod, Massachusetts," 22. tourism activities to society and the local community.172 In order to achieve adequate site selection, constructed wetlands must be located near the water source, provide adequate space, have proper slope to allow water to flow through the system naturally with gravity, be above the water table and not be located within a floodplain.173 The hope for these systems is that they can be employed in diverse locations from rural to urban communities, in other climates and in other countries to produce small-scale, multi-functional landscapes to enhance the environment and contribute to system resilience.174
172 E. Devabalane, "Strategies for Sustainable Development of Wetland Resources: Lake Ousteri, Puducherry," in Implementing
Campus Greening Initiatives: Approaches, Methods and Perspectives, eds. Walter Leal Filho, Nandhivarman Muthu, Golda Edwin,
Mihaaela Sima (Switzerland: Springer International Publishing, 2015), 127, accessed January 9, 2021, https://doi-org, proxy.library.
carleton.ca/10.1007/978-3-319-11961-8.
173 Kellie Fenton, "IInovative Waste Water Strategies in the Landscape: The Application of Green Infrastructure Principles in
Cape Cod, Massachusetts," 23.
174 Kellie Fenton, "Innovative Waste Water Strategies in the Landscape: The Application of Green Infrastructure Principles in
Cape Cod, Massachusetts," 86. 


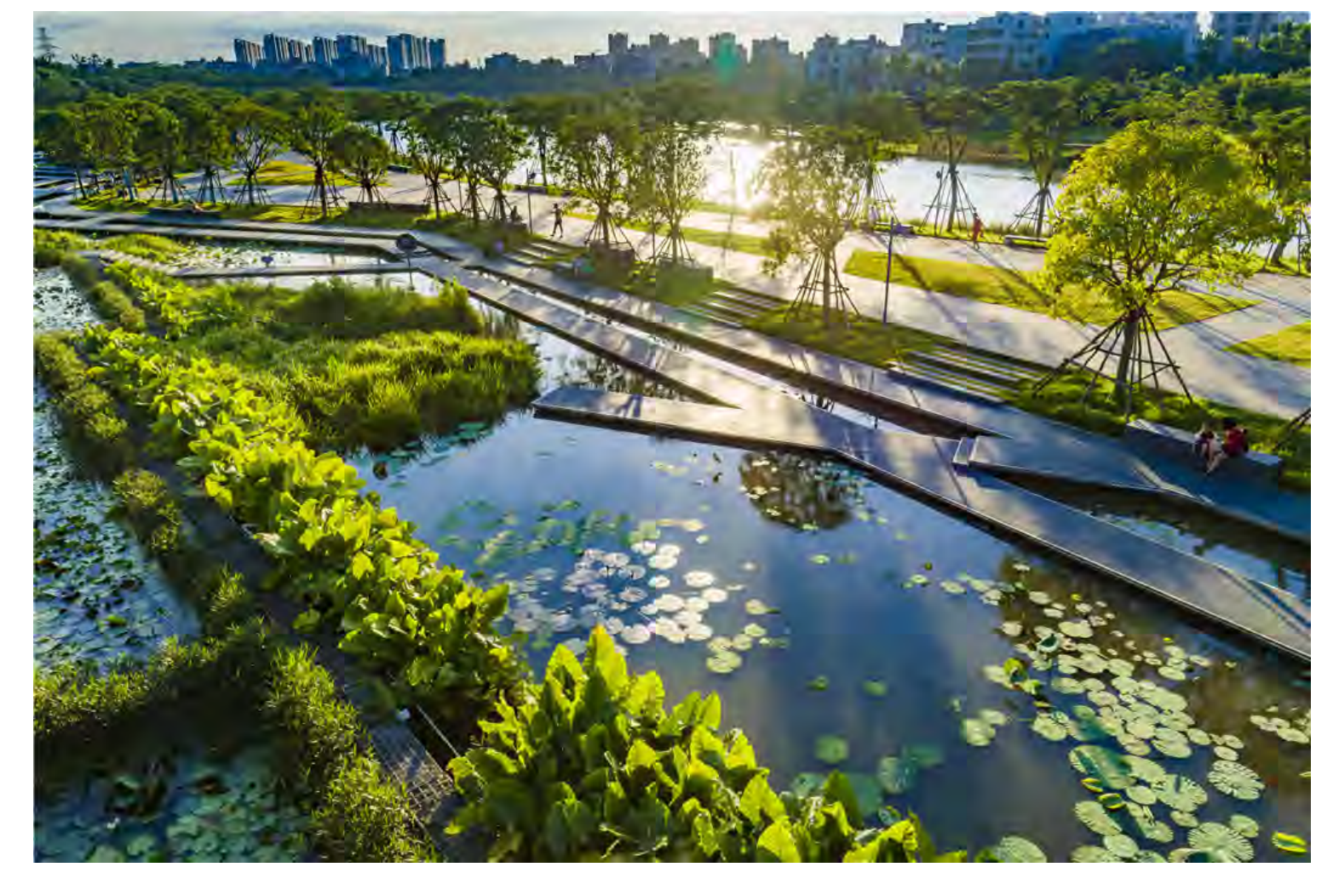

Figure 20: Photograph of a Meishe Rlver Greenway and Fengxiang Park by Turnescape. (https:// wwwturenscape.com/en/proj-
ect/detail/4676.htm)

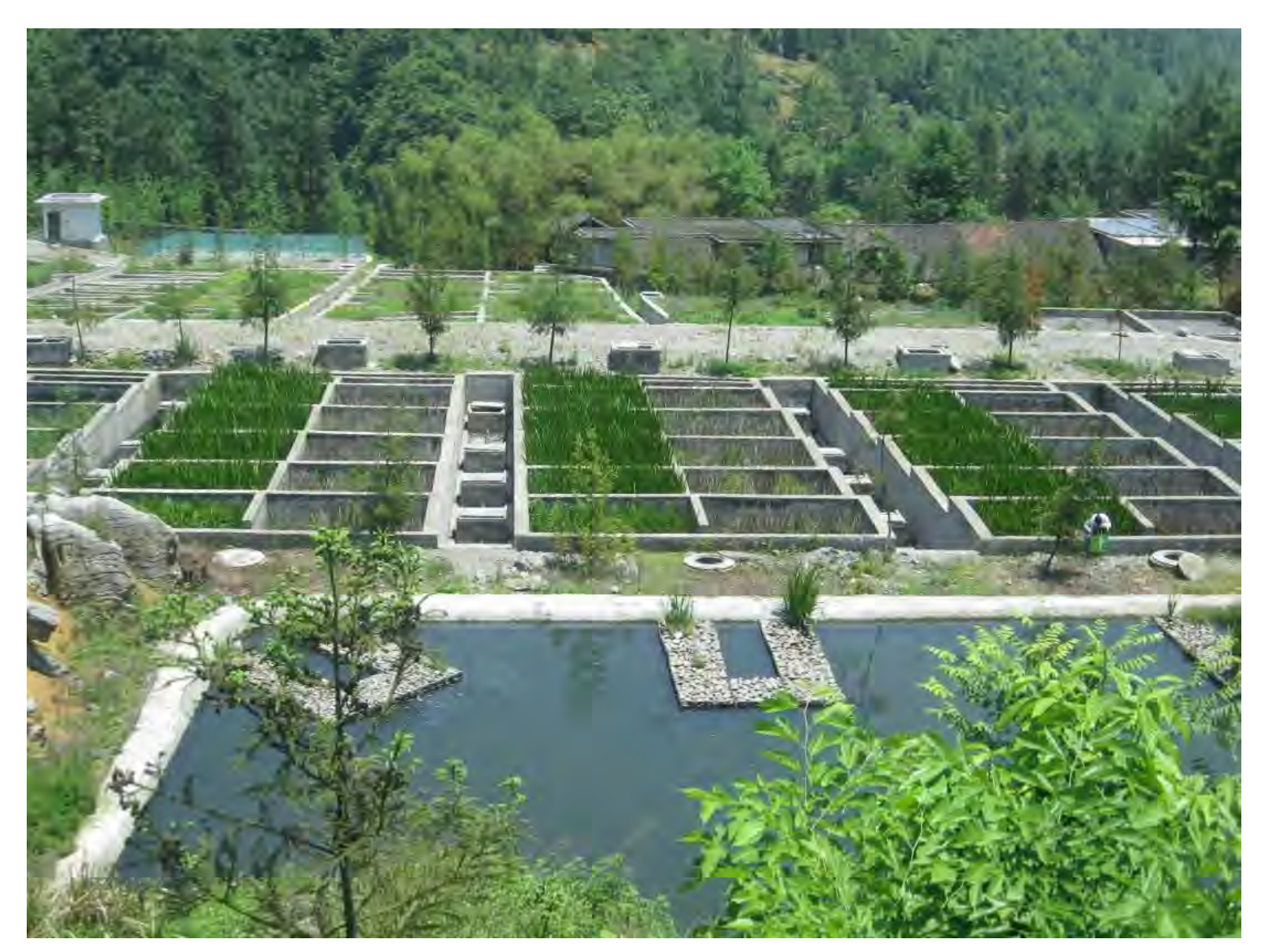

Figure 21: Photograph of the Qinghe constructed wetland wastewater treatment plant in Baishiyi Town, Chongaing. (http: //www.
environmentinformation.cn/Technologies/201811/220181115_-99523.h.hml) 

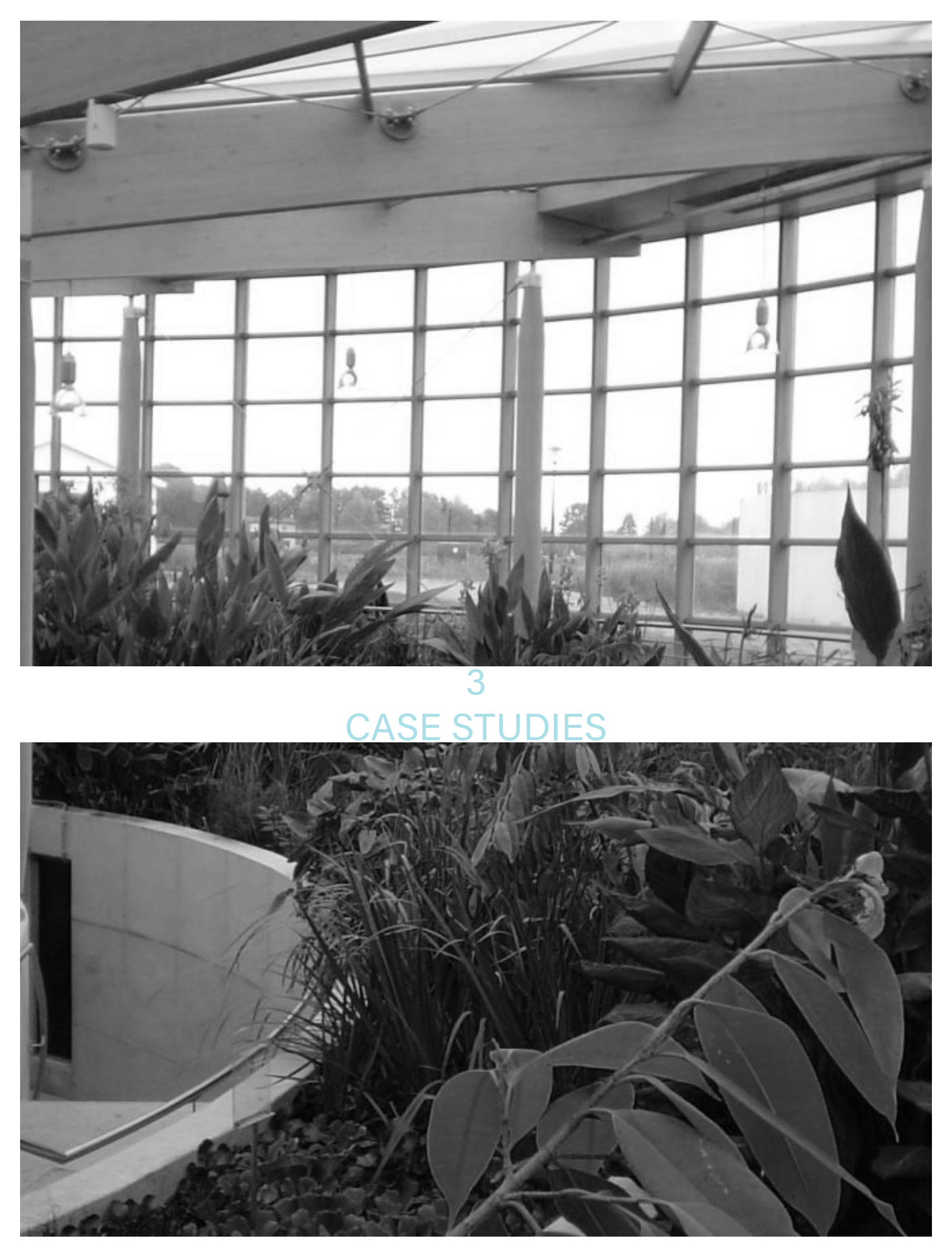

Figure 22: Photograph of the Living Machine at Emmen Zoo in the Netherlands.. (http://2030palette.org/constructed-wetland/)
Among numerous other sustainable design decisions included throughout the case study, the Sidwell Friends School by Kieran-Timberlake Associates in Washington DC acts as a prime example of wastewater treatment integration using an ecological system. The project was built in 2007 as the world's first LEED-Platinum K-12 school building. ${ }^{175}$ It encompasses both the renovation and addition to an existing 55 year-old facility and promotes environmental stewardship by example.176 For water management, it employs constructed wetlands as well as other secondary technologies including water-efficient landscaping, green roofs, and rooftop agriculture.177 These landscape elements use more than 80 species of native plantings to eliminate the need for irrigation or pesticides. ${ }^{178}$ The wetlands culminate in a rain garden and biology pond surrounded by terraces and steps that can also be converted into an outdoor classroom to serve as an asset for the students while the green roof also supports a 1000 square foot rooftop classroom that can be used for agriculture and other biological education initiatives. ${ }^{19}$

In combination, these systems are primarily intended to reduce stormwater runoff, improve the quality of infiltrated runoff and reduce municipal water use.180 The system is able to treat 3,000 gallons of wastewater per day resulting in water consumption being reduced by $93 \%{ }^{181}$ The wastewater treatment process begins with water from the toilets and sinks being sent to a solid settling tank, then cycled through

175 Landscape Performance Series, "Sidwell Friends Middle School" Landscape Architecture Foundation, accessed January 9 , 2021, https:// www landscapeperformance.org/case-study-brief//sidwell-friends-middle-school 176 American Institute of Architects, "Sidwell Friends Middle School." American Institute of Architects, accessed January 9, 2021 hetps.//www.alatopten.org/node/140.

177 Kellie Fenton, Innovative Waste Water Strategies in the Landscape: The Application of Green Infrastructure Principles in

178 Landscape Performance Series, "Sidwell Friends Middle School."

180 American Institute of Architects, "Sidwell Friends Middle School"

181 Kellie Fenton, "Innovative Waste Water Strategies in the Landscape: The Application of Green Infrastructure Principles in Cape Cod, Massachusetts," 32. 
the terraced constructed wetlands and finally filtered for final treatment where it is then stored to be used in the toilets and sinks of the building. 182 The tertiary treatment includes a trickling filter, a recirculating sand filter, and a UV disinfection uniti.183 The constructed wetlands, covering an area of 5,500 sq. ft., employ a subsurface flow system to limit human interaction with the wastewater that takes 2.9 days to process the wastewater.184

This case study has determined some important conclusions with regards to closed-loop local wastewater treatment and management using living systems. Occupying the courtyard, the constructed wetland is designed to treat stormwater and wastewater to accomplish numerous benefits including preventing 317,900 gallons of wastewater from entering the District of Columbia's overburdened sewer system annually, saving $\$ 1,687$ in sewer charges, reducing potable water consumption by an average of 8,500 gallons per month by reusing treated wastewater to flush toilets, providing educational opportunities for students and visitors and promoting environmental awareness with over 10,000 visitors attending student-run tours of the site over the first 5 years. ${ }^{185}$ It was determined that cleaning wastewater and using it on-site can also be costly with pumps being required to circulate water throughout the system and large areas required to meet treatment standards while still requiring external energy and drinking water sourcing. ${ }^{186}$ Overall, this project demonstrates how water management strategies can be employed to improve spatial experience and serve as an asset for the inhabitants of the building. By integrating ecological water 182 Kellie Fenton, "Innovative Waste Water Strategies in the Landscape: The Application of Green Infrastructure Principles in Cape Cod, Massachusetts," 32.

Water Strategies in the Landscape: The Application of Green Infrastructure Principles in Cape Cod, Massachusetts," 32 .
185 Kellie Fenton, "Innovative Was

Wer Strategies in the Landscape: The Application of Green Infrastructure Principles

Water Strategies in the Landscape: The Application of Green Infrastructure Principles in

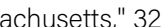

management systems, they processes become part of the everyday experience while simultaneously achieveing water reuse and treatment goals. 

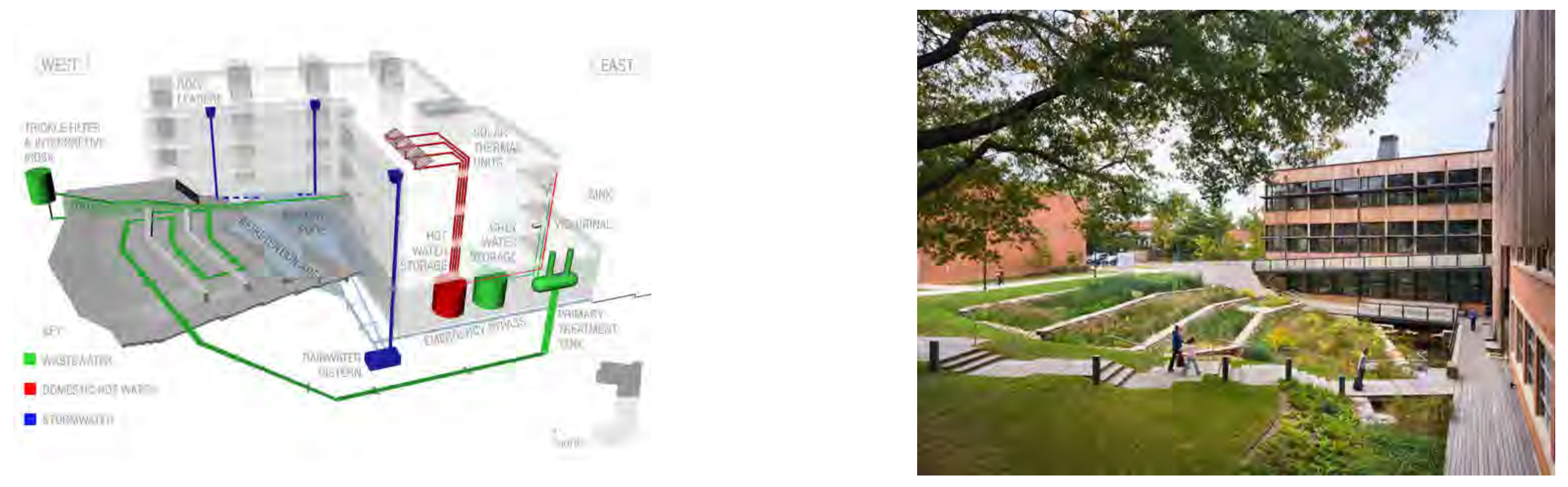
Constructed Wetlands - Wakodahatchee Wetlands (Delray Beach, FL)

The Wakodahatchee Wetlands, built in 1996 by WGI in Delray Beach, Florida, are a prime example of taking advantage of a natural landscape and its ecological processes to finish the treatment of wastewater. The wetlands were created as a centralized system using constructed wetlands for tertiary treatment of partially treated water from the wastewater treatment plant instead of the previous tactic of direct outfall to the ocean.187 The landscape acts as a response to the development pressures being put on the east coast of Florida using the wetland ecosystem to naturally filter and finish the wastewater influent ${ }^{188}$ The wetlands cover 50 acres, divided into eight separate marsh areas, on land owned by utilities and demonstrate how underutilized lands can be transformed into a wetland ecosystem for the benefit of the community.189 The wetland receives $2,000,000$ gallons of wastewater per day from the nearby reclamation facility and holds over 20,000,000 gallons of water that is treated in the different wetland communities, each designed to manage water and foster biodiversity. ${ }^{190} \mathrm{~A}$ boardwalk provides public circulation to experience the biodiversity throughout the site including over 178 species of bird as well as alligators, turtles, rabbits, fish, frogs, and raccoons. ${ }^{191}$ Open pond water areas attract waterfowl and diving birds, emergent marsh areas encourage the growth of smaller nesting bird communities, shallow shelves provide habitat for herons and egrets, islands with shrubs and snags serve as roosting, nesting and basking sites and forested wetland areas provide long-term habitat development ${ }^{192}$ Overall, the wetlands 187 Kellie Fenton, "Innovative Waste Water Strategies in the Landscape: The Application of Green Infrastructure Principles in Cape Cod, Massachusetts," 33.

Water Strategies in the Landscape: The Application of Green Infrastructure Principles in Cape Cod, Massachusetts, 33.

Water Strategies in the Landscape: The Application of Green Infrastructure Principles in

Wer Strategies in the Landscape The Application of Green Infrastructure Principles in

192 Kellie Fenton, "Innovative Waste Water Strategies in the Landscape: The Application of Green Infrastructure Principles in Cape Cod, Massachusetts," 34 provide various ecosystem services including providing food and habitat for many of Florida's threatened and endangered species and recreational activity such as bird watching while continuously detaining stormwater, protecting downstream areas from flooding and naturally purifying water containing nutrients like nitrogen and phosphorus without producing sludge or relying on fossil-fuel based energies. ${ }^{193}$ This project serves as a prime example of a large scale constructed wetland that achieves treatment goals while also including the public and promoting biodiversity. Additionally, the creation of such a large naturalized area displays the possibilities of ecological water treatment technology. However, the pedestrian circulation in this project does not seem sufficient enough to generate a real public interaction with the landscape and serves as more of a viewing promenade than an experiential asset.
193 Kellie Fenton, "Innovative Waste Water Strategies in the Landscape: The Application of Green Infrastructure Principles in Cape Cod, Massachusetts," 34 

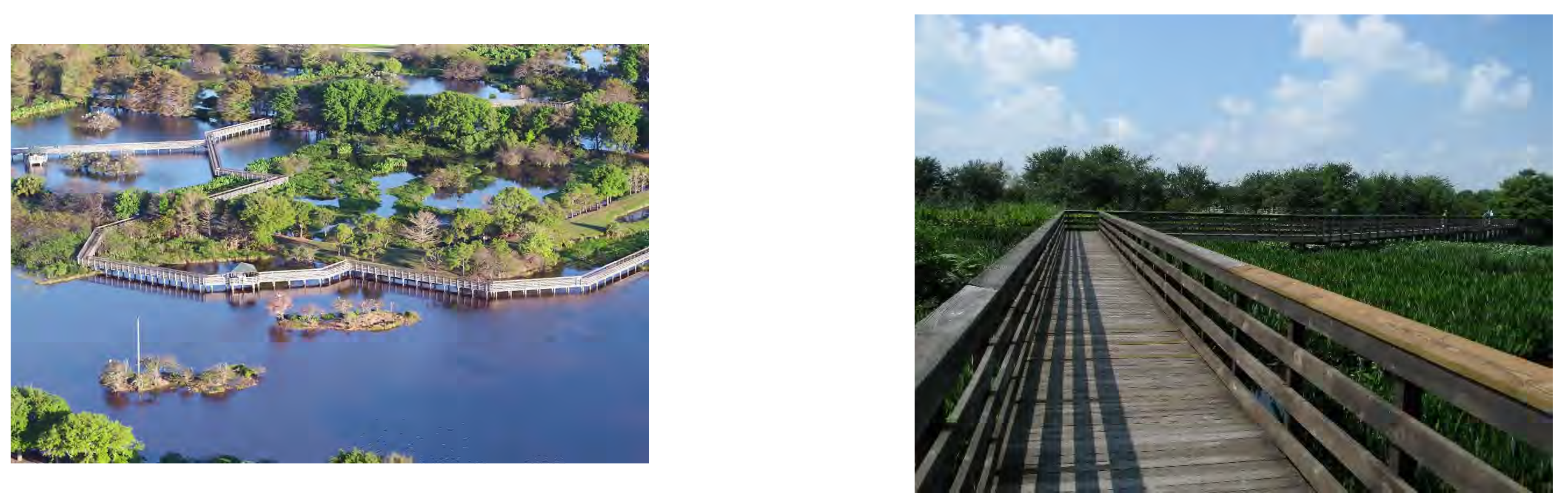
Occupying a linear 14-hectare area and built in 2010 by Turenscape, Houtan park is a regenerative landscape located on the bank of Shanghai's Huangpu River that combines constructed wetlands, ecological flood control, reclaimed industrial structures and materials and urban agriculture to treat polluted river water and restore the formerly-industrial brownfield waterfront site. ${ }^{194}$ In response to the polluted adjacent waterway, Houtan Park attempts to transform the degraded industrial landscape into a safe and attractive public space. ${ }^{195}$ Using specially selected wetland plants, the constructed wetlands consist of several cascades and terraces that oxygenate the nutrient rich river water, remove and retain nutrients and reduce suspended sediments while also providing pleasant water features and re-establishing a connection to the waterway. ${ }^{196}$ Overall, the landscape can treat up to 2,400 cubic metres of water from Lower Grade V to Grade III levels that can be used for various non-potable uses. ${ }^{197}$ The project acts as a site-specific case study for integrating public experience within natural water treatment technologies to improve spatial and physical relationships for pedestrians through circulation networks and the insertion of public spaces. It further demonstrates the possibilities of improving an existing ecosystem such as a polluted river by adding water management strategies along its banks, proving that simple additions can have considerable positive impacts.

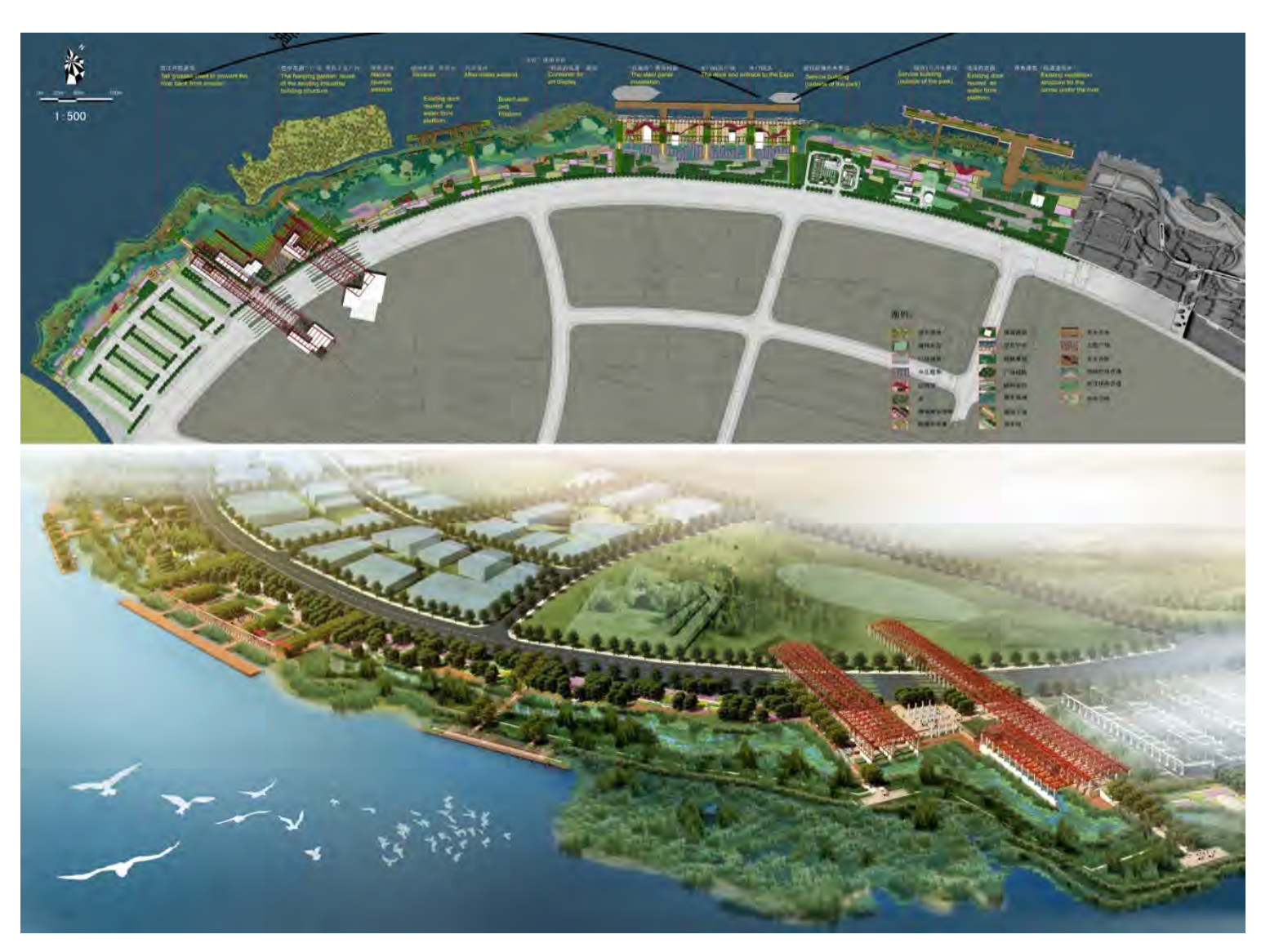




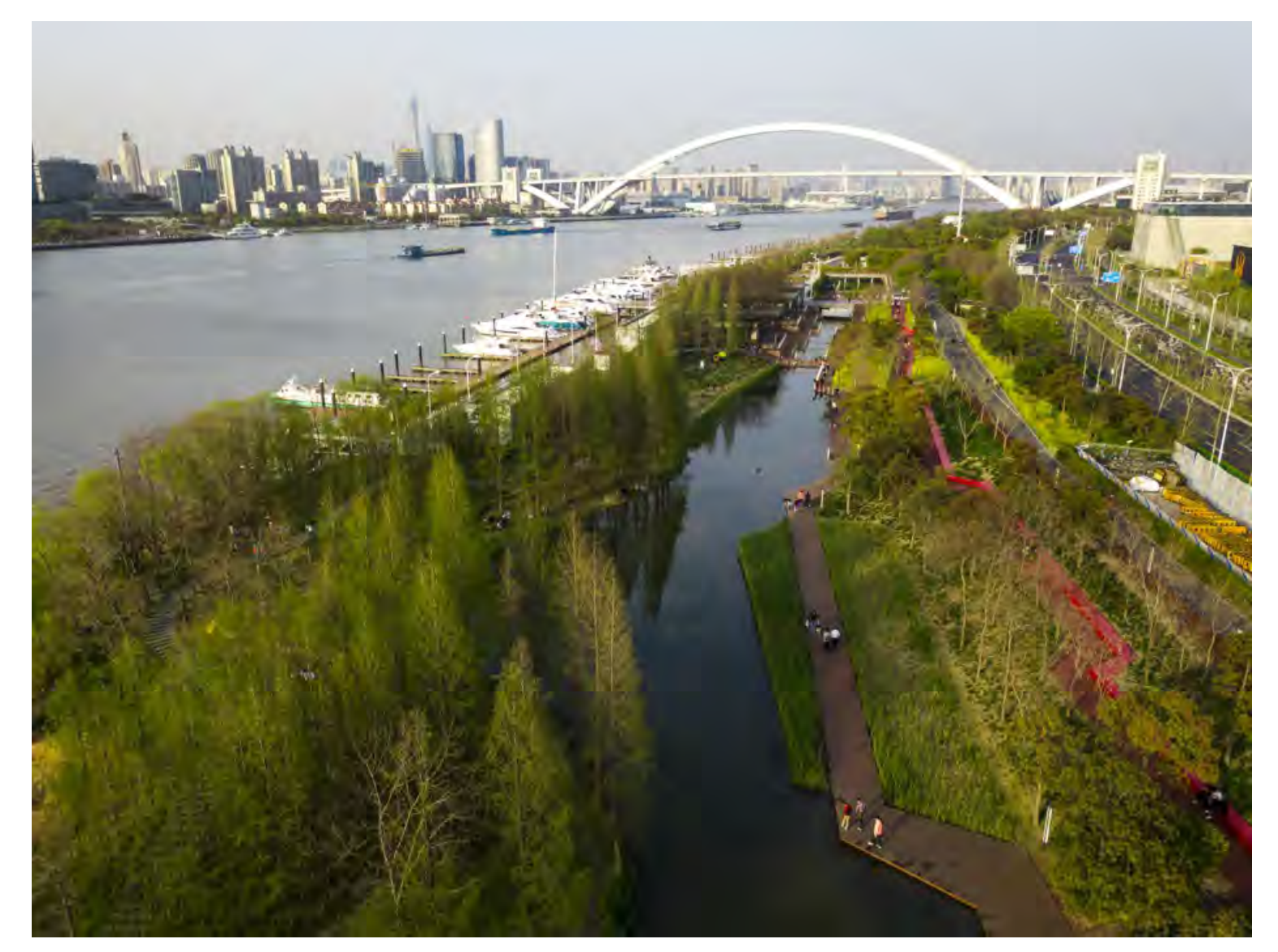

Figure 28: Photograph of public circulation and constructed wetlands at Houtan park. (https://www.turenscape.com/en/project/
detail/4647.html)
Located in Sechelt, British Columbia, the Sechelt Water Resource Centre is a prime example of integrating and testing Living Machine technologies on a large scale. Built in 2015 by PUBLIC Architecture+Communication and covering 1800 square metres, the Sechelt Water Resource Centre is an ecological municipal water treatment plant that uses biological systems to clean wastewater while capturing resources such as biosolids, heat and water for industry, parks and agriculture. ${ }^{198}$ The facility uses the first Organica Water Living Machine in North America and currently treats the wastewater of 6,000 local residents with the capacity for a population of $14,000^{199}$ The system handles an average daily flow of 4000 cubic metres and peak flow of 6000 cubic metres but can be expanded for a flow of 8,000 cubic metres per day to meet future development. ${ }^{200}$ Primary treatment consists of $6 \mathrm{~mm}$ fine screens and cyclonic grit separation that leads to secondary treatment in four Organica Fed Batch Reactors each with a volume of 1000 cubic metres. ${ }^{201}$ After primary treatment, the roots of a variety of plants within the Organica Reactors provide the environment for bacteria to thrive that decompose wastewater contaminants with the resulting wastewater sent through UV disinfection before release. ${ }^{202}$ Tertiary treatment uses membrane filtration to $20 \mathrm{~nm}$ in tandem with UV disinfection to achieve effluent quality with suspended solids $<5 \mathrm{mg} / \mathrm{L}$, biochemical oxygen demand $<5 \mathrm{mg} / \mathrm{L}$, turbidity $<1 \mathrm{NTU} / \mathrm{L}$ and coliforms median $<1$ CFU/100mL. ${ }^{203}$ The facility achieves ten times fewer discharged solids and double the treatment capacity of the conventional facility it replaced at half the cost. ${ }^{204}$ 198 PUBLIC, "Sechelt Water Resource Centre/PUBLIC," ArchDaily, accessed Janary 9, 2021, https://www.archdaily. com/896286/sechelt-water-resource-centre-public?ad_medium=gallery.

(1) -10\%20WRC\%20Fast\%20Facts.pdf

201 District of Sechelt, "Wact Resol

202 PUBUIC "Sechelt Water Resource Centre/PUB FUC"

203 District of Sechelt. "Water Resource Centre Fast Facts."

204 PUBUC. "Sechelt Whar Resource Centre/PUBUC" 
instead of dealing directly with human waste and the facility acts as an asset for the neighbouring hosting tours and providing opportunities for sustainable education. ${ }^{205}$

The project works as a perfect case study for the benefits of implementing the Organica Food Chain Reactor Model which is an adapted Living Machine system that works to improve the aesthetic appearance and experiential qualities of wastewater treatment while also meeting treatment goals in a condensed area.

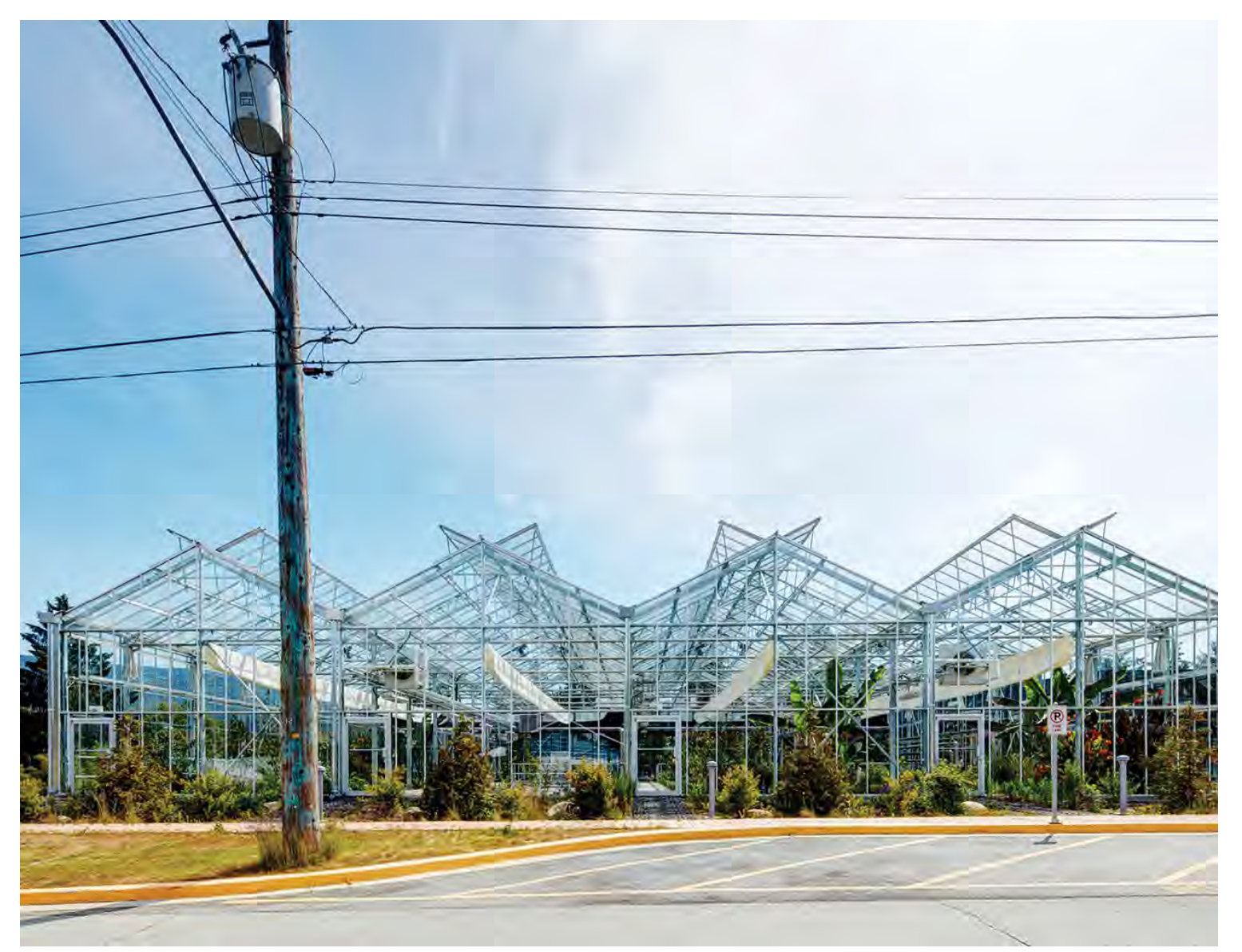


The Port of Portland office project by ZGF Architects demonstrates the implementation of a Living Machine on the interior of a commercial building to display its technology and improve the interior experience. Built in 2010, the Port of Portland office building is a 200,000 square foot facility showcasing numerous sustainability principles including a Living Machine, created by Living Machine Systems, located in its lobby. ${ }^{206}$ Occupying 70 square feet, the Living machine is designed to be a visually and aesthetically appealing asset for the building. ${ }^{207}$ Using ecological systems, the Living Machine accomplishes the decentralized treatment of site-produced wastewater to freshwater standards without the chemicals, odor, by-products, or high energy use required by conventional systems. ${ }^{208}$ The system is modelled as an engineered subsurface flow, tidal wetland system, pumping wastewater into the planted wetland basins in an alternating pattern mimicking tidal flows and allowing oxygen and nutrient replenishment for the organisms in the system before refilling. ${ }^{209}$ Before entering the wetland cells, wastewater is sent through a primary settling tank where large solids are settled and primary treatment is achieved. ${ }^{210}$ Secondary treatment comprises four tidal flow wetland cells in the lobby of the building with two additional tidal flow cells and four vertical flow polishing cells on the exterior of the building that are planted with native and naturalized plant species. ${ }^{211}$ The porous gravel substrate offers ample surface area for the thriving of biofilms, microcrustaceans, and protozoans that act together 206 Living Machine Systems, L3C, "Port of Portland Headquarters," Sustainable Water, 1-2, accessed January 9, 2021, http:// sustainablewater.com/wp-content/uploads/2013/OT/POP-Case-Study-070213.pd

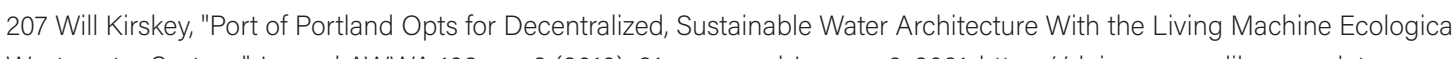
21.

208 Will Kirskey, Port of Portland Opts for Decentralized, Sustainable Water Architecture With the Living Machine Ecological 209 will Kiskey "Port 
to treat the wastewater in the system. ${ }^{212}$ The tidal-flow wetland cells use microbial communities attached to the planted and substrate media to remove pollutants from the wastewater whereas the vertical flow polishing cells remove any remaining organic material, ammonia and TSS. ${ }^{213}$ The system can treat up to 5,000 gallons of wastewater per day and uses UV disinfection as a final tertiary treatment to ensure biological safety of recycled water. ${ }^{214}$ The treated water can then be used for landscape irrigation, toile flushing, industrial processes, washing equipment or animal areas, landscape water features and many other uses. ${ }^{215}$ Overall, the system resulted in a 75\% reduction in water use and is able to treat all the wastewater from the 500 employees. ${ }^{216}$ The project acts as a prime example of how Living Machine technologies can be implemented on a smaller scale to enhance the experiential qualities of a building's interior while simultaneously achieving treatment goals within a controlled environment. The fact that the system can be implemented inside supports the claim that using biofilters controls odor production and allows for the benefits of the plants to impact the interio environment. It is assumed that this concept can be expanded to a larger scale to meet higher treatment demands while maintaining the benefits outlined in this case study.

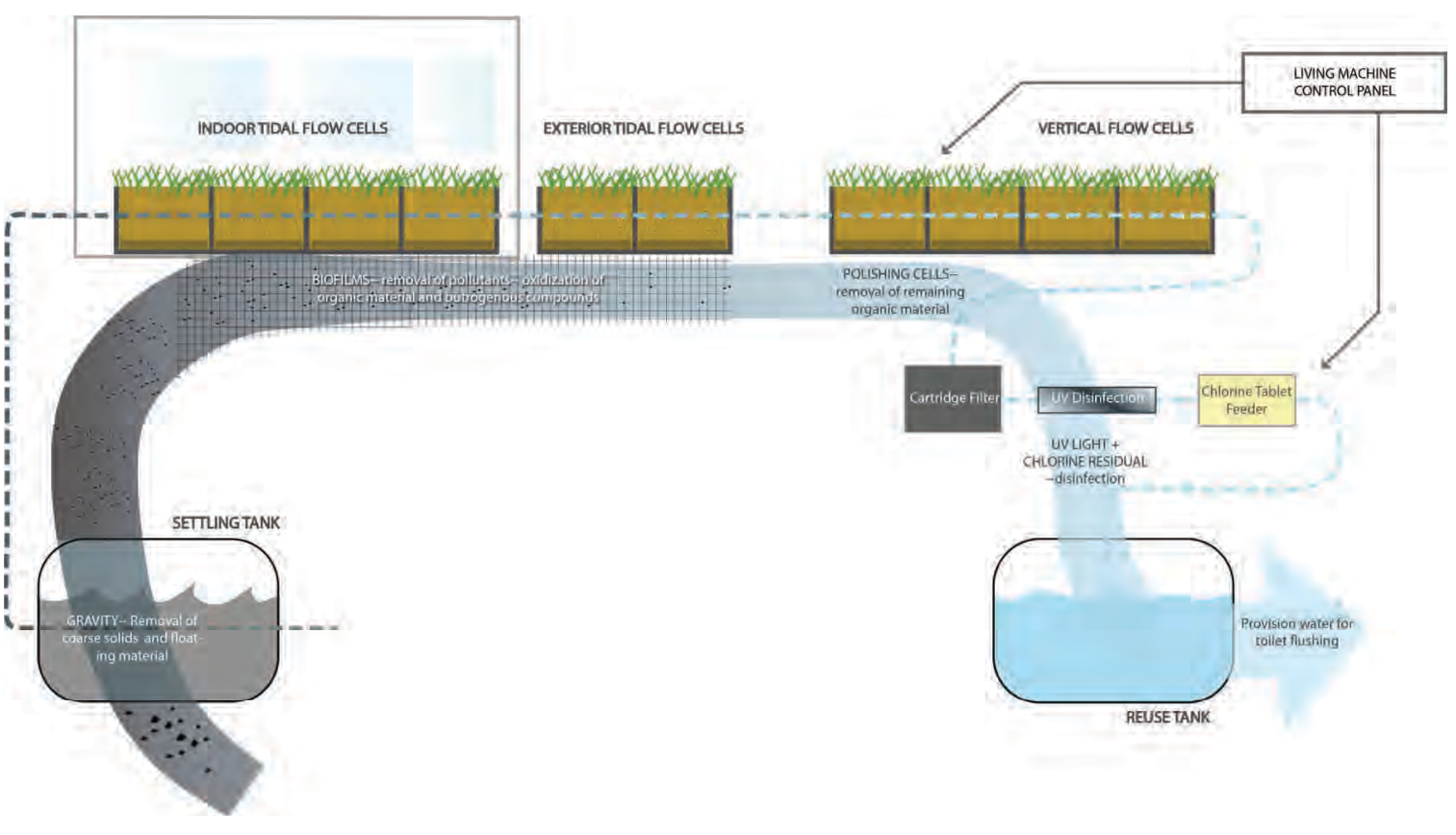

212 Will Kirskey, "Port of Portland Opts for Decentralized, Sustainable Water Architecture With the Living Machine Ecological Wastewater System," 21.

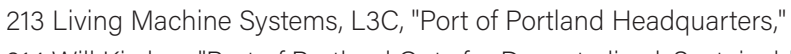

Whit Kirkey, Port of Portland Opts for Decentralized, Sustainable Water Architecture With the Living Machine Ecologica 215 Will Kirskey "Port of Por

ortland Opts for Decentralized, Sustainable Water Architecture With the Living Machine Ecologica 


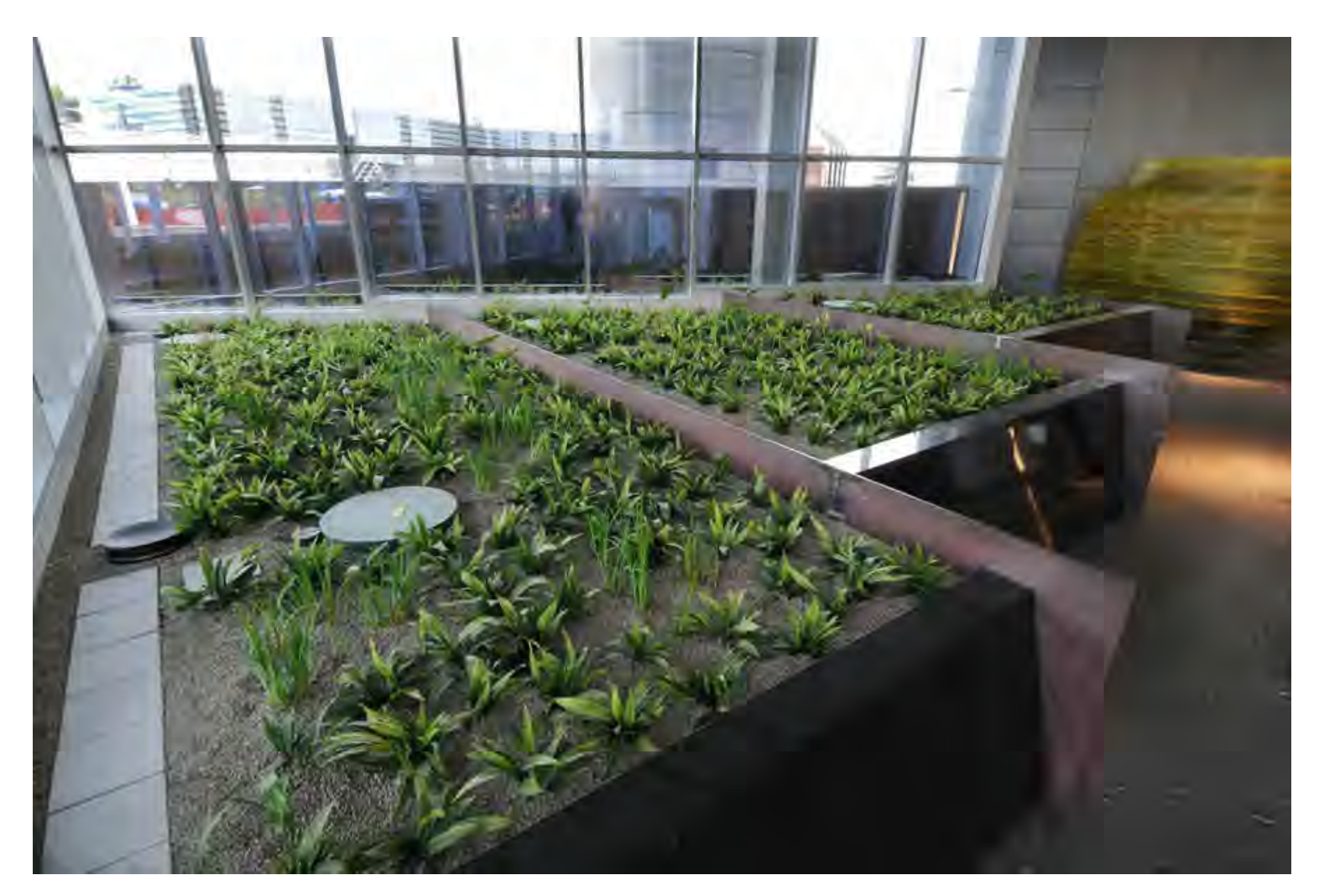

Figure 32: Photograph of the wetland cells in the lobby at the Port of Portland facility. (https://djcoregon.com/news/2011/11/09/
green-wastewater-treatment-systems-dont-work-as-well-as-hoped//)
The Omega Centre for Sustainable Living by BNIM Architects demonstrates the possibilities of Living Machines serving as a community asset for education and influencing sustainable practices. Built in 2009, the Omega Centre is a LEED-Platinum and Living Building Certified natural wastewater treatment facility located in Rhinebeck, New York. ${ }^{217}$ The facility consists of a 4,500 square foot greenhouse housing a living machine designed by John Todd Ecological Design, exterior constructed wetlands and a classroom. ${ }^{218}$ The system treats wastewater through a series of interior anoxic tanks that lead to a pair of exterior constructed wetlands using a subsurface flow system containing a series of beds three feet deep. ${ }^{219}$ This system uses plants, bacteria, algae, snails and fungi to treat wastewater in a closed-loop natural hydrologic cycle that replenished groundwater aquifers through percolation.,200 This groundwater aquifer then supplies the potable water used for the facility and is recycled through the system once used. ${ }^{221}$ Additionally, rainwater is collected in cisterns after going through UV disinfection, used for direct greywater use throughout the facility and, after use, is also returned to the wastewater treatment system to begin the cycle again.222 In total, this system harvests 16,476 gallons of water per year for reuse through wastewater and rainwater recycling. ${ }^{223}$ The wetlands contain native plants and microorganisms,

217 Jeff Kosmacker, "Omega Center for Sustainable Living Marks 10th Anniversary of Environmental Innovation \& Commitment to Climate Action," Omega (2019), accessed January 9, 2021, https://www.eomega.org/about-omega/press-center/omega-

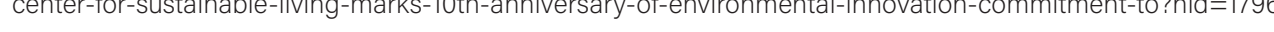
218 Jeff Kosmacker, "Omega Center for Sustainable Living Marks 10th Anniversary of Environmental Innovation \& Commitment to Climate Action.

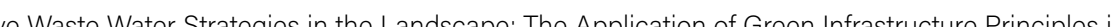
Cape Cod,

Massachusetts, 36

Ongar Center for Sustainable Living Marks 10th Anniversary of Environmental Innovation \& Commitment

221 International Living Future Institute, "Certified Living: Omega Centre for Sustainable Living," International Living Future Inthute, accessed January 9, 2021, https://living-future.org/lbc/case-studies/omega-center-for-sustainable-living/.

ing: Omega Centre for Sustainable Living " 
such as cattails and bulrushes used to reduce BOD, remove odorous gases, continue denitrification and harvest nutrients like phosphorus. ${ }^{224}$ Furthermore, the facility offers educational benefits for environmental organizations, activists, educators and students to learn about the natural processes occurring at the facility. ${ }^{225}$ The project is a perfect example of integrating Living Machine technologies within a community setting for the benefit of all inhabitants that can be scaled and repeated on a site-specific basis. Additionally, the public interaction with the interior reactors demonstrates the educational possibilities of these systems that can be employed on a larger scale.

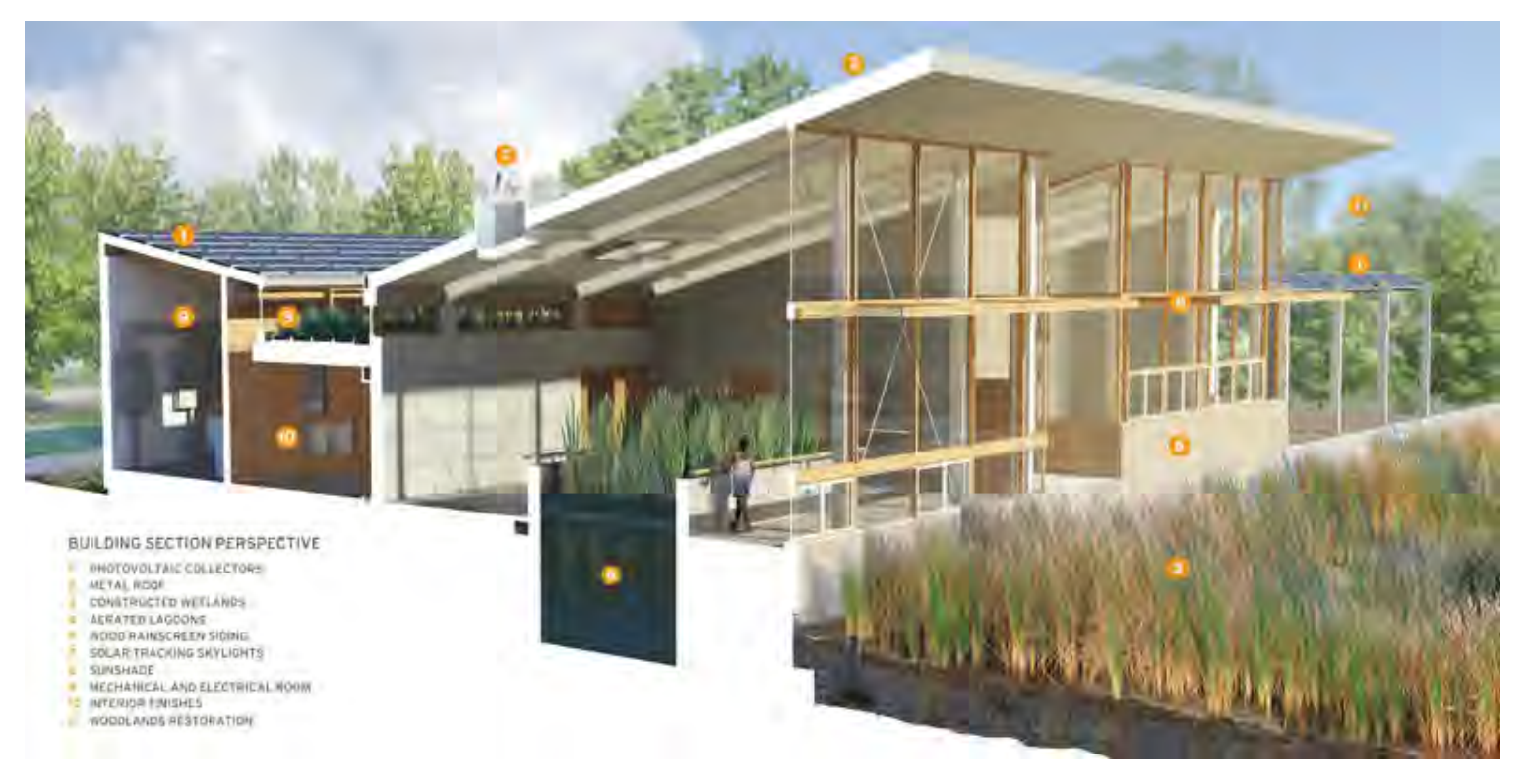


The Living Machine in South Burlington by Ocean Arks International acts as one of the original examples of the application of Living Machines and operated from 1995 to 2001 to test the effectiveness of ecological treatment systems. ${ }^{226}$ It was built by Living Technologies Inc. in tandem with Dr. John Todd and Ocean Arks International. ${ }^{227}$ The system was designed to treat 80,000 gallons per day of screened and degritted wastewater. $^{228}$ It covered an area of 7800 square feet, equivalent to $0.00038 \%$ of Burlington's combined living space, and was able to process 15\% of Burlington's wastewater with a hydraulic retention time of 2.8 days. ${ }^{229}$ It was built adjacent to the city's centralized wastewater treatment plant to divert water to be treated by ecological processes through two treatment paths, each with five aerobic reactors, a clarifier, and three ecological fluidized beds. ${ }^{230}$ The open aerobic reactors used diffusers and floating plants to maintain a diversity of plant species that, in tandem with aeration, hosted a variety of organisms that digested nutrients and pollutants in the wastewater. ${ }^{231}$ This system was able to reduce biochemical oxygen demand (BOD), total suspended solids (TSS), ammonia and total nitrogen. ${ }^{232} \mathrm{BOD}, \mathrm{TSS}$ and total nitrogen were treated to $<10 \mathrm{mg} / \mathrm{L}$, Nitrate was reduced to $<5 \mathrm{mg} / \mathrm{L}$, and Ammonia was reduced to $<1 \mathrm{mg} / \mathrm{L}$. ${ }^{233}$ The system resulted in an overall BOD and TSS removal in excess of $95 \%$ and total

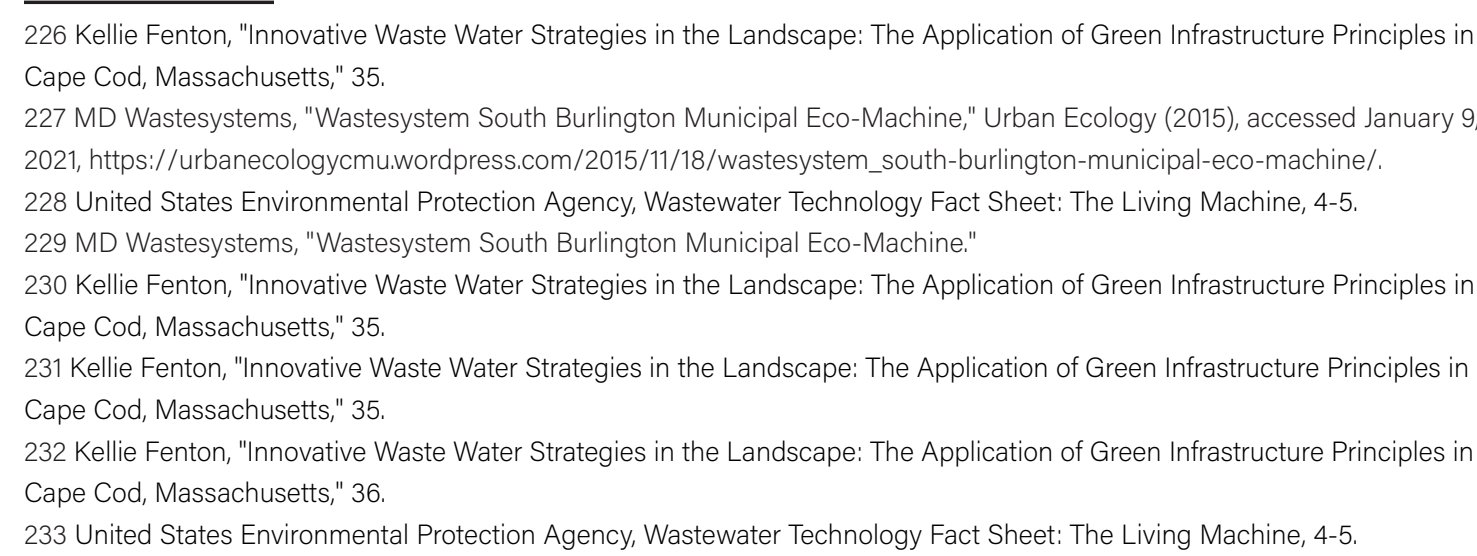$$
233 \text { United States Environmental Protection Agency, Wastewater Technology Fact Sheet: The Living Machine, 4-5. }
$$ 
phosphorus removal of 50\%. ${ }^{234}$ However, the effluent from the system had coliform levels above $1000 \mathrm{MPN} / 100 \mathrm{~mL}$, thus indicating that disinfection may be required as an additional tertiary treatment to achieve desired effluent standards. ${ }^{235}$ The system resembles more of a garden than a water treatment plant and was used as an educational tool for schools and universities. ${ }^{236}$ This project serves as the pilot project and proof of concept for the function and performance of the Living Machine as a viable system and, although it needed some improvements udring its operation, it showcased the possibilities of ecological wastewater treatment technologies that influenced al subsequent developments in the sector.

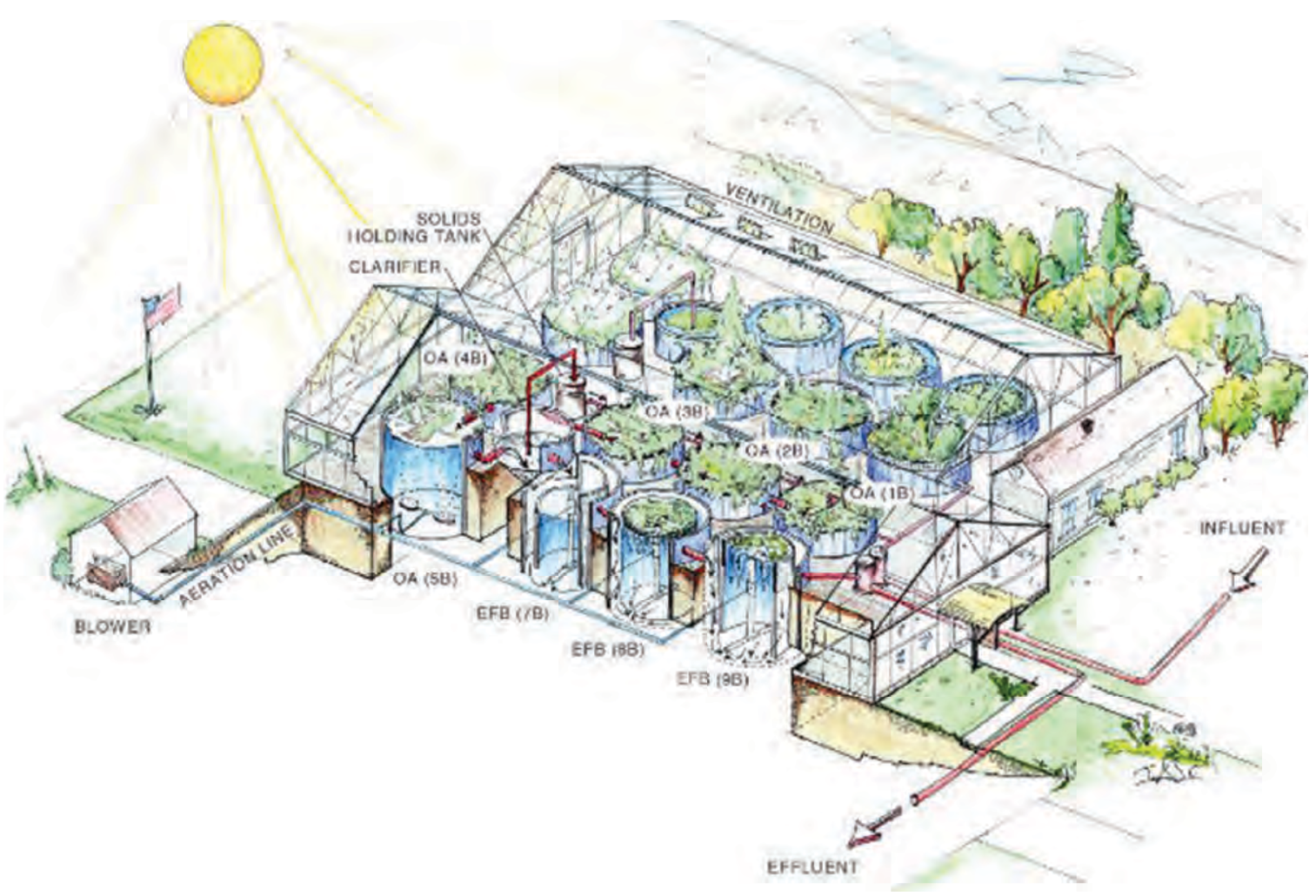




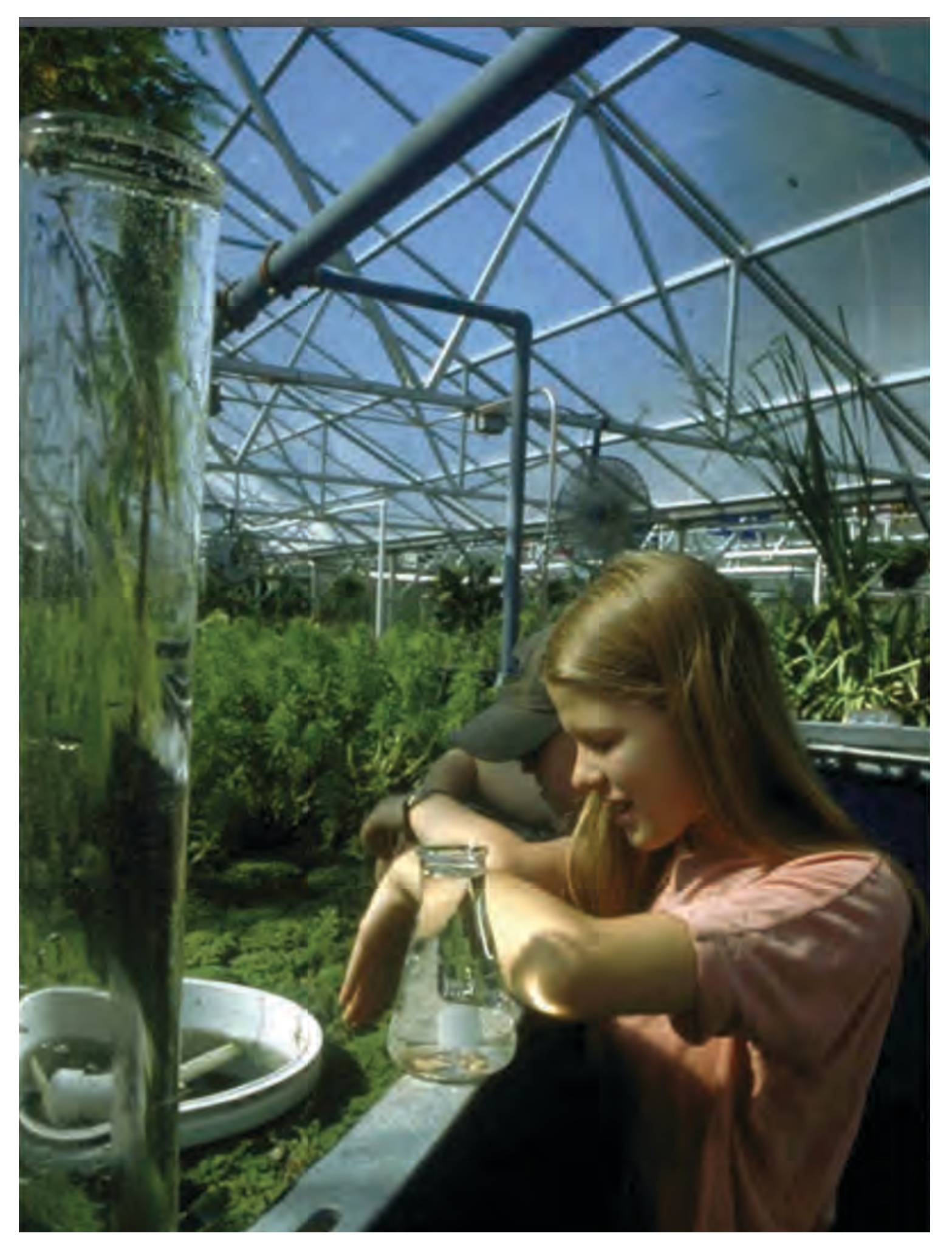

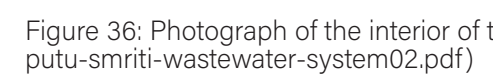
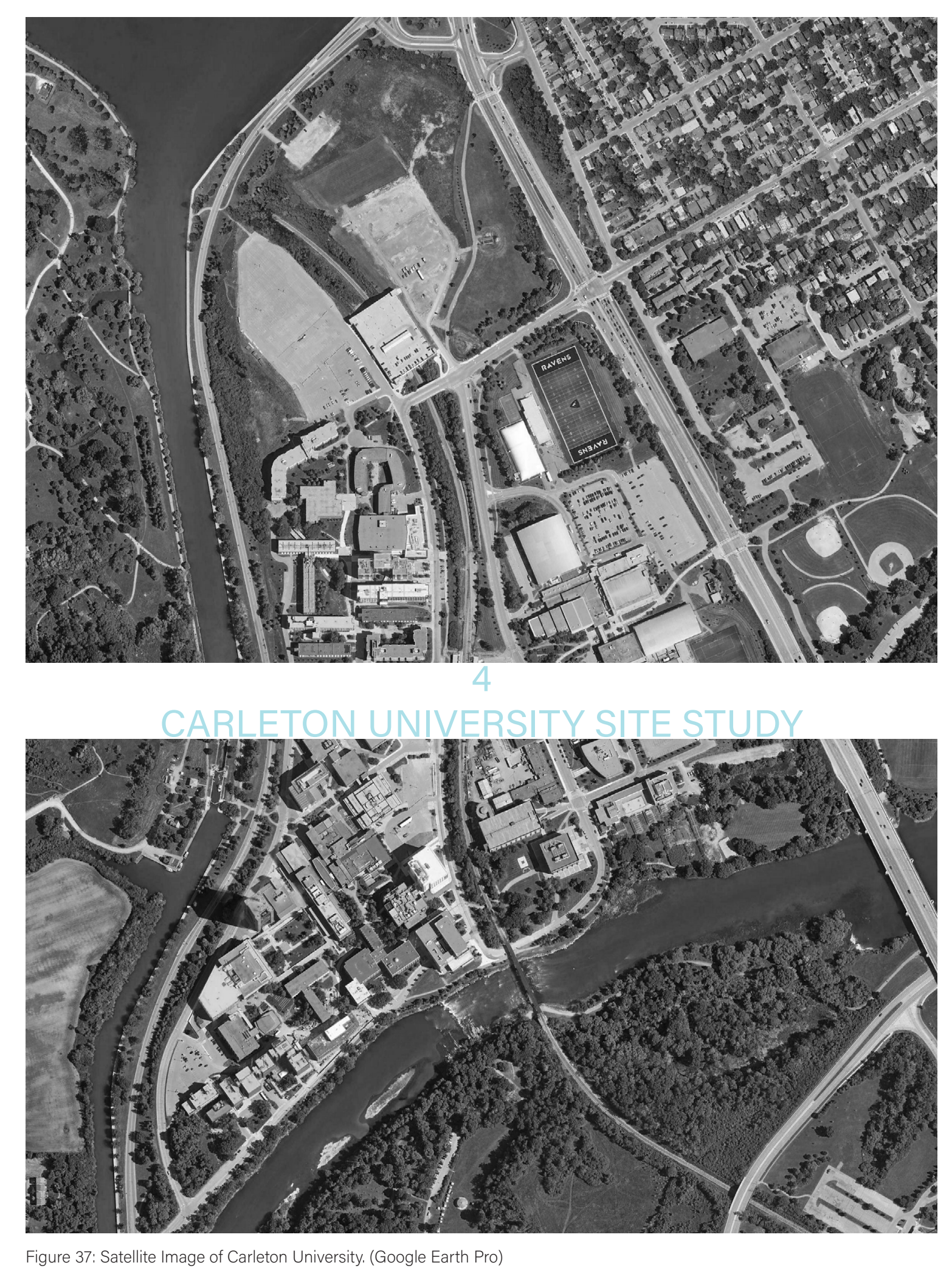

Figure 37: Satellite Image of Carleton University. (Google Earth Pro) 
and the other where Bronson crosses the River. As has been explained in earlier

Based upon previous research, the focus was turned to Carleton University and the current campus characteristics in order to determine courses of action for implementing water-based technologies to improve the campus relationship with water and the school's overall public spatial experience. Carleton University is located at an important junction in the waterways of Ottawa, serving as the divider between the Rideau River and Canal and bordering both of them, and therefore has an important role to play in its water management. However, water management is scarcely mentioned in the sustainability discourse around campus. Upon examination of the campus water management plant, specific issues regarding stormwater and wastewater have been identified.

Carleton has a large stormwater catchment area covered extensively with impermeable surfaces in the form of low-rise buildings and asphalt and concrete paving. In addition, because of this extensive surface covering, the large infiltration zones that do still exist are located mainly on the periphery with minimal infiltration occurring in the inner campus. This, and the campus's location on poorly draining soils, produces extensive stormwater runoff that is mostly uncontrolled. As is typical with most other places in the world, stormwater on campus is dealt with by collecting the water, hiding it in stormwater drains and letting it runoff discretely somewhere further downriver. The resulting stormwater runoff on campus is mostly captured by a stormwater sewer network that dumps the untreated water directly into the Rideau River through five main outlets spread across the southern bank of campus. Stormwate that is not captured by the sewers becomes surface runoff that generally flows from the northwest to the southeast across campus and discharges from two main locations also on the southern bank of campus, one where the tracks begin to cross the River

sections, this uncontrolled runoff leads to flooding during extreme events and picks up any pollutants present on the surface of the landscape and transports it directly to the receiving water resulting in water contamination. The southeast portion of campus is already located in a flood zone and contains a small natural wetland that can treat a small portion of the stormwater before its release but is not large enough to handle the volumes from the entire campus area (See Figure 38). There is an opportunity to collect rooftop stormwater and redirect it to the centre of campus in order to treat it or delay its release into the river to prevent flooding and pollution. In order to help alleviate the effects of this stormwater runoff and help with preventing downstream flooding, it was determined that measures should be implemented to intercept, store and treat stormwater on campus instead of allowing the untreated excess runoff that currently occurs.

To understand the amount of water that is released through runoff produced on campus, campus stormwater runoff was estimated using the Rational Method.

Calculations:

$\mathrm{Qp}=\mathrm{CiA}, \mathrm{Tc}=15 \mathrm{~min}, \mathrm{Td}=1 \mathrm{hr}, \mathrm{C}($ pervious $)=0.2, \mathrm{C}($ impervious $)=0.8$ $A($ total $)=62 \mathrm{ha}$

$A($ pervious $)=62$ ha $\times 0.3(30 \%$ of campus permeable $)=18.6 \mathrm{ha}$

$A($ impervious $)=62 \mathrm{ha} \times 0.7(70 \%$ of campus impermeable $)=43.4 \mathrm{ha}$

$1 \mathrm{hr} / 50 \mathrm{yr}$ Storm $(i=40 \mathrm{~mm} / \mathrm{hr}, \mathrm{d}=40 \mathrm{~mm})$

Qp50,i $=(0.8)(40 \mathrm{~mm} / \mathrm{hr})(43.4 \mathrm{ha})(2.78)=3860.86 \mathrm{~L} / \mathrm{s}, \mathrm{Qp50}, \mathrm{p}=(0.2)(40 \mathrm{~mm} / \mathrm{hr})$ $(18.6 \mathrm{ha})(2.78)=413.66 \mathrm{~L} / \mathrm{s}$

Sum Qp50 $=3860.86 \mathrm{~L} / \mathrm{s}+413.66 \mathrm{~L} / \mathrm{s}=4274.52 \mathrm{~L} / \mathrm{s},(4274.52 \mathrm{~L} / \mathrm{s})(0.001 \mathrm{~m} 3 / \mathrm{L})$ $(3600 \mathrm{~s} / \mathrm{hr})=15,388.27 \mathrm{~m} 3 / \mathrm{hr}$

$15,388.27 \mathrm{~m} 3 / \mathrm{hr} \times 1.25 \mathrm{hr}(\mathrm{Td}+\mathrm{Tc})=19,235.34 \mathrm{~m} 3$

$1 \mathrm{hr} / 10 \mathrm{yr}$ Storm $(\mathrm{i}=30.6 \mathrm{~mm} / \mathrm{hr}, \mathrm{d}=30.6 \mathrm{~mm})$

Qp10,i $=(0.8)(30.6 \mathrm{~mm} / \mathrm{hr})(43.4 \mathrm{ha})(2.78)=2953.56 \mathrm{~L} / \mathrm{s}, \mathrm{Qp10}, \mathrm{p}=(0.2)(30.6 \mathrm{~mm} /$ 
$\mathrm{hr})(18.6 \mathrm{ha})(2.78)=316.45 \mathrm{~L} / \mathrm{s}$

Sum Qp10 $=2953.56 \mathrm{~L} / \mathrm{s}+316.45 \mathrm{~L} / \mathrm{s}=3270.01 \mathrm{~L} / \mathrm{s},(3270.01 \mathrm{~L} / \mathrm{s})(0.001 \mathrm{~m} 3 / \mathrm{L})$

(3600s/hr) $=11,77236 \mathrm{~m} 3 / \mathrm{hr}$

$11,772.36 \mathrm{~m} 3 / \mathrm{hr} \times 1.25 \mathrm{hr}(\mathrm{Td}+\mathrm{Tc})=14,715.45 \mathrm{~m} 3$

$1 \mathrm{hr} / 2 \mathrm{yr}$ Storm $(\mathrm{i}=19.8 \mathrm{~mm} / \mathrm{hr}, \mathrm{d}=19.8 \mathrm{~mm})$

$\mathrm{Qp} 2, \mathrm{i}=(0.8)(19.8 \mathrm{~mm} / \mathrm{hr})(43.4 \mathrm{ha})(2.78)=1911.13 \mathrm{~L} / \mathrm{s}, \mathrm{Qp}, 2, \mathrm{p}=(0.2)(19.8 \mathrm{~mm} / \mathrm{hr})$ $(18.6 \mathrm{ha})(2.78)=204.76 \mathrm{~L} / \mathrm{s}$

Sum Qp,2=19,11.13L/s $+204.761 \mathrm{~L} / \mathrm{s}=2115.89 \mathrm{~L} / \mathrm{s},(2115.89 \mathrm{~L} / \mathrm{s})(0.001 \mathrm{~m} 3 / \mathrm{L})$

$(3600 \mathrm{~s} / \mathrm{hr})=7617.2 \mathrm{~m} 3 / \mathrm{hr}$

$7617.2 \mathrm{~m} 3 / \mathrm{hr} \times 1.25(\mathrm{Td}+\mathrm{Tc})=9521.5 \mathrm{~m} 3$

Therefore, the entire campus would produce an estimated 19, $235.34 \mathrm{~m} 3$ of unmanaged runoff during a 1-hour 50-year storm, $14,615.45 \mathrm{~m} 3$ during a 1-hour 10year storm, and $9521.5 \mathrm{~m} 3$ during a 1-hour 2-year storm. These figures indicate the enourmous amounts of stormwater runoff that enter the surrounding waterways unimpeded during various storm events on Campus.

With regards to wastewater, campus sewage is an increasing issue requiring specific attention since volumes are continuing to rise with an increasing student population. ${ }^{237}$ Campus sewage has been shown to have biochemical oxygen demand (BOD) not higher than 600mg/L and a chemical oxygen demand (COD) not higher than $700 \mathrm{mg} / \mathrm{L}$ while also showing the presence of heavy metals such as barium, iron, copper, strontium, cadmium and lead as well as phenols that can transform into micropollutants. ${ }^{238}$ Compared to domestic raw sewage, campus sewage typically has a higher BOD, lower COD and a similar pH while also possessing total suspended solids measuring 6-695.8 mg/L, total phosphorus measuring 3.1-11.8 $\mathrm{mg} / \mathrm{L}$ that can lead to eutrophication of water, and N-NH3 measuring 6.1-199 mg/L. ${ }^{239}$ Furthermore, being that raw sewage comes from human excreta (feces and urine), it contains numerous 237 Nasuha Safie, Nurliyana and Abu Zahrim Yaser, "Sewage Treatment in Campus for Recycling Purpose," 207. 239 Nasuha Safie Nurliyen and Abu Zahrim Yaser "Semage Treatnentin Campus for Recycling Pupose," 208-200. bacteria and viruses such as Eschericia Coli, total coliforms, intestinal enterococci, sulfate-reducing clostridia, bacteroides and amphizoic protozoa that can cause endemic waterborne diseases. ${ }^{240}$ Thus, raw sewage possesses numerous contaminants that must be remedied during the treatment process before reuse. However, considering the variety, the levels of contaminants in campus wastewater is considered fairly low and makes it safe for natural treatments before reuse. ${ }^{241} \mathrm{All}$ of the wastewater currently produced at Carleton feeds into the Ottawa network via a single outlet on its eastern edge. Within campus, there are only two sewer lines that pass from the west side of campus to the east side across the O-train tracks (See Figure 39). It is at these two lines crossing the tracks where the best opportunity occurs to intercept sewage for treatment as a way of relieving Ottawa's sewage network and reducing Carleton's wastewater impact downstream.

In order to better understand these wastewater issues, the volume produced by Carleton University was estimated in two ways. Based on measurements indicating that Carleton used approximately 425,796 cubic metres of water in 2016, it was assumed that all of this water was turned into wastewater and fed into the sewage network. ${ }^{242}$ This resulted in a total daily wastewater production estimated at 1,167 cubic metres. Further estimations also predicted that Carleton would use as much as 1,697 cubic metres of water per day in the future. ${ }^{243}$ To provide an alternative estimate of wastewater production, a separate set of calculations was conducted based on an average daily wastewater production of $300 \mathrm{~L}$ of wastewater per person per day and considering the different populations on campus. ${ }^{244}$ The 27,912 off-campus students were estimated

240 Nasuha Safie, Nurliyana and Abu Zahrim Yaser, "Sewage Treatment in Campus for Recycling Purpose," 208-209. 241 Nasuha Safie, Nurliyana and Abu Zahrim Yaser, "Sewage Treatment in Campus for Recycling Purpose," 235-236 242 Sustainability Carleton University, Carleton University Energy Master Plan (Ottawa: Carleton University, 2018), 35, accessed January 9, 2021, https://carleton.ca/fmp/wp-content/uploads/Sustainability-Energy-Master-Plan-2018-21-update.pd

.

244 Banu Ormeci "An Overview of Water Supply, Use and Treatment in Canada" 117-118 
to produce $10 \%$ of their average wastewater on campus over five days per week amounting to an average of 596 cubic metres of wastewater per day. The 3610 oncampus students were estimated to produce $90 \%$ of their wastewater on campus over seven days a week amounting to an average of 975 cubic metres of wastewater per day. The 965 faculty were estimated to produce $20 \%$ of their wastewater on campus over five days per week amounting to an average of 41 cubic metres of wastewater per day. The 1317 staff members were estimated to produce 10\% of their wastewater on campus over seven days per week amounting to an average of 40 cubic metres of wastewater per day. The 836 contract instructors were estimated to produce 10\% of their wastewater on campus over five days per week amounting to an average of 40 cubic metres of wastewater per day. The 105 library staff were estimated to produce $10 \%$ of their wastewater on campus over seven days per week amounting to an average of 3 cubic metres of wastewater per day. In total, these volumes amounted to Carleton producing approximately 1,672 cubic metres of wastewater per day which falls within the projected estimations. These large amounts of wastewater would all have to be captured and treated in order to completely close off the campus from the rest of Ottawa and alleviate the system.

Aside from the stormwater and wastewater situations, other campus relationships were also documented in order to determine how implementing water management technologies could improve the campus experience. Transportation relationships were analyzed first to determine existing circulation and opportunities for facilitating better connections across campus. Carleton possesses an extensive road network that gives vehicle access to the campus. The main road network circumnavigates the centre of campus and is supported mainly with parking zones primarily occupying the periphery, except in some select instances in the campus centre. There exists the opportunity to remove the central parking zones in order to free up this space for better use as a key campus area and to lower the amount of traffic throughout the inner campus. Carleton also has three main transit entries and exits to campus: the first is a shared vehicle/bus route road access at the northeastern edge along Bronson avenue, the second is the northbound train line at the northern edge of campus, and the third is the southbound train line at the southern edge of campus. These transit lines meet to create a central transit zone in the middle of campus that acts as the main entry point for much of Carleton's population (See Figure 40). There is the opportunity to position infrastructure in the central transit zone while revamping the existing transit relationships at Carleton by improving the road network for transit or pedestrian use.

Pedestrian access to Carleton is served by an extensive network of surface pedestrian and bike paths that include four possible areas to cross from the west to east sides of campus across the train tracks. The campus is connected to several major pedestrian thoroughfares including the Rideau River and Canal pathways and is mostly contained within a 10-minute walking radius and a 5-minute biking radius, making it very accessible for pedestrian circulation. In addition to surface paths, Carleton also possesses an extensive tunnel network connecting all its buildings underground and an intervention could tie into this existing network to reinforce its unique importance to the university (See Flgure 41). There exists the opportunity to create new train track crossing zones to help better connect both sides of campus while also promoting a more pedestrian friendly campus.

Lastly, academic distribution and public space were examined to explore how existing networks could be enhanced for public appeal. Carleton claims that it possesses extensive green space scattered across campus through quad networks but these zones are in fact smaller than expected when considering the campus footprint 
with multiple larger zones only existing along the periphery and disconnected from the rest of campus. Along the path around the central spine, there is limited existing green space that is unprogrammed and dominated by impermeable surfaces and ageing campus buildings. It is clear that there has been an intent on maintaining a façade of green space for the central spine facing institutional buildings on either side. However, there is a lack of programmed and useful green space within this space and it is being continually removed and replaced by impermeable surfaces as Carleton expands (See Figure 42). There exists the opportunity to create a large central green zone that occupies the inner campus in order to improve campus communal experience and environmental biodiversity while connecting and extending the existing quad network across campus and providing a clear connection to the Rideau River to the south.

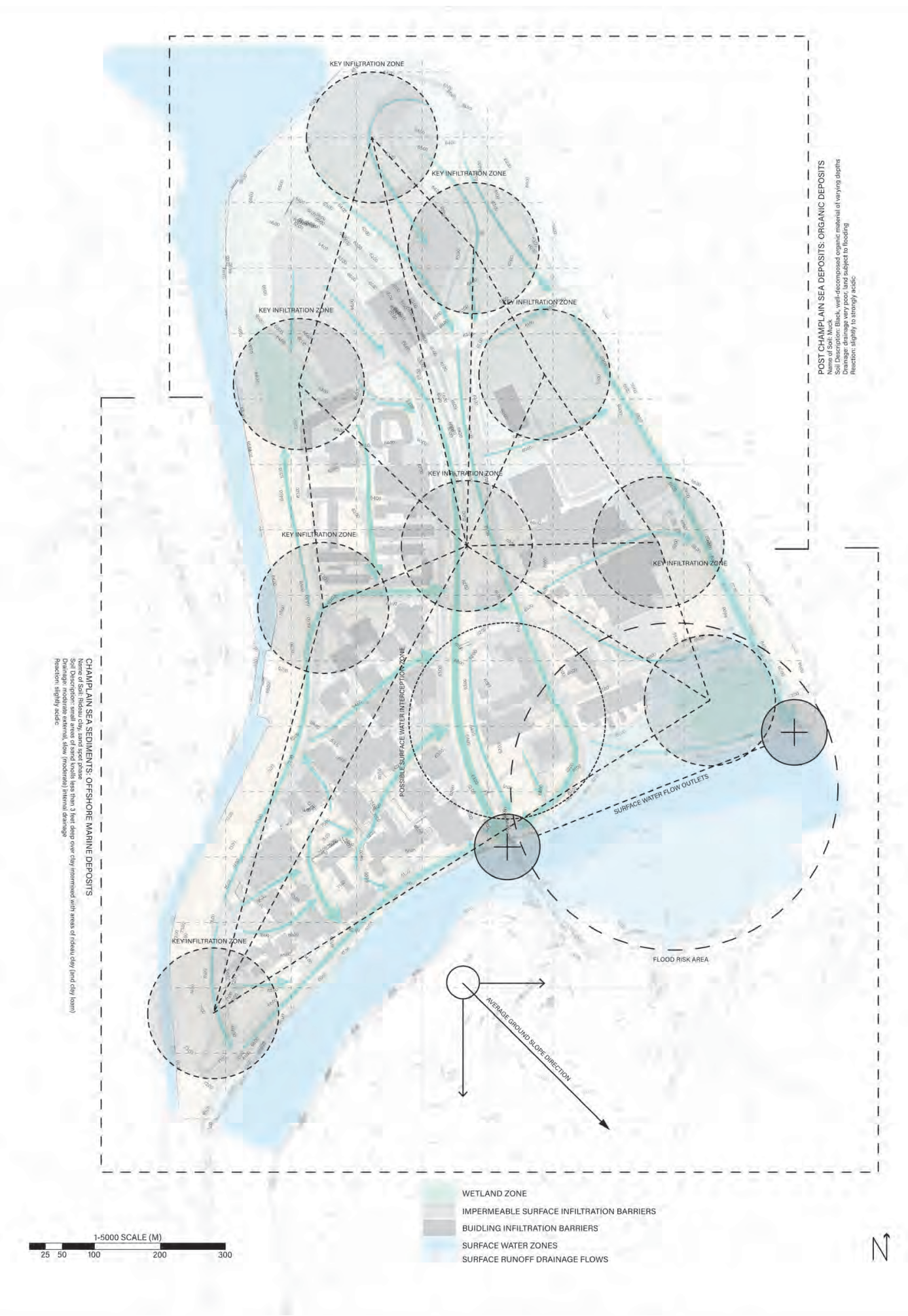

Figure 38: Map of existing topographic characteristics and surface water flow at Carleton University. 


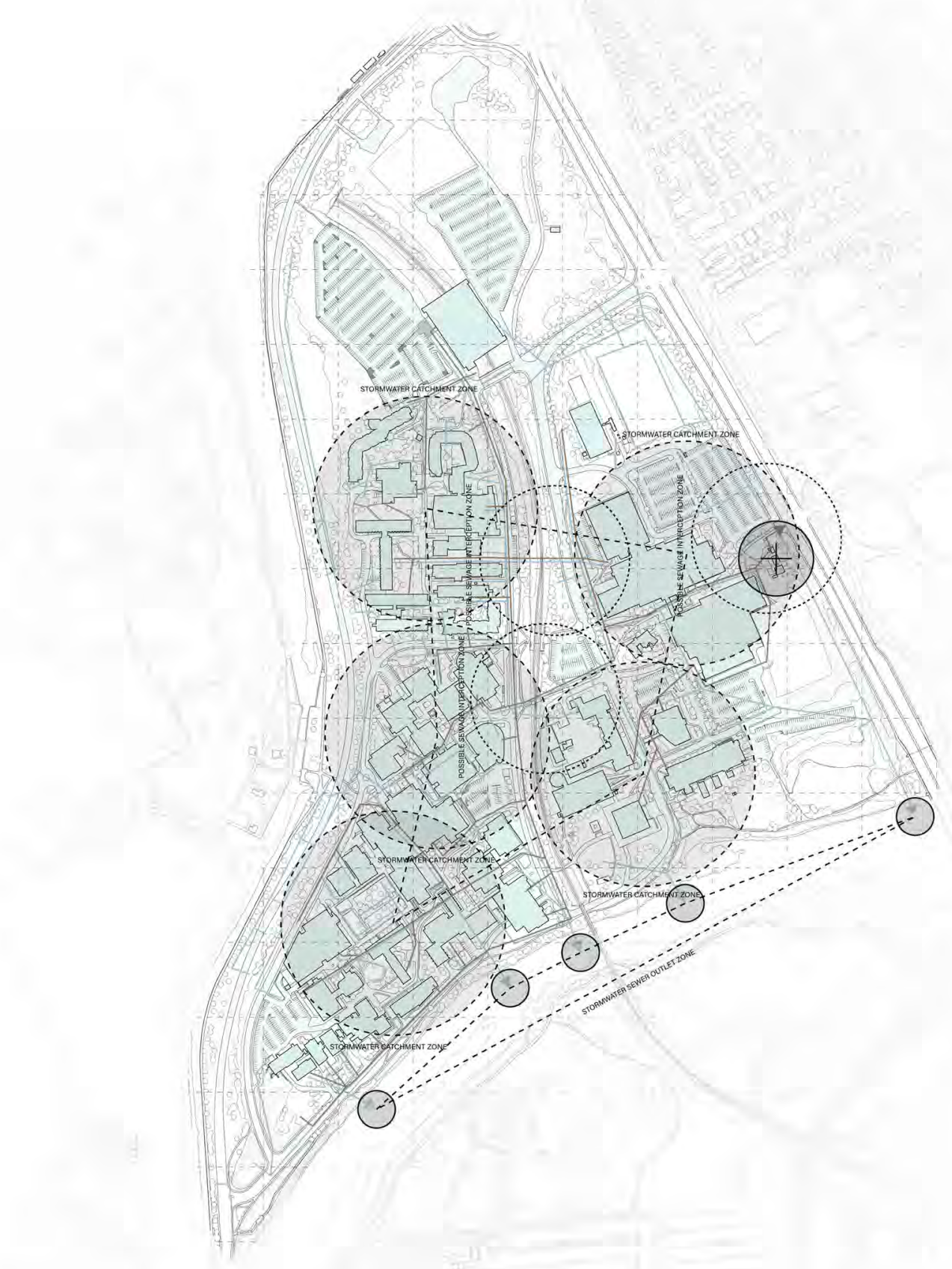

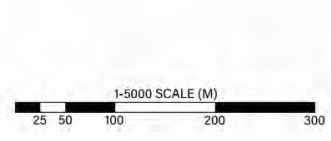

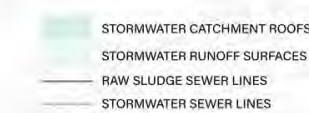

Figure 39: Map of existing stormwater and wastewater networks at Carleton University.
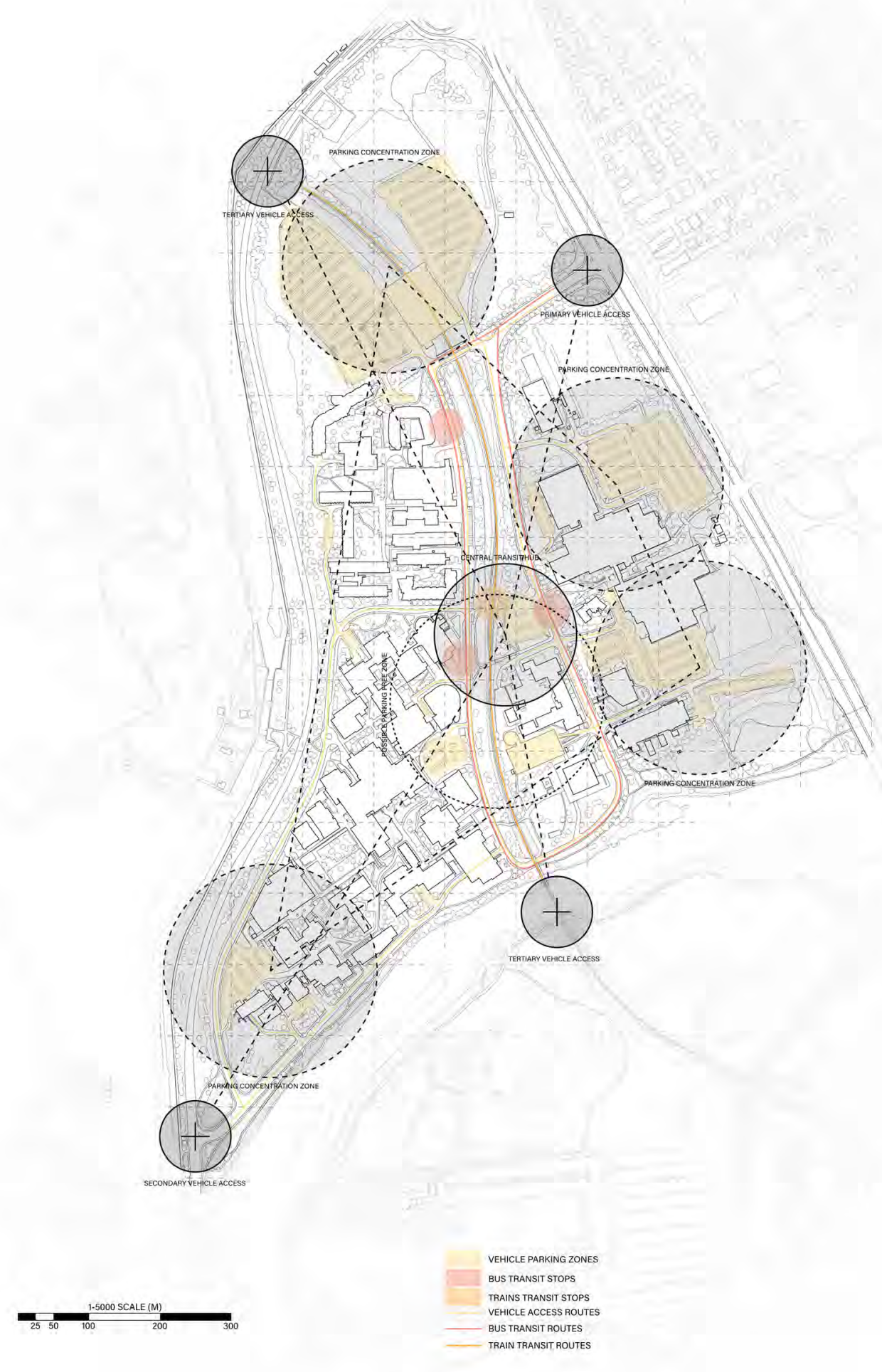

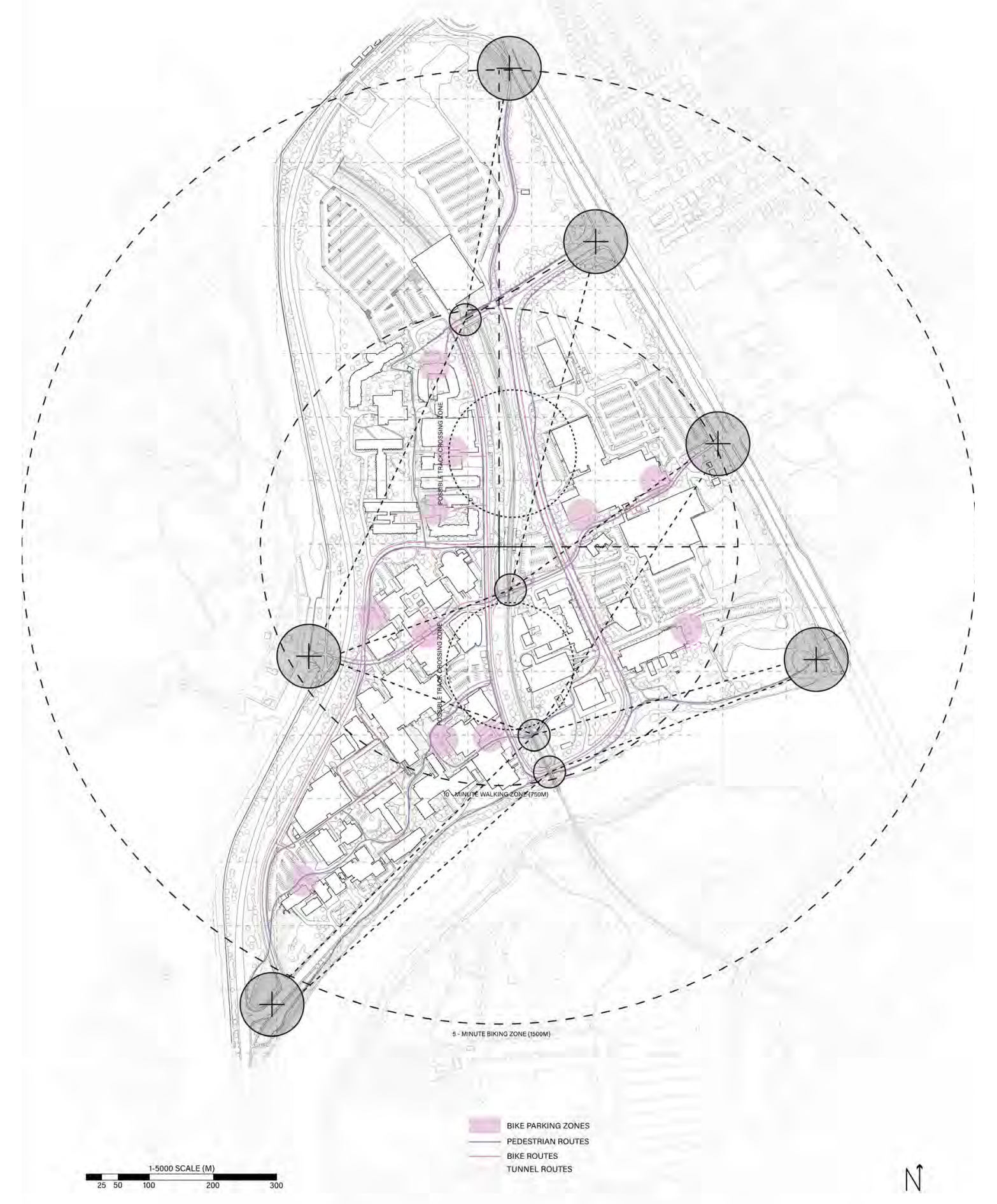

N
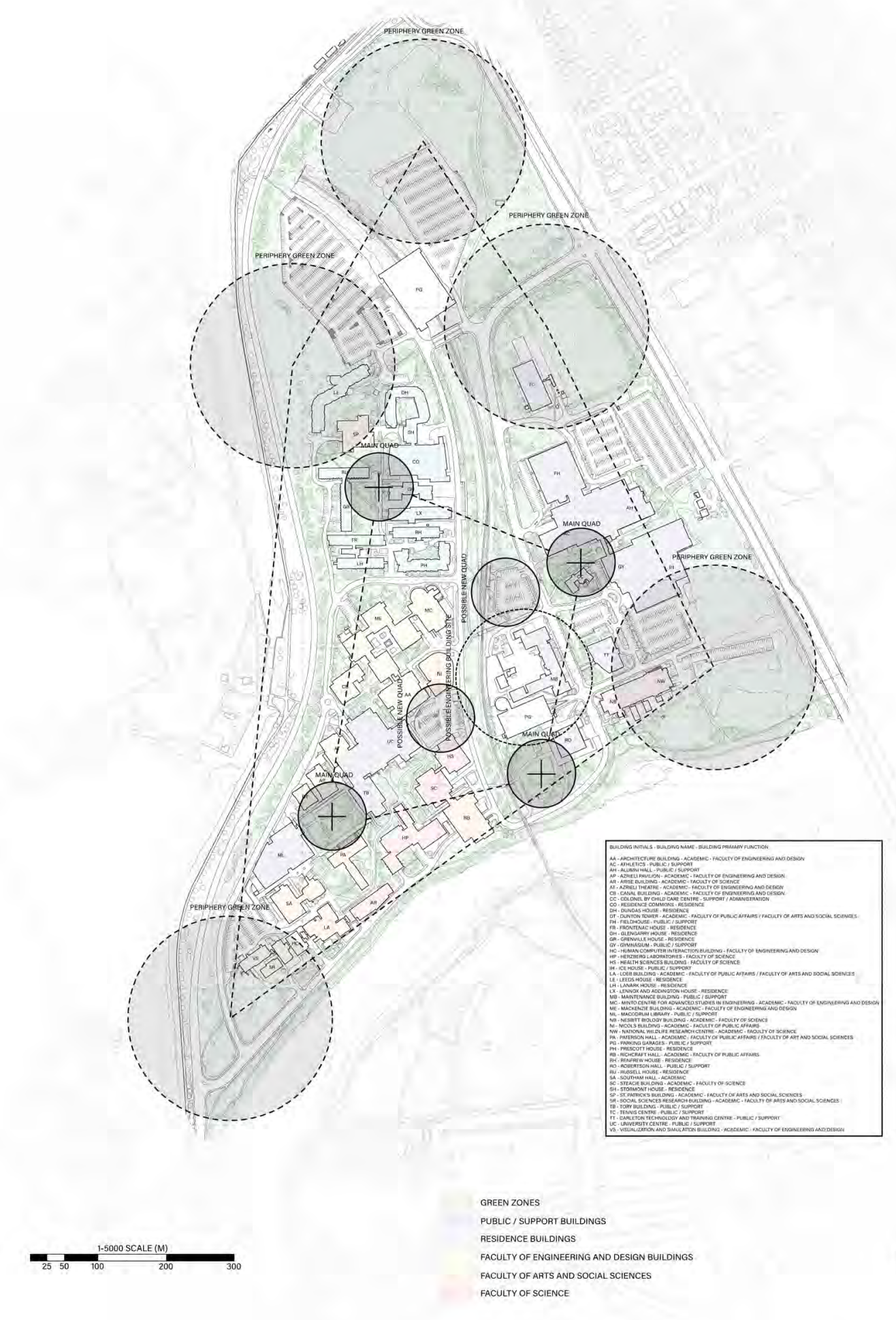

$\hat{N}$ 
After preliminary documentation and analysis of the current state of water and public experience at Carleton's campus, it was determined that the campus has several opportunities to improve campus relationships through the use of water management technologies. As it stands, Carleton uses vast amounts of clean water and flushes this down the drain without a second thought while also providing little to no stormwater management across campus allowing huge amounts of stormwater runoff to leave campus untreated and unobstructed. Furthermore, there is a disconnect across campus between the circulation arteries, the various green spaces and the neglected central spine. Therefore, the central spine of campus was determined to be the ideal location for a new University Center aimed at revitalizing campus experience by improving water management. The resulting project aims at reimagining the derelict central spine into a focal point of campus activity for future development.

Carleton offers a unique campus experience being bordered by two important waterways in Ottawa and, therefore, water should play an important role in its identity. Based upon observations of campus dynamics several opportunities exist to improve the campus using ecological water management technologies. The opportunity then exists to reclaim and reuse stormwater and wastewater on campus in order to produce a more sustainable urban water cycle at Carleton University to help close the loop between water supply and wastewater disposal and benefit Ottawa as a whole. ${ }^{245}$ The proposed interventions offer a two-prong approach to water management at Carleton within the central spine of campus. The first goal is to reduce the impact of stormwater runoff from Carleton's extensive impermeable surfaces that leads to pollution and flooding along the Rideau River and the second is to reduce the campus impact on

245 Kirsten Exall, Jiri Marsalek and Karl Schaefer, "Water Reuse in Canada: Opportunities and Challenges," 253. polluting Ottawa's waterways (See Figure 43). To address the first, the interventions intercept sanitation lines crossing campus, directing the water to a central living machine in the central spine in order to treat the wastewater for reuse. For the second the interventions collect stormwater from roofs and other surfaces across campus and direct it towards the central spine where it will mix with surface stormwater runoff then travel through canals to constructed wetlands in the southern tip of the spine where it can be stored, treated and slowly released into the river (See Figure 44).

With regards to transportation, the main goals of the interventions are to reduce the vehicular traffic through the inner campus, better connect both sides of campus across the train line and improve sustainable transportation options. Parking is removed from the central spine in order to reduce traffic within the campus while campus connectivity and public circulation are improved by creating new train crossing routes for pedestrians and bikes. A new bike path along the central spine crosses the Rideau River and provides a better public connection between Dow's Lake to the north and the Rideau River to the south. New bike parking zones and improvements to the existing train station are also employed to promote sustainable transportation and integrate the newly designed elements and the campus whole (See Figure 45).

The main goals of the interventions with regards to the public realm are to create large public spaces in the central spine and bolster connections to other important green spaces across campus in order to improve public experience and use land more efficiently and creatively. The interventions remove and replace existing impermeable surfaces in the central spine with planted land to create a campus-wide interstitial green zone that divides campus and acts as a large central quad. The interventions are also strategically located to be adjacent to the future campus entry quad and existing 
academic core while extending this zone of influence to the central spine to bridge the gap between both sides of campus as the academic footprint grows (See Figure 46),

Together, the multi-faceted design approaches share the goal of improving the campus relationship with water by making these ecological water management networks visible and experiential in order to improve campus connectivity, sustainability, and spatial experience as a whole. The hope is that these interventions could help to make Carleton a more welcoming campus that serves as a site-specific and localized example of campus rejuvenation to be replicated across Canada and abroad.
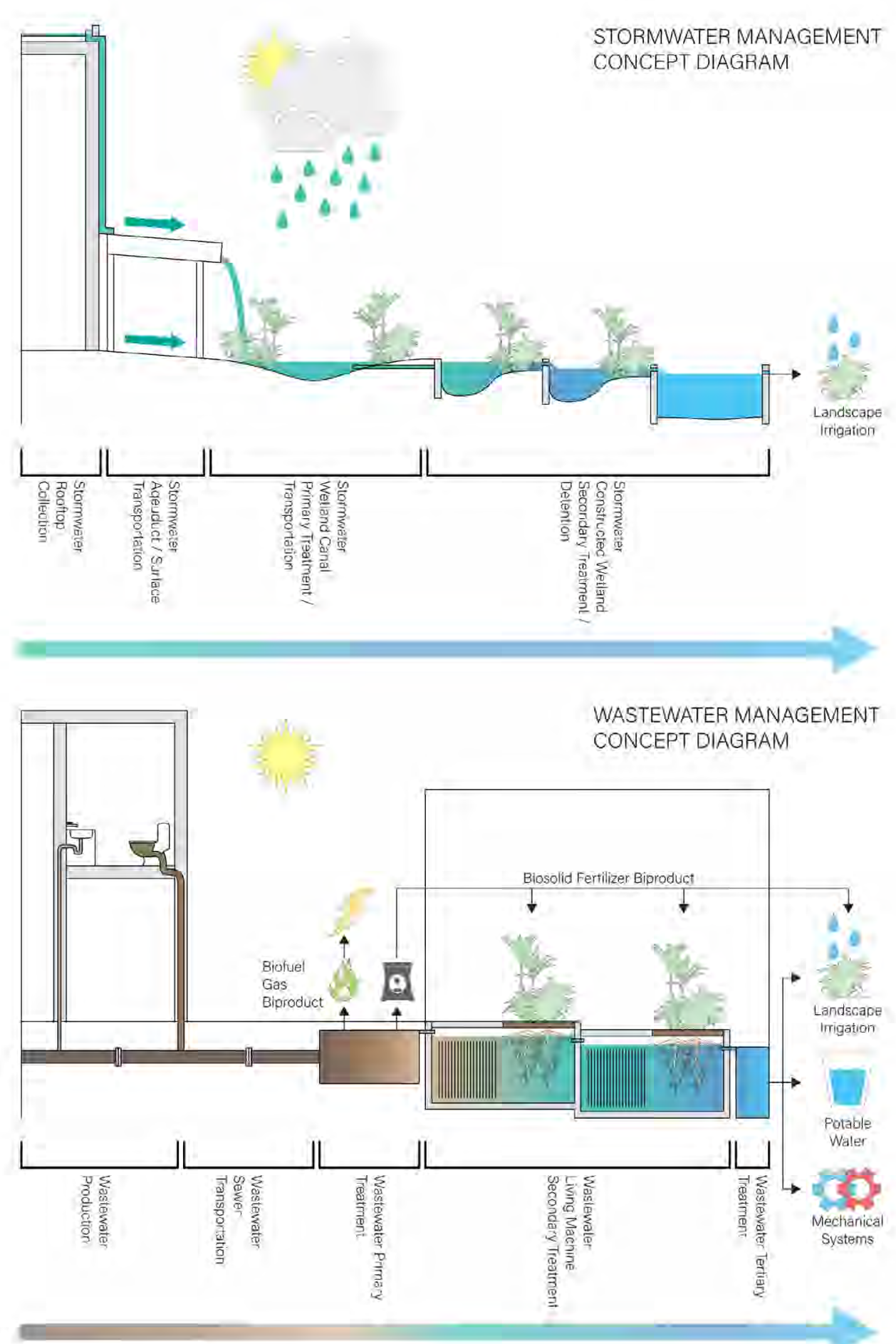

Figure 43. Diagram of proposed conceptual water management networks. 


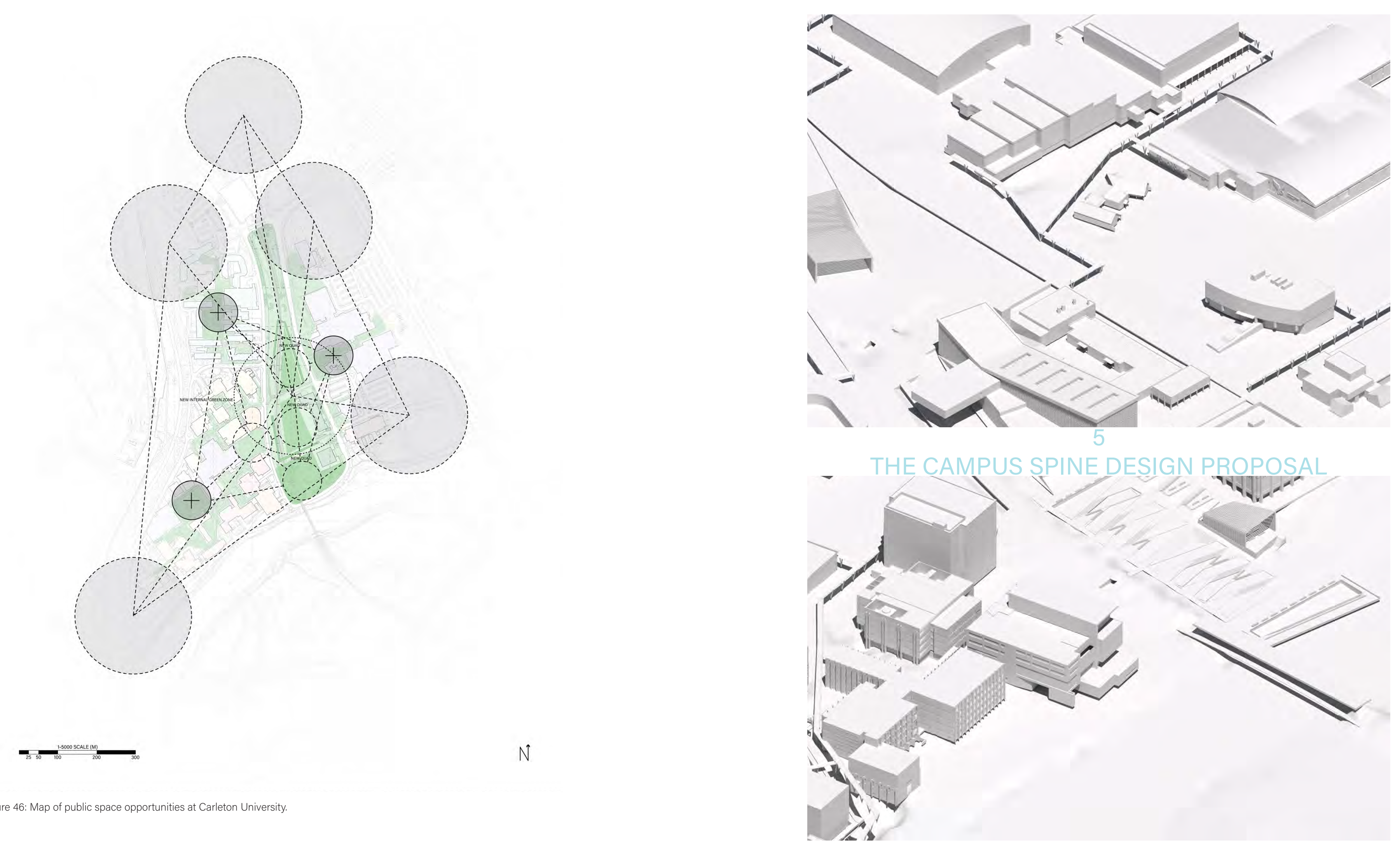
In order to achieve the goals outlined during the documentation process, the campus was analyzed and a series of strategic interventions were proposed. The central spine of campus is to be reinvented to become a new infrastructural centre that acts to treat both stormwater and wastewater for recycling in various facets across campus while simultaneously improving the campus experience. Entwined within the design of these interventions is an understanding that mimicking natural water systems can help to reintegrate waterfront improvements into the surrounding urban fabric as socially and ecologically responsible developments. ${ }^{246}$ The hope is that the interventions will help influence Carleton to generate a more active and sustainable relationship with its adjacent water resources to improve the health of the ecosystem.

The first step in the intervention process is instituting better water management through two networks. Stormwater is collected from all campus building roofs and directed to the central spine by several aqueduct tendrils reaching out across campus. Once in the central spine, wetland canals gather the aqueduct stormwater as well as surface runoff and transport it towards the southern edge of the central spine where a constructed wetland park stores and ecologically treats the water before its release into the Rideau River. On another level, the new University Center site houses a large living machine that intercepts the existing sewage lines that cross under the train tracks and treats all the wastewater produced on campus through ecological means for reuse (See Figure 48). By making these processes visible and accessible, an underlying educational agenda can be created that teaches Carleton students and the surrounding community about the prospects that these technologies offer for a sustainable future

246 Zoe Ryan, Building with Water: Concepts, Typology, Design, 25. also act to reinvigorate existing spaces across campus while also fostering new ones along their path and within the central spine. The aqueducts act as living tendrils that enliven green spaces leading to the central spine. The canals provide longitudinal wetlands along the new pedestrian and bike path that crosses the campus through the central spine and connect Dow's Lake to the Rideau River. The canals further spill into internal causeways that connect both sides of campus through the new central transit zone and university centre. The constructed wetlands frame a new park that celebrates water and provides spaces for gathering that reinforce the biodiversity of natural wetland water processes and create a clear connection to the Rideau River. The living machine puts the processes of ecological wastewater treatment on display for experiential and educational purposes while also integrating within built atmospheres and improving building health (See Figure 49).

The culmination is a series of components that transform the campus experience through the use of water management technologies. The aqueducts, wetland canals, constructed wetland park and university centre living machines are all designed as specified zones that integrate with the campus and contribute to the greater goals of the project (See Figure 50). All these aspects are intended to showcase how implementing water-based technologies for better water management can be beneficial to the campus experience by reinvigorating active public spaces, providing better campus connections and meeting sustainability goals 


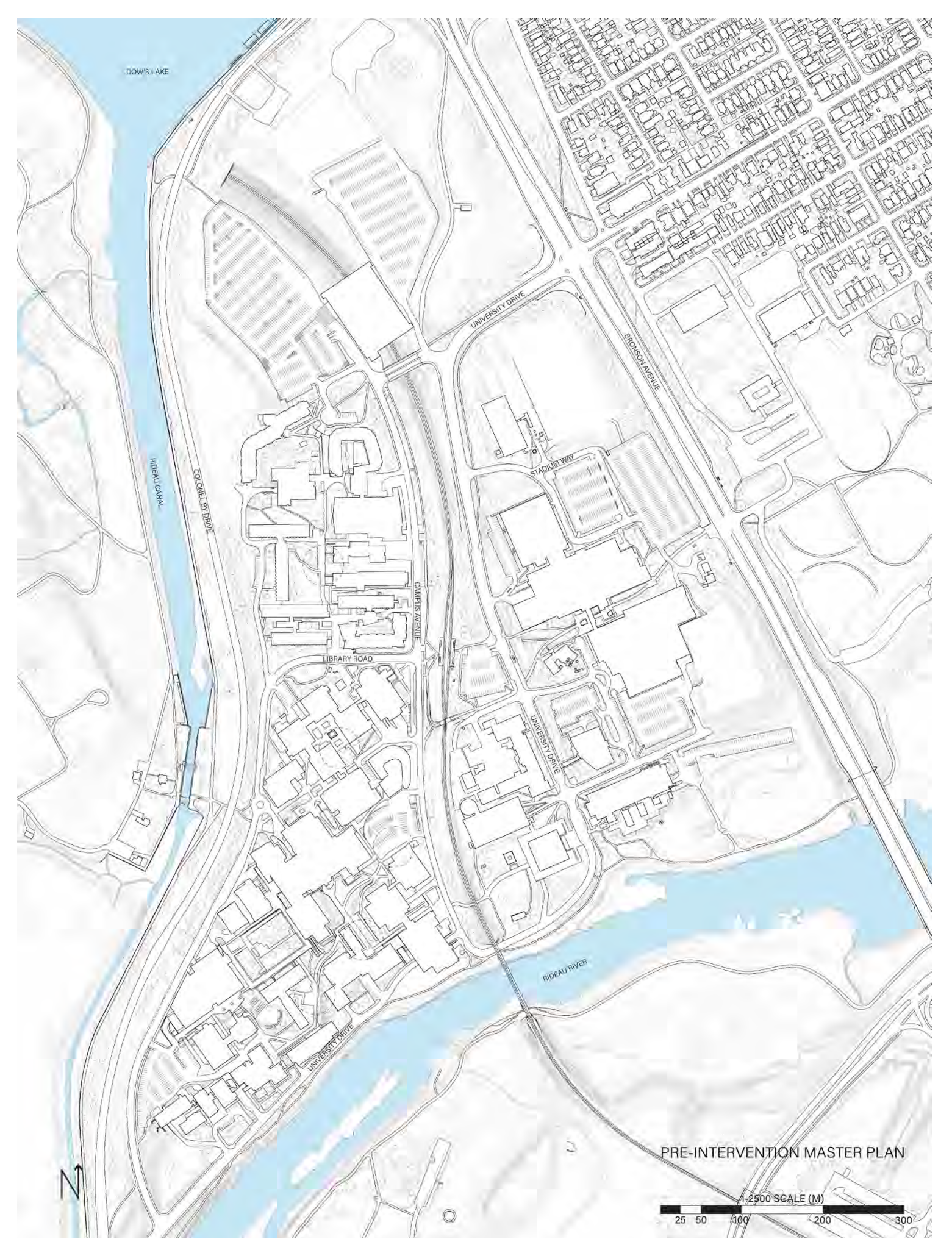

Figure 47: Map of existing conditions at Carleton University.

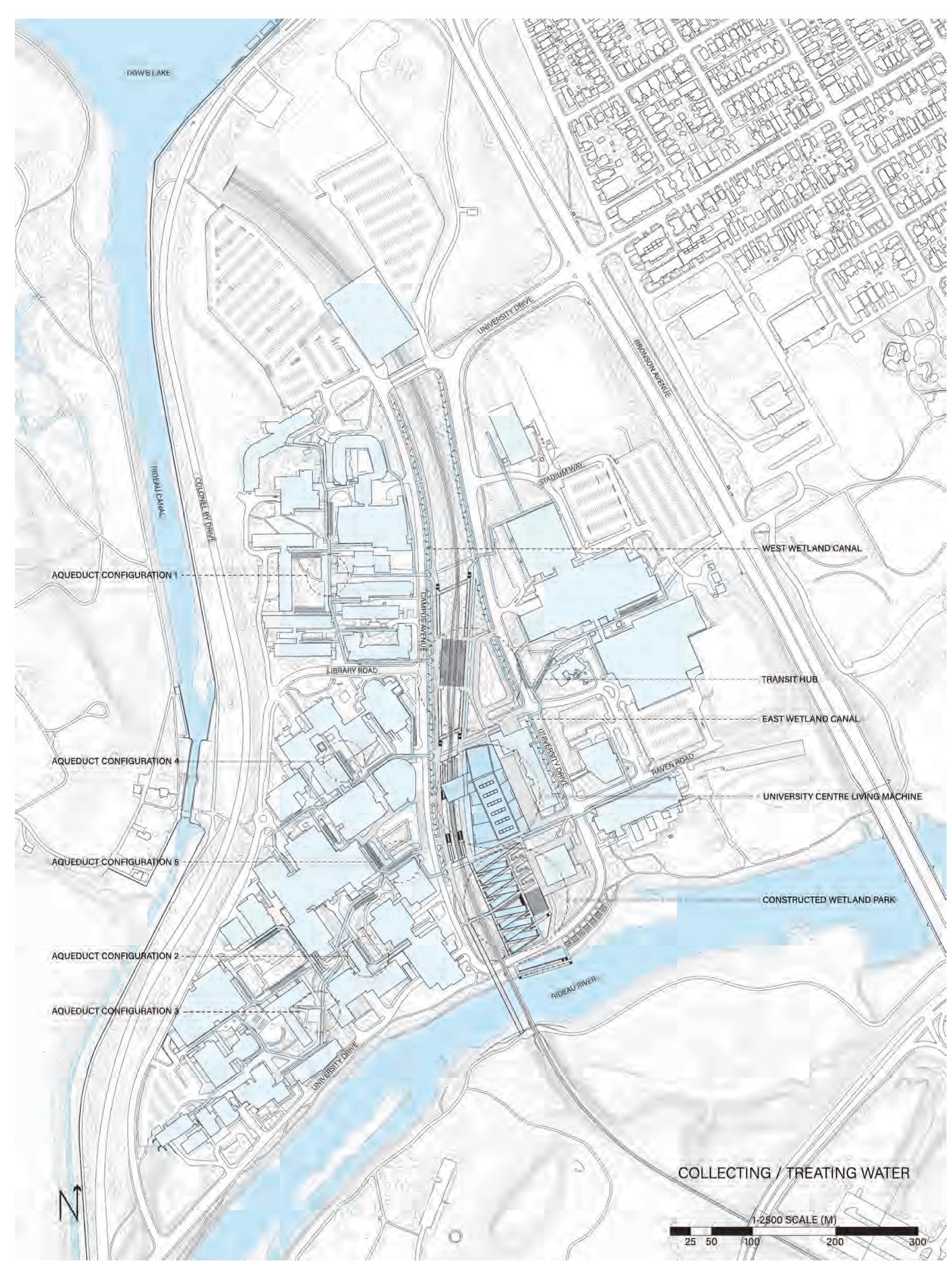

Figure 48: Map of proposed water management interventions at Carleton University 


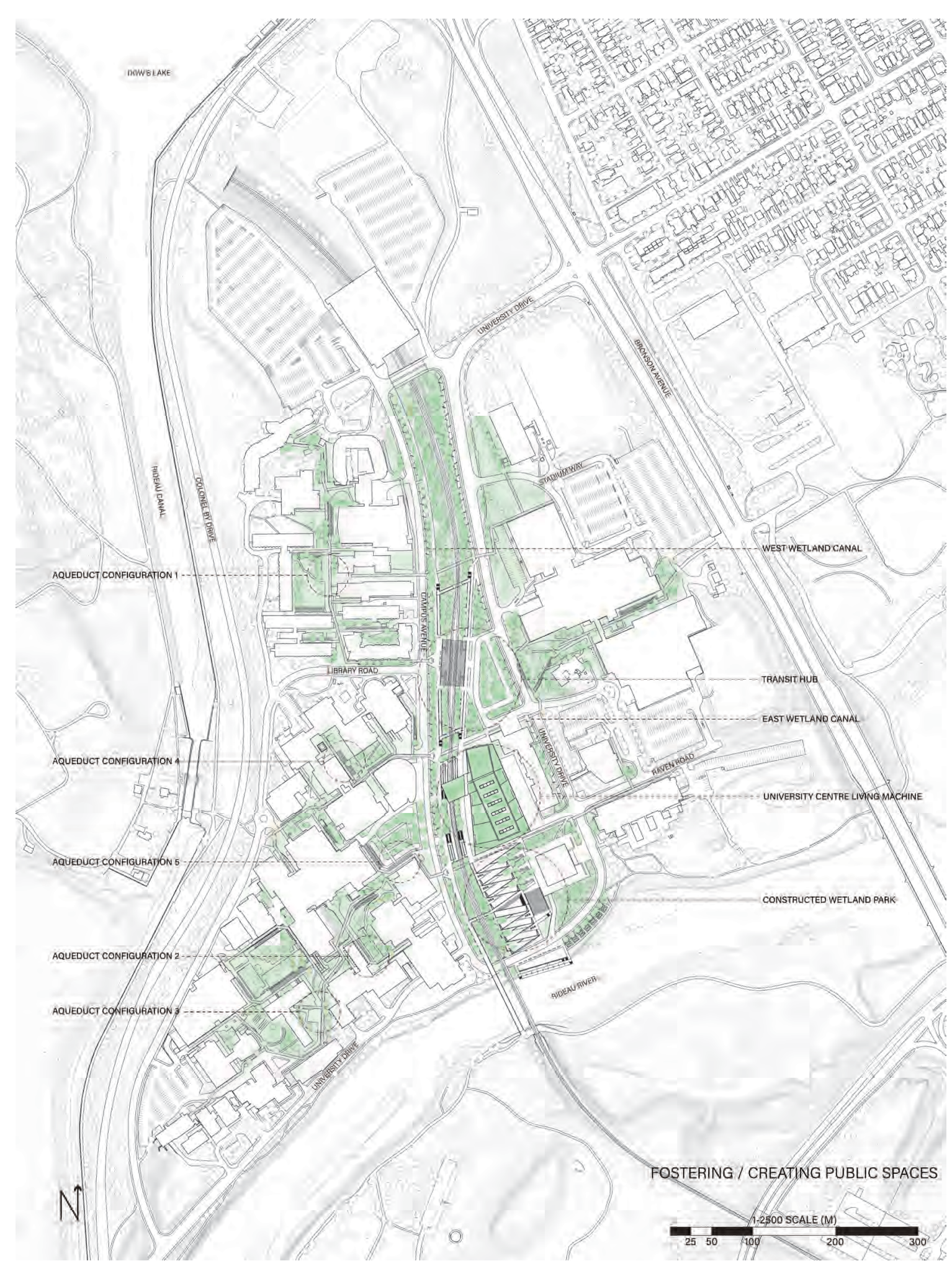

Figure 49: Map of proposed public space interventions at Carleton University.

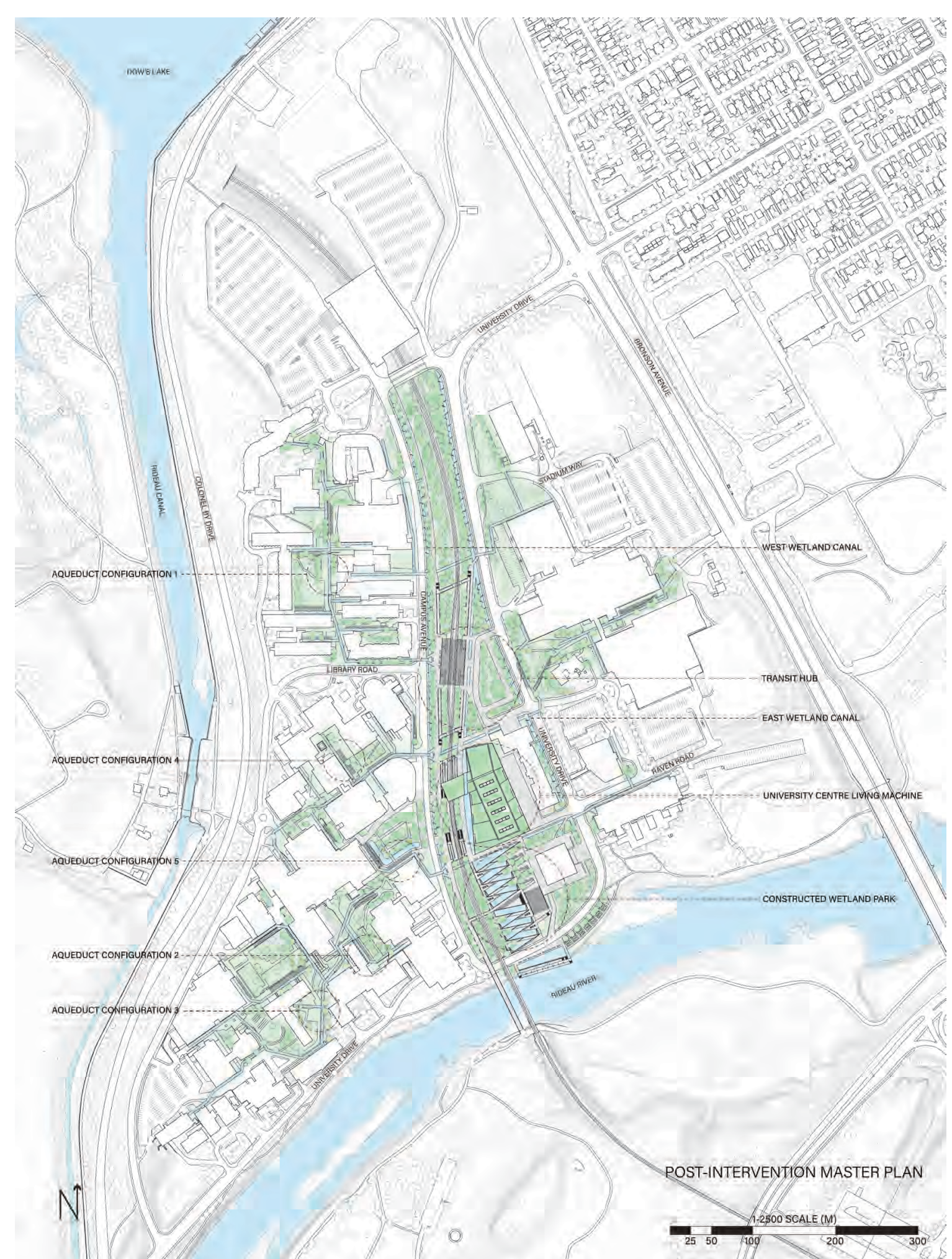

Figure 50: Map of proposed new master plan for Carleton University 


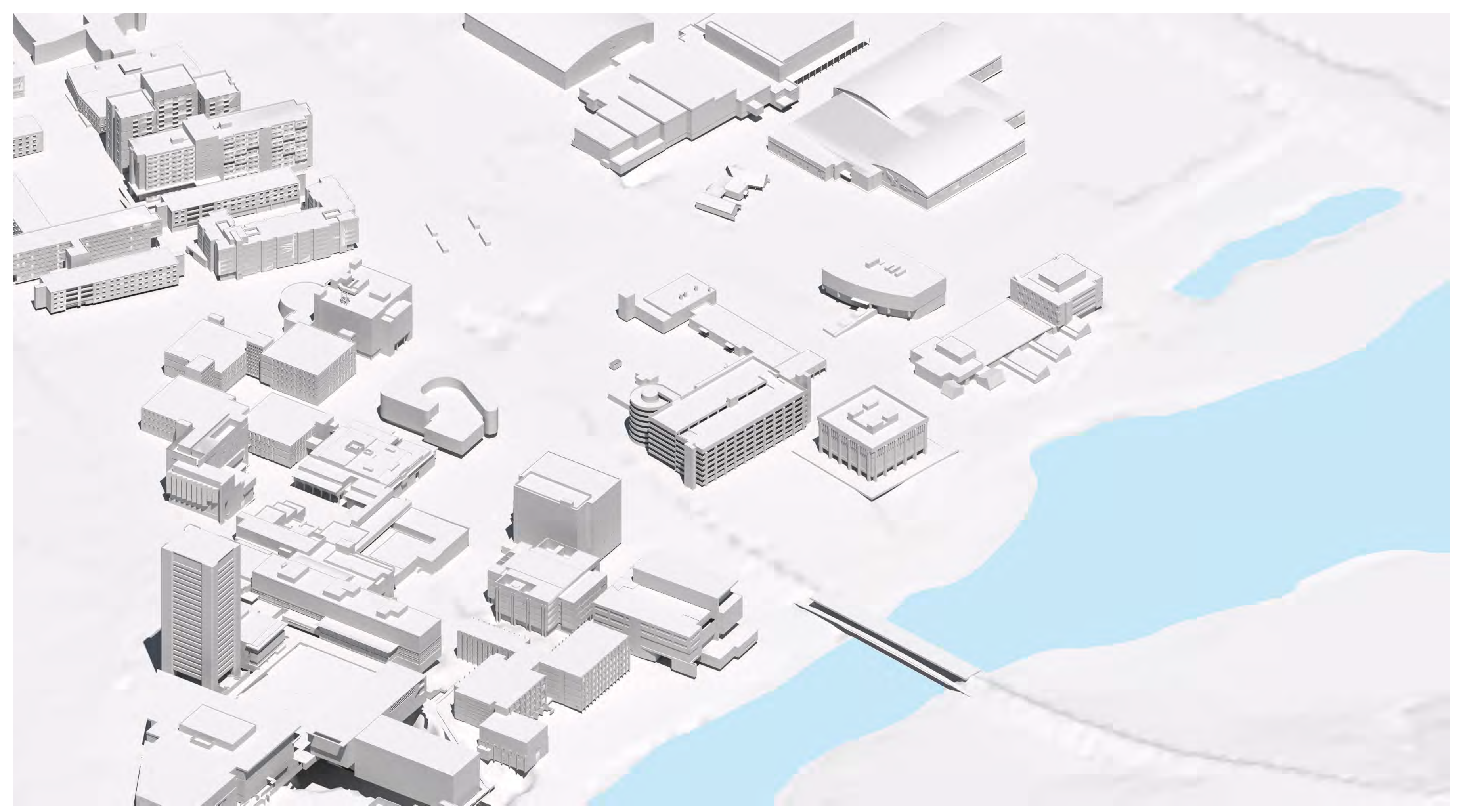

Figure 51: Volumetric axo of the current campus. 


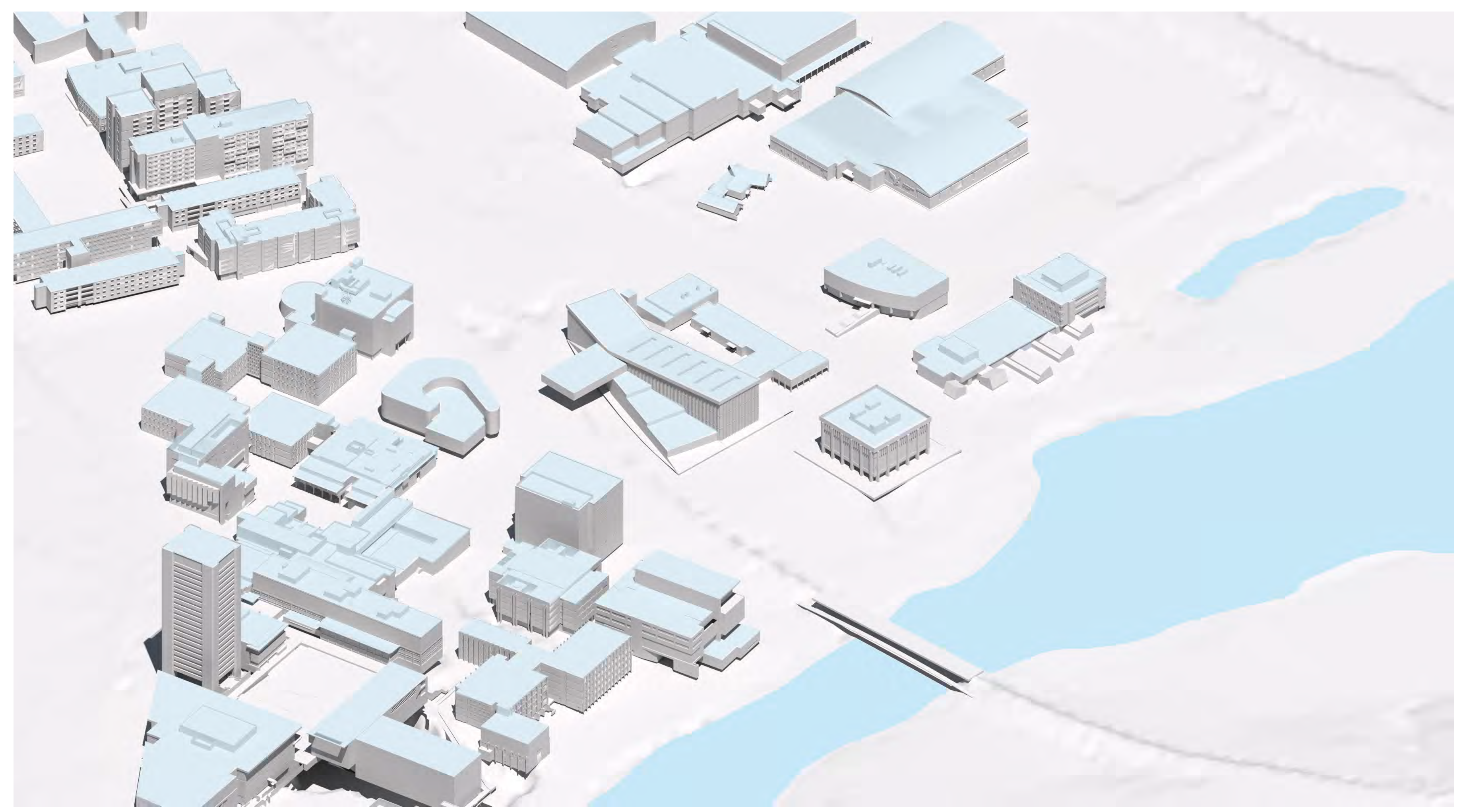

Figure 52: Volumetric axo of the UC Living Machine put into the current campus. 


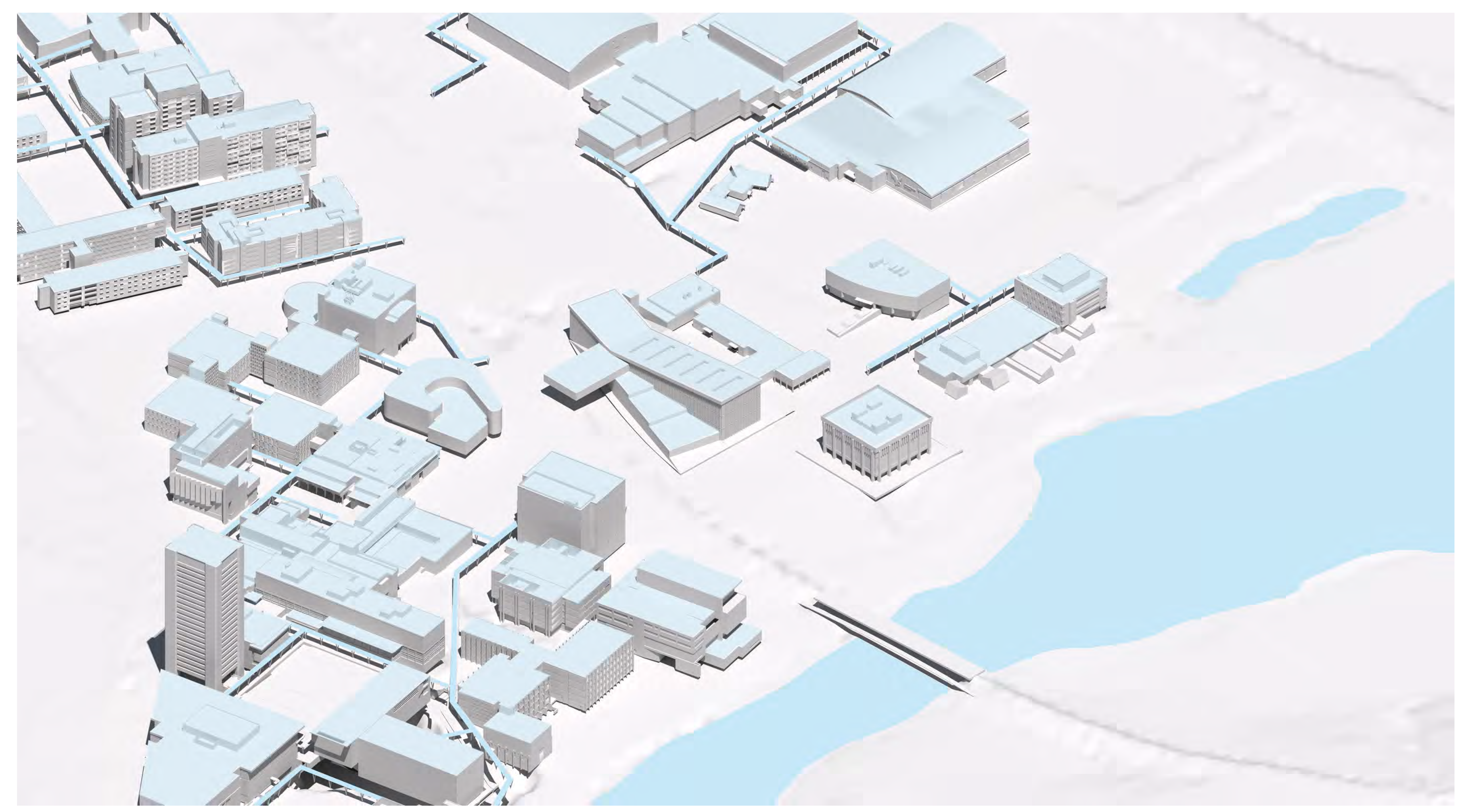




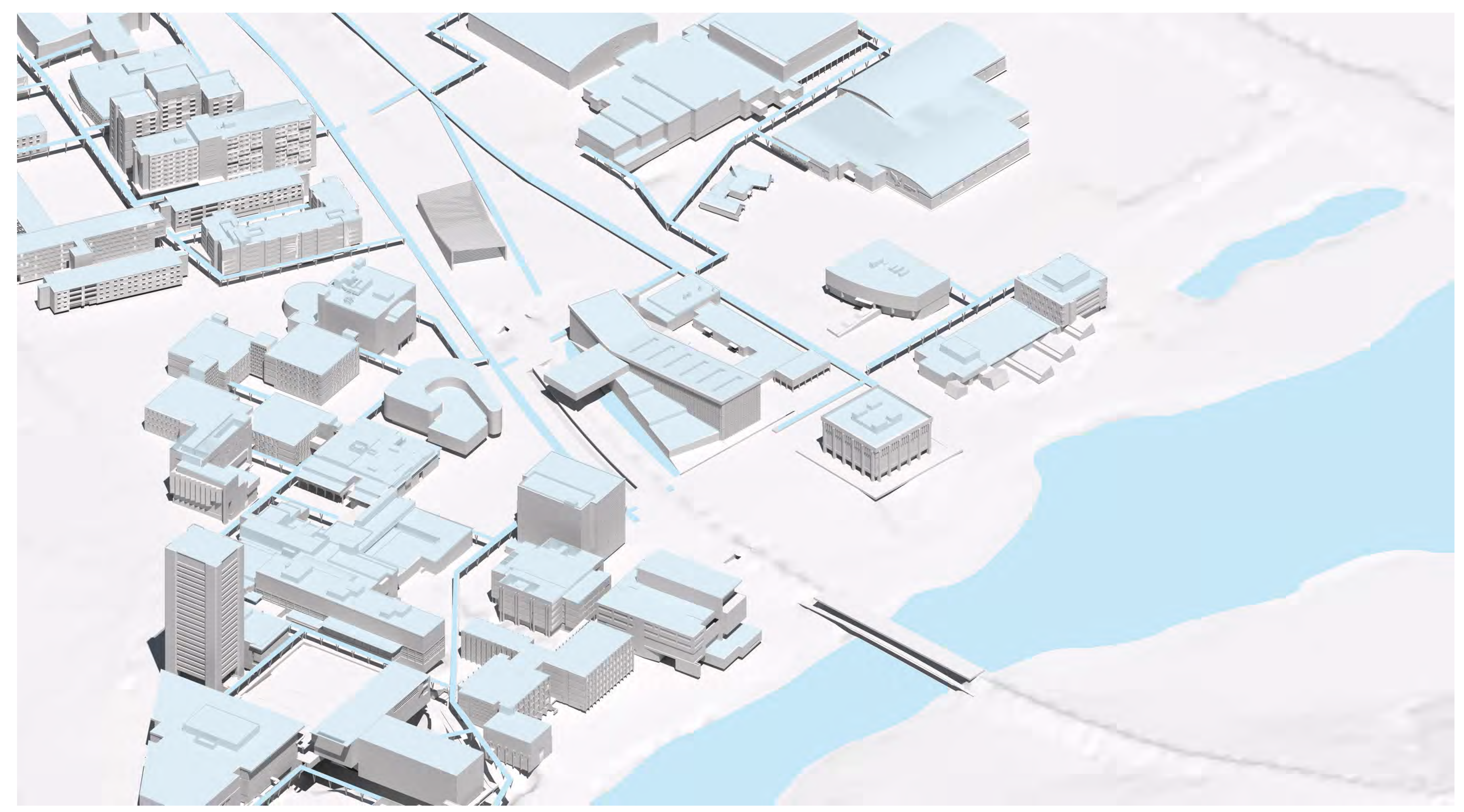




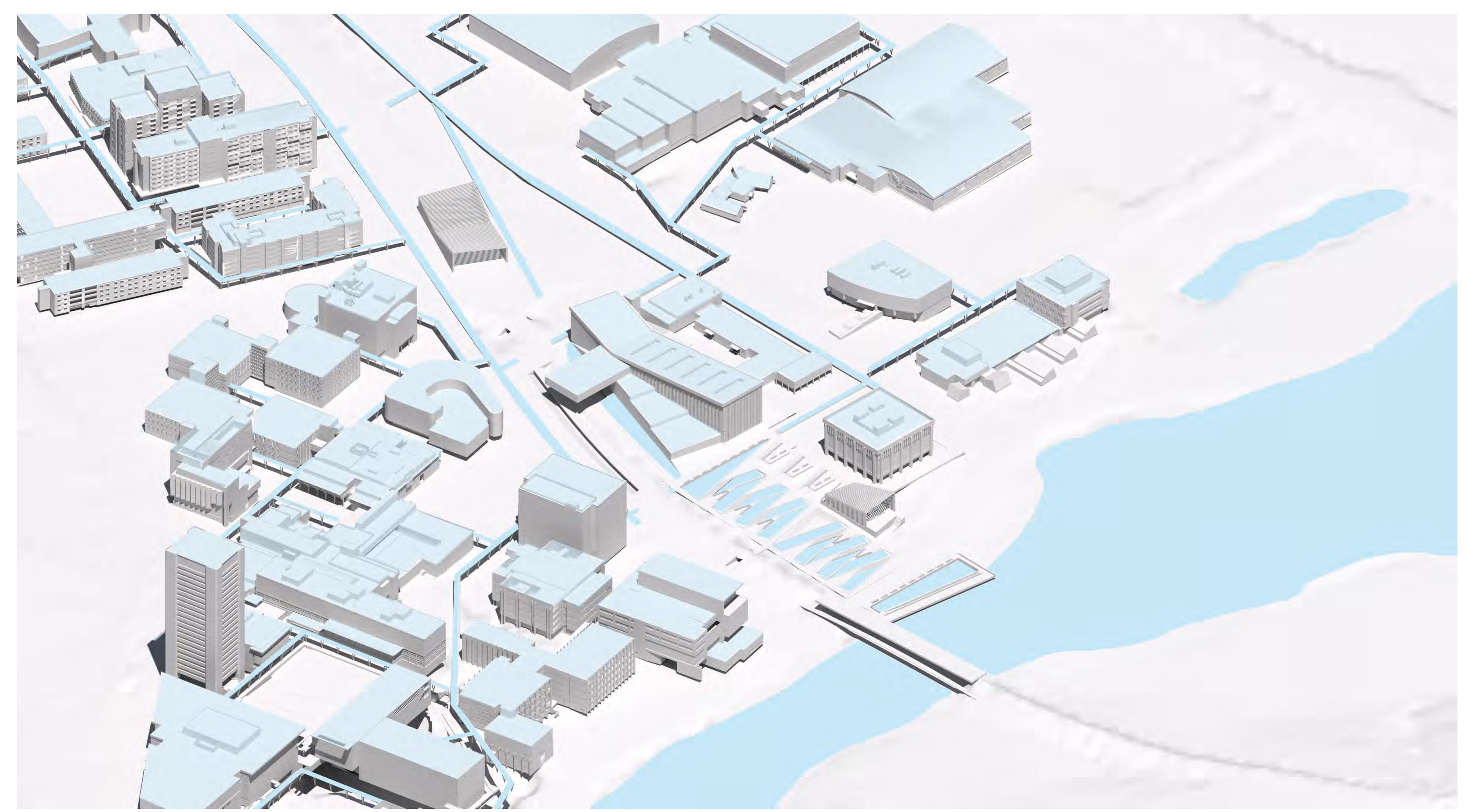

Figure 55: Volumetric axo of the constructed wetland park put into the current campus. 


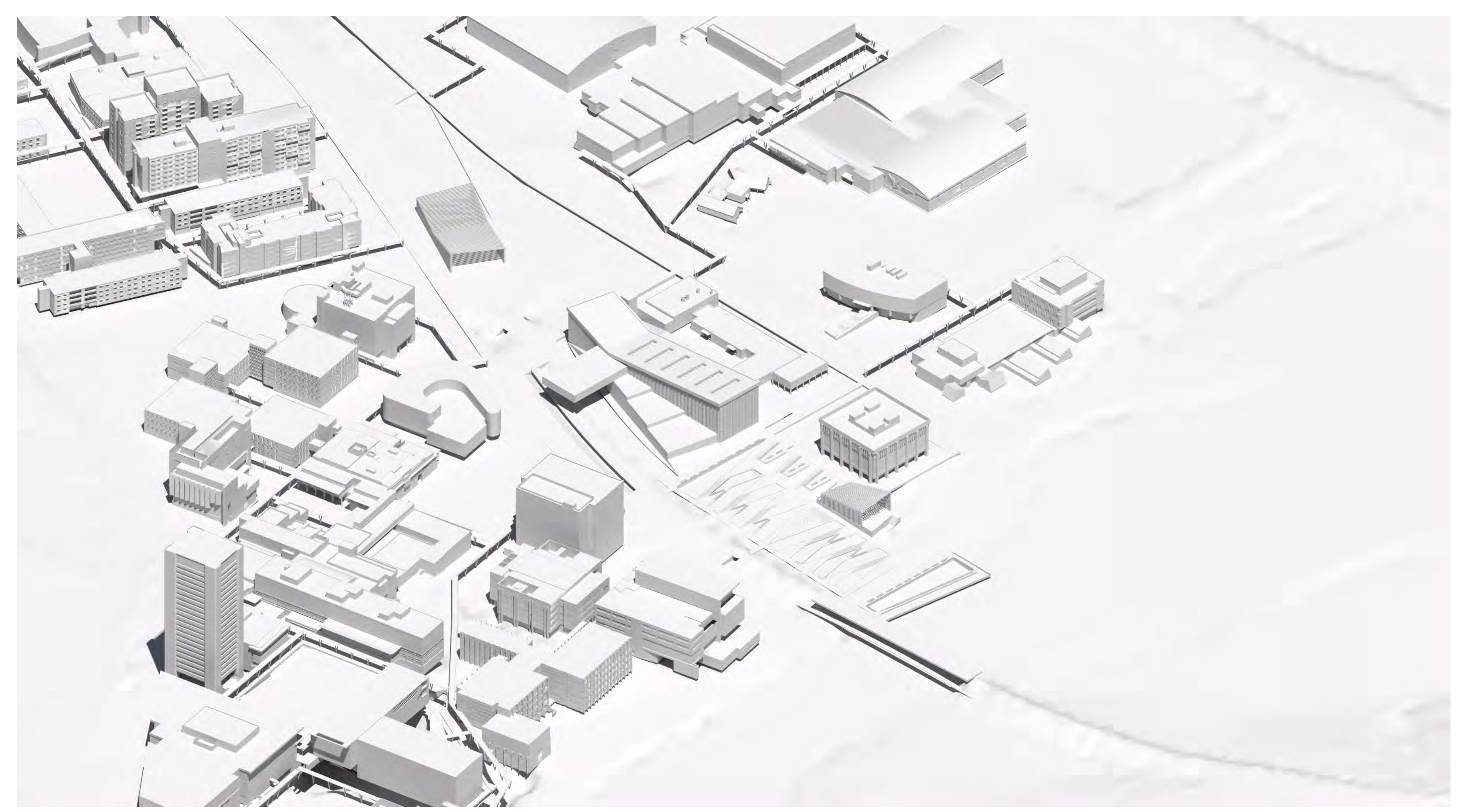


The new University Centre site houses a Living Machine system designed to treat all of the wastewater produced on Carleton's campus to create a closed loop water system. A typical Living Machine system, as described earlier, treats wastewater using plant roots with both attached and suspended growth in a series of anaerobic, anoxic, and aerobic reactors that promote biological processes within a botanical garden space. Building off typical Living Machine principles, the Organica Food Chain Reactor offers another variety of Living Machine and treats water with similar processes of attached growth on plant roots but adds a bio-mimicking web instead of only natural media in order to concentrate the treatment processes allowing for higher treatment volumes in a smaller space. By combining both the typical Living Machine and Organica systems, the University Centre Living Machine takes a hybrid approach that combines the benefits from either system to optimize their experiential quality and produce high quality effluent that can be recycled for various applications. Within the system, ample plant-life as well as bio-mimicking webs allow for high volumes of treatment in a small space without sacrificing the atmospheric qualities of only using plants as a treatment medium (See Figure 58).

The hybrid Living Machine employs a linear series of treatment systems in order to produce a clean effluent. Collected wastewater is stored in influent holding tanks that lead through mechanical filters to achieve preliminary treatment. The water then passes into anaerobic digesters to achieve primary treatment before entering the reactor series. The reactor series consists of two anoxic reactors and four open aerobic reactors that achieve secondary and partial tertiary treatment. Each reactor is covered by a growth medium structure planted with a variety of wetland plants whose roots are suspended in the reactor below and is filled with a biofiber membrane that, in tandem with the hanging roots from the plants above, create an extensive surface area for the treatment processes. The plants and growing medium covering the reactors also acts as an effective continuous biofilter that creates an odorless atmosphere within the space, further enhancing the enjoyment of the plants. Inlet and outlet pipes connect the reactors with each reactor having a bypass pipe in case maintenance is required on a specific module within the system (See Figure 59). Finally, the water enters a discfilter and a UV treatment system that together achieve tertiary treatment.

This complex system produces a clean effluent product with several useful byproducts offering various applications. By the end of the reactor series, the system produces recyclable greywater effluent that can be used for irrigation, sinks and toilets, or to generate steam to heat the campus in the central heating plant housed in the adjacent Mechanical Building. Alternatively, it can also produce potable water afte tertiary treatment to be recycled for consumption throughout campus. By creating a closed-loop water system, the use of reclaimed water reduces the overall water consumption on campus and lowers its reliance on exterior sources. Additionally, biogas produced from the anaerobic digester can be processed into biofuel to be used in a combined heat and power plant to power the University Centre and other adjacent buildings while the sludge generated throughout the treatment processes can be recycled for fertilizing the plant life of the system and throughout campus.

In order to size this hybrid system, wastewater production calculations for Carleton University and the Sechelt Water Resource Centre Organica Food Chain Reactor Case Study were used as a baseline. Each series module within the Sechelt system is currently designed to accommodate 1000 cubic metres of wastewater per day which can currently manage over half of Carleton's wastewater. This means that a Living Machine based on the size of two of the Sechelt modules would be able to 
manage all of Carleton's wastewater production with excess capacity to meet future demands.

\section{Calculations:}

Sechelt Water Resource Centre was used as a basis for these calculations and has the ability to treat 4000 cubic metres of wastewater per day in an 1800 square metre facility. ${ }^{247}$ The facility achieves this with 4 series of batch reactors with total volumes of 1000 cubic metres along with a 907 cubic metre influent holding tank, 400 cubic metre secondary

equalization tank, and 400 cubic metre sludge holding tank. ${ }^{248}$

Based on these parameters, and on the future wastewater production models for Carleton University that predict wastewater production

of 1,697 cubic metres per day, it was determined that one enlarged Living

Component sizing for the living machine handling the entire load (up to $2000 \mathrm{~m} 3$ per day):

Influent holding tanks: $2 \times 240 \mathrm{~m} 3(8 \times 10 \times 3 \mathrm{~m})$

Anaerobic digesters: $2 \times 240 \mathrm{~m} 3(8 \times 10 \times 3 \mathrm{~m})$

Reactors: $6 \times 400 \mathrm{~m} 3(5 \times 20 \times 4 \mathrm{~m})$

Discfilter: $4 \times 90 \mathrm{~m} 3(3 \times 10 \times 3 \mathrm{~m})$

The reactor modules occupy the central space of the new University Centre building with preliminary and primary treatment systems hidden under the entry space and tertiary treatment systems hidden under the adjacent supporting spaces. With the living machine acting as the focal point for public gathering space, water-based technology will be made part of the everyday experience and the plants from the system will create a sort of botanical garden to enhance the physical and spatial quality of the interior space. The cascading reactors shape occupiable concrete terraces with wooden seating for public interaction and leisure that flow towards the end of the central space. At the end of the central space is a cascading water feature for the treated water from the reactors providing a sensory way to experience the final product of the 247 District of Sechelt, "Water Resource Centre Fast Facts."

248 District of Sechelt. "Water Resource Centre Fast Facts." treatment process. The space is contained by a glass-clad glue-laminated column and beam structure with overhanging wooden bridges that allow all circulation avenues to pass either between or over the planted living machine modules. Overall, the living machine is made central to the building experience and is used to shape the adjacent constructed volumes making it so the central space is accessible and experienced from all parts of the building (See Figures 60,61). The centrality of the system also makes it a point of interest and an educational tool for community and campus visitors alike that can help to generate a discourse on sustainable water management practices.

The Living Machine acts as the grounding node shaping the rest of the University Centre building with adjacent support spaces following the directionality of the reactors and the only volume breaking this mold being the space that cantilevers above the tracks to connect the central spine to the rest of the campus. To reinforce this connection, a large plaza is created that crosses underneath the tracks and bridges the gap between the main university entry quad and the new University Centre. Together, these interventions create a interconnected campus experience that can allow for strengthened bonds between the current campus and future growth. 


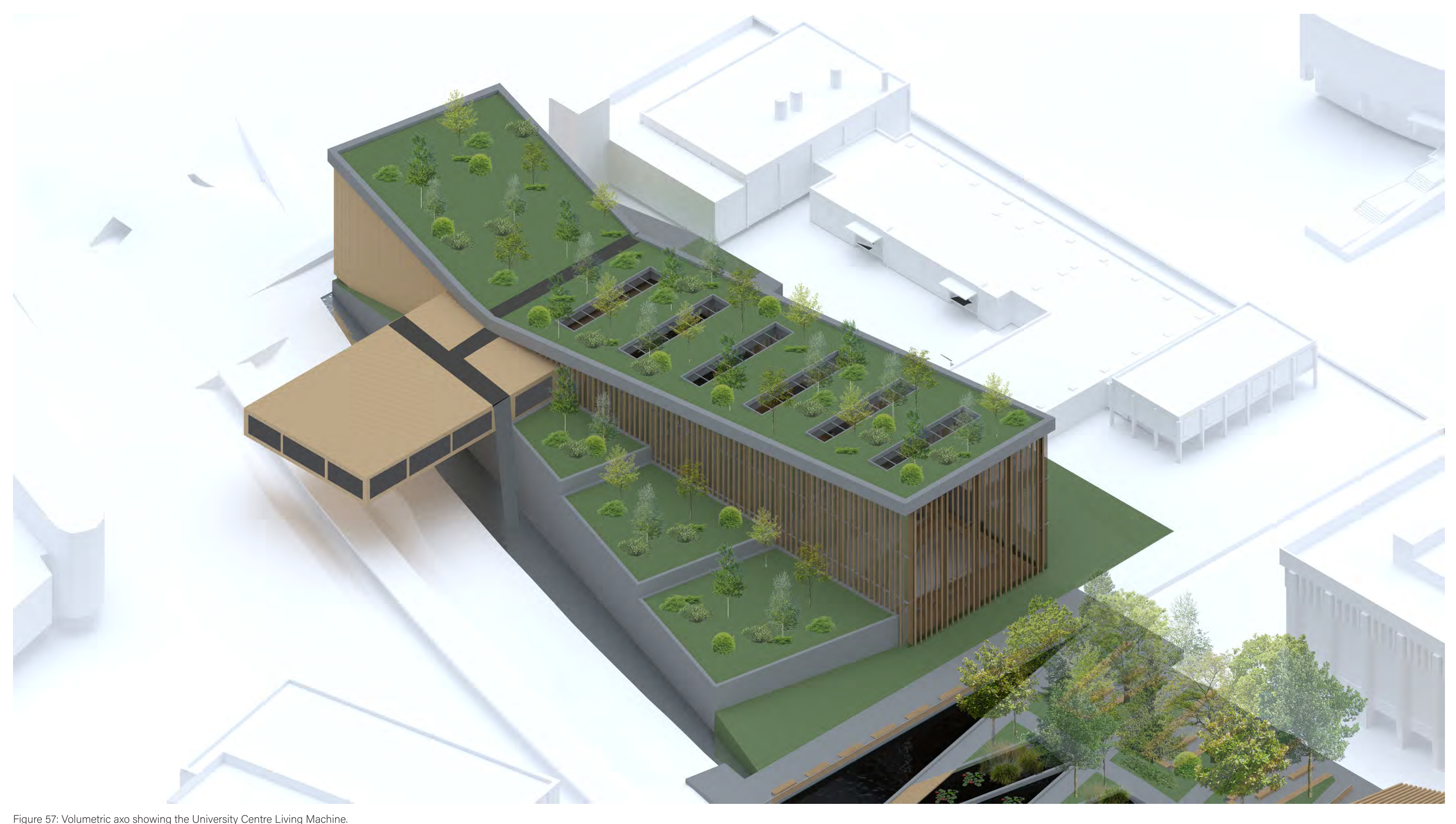



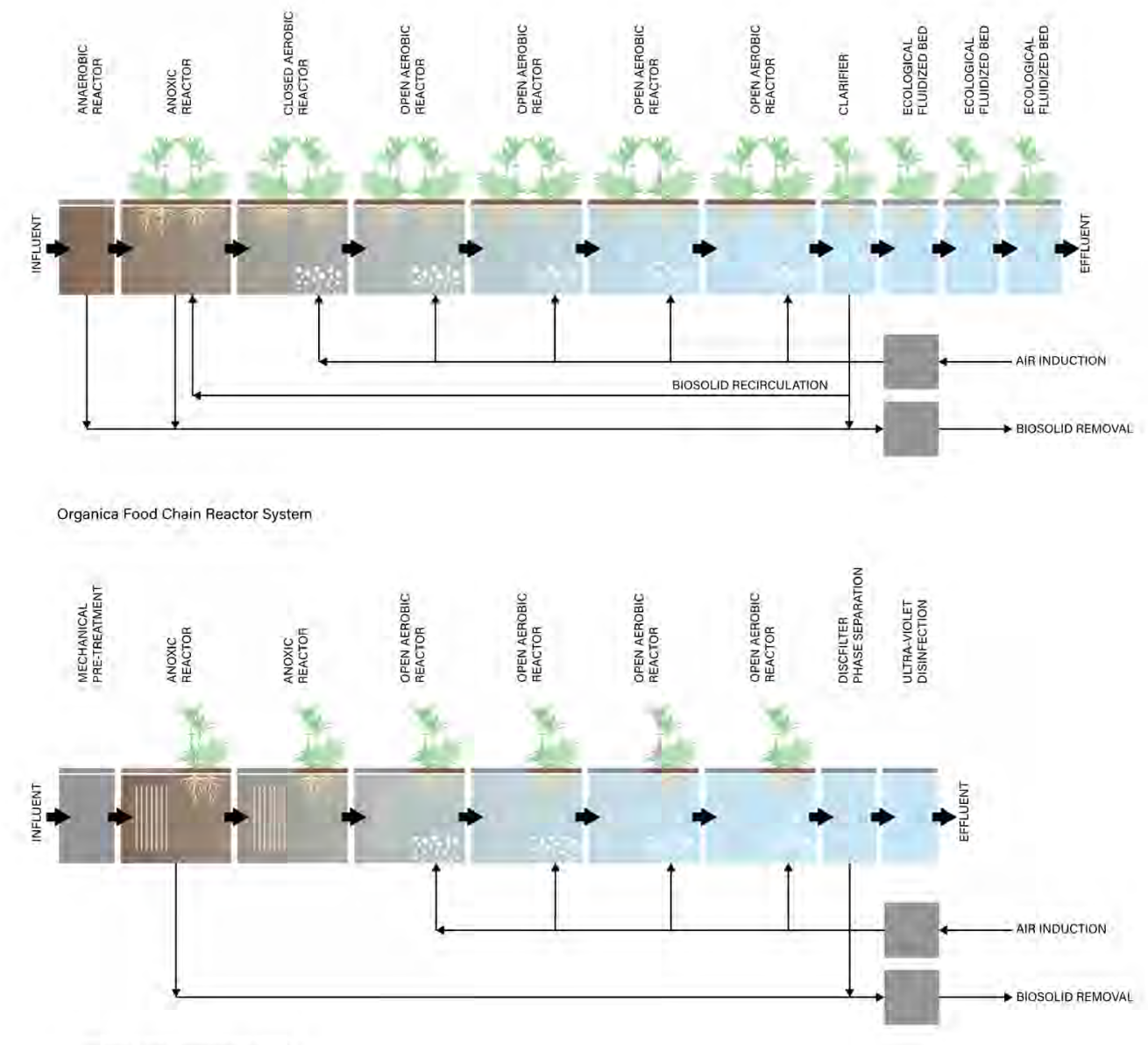

Hybrid Living Machine System

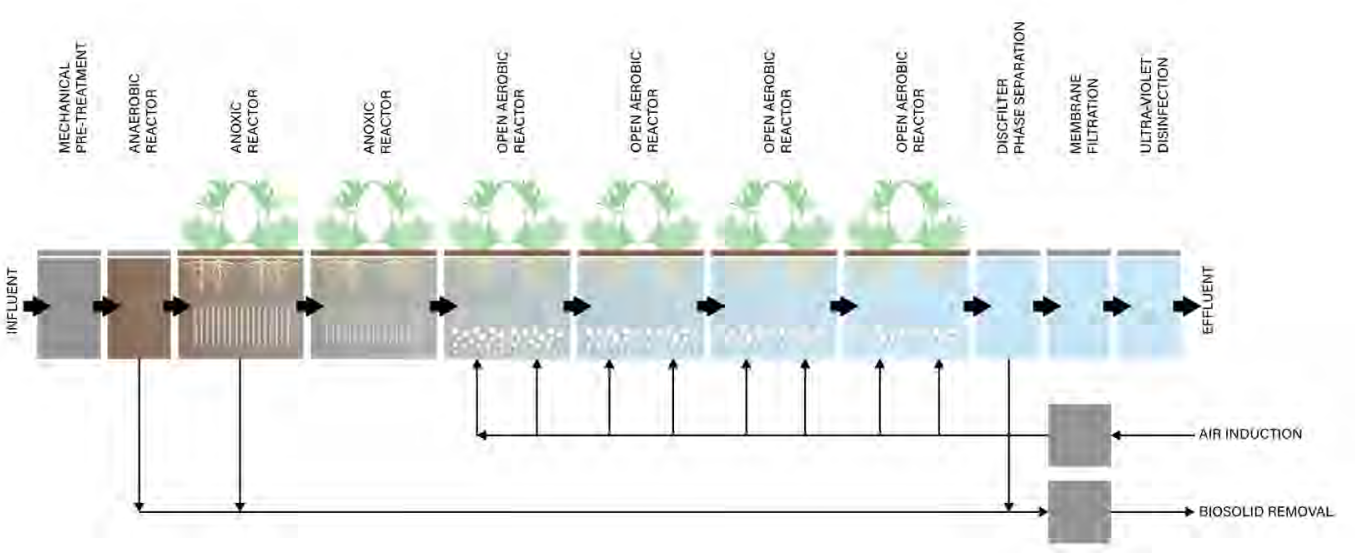

Figure 58: Schematic diagram of proposed Living Machine system.

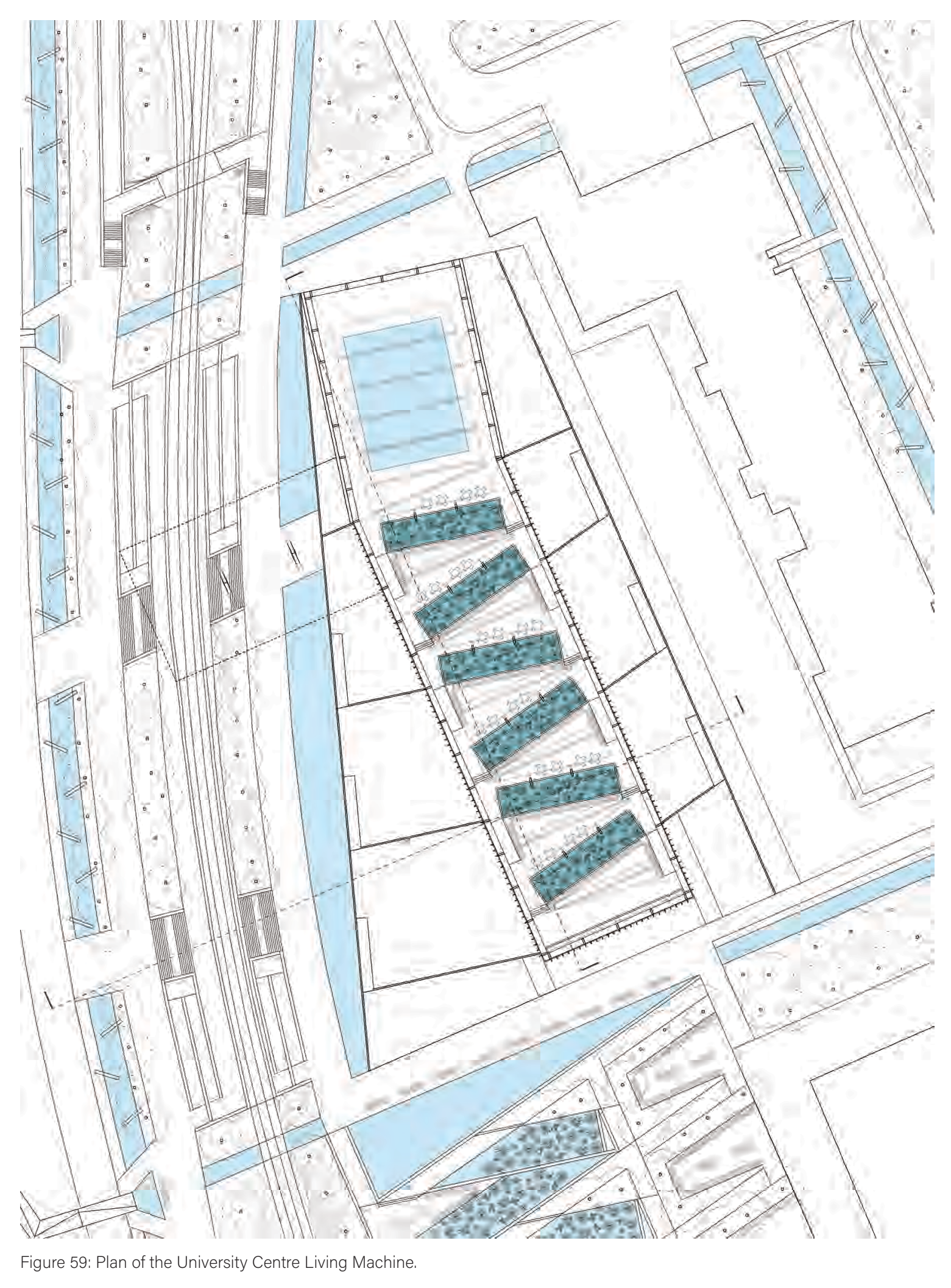

127 


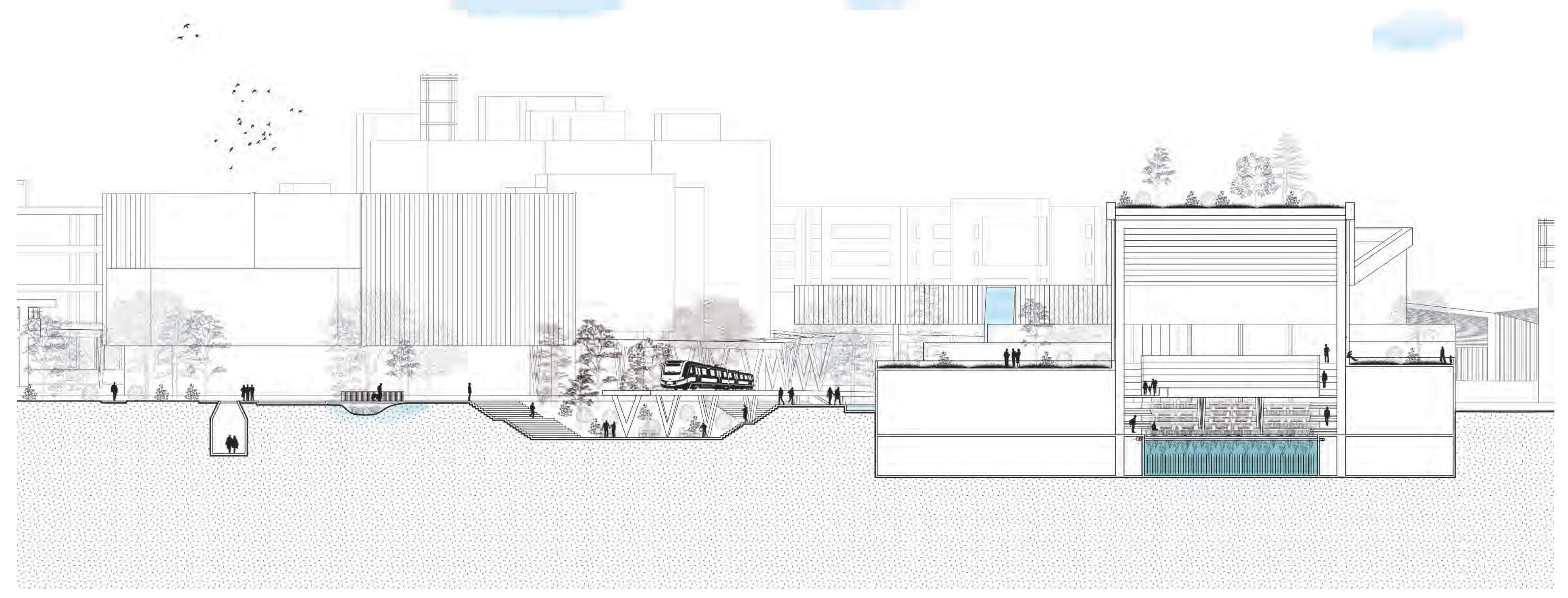

Figure 60: Transverse section of the University Centre Living Machine. 


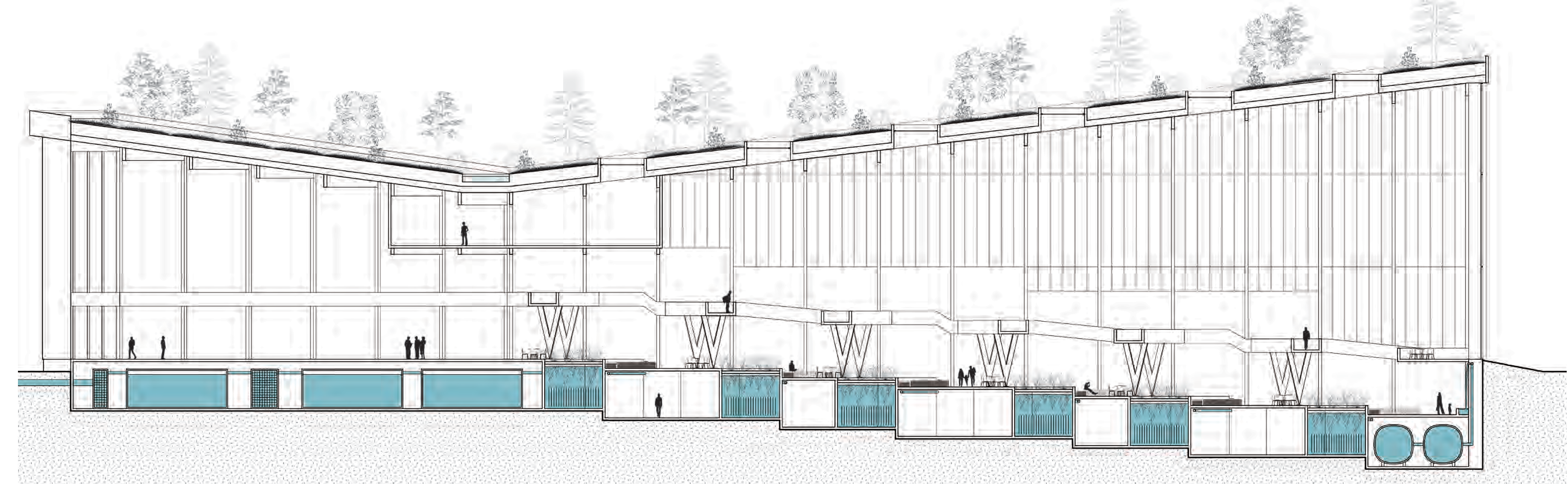

Figure 61: Longitudinal section of the University Centre Living Machine. 


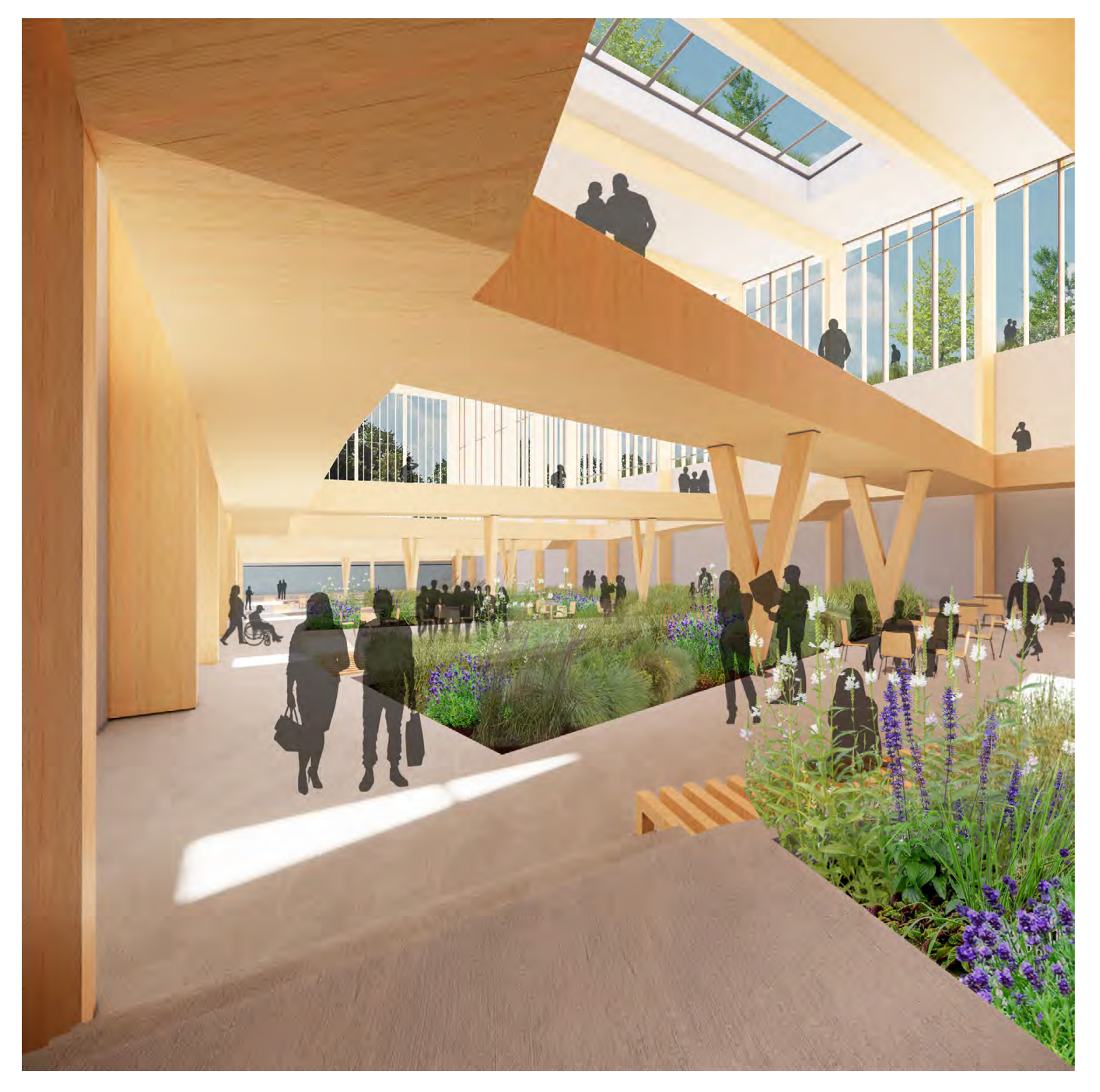

Figure 62: Rendering looking south at the University Centre Living Machine.

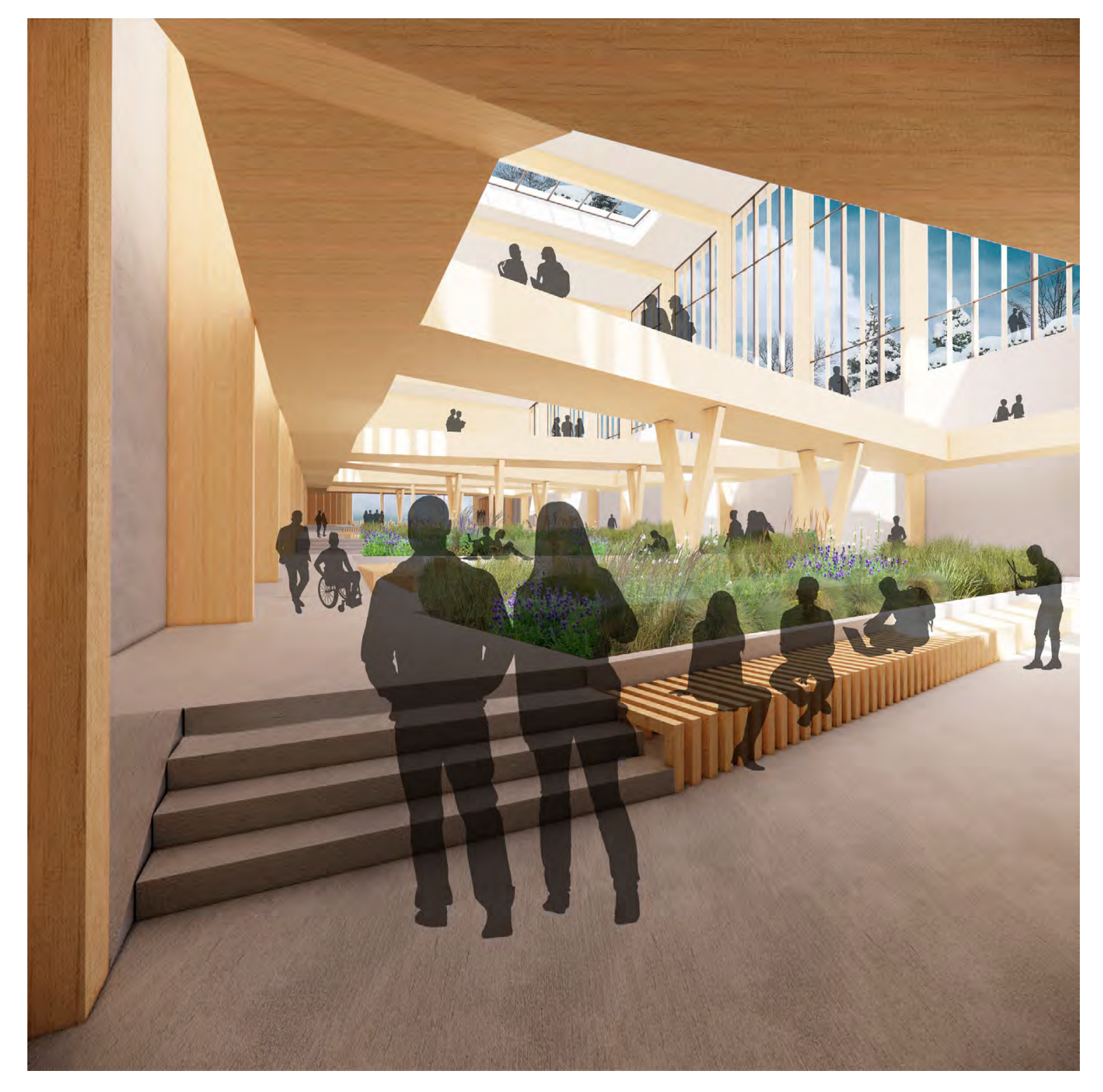

Figure 63: Rendering looking north at the University Centre Living Machine 


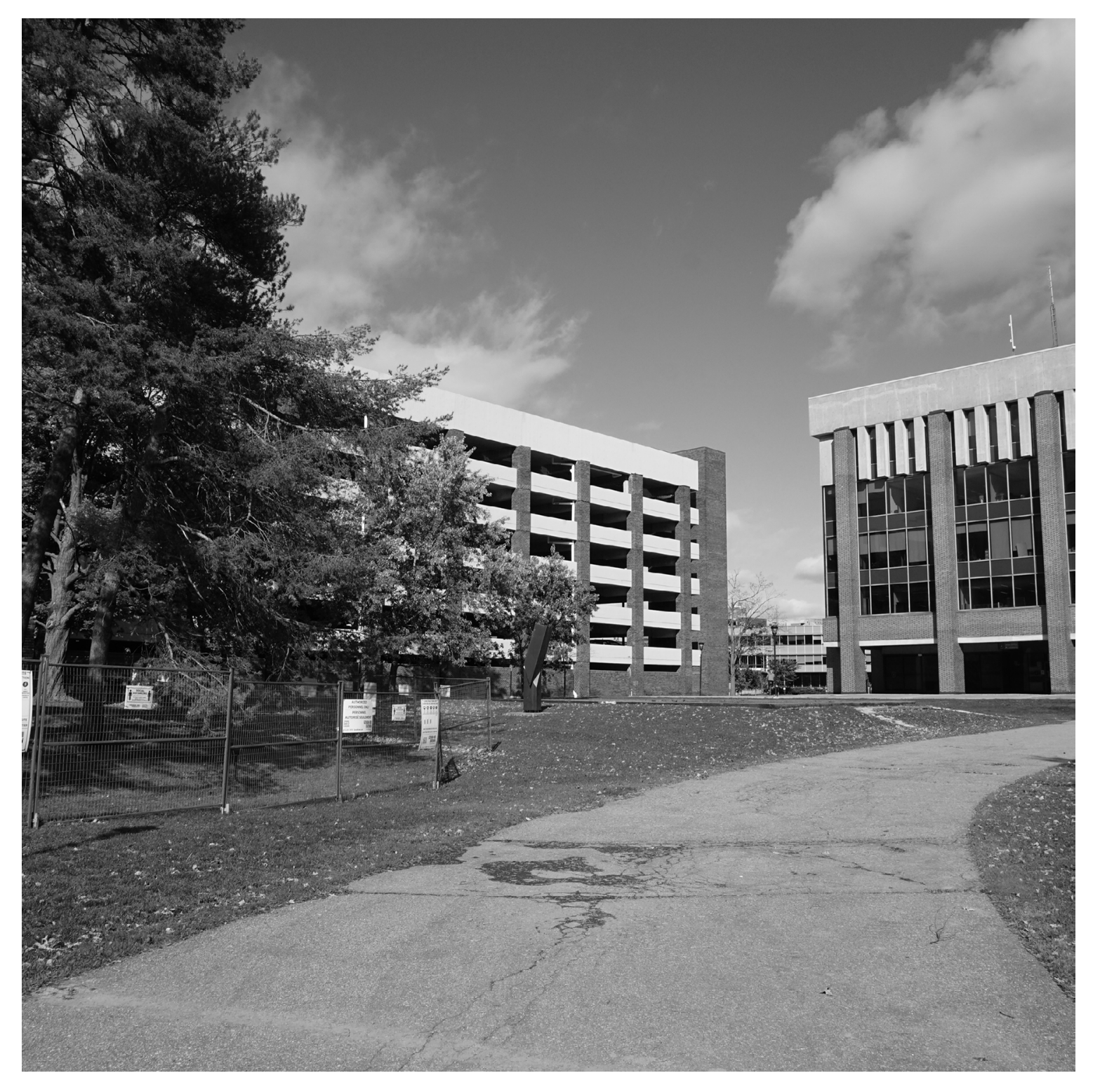

Figure 64: Before photograph of the University Centre Living Machine site.

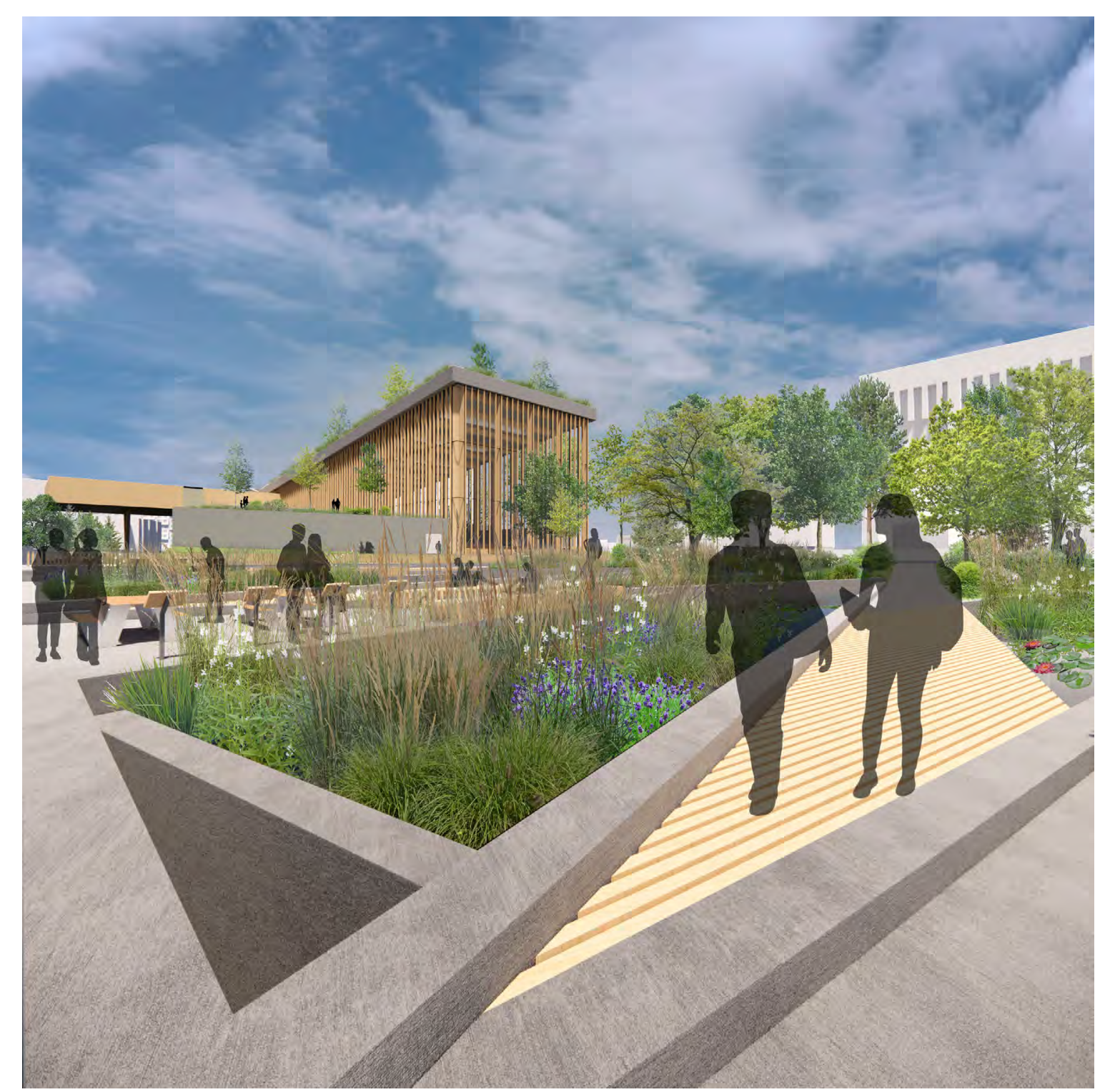

Figure 65: After rendering of the University Centre Living Machine site. 


$$
\frac{1}{c}
$$


the aqueduct adapting to flat pathways with flat ground to either side. A retaining wall

In order to capture stormwater from across campus and transport it to the central spine for detention and treatment, a series of aqueducts and canals are employed. The aqueducts serve a multi-purpose function. Primarily they act to transport stormwater from campus rooftops to the central wetland canals while also being able to reinforce and foster public spaces along their path and make the collection of stormwater visible (See Figure 68). The basic structure of the aqueducts consists of alternatively-folded steel planes used to transport the water and control its flow rate passively and are supported by heavy timber struts to maintain consistent natural connections. This aqueduct structure is supported by dynamic concrete retaining walls and pathways to provide a strong base for the collection structures above. The aqueduct networks are also supported by wetland bioswales flowing adjacent to the retaining walls in order to direct surface runoff to the central spine and promote infiltration along their path This basic structure is complemented by a kit of parts that can be implemented and adjusted in order to meet various environmental and experiential parameters along their path across campus.

The adaptability of the aqueduct network is outlined in a series of configurations that arrange the infrastructural kit of parts together in response to the characteristics of specific campus locations intended to bolster existing pathways and foster dynamic spatial relationships. The first configuration demonstrates the aqueduct adapting to flat pathways with sloped ground to one side. A retaining wall grows from the path following the slope of the aqueduct to reinforce the soil to one side while also supporting wooden seating and a wetland bioswale. This configuration provides the opportunity to stop and enjoy the surrounding space along the path while maintaining efficient circulation through less busy areas (See Figure 69). The second configuration outlines grows from the path following the slope of the aqueduct to support a wetland bioswale and a growing screen to shield unsightly building facades. This configuration directs the pedestrian attention towards a specific viewpoint while maintaining an open thoroughfare and shielding the pedestrian with plant growth (See Figure 71). The third configuration outlines the aqueduct adapting to sloped pathways with sloped ground to either side. The aqueduct follows the slope of the path while providing wetland bioswales on either side. This configuration allows for a continuous and unimpeded thoroughfare for busier paths while being partially contained by wetland plantings to either side (See Figure 73). The fourth configuration outlines the aqueduct adapting to flat pathways with flat ground to either side. A retaining wall grows from the path following the slope of the aqueduct and supports a pergola construction that shelters a newly contained public space along the pathway with a wetland bioswale on one side. This configuration creates a point of interest along the path and allows for public interaction in a controlled environment that creates a hierarchy of space (See Figure 75). The fifth configuration outlines the aqueduct adapting to flat pathways with flat ground to either side. A retaining wall grows from the path following the slope of the aqueduct containig a bioswale and supports a canopy construction that frames a larger interstitial wetland zone on the other side. This configuration provides a stopping point along the path while also framing views and protecting pedestrians travelling underneath (See Figure 77). These aqueduct compositions showcase the adaptability of the aqueduct infrastructure kit of parts demonstrating the ability of the network to respond to various landscape and spatial characteristics.

Overall, the aqueducts help to encourage the growth and improvement of existing public spaces on campus while also rejuvenating neglected ones (See Figure 
80). By directing stormwater across campus, the aqueducts cultivate plant life and healthy groundwater levels while also framing these spaces for pedestrian experience Located high above the ground plane and implemented on an institutional scale, the aqueduct stormwater collection networks are placed on display and given gravitas for all pedestrians following their paths to experience. Because they border existing pathways throughout the university and terminate in dramatic fashion at the wetland canals, the aqueducts also continuously provide direction and connection to the centra spine.

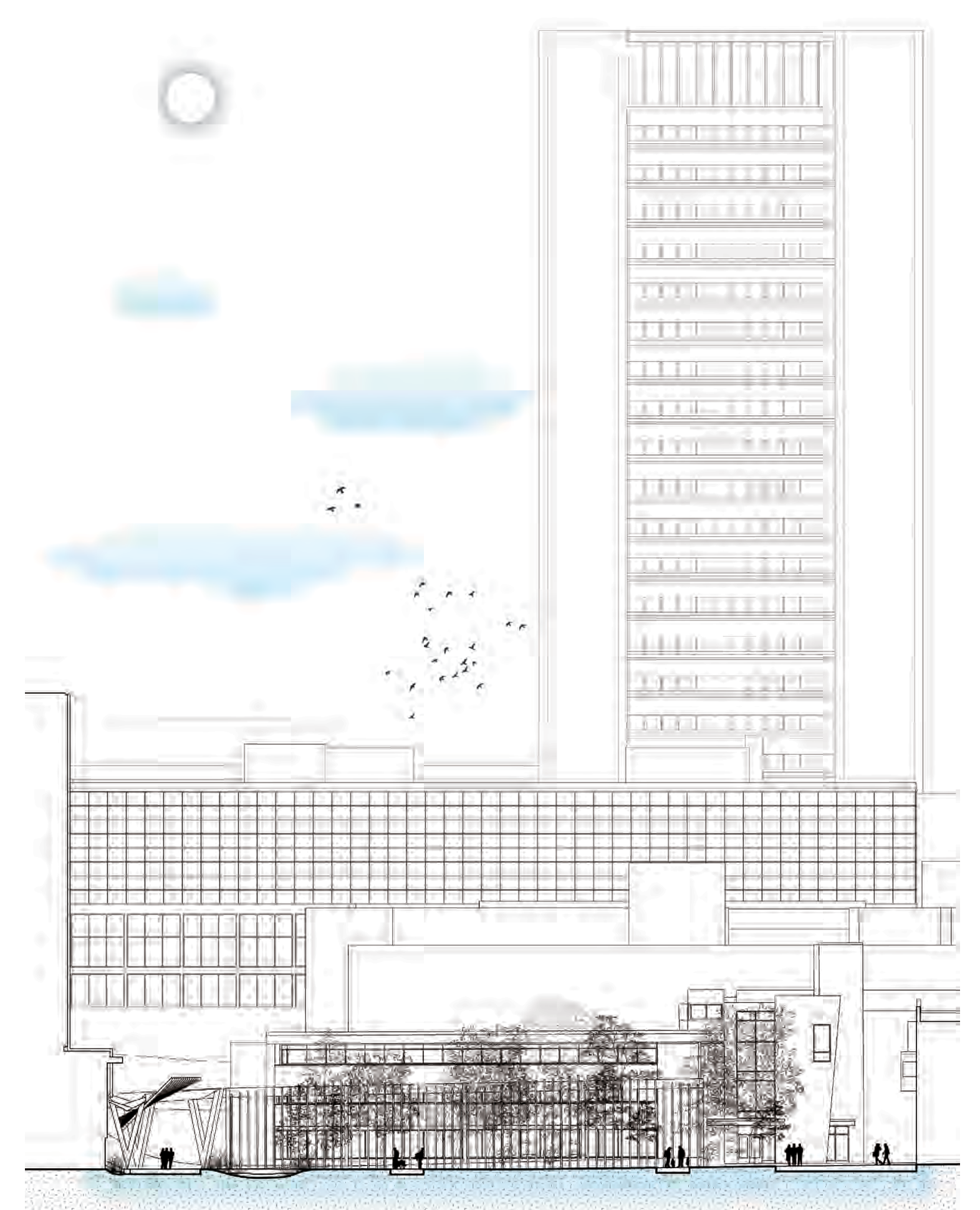

Figure 68: Section across an aqueduct where it meets a public space. 

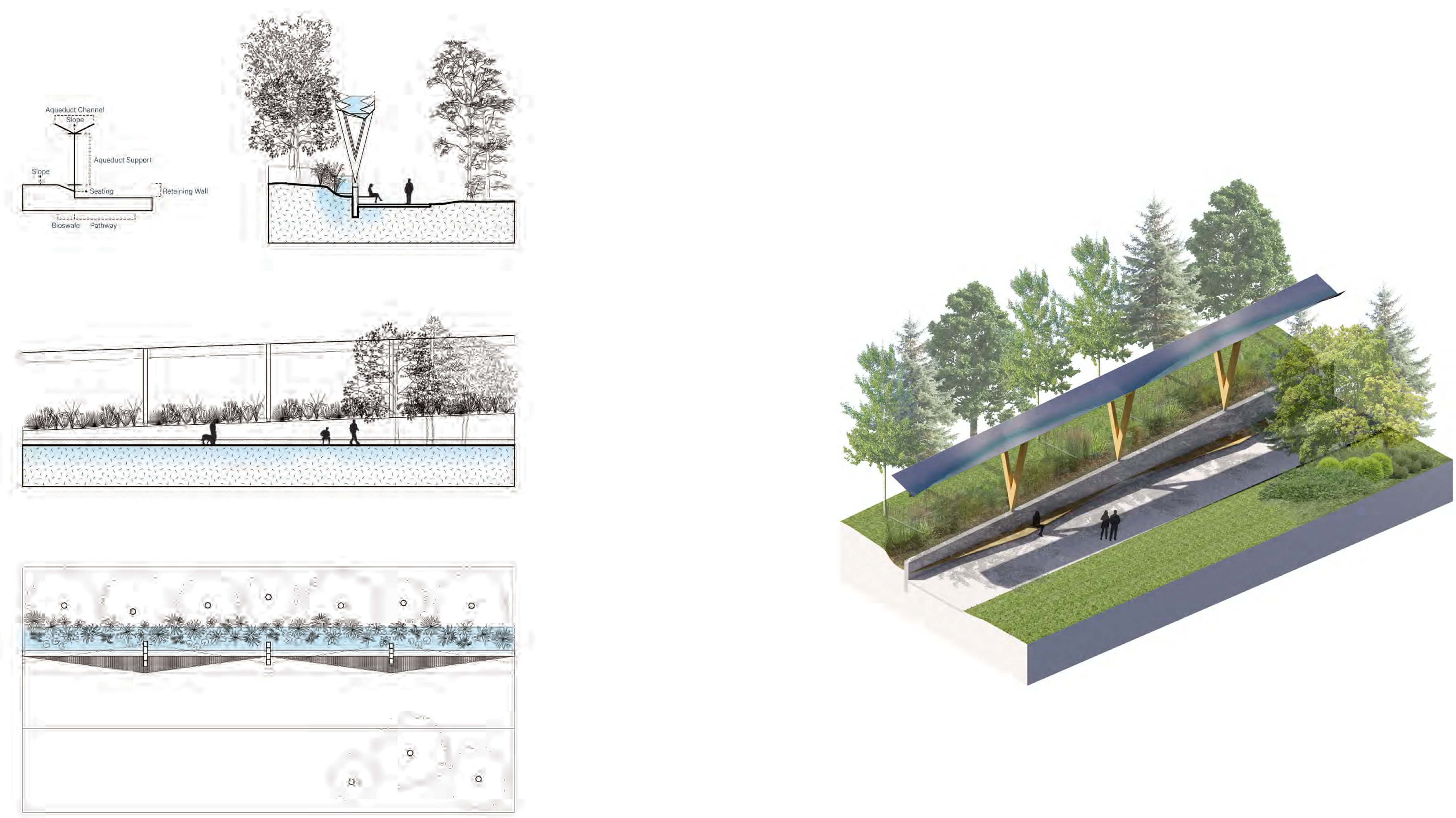

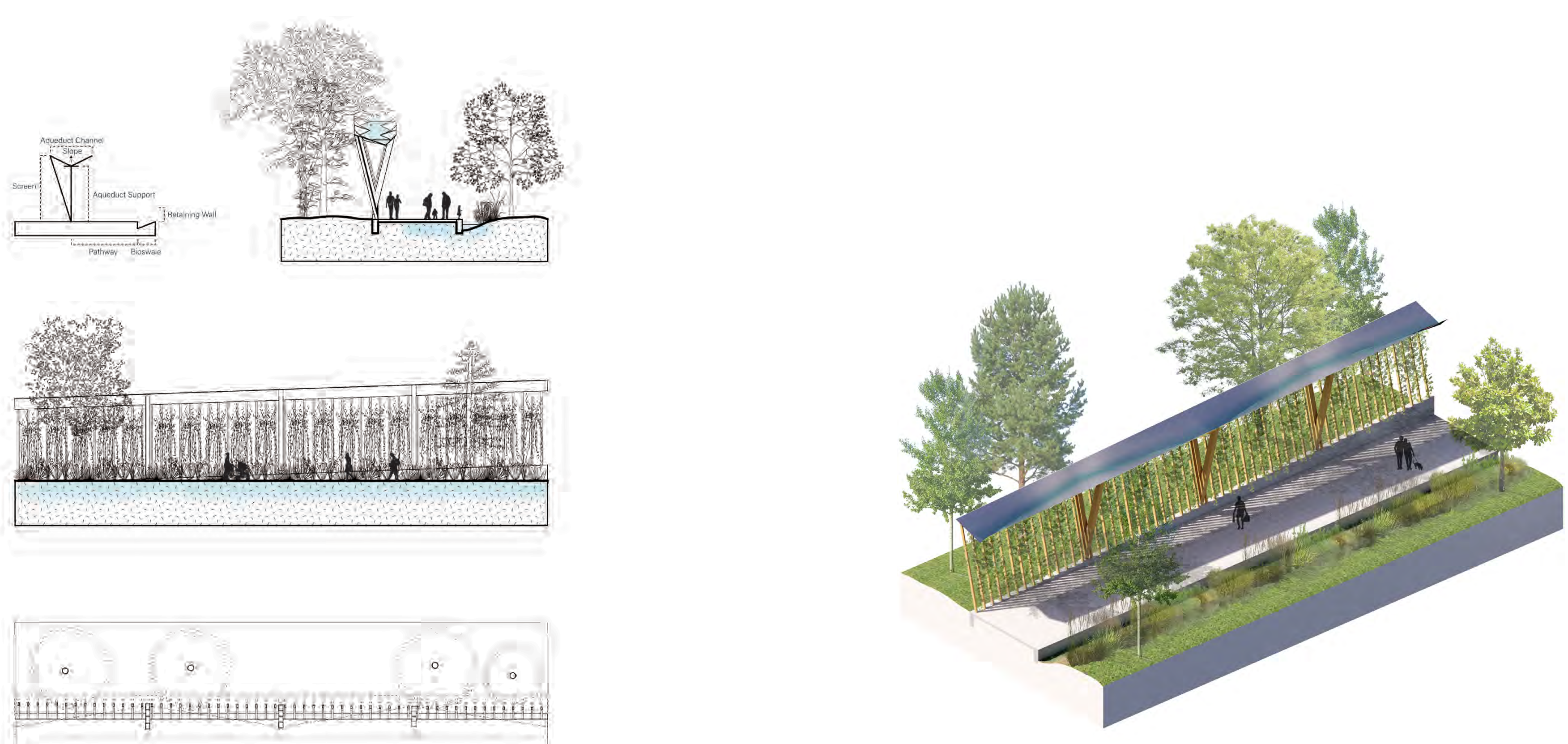

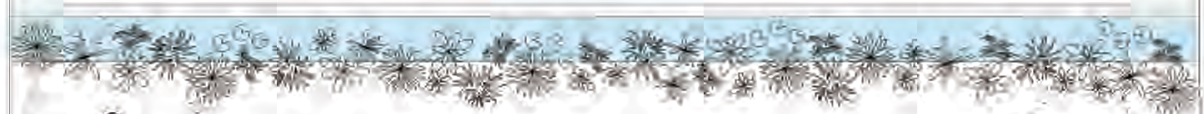

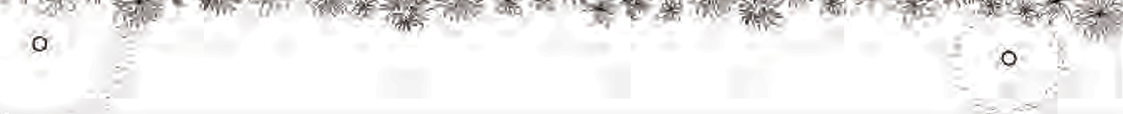



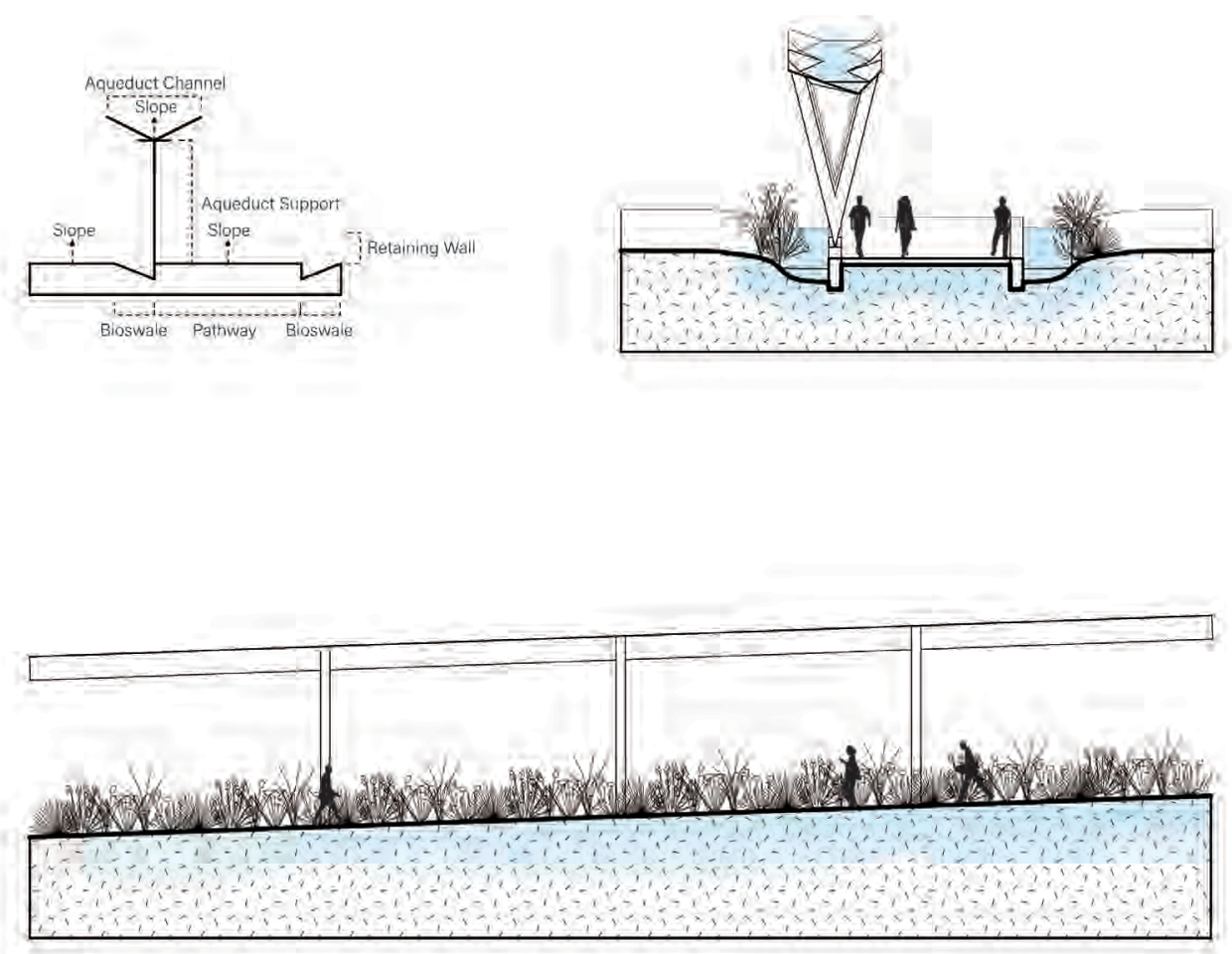

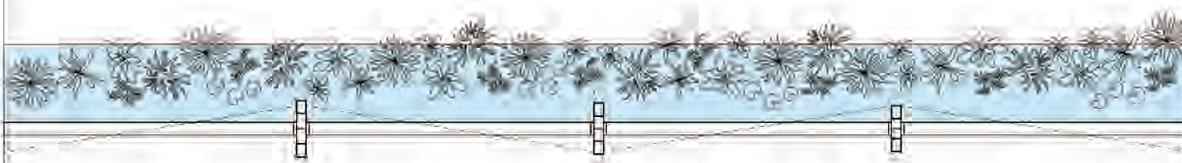

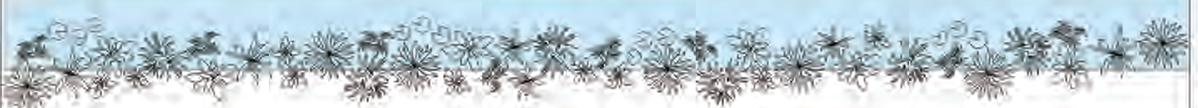

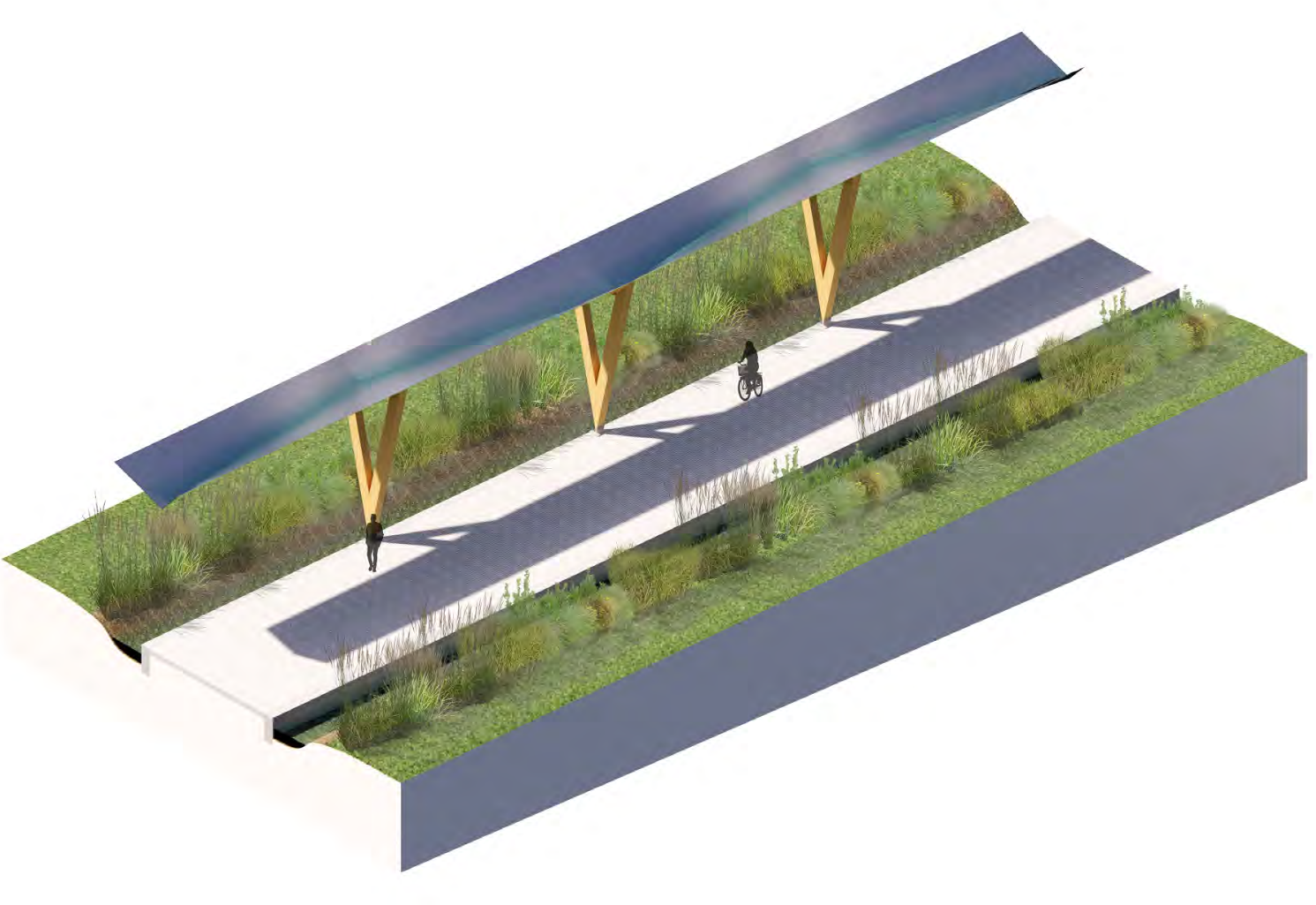

Figure 74: Rendering of aqueduct configuration 3 


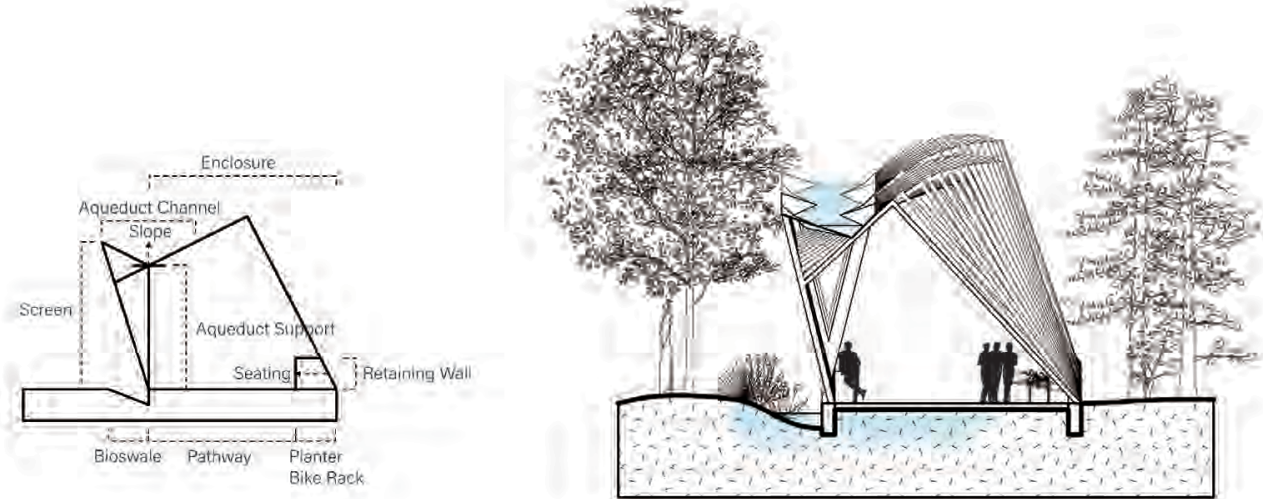

1)

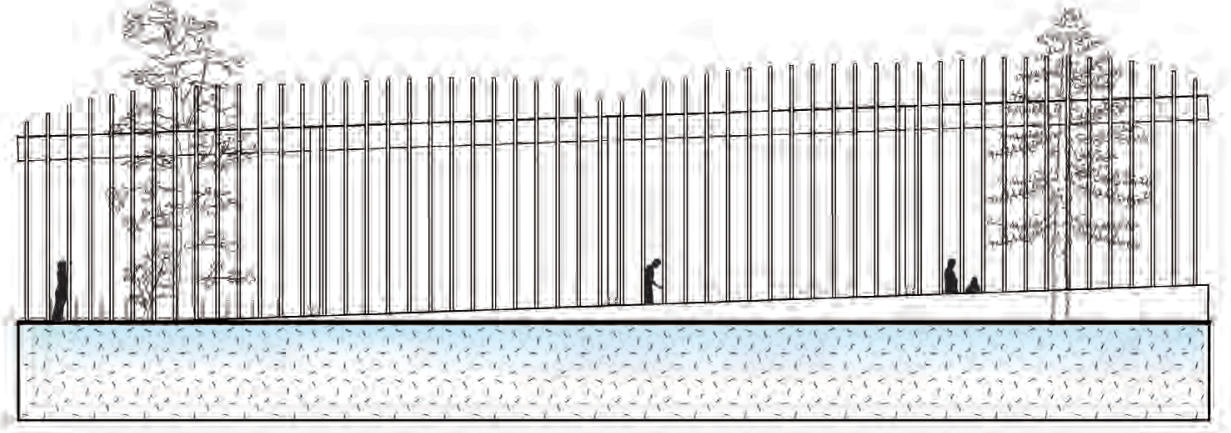

$0.00 \%$. Mrin

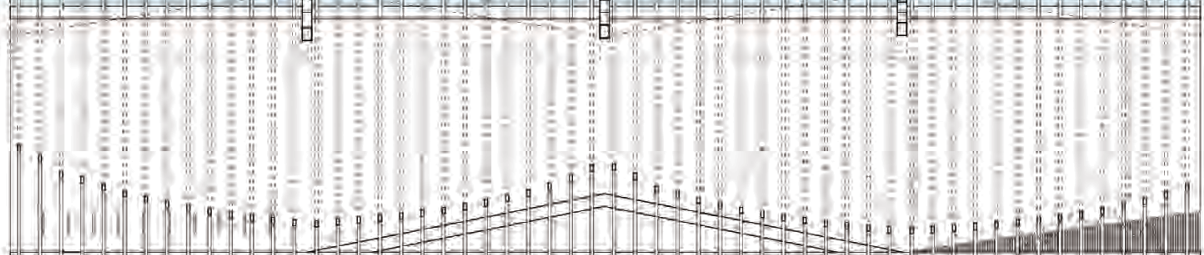

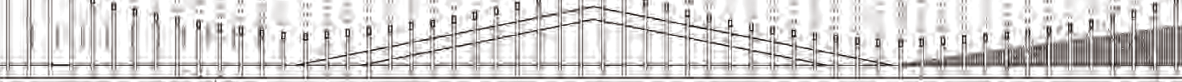

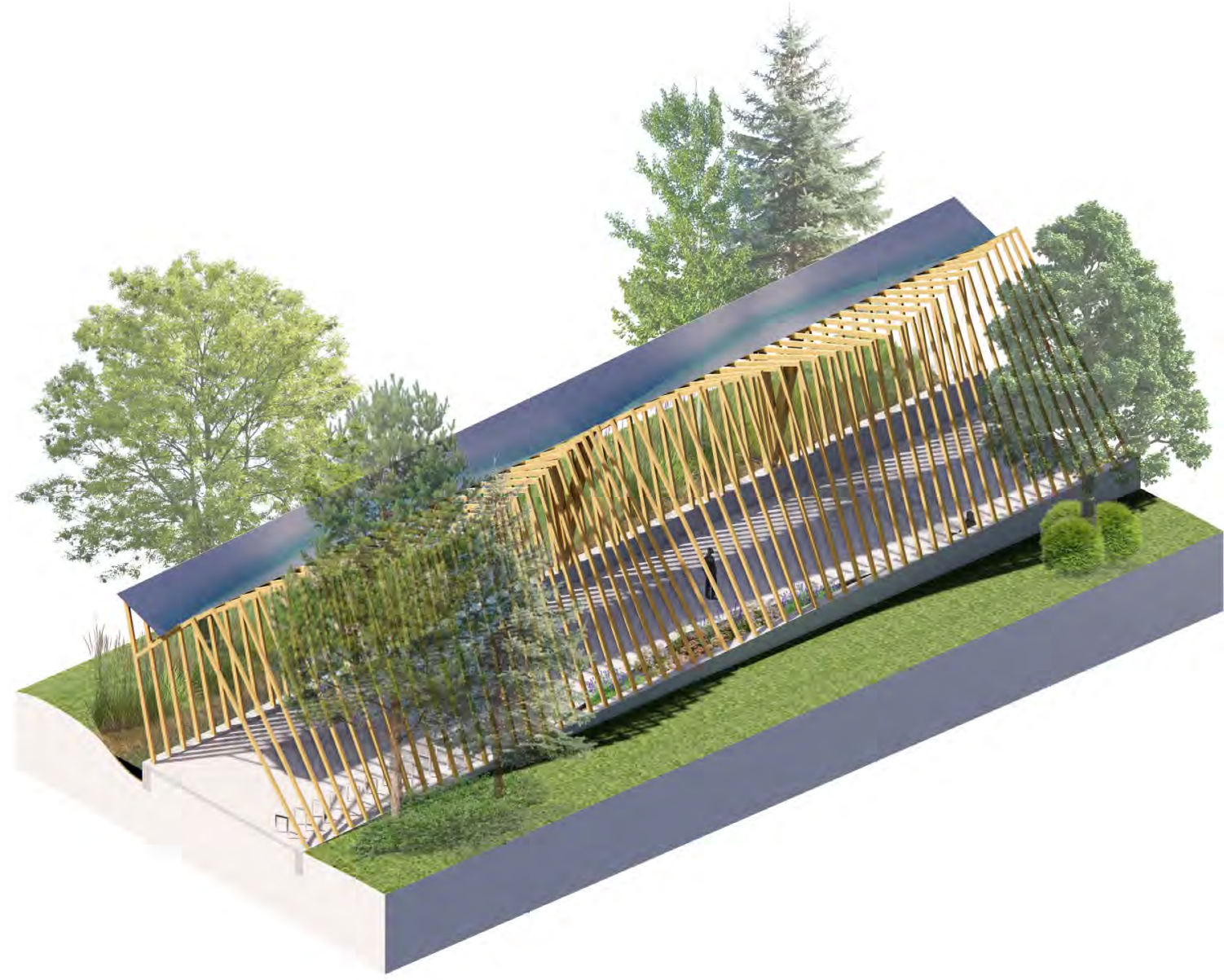

Figure 76. Rendering of aqueduct configuration 4 

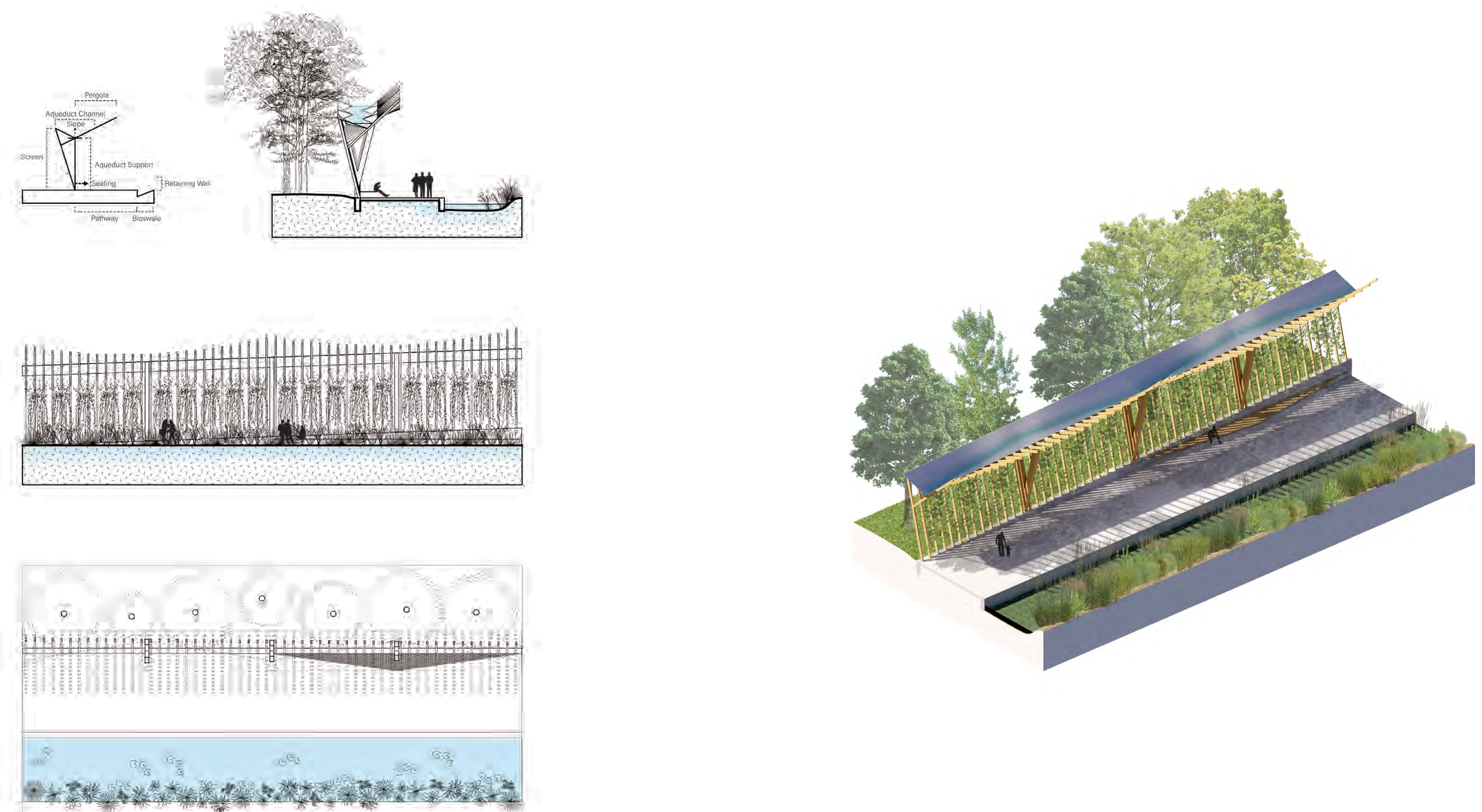

$$
\begin{aligned}
& \text { 41971น1 } \\
& \text { (I) }
\end{aligned}
$$

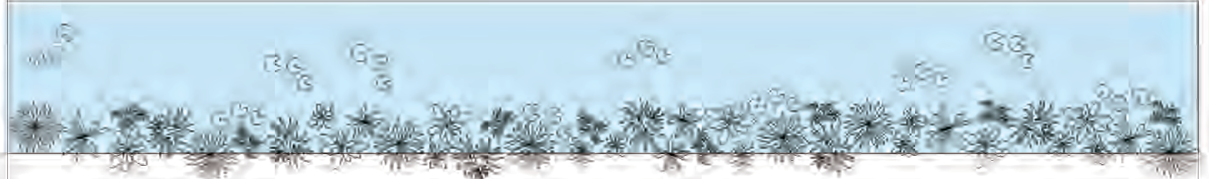




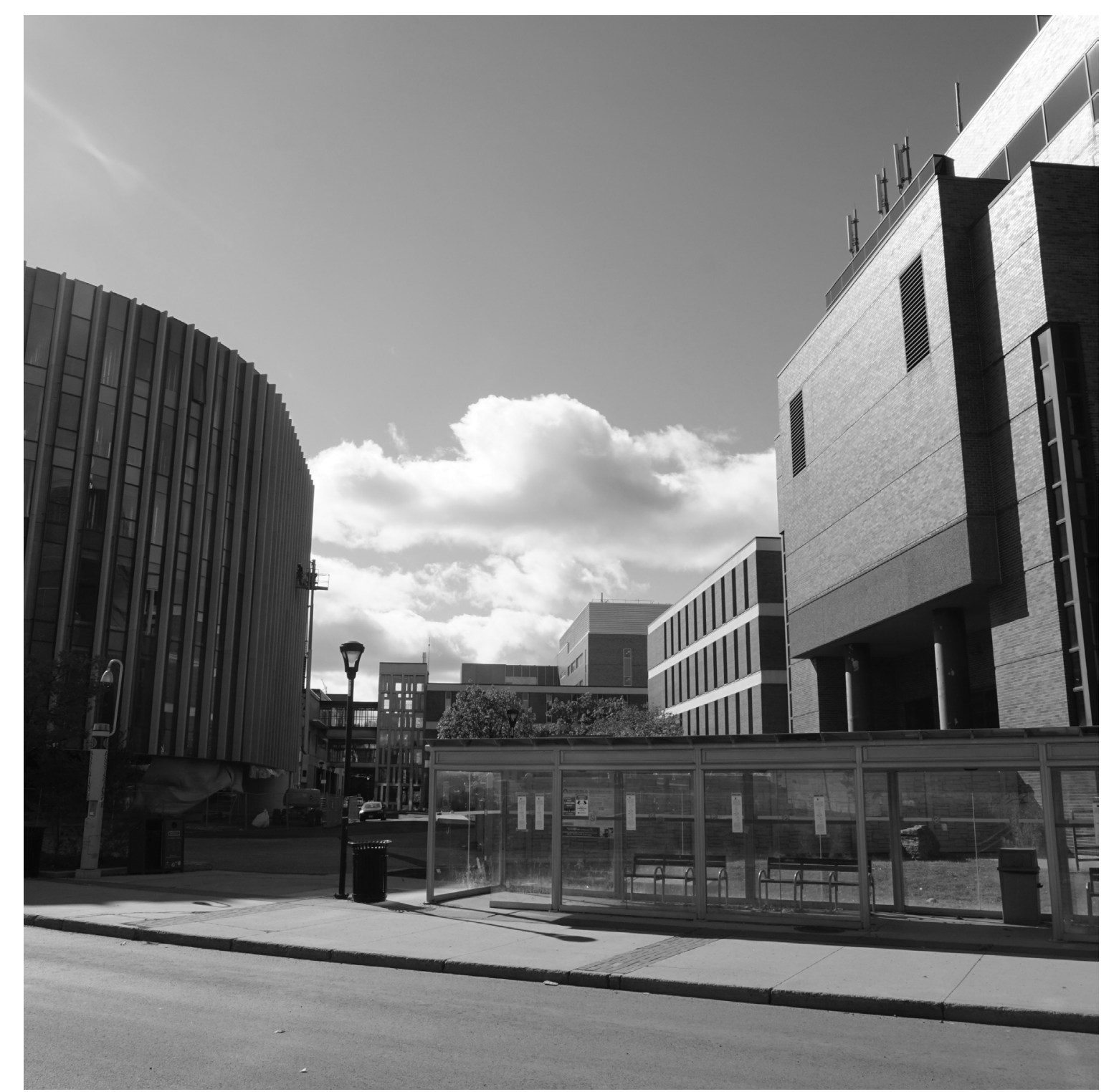

Figure 79. Before photograph of an aqueduct site.

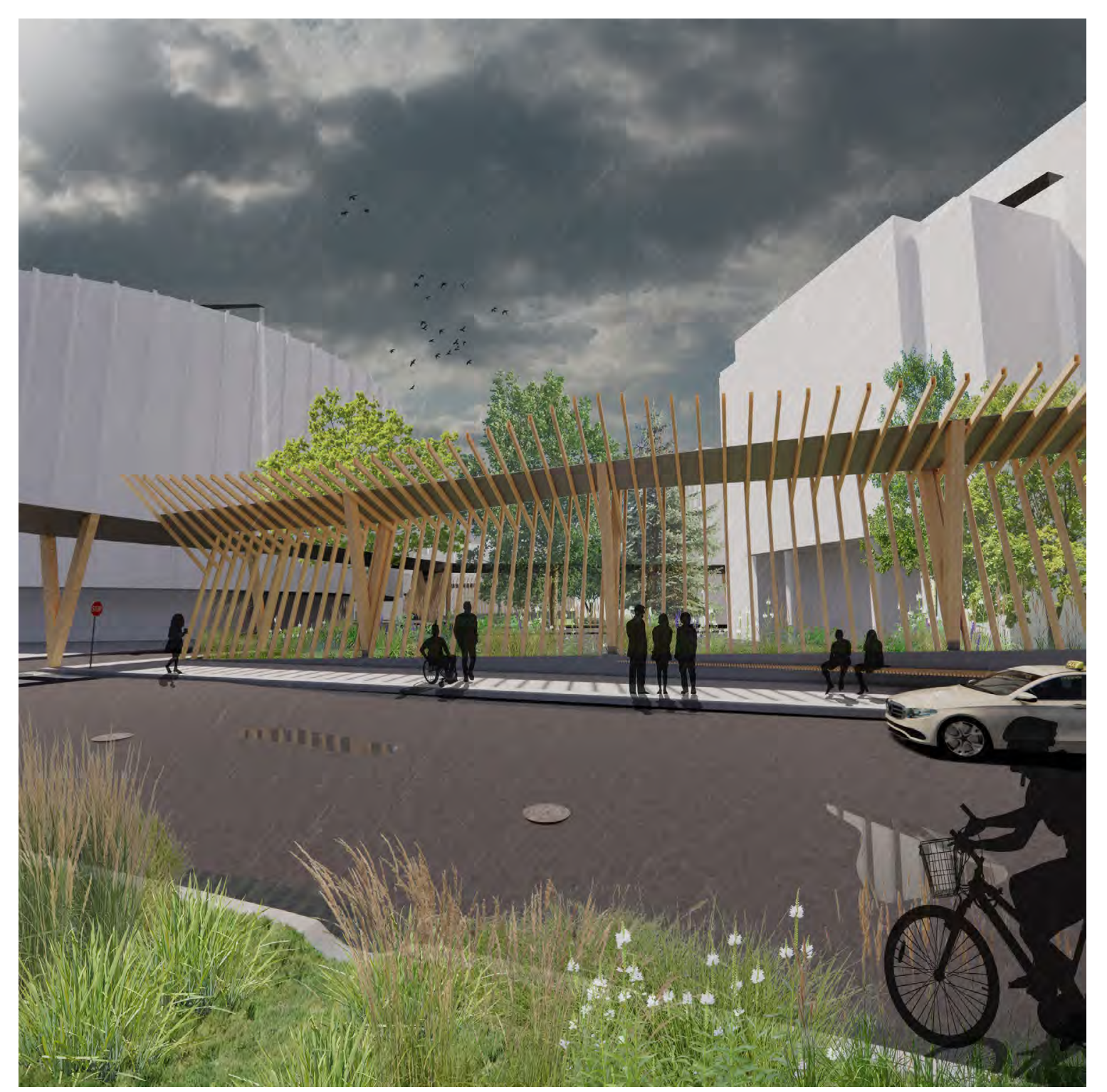

Figure 80: After rendering of an aqueduct site. 
Being fed directly by the incoming aqueducts directing water from the furthest points of campus, the free water wetland canals that flank the central spine on the east and west sides are able to sustain a long green swath across campus (See Figure 81) Other than the aqueducts sources, the canals also collect surface runoff that is helped by the bioswales of the aqueduct infrastructure and naturally flows towards them. Consisting of a continuous trench with flow controlling concrete wiers, the canals support a diverse wetland habitat that partially treats the incoming stormwater through natural processes along its way to the constructed wetland park in the south. Furthermore they act to store water and incite groundwater recharge through infiltration. Where the aqueducts meet the canals, diverging causeways are created that cut towards the interior of the central spine in order to connect the canals on either side of the central spine with the interventions of this area including the new transit centre, University Centre and constructed wetland. The causeways shape the crossing points for the new underground train track crossings allowing for circulation that follows the flow of water and maintains a close connection to these water networks throughout the pedestrian experience. This makes it so that all parts of the water management interventions are closely integrated and work together to bring awareness to the dynamic water management processes occurring in the central spine.

The habitat supported by the wetland canal provides an appealing public experience and reinforces the longitudinal pedestrian path that crosses from north to south along the central spine (See Figure 82). They create a natural promenade across the central spine that allows for circulation in all directions to maintain connections between both sides of campus and the waterways that border it to the north and south. At the intersections between the aqueducts and the canals, dramatic waterfalls are created with paths to either side and public seating allowing for freedom of circulation and enjoyment of the space. Therefore, the canals also provide the transition point between the rest of campus and the central spine in order to differentiate the spatial experience between them and create a threshold into the repurposed central zone 


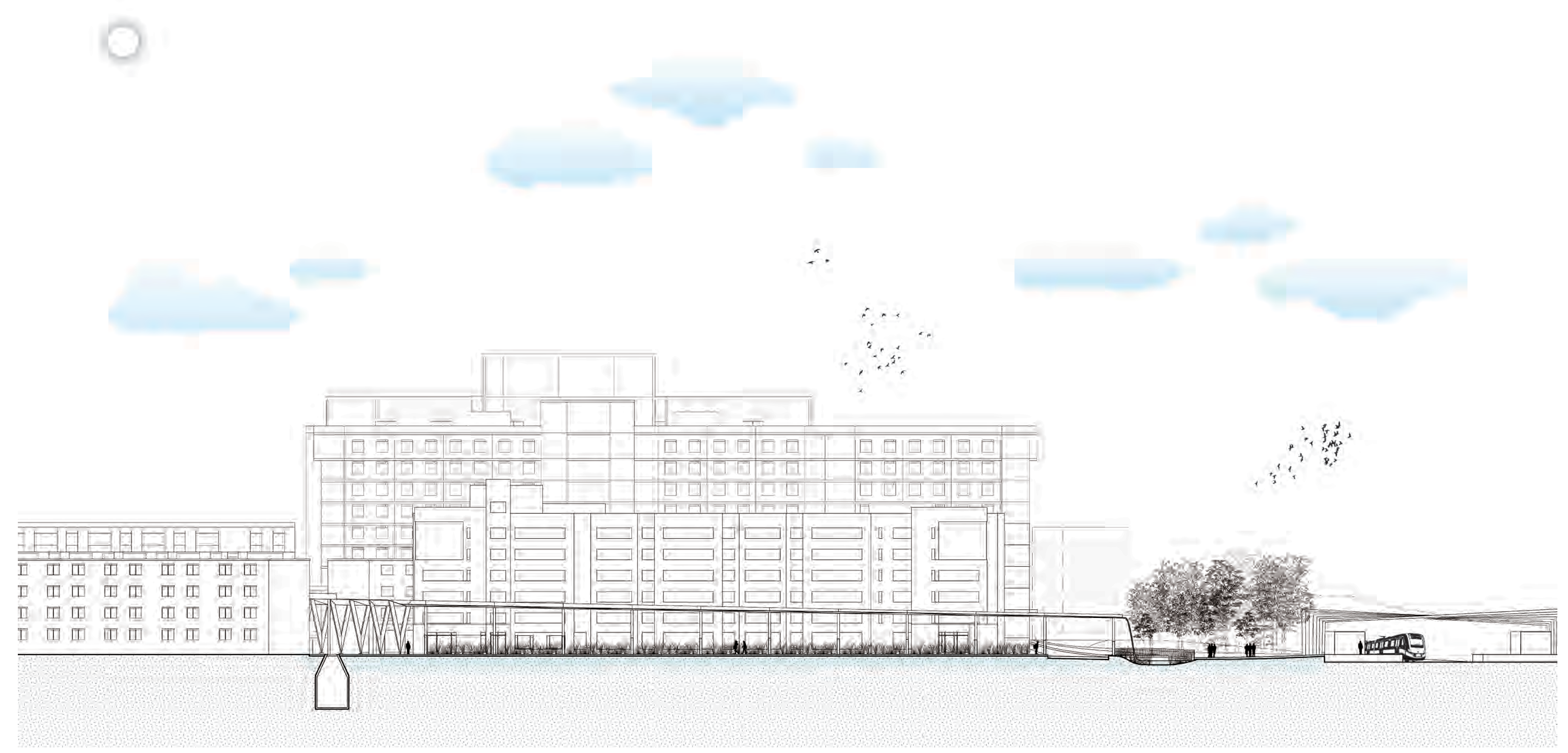




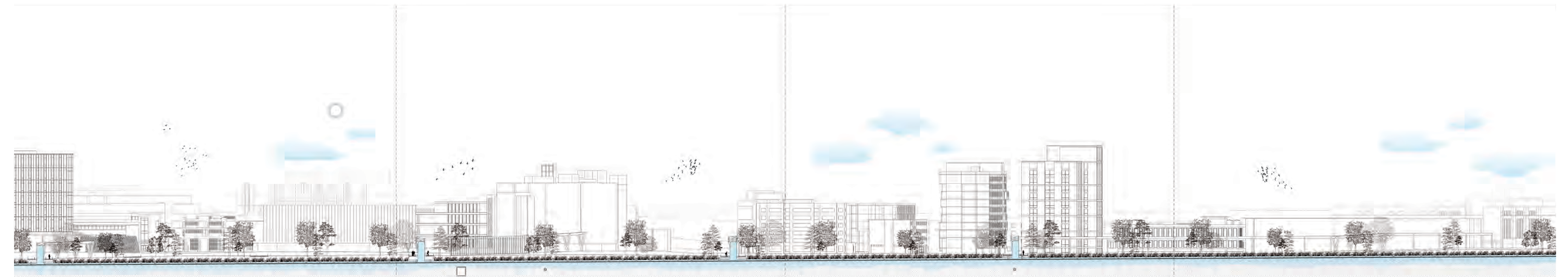


$\therefore$

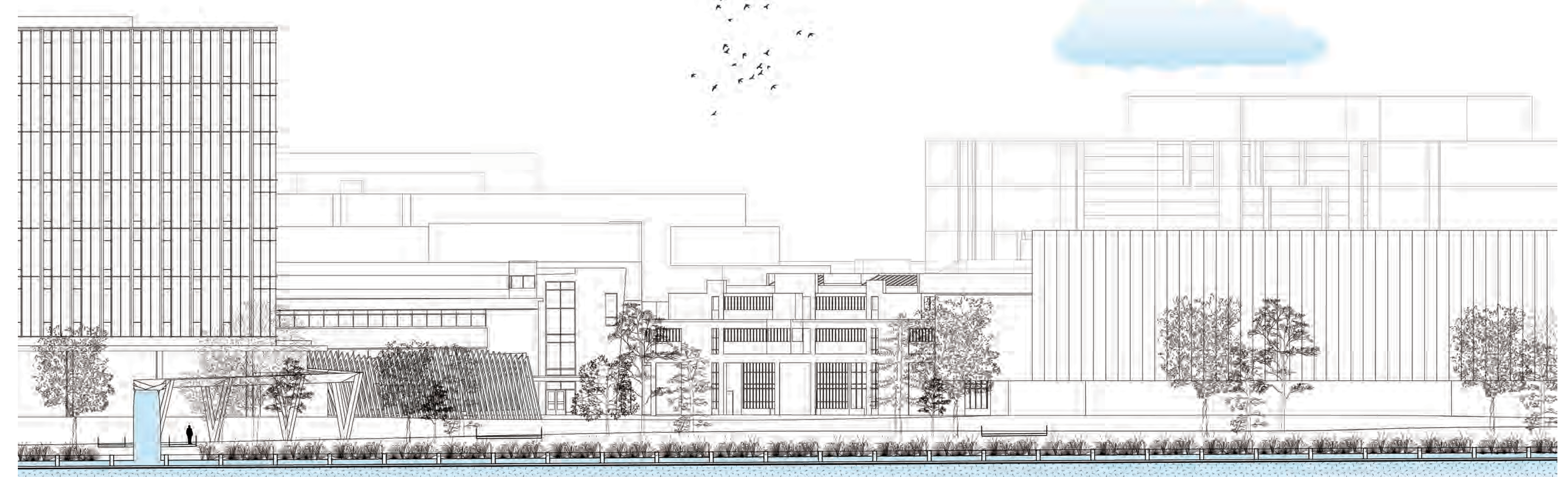

Figure 83: Section part 1 along the the western canal in the central spine. 


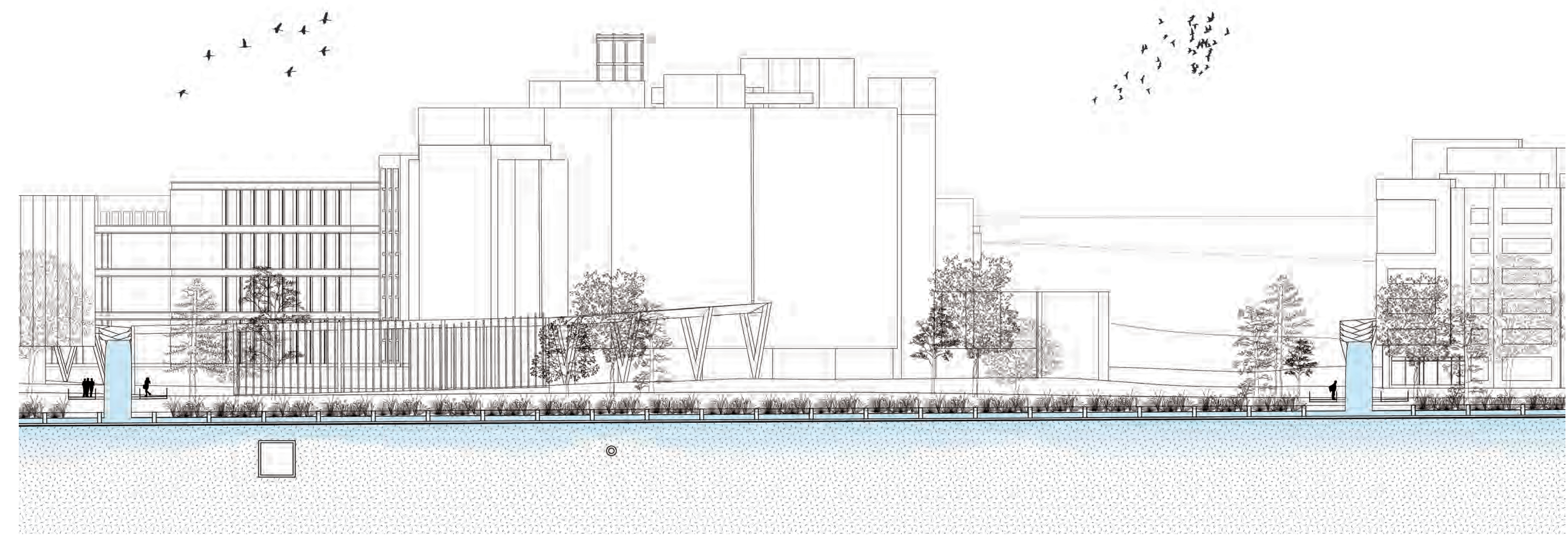

Figure 84: Section part 2 along the the western canal in the central spine 


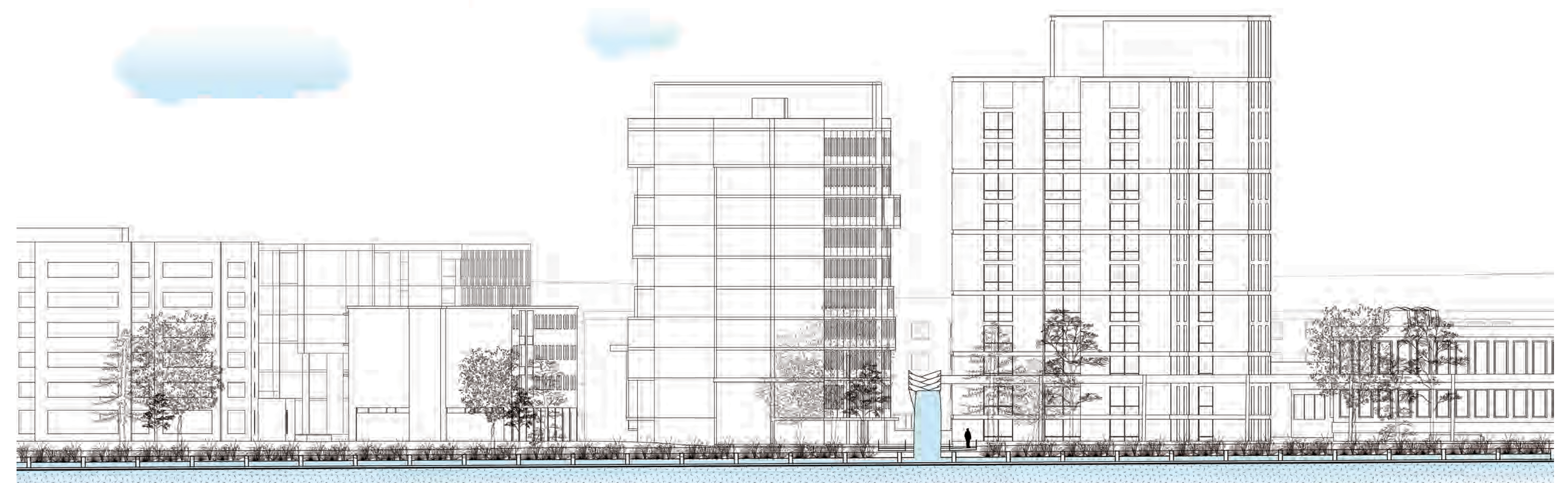

(c)

Figure 85: Section part 3 along the the western canal in the central spine. 


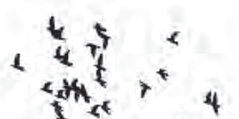

$$
\begin{aligned}
& \text { t? }
\end{aligned}
$$

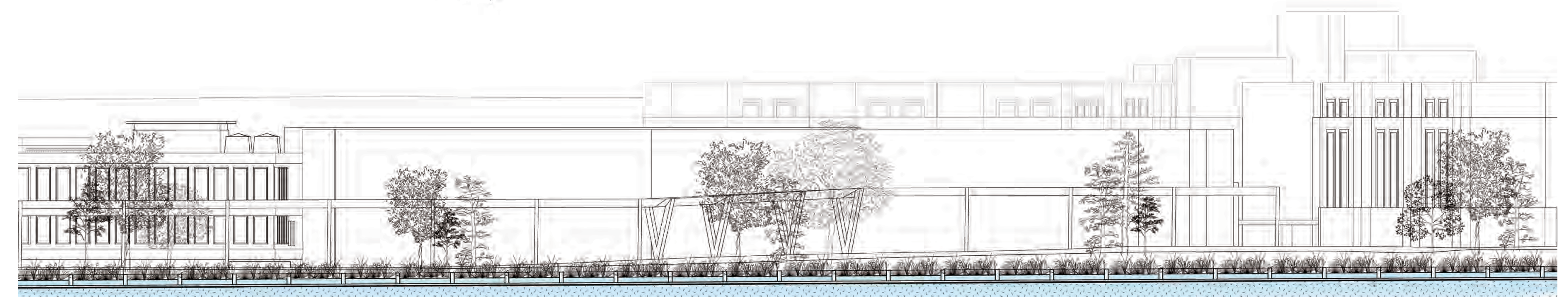

Figure 86: Section part 4 along the the western canal in the central spine. 


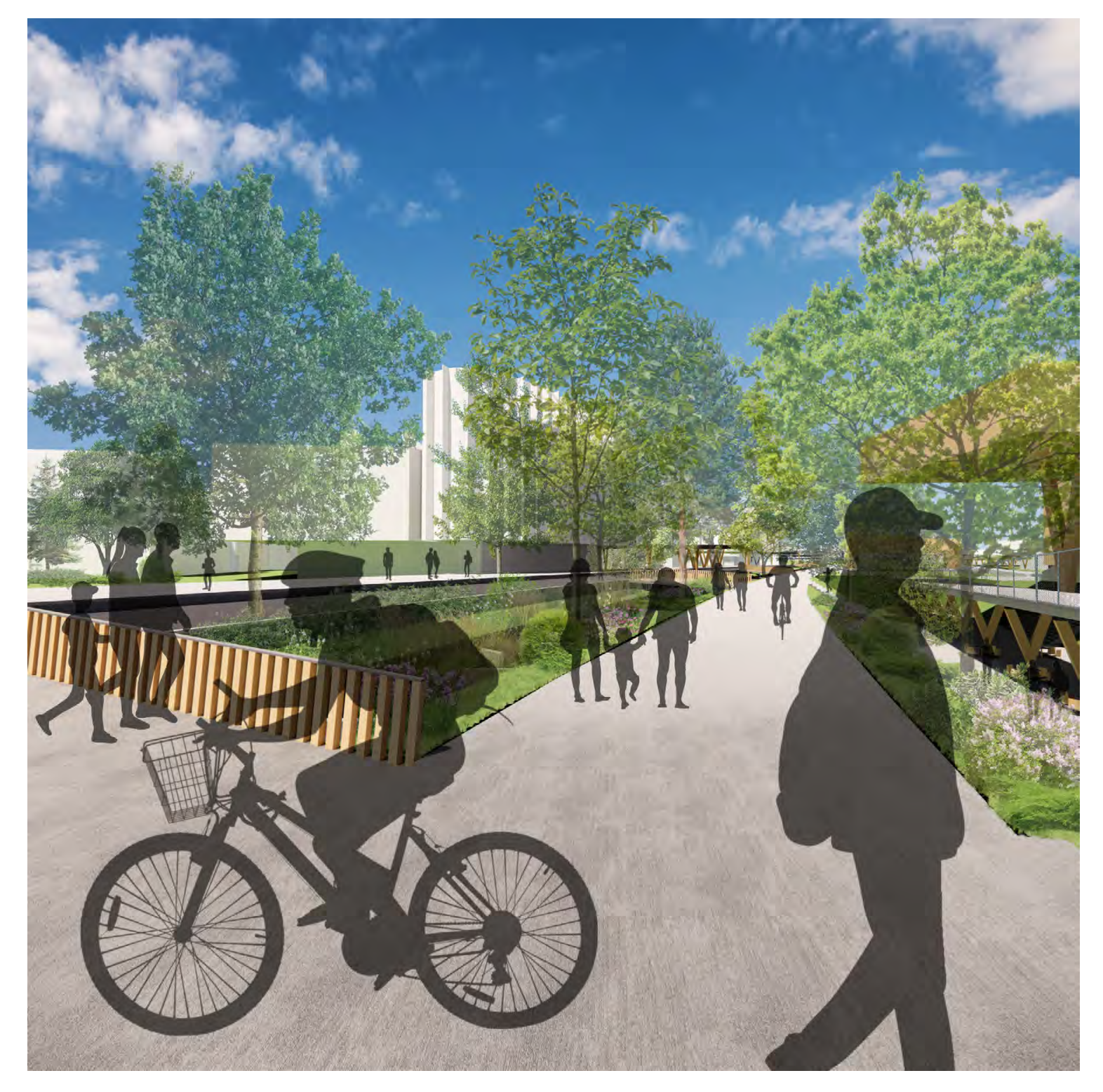

Figure 87: Rendering looking north at the wetland canal.

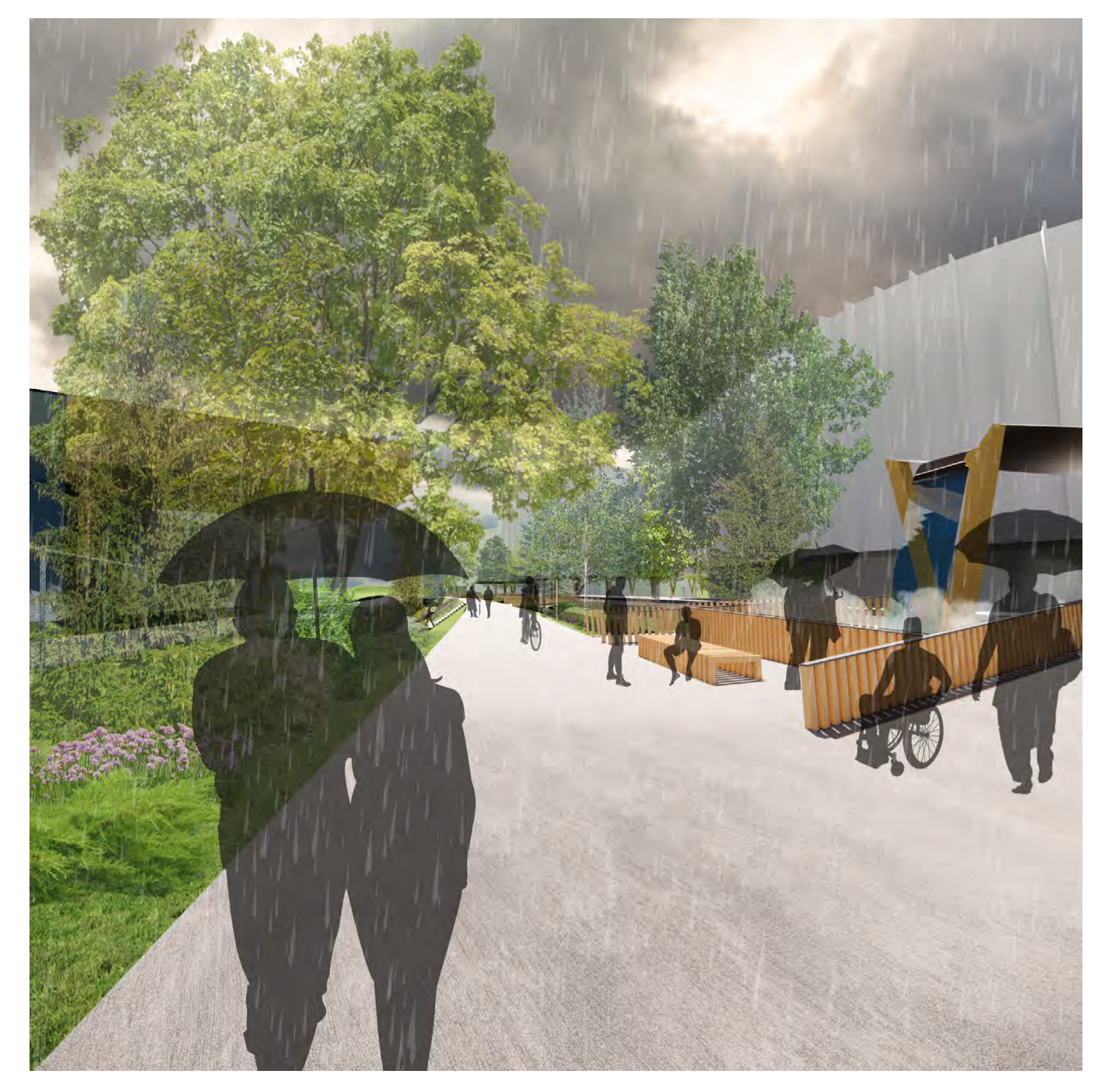

Figure 88: Rendering looking south at the wetland canal. 


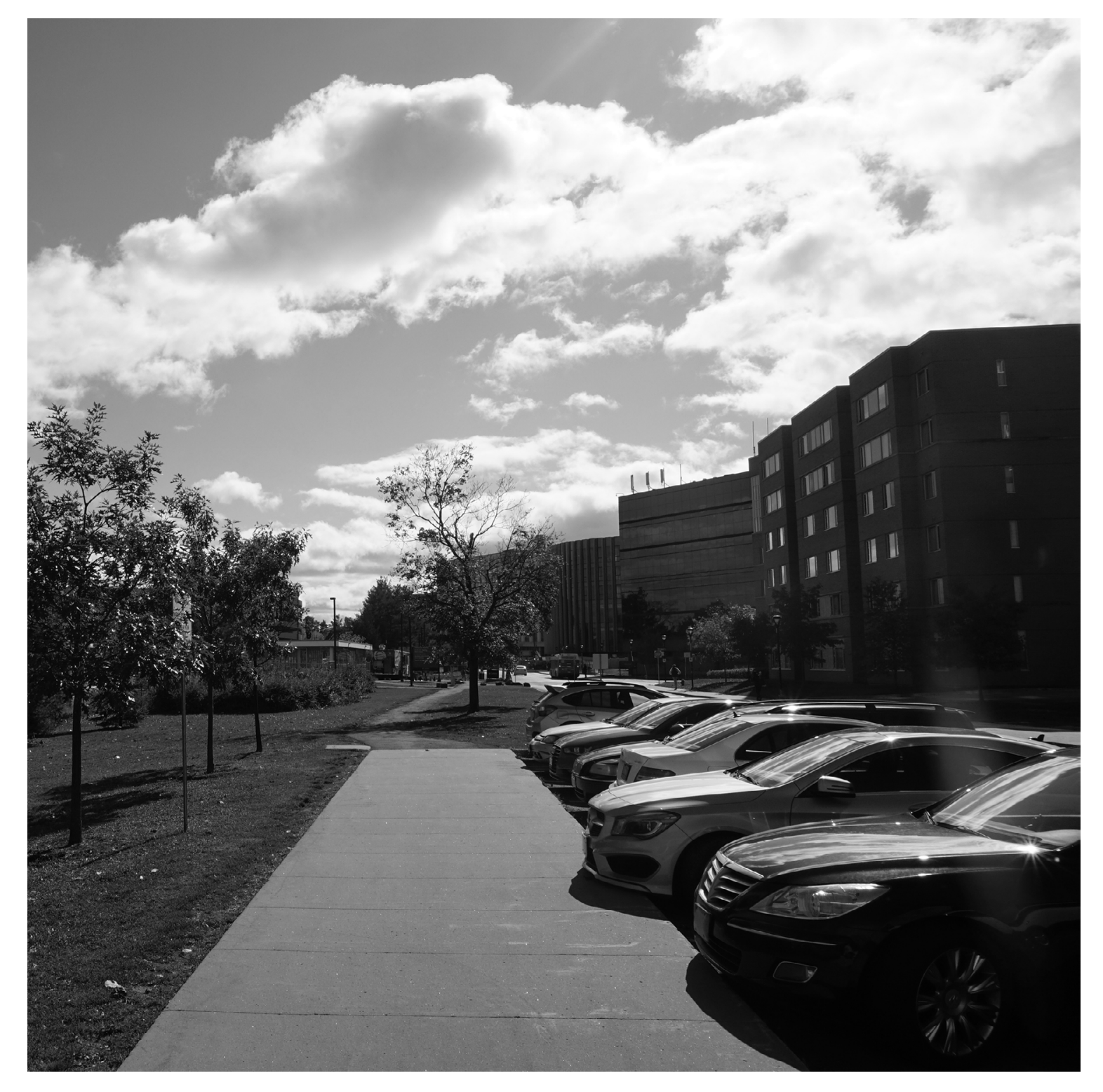

Figure 89: Before photograph of the wetland canal site.

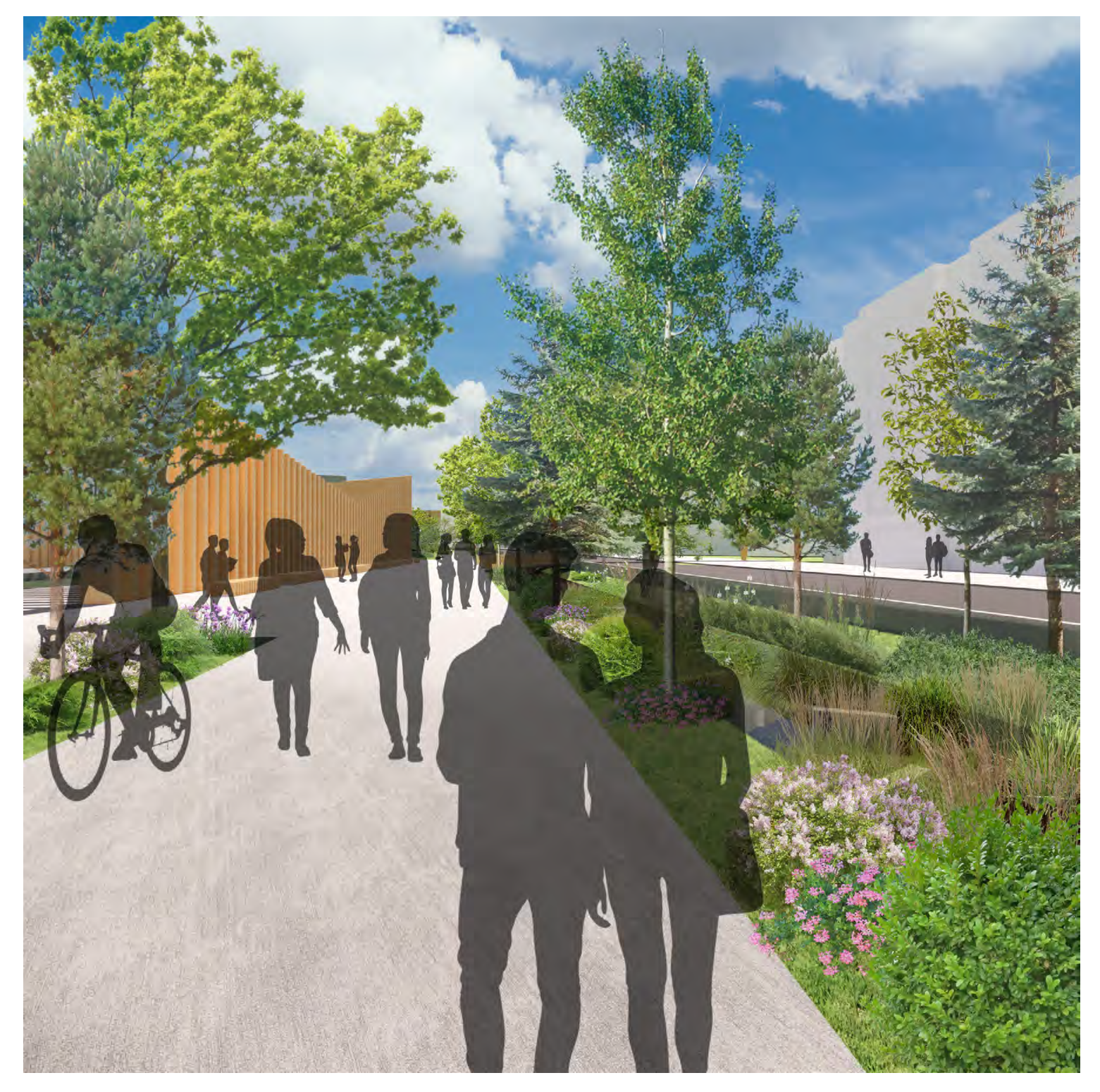

Figure 90: After rendering of the wetland canal site. 
$\mathrm{Qp}=\mathrm{CiA}, \mathrm{Tc}=15 \mathrm{~min}, \mathrm{Td}=1 \mathrm{hr}, \mathrm{C}($ pervious $)=0.2, \mathrm{C}($ impervious $)=0.8$

At the culmination of the stormwater journey is a constructed wetland park in the southern end of the central spine. The constructed wetland is organized as a linear series of free water and surface flow wetland cells that move collected stormwater in a meandering fashion to optimize storage and ecological water treatment processes (See Figure 92). Each cell consists of an inlet leading to a forebay for settling solids followed by a planting zone where the ecological treatment processes are concentrated. After each planted zone is a water level control outlet structure leading to the next cell. Each cell also contains a bypass pipe leading from the previous to the next cell in case maintenance is needed on any individual cell (See Figure 99). Overall, the wetland park works to promote groundwater infiltration, evapotranspiration, stormwater treatment, and water detention to create a robust stormwater management system. These all achieve the goal of storing, treating and detaining stormwater runoff for the purposes of relieving the polluting and flooding impacts of neglected stormwater runoff on campus.

The constructed wetlands are sized using the rationale method and based on calculations according to area and volume-based sizing methods. These guidelines state that the Wetland to Catchment Area Ratio (WCAR) should be greater than $2 \%$ and the wetland should be large enough to capture at least $90 \%$ of the total volume of all storm events or the runoff volume of the $90^{\text {th }}$ percentile storm. ${ }^{249}$ The calculations assume ideal conditions and maximum capacity for all components of the systems and neglect any possible blockages, breakdowns or sediment build-up reducing the holding capacity for one or multiple components.

\section{Calculations:}

249 Rajika Jayaratne, Roger Seyb, Mike Martindale and James Shuang Li, "Constructed Wetland Design Practices and Performances: An Overview," Sormwater Conference (2010): 4-5, accessed January 9, 2021, https://www.waternz.org.nz/ Attachment?Action=Download\&Attachment_id=1240

$A($ total $)=62 \mathrm{ha} \times 0.6(60 \%$ campus stormwater runoff collected $)=37.2 \mathrm{ha}$ or $372,000 \mathrm{~m} 2$

$A($ pervious $)=37.2 \mathrm{ha} \times 0.2(20 \%$ runoff collected over pervious $)=7.44 \mathrm{ha}$ $\mathrm{A}($ impervious $)=37.2 \times 0.8(80 \%$ runoff collected over impervious $)=$ 29.76ha

$1 \mathrm{hr} / 50 \mathrm{yr}$ Storm $(i=40 \mathrm{~mm} / \mathrm{hr}, \mathrm{d}=40 \mathrm{~mm})$

Qp50,i $=(0.8)(40 \mathrm{~mm} / \mathrm{hr})(29.76 \mathrm{ha})(2.78)=2647.45 \mathrm{~L} / \mathrm{s}, \mathrm{Qp50,p}=(0.2)$ $(40 \mathrm{~mm} / \mathrm{hr})(7.44 \mathrm{ha})(2.78)=165.47 \mathrm{~L} / \mathrm{s}$

Sum Qp50 $=2647.45 \mathrm{~L} / \mathrm{s}+165.47 \mathrm{~L} / \mathrm{s}=2812.92 \mathrm{~L} / \mathrm{s},(2812.92 \mathrm{~L} / \mathrm{s})$

$(0.001 \mathrm{~m} 3 / \mathrm{L})(3600 \mathrm{~s} / \mathrm{hr})=10126.51 \mathrm{~m} 3 / \mathrm{hr}$

$10126.51 \mathrm{~m} 3 / \mathrm{hr} \times 1.25 \mathrm{hr}(\mathrm{Td}+\mathrm{Tc})=12658.14 \mathrm{~m} 3$

$1 \mathrm{hr} / 10 \mathrm{yr}$ Storm $(\mathrm{i}=30.6 \mathrm{~mm} / \mathrm{hr}, \mathrm{d}=30.6 \mathrm{~mm})$

Qp10,i $=(0.8)(30.6 \mathrm{~mm} / \mathrm{hr})(29.76 \mathrm{ha})(2.78)=2025.3 \mathrm{~L} / \mathrm{s}, \mathrm{Qp} 10, \mathrm{p}=(0.2)$

$(30.6 \mathrm{~mm} / \mathrm{hr})(7.44 \mathrm{ha})(2.78)=126.58 \mathrm{~L} / \mathrm{s}$

- Sum Qp10=2025.3L/s $+126.58 \mathrm{~L} / \mathrm{s}=2151.88 \mathrm{~L} / \mathrm{s},(2151.88 \mathrm{~L} / \mathrm{s})$

$(0.001 \mathrm{~m} 3 / \mathrm{L})(3600 \mathrm{~s} / \mathrm{hr})=7746.77 \mathrm{~m} 3 / \mathrm{hr}$

$-7746.77 \mathrm{~m} 3 / \mathrm{hr} \times 1.25 \mathrm{hr}(\mathrm{Td}+\mathrm{Tc})=9683.46 \mathrm{~m} 3$

$1 \mathrm{hr} / 2 \mathrm{yr}$ Storm $(i=19.8 \mathrm{~mm} / \mathrm{hr}, \mathrm{d}=19.8 \mathrm{~mm})$

Qp2,i $=(0.8)(19.8 \mathrm{~mm} / \mathrm{hr})(29.76 \mathrm{ha})(2.78)=1310.49 \mathrm{~L} / \mathrm{s}, \mathrm{Qp}, 2, \mathrm{p}=(0.2)$

$(19.8 \mathrm{~mm} / \mathrm{hr})(7.44 \mathrm{ha})(2.78)=81.91 \mathrm{~L} / \mathrm{s}$

Sum Qp,2=1310.49L/s $+81.91 \mathrm{~L} / \mathrm{s}=1392.4 \mathrm{~L} / \mathrm{s},(1392.4 \mathrm{~L} / \mathrm{s})(0.001 \mathrm{~m} 3 / \mathrm{L})$

$(3600 \mathrm{~s} / \mathrm{hr})=5012.64 \mathrm{~m} 3 / \mathrm{hr}$

$5012.64 \mathrm{~m} 3 / \mathrm{hr} \times 1.25(\mathrm{Td}+\mathrm{Tc})=6265.8 \mathrm{~m} 3$

Water Management Sizes (Max Capacity)

Constructed Wetland: $A=3174.5 \mathrm{~m} 2, V=3174.5 \mathrm{~m} 2 \times 1 \mathrm{~m}=3174.5 \mathrm{~m} 3$

Aqueduct Wetland Bioswale: $\mathrm{A}=3550 \mathrm{~m} 2 \times 0.5 \mathrm{~m}=1775 \mathrm{~m} 3$

Canal Wetland: $A=(2416.6 \mathrm{~m} 2+2337.6 \mathrm{~m} 2)=4754.2 \mathrm{~m} 2, \mathrm{~V}=4754.2 \times 1 \mathrm{~m}=$ 4754.2m3

Water Storage: (Canals) $A=1660 \mathrm{~m} 2, V=1660 \mathrm{~m} 2 \times 1 \mathrm{~m}=1660 \mathrm{~m} 3$, (Park Stor age) $A=755.4 \mathrm{~m} 2, V=755.4 \mathrm{~m} 2 \times 3.5 \mathrm{~m}=2643.9 \mathrm{~m} 3$, (Flood Storage) $A=225 \mathrm{~m} 2$

Wetland Area Sum: $A=3174.5 \mathrm{~m} 2+3550 \mathrm{~m} 2+4754.2 \mathrm{~m} 2+2640.4 \mathrm{~m} 2=$ $14,119.1 \mathrm{~m} 2$

Wetland Volume Sum: V $=3174.5 \mathrm{~m} 3+1775 \mathrm{~m} 3+4754.2 \mathrm{~m} 3+4866.4 \mathrm{~m} 3=$ $14,570.1 \mathrm{~m} 3$ 
Wetland to Catchment Area Ratio (WCAR) $=14,199.1 \mathrm{~m} 2 / 372,000 \mathrm{~m} 2=0.038$ or $3.8 \%, 2 \%<3.8 \%<5 \%$ (Meets Guidelines)

Wetland Volume vs 50yr Storm Volume $=14,570.1 \mathrm{~m} 3 / 12,658.14 \mathrm{~m} 3=1.151$ or $115.1 \%$, 90\%<115.1\% (Exceeds Guidelines)

Wetland Volume vs 10yr Storm Volume $=14,570.1 \mathrm{~m} 3 / 9683.46 \mathrm{~m} 3=1.505$ or $150.5 \%, 90 \%<150.5 \%$ (Exceeds Guidelines)

Wetland Volume vs $2 y r$ Storm Volume $=14,570.1 \mathrm{~m} 3 / 6265.8 \mathrm{~m} 3=2.325$ or 232.5\%, 90\%<232.5\% (Exceeds Guidelines)

Therefore, the stormwater management network can capture $115.1 \%$ of the volume of a 1-hour 50yr storm, 150.5\% of the volume of a 10yr storm, and $232.5 \%$ of a 2yr storm. Thus, at maximum capacity, the overall stormwater management system is well-sized to capture and treat most of the precipitation events that Ottawa receives on an annual basis while maintaining a healthy ecosystem.

The sloping constructed wetland array offers various vertical and horizontal experiential qualities and maintains a clear connection to the Rideau River while promoting numerous public spaces and allowing efficient pedestrian circulation (See Figure 93). Each wetland cell helps to shape the park by providing occupiable terraces within the array where public seating spaces are slotted (See Figure 94). Bridges across specific cells allow for direct experience of the treatment processes and supported biodiversity. A central sunken public space floods during large storm events when the constructed wetland overflows to showcase water volumes and store this excess water while allowing for gathering and small performances when not flooded. Adjacent to the wetland array is a series of more private gathering spaces as well as an elevated public pavilion that frames panoramic views of Rideau River and provides a space for hosting campus events. At the bottom of the wetland array is a containment pond that stores the treated water to support aquatic life and irrigate adjacent communal agricultural projects before being released into the Rideau River through overflow. The containment pond supports a waterfront pavilion that offers a direct connection to the Rideau River with an elevated circulation path and a lower recreation zone where the public can directly experience and interact with the seasonally fluctuating water levels at the river's edge (See Figure 96) 


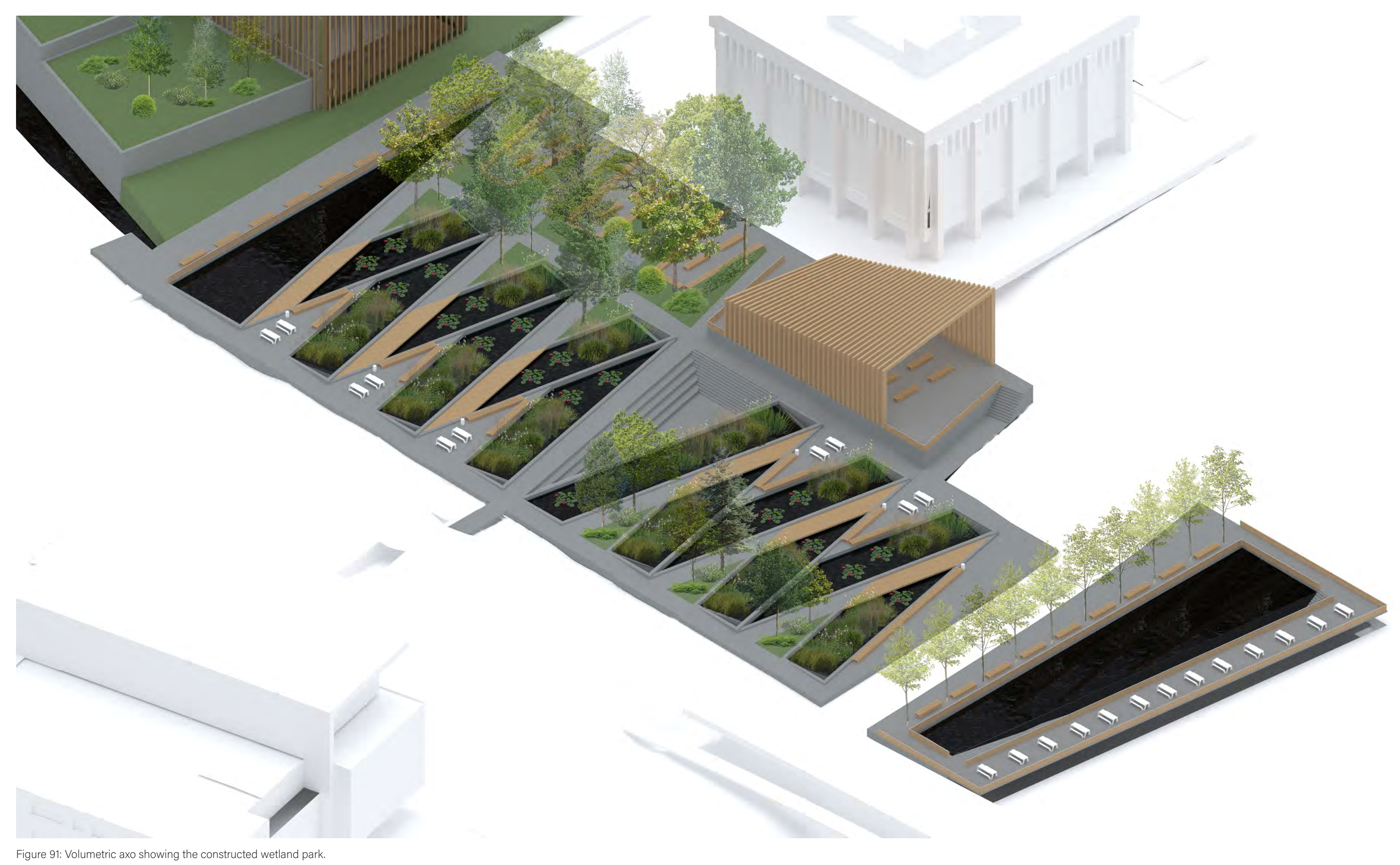

Figure 91: Volumetric axo showing the constructed wetland park. 


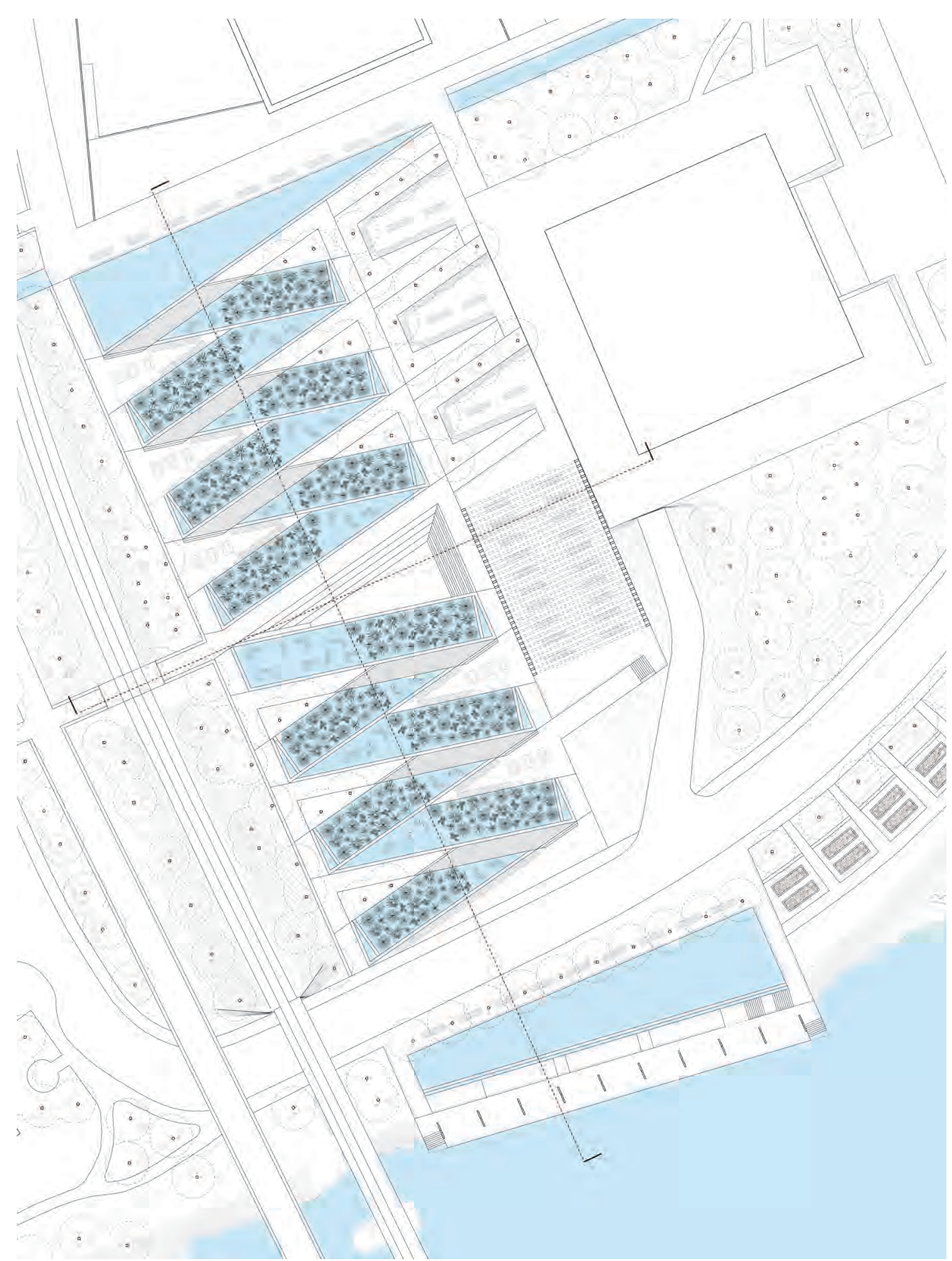

Figure 92: Plan of the constructed wetland park.

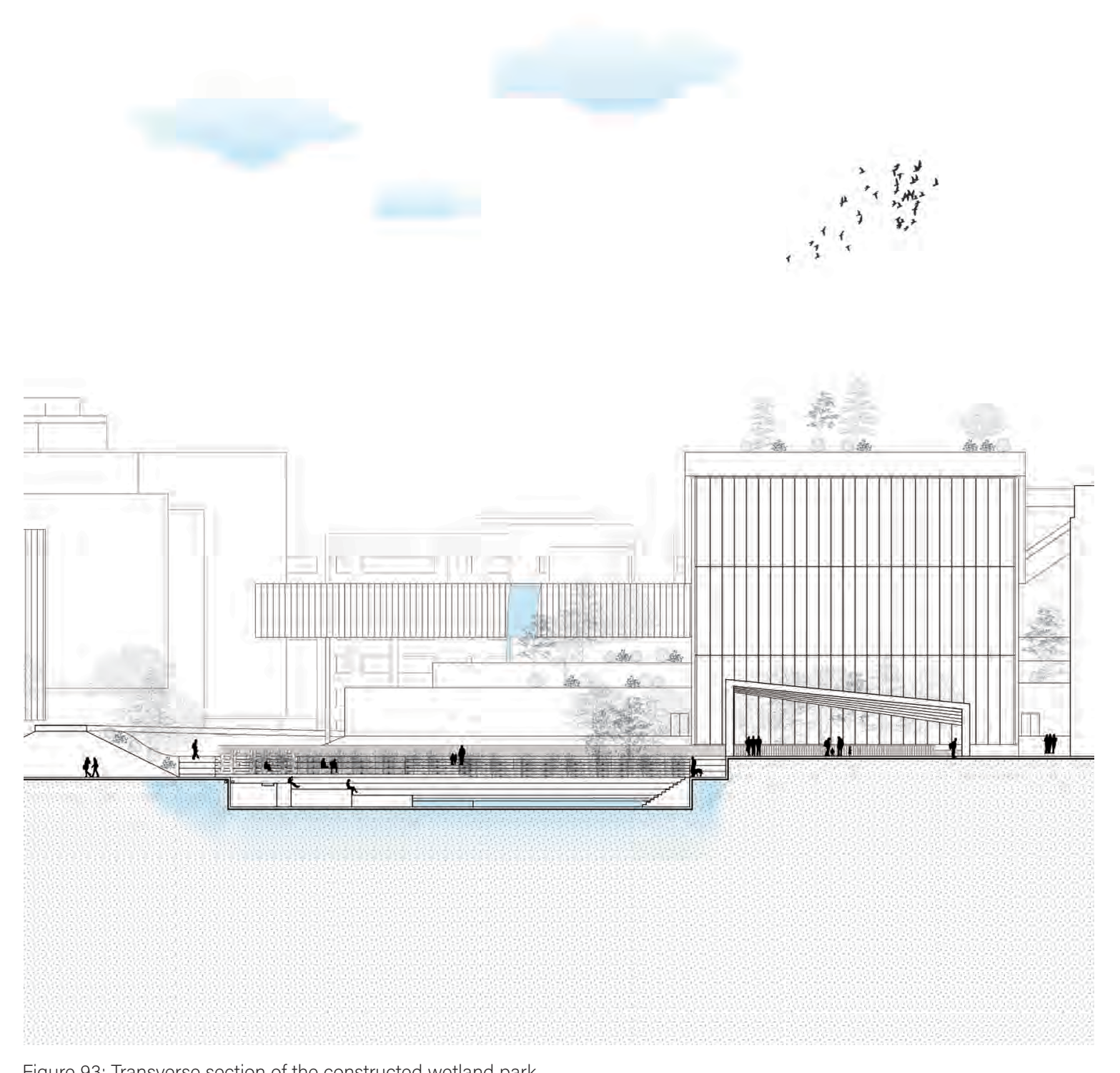

Figure 93: Transverse section of the constructed wetland park 


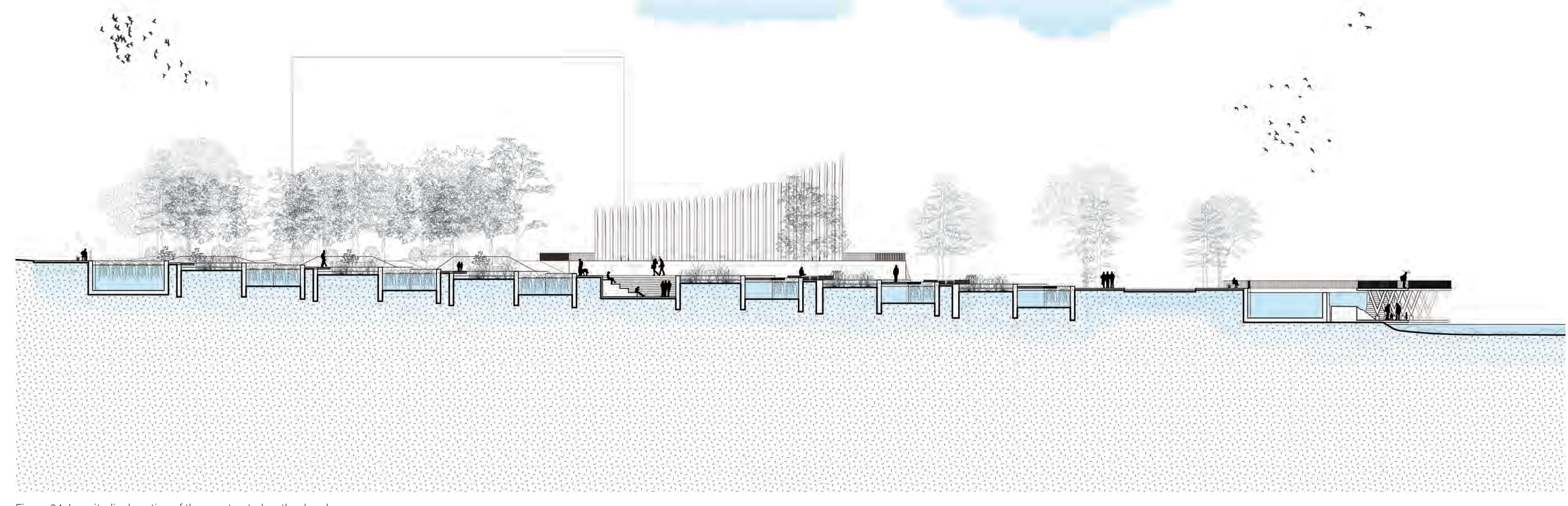




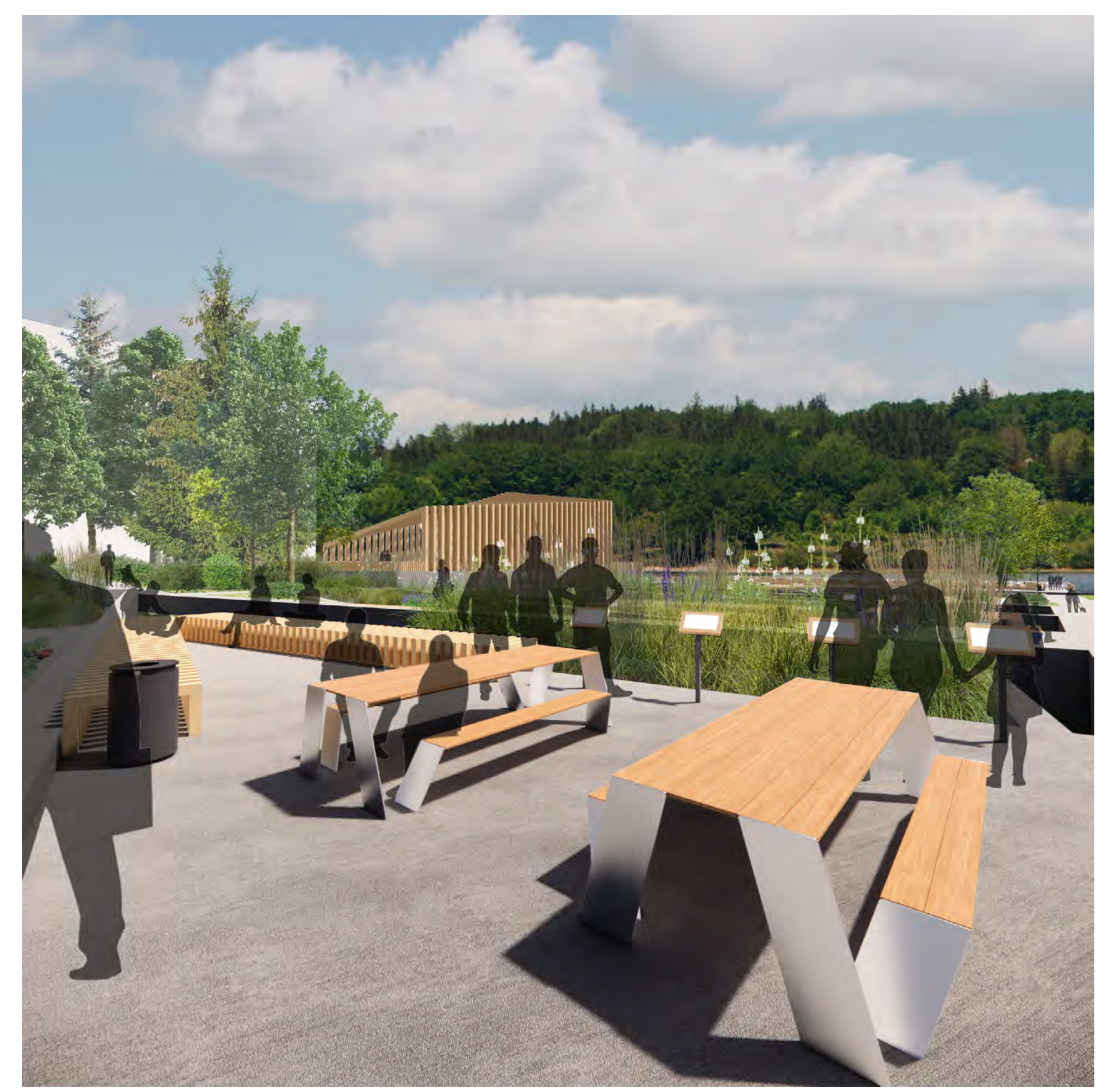

Figure 95: Rendering looking southwest at the constructed wetland park

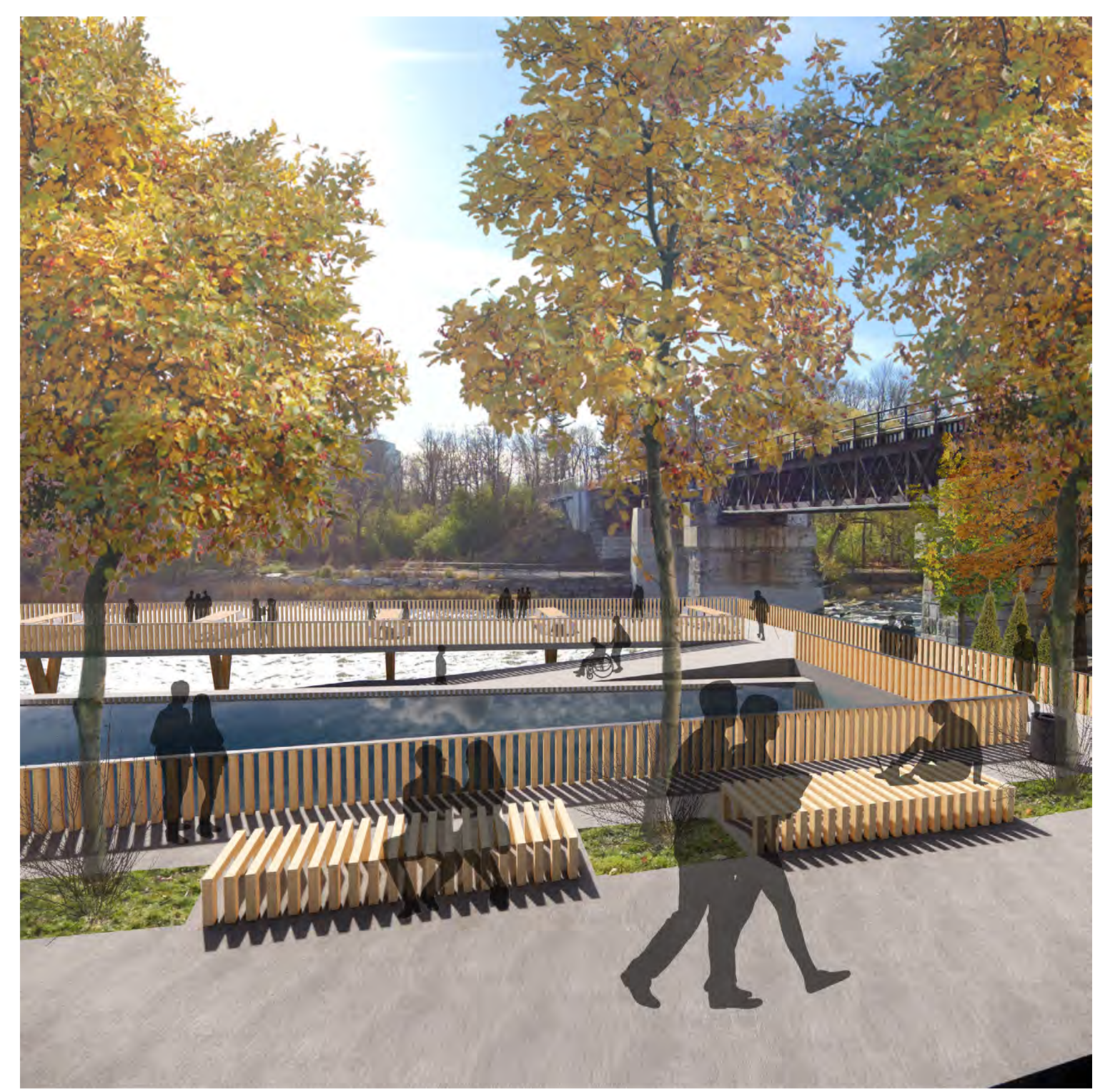

Figure 96: Rendering looking southeast at the constructed wetland park. 


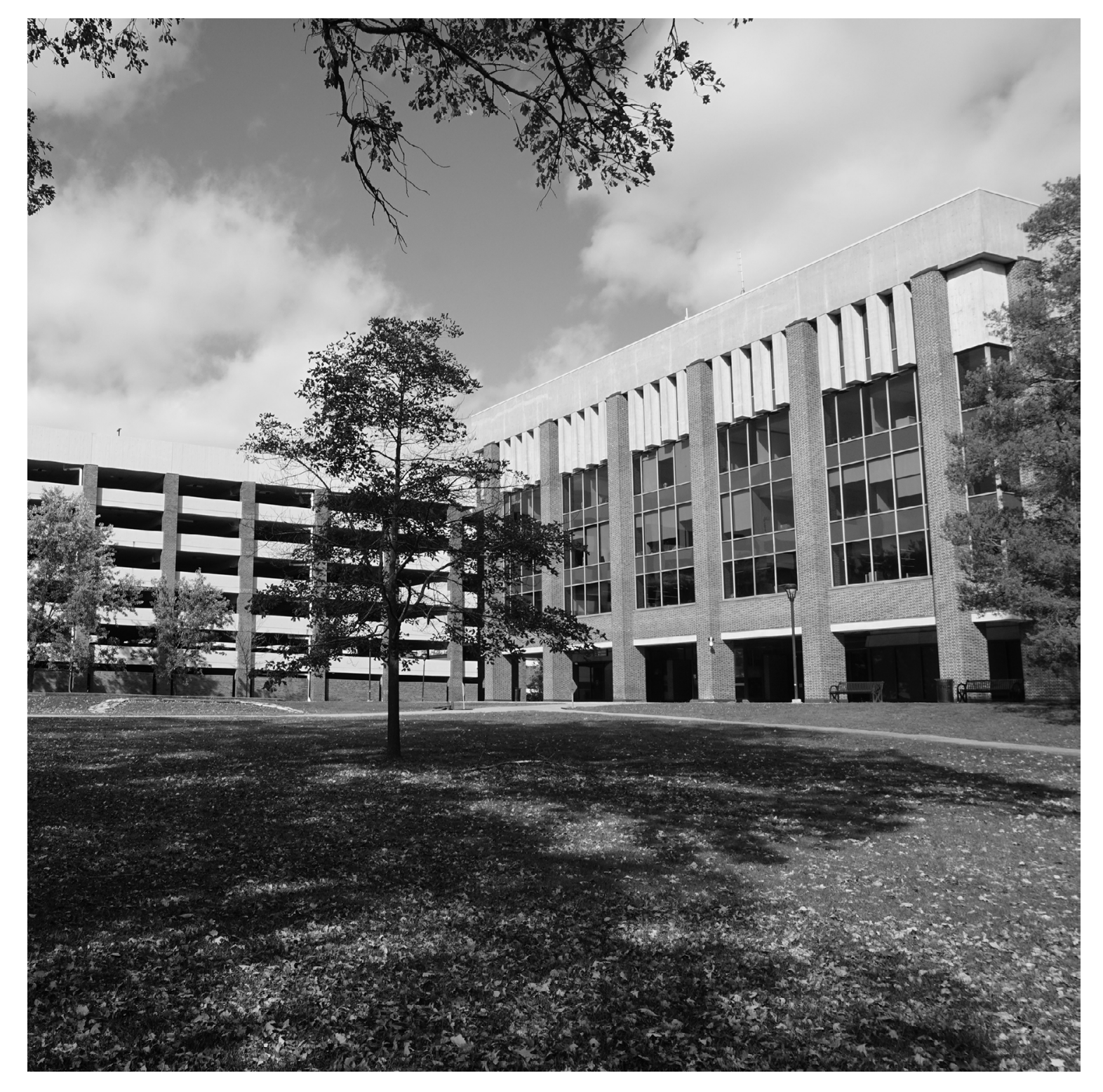

Figure 97: Before photograph of the constructed wetland park site.

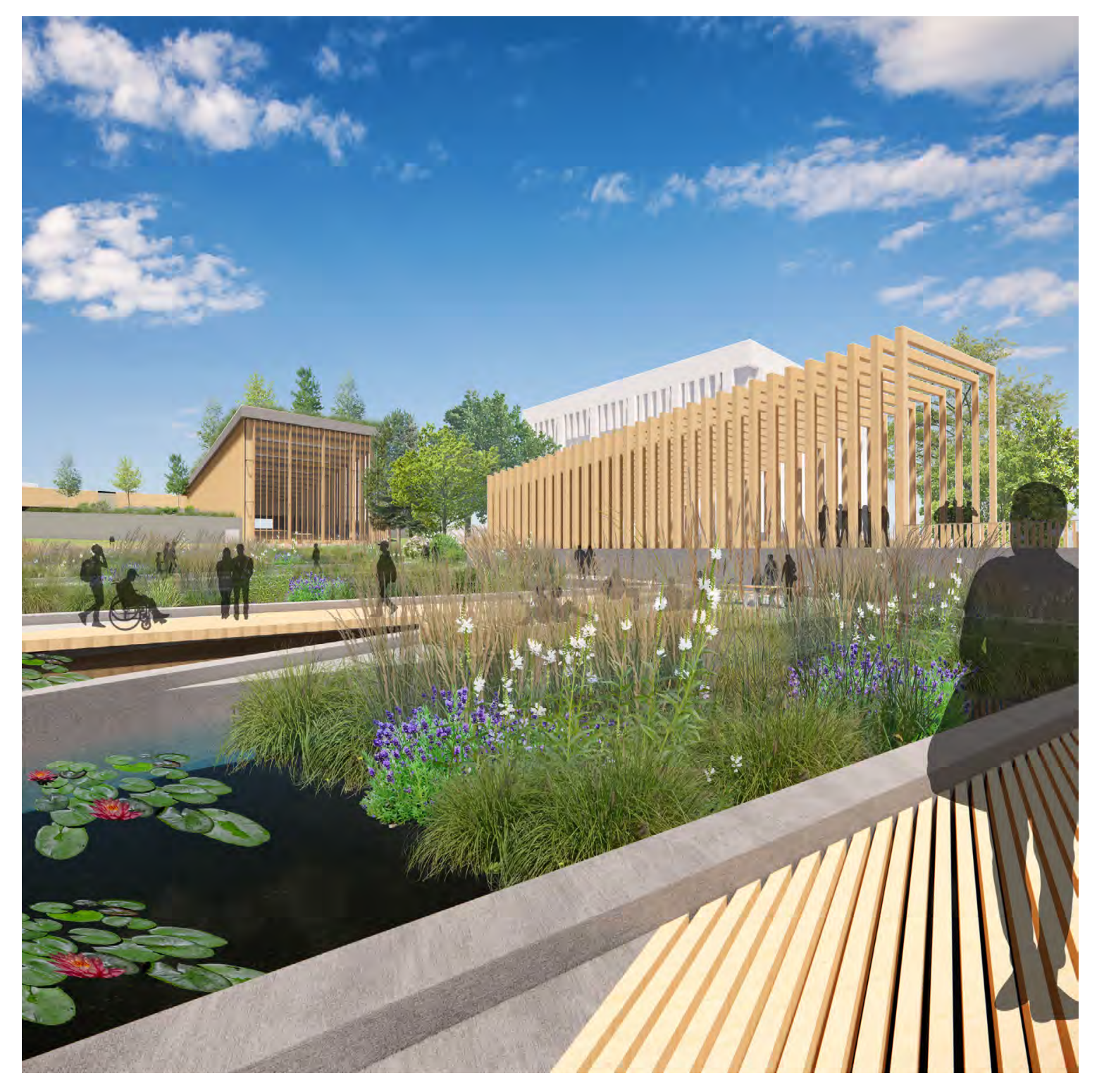

Figure 98: After rendering of the constructed wetland park site. 


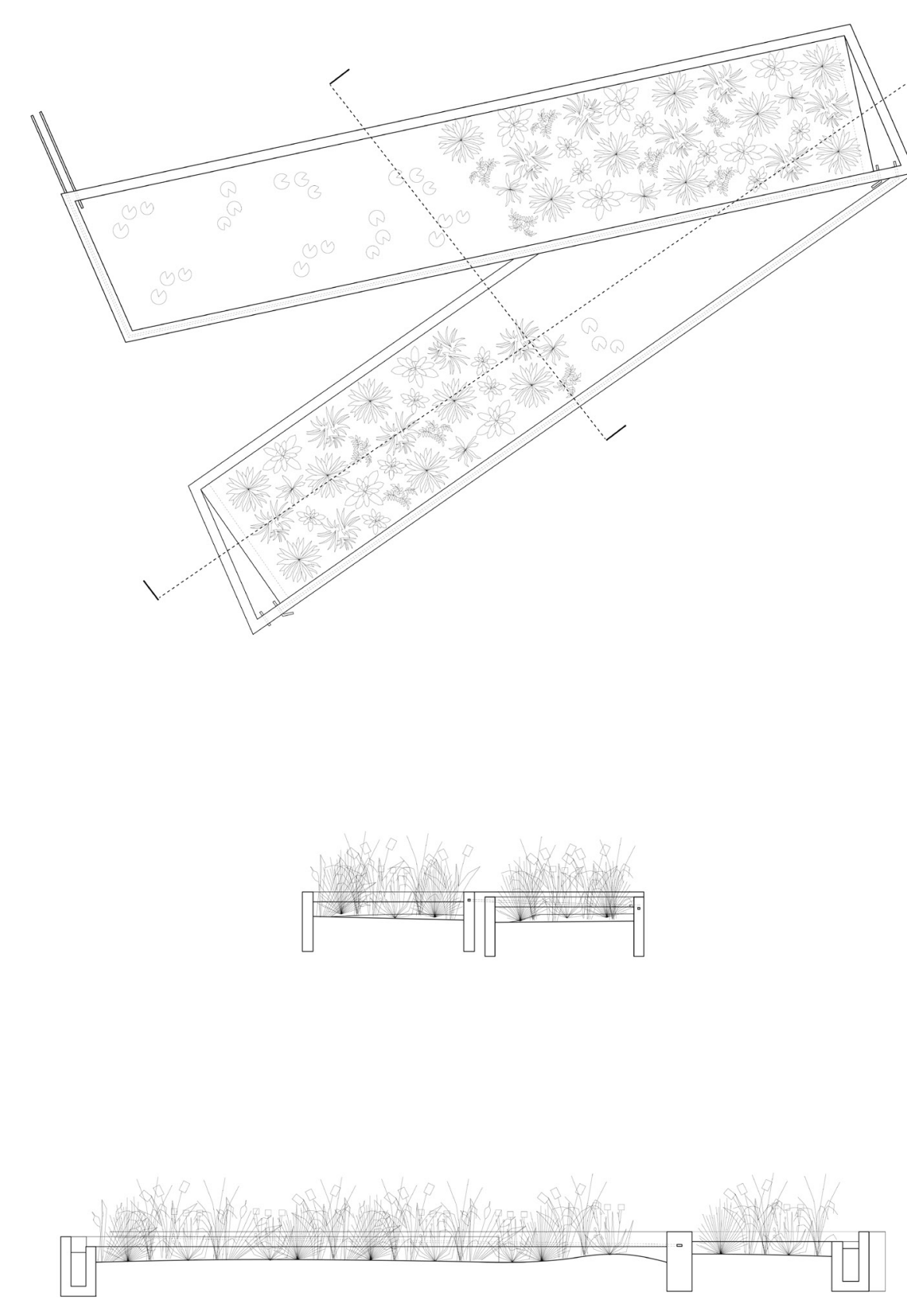

Figure 99: Plan and sections of the constructed wetland modules.

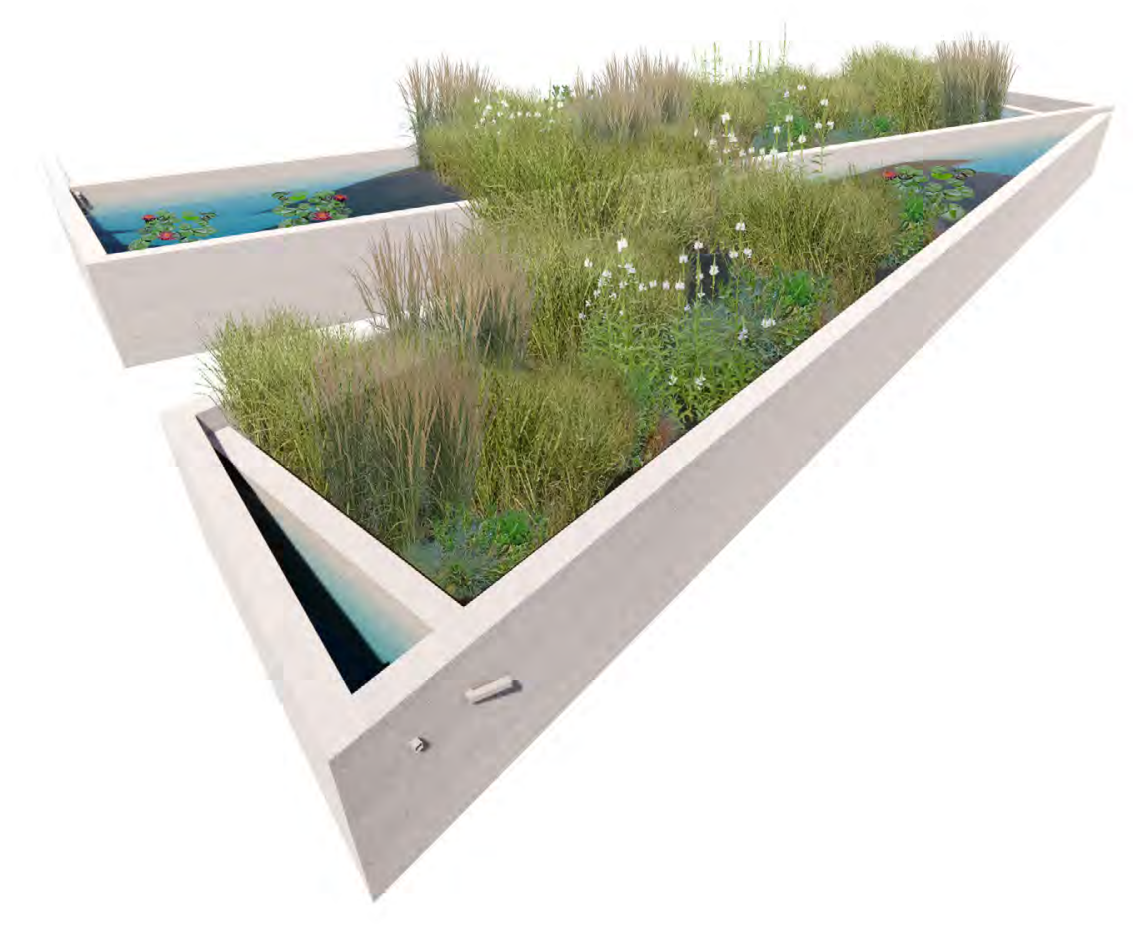


With plants taking front stage within this project, their selection and dispersion is of special importance. Various Ontario native wetland plants were chosen for several functions throughout the project depending on their planting conditions and possible functions within the systems while invasive species were avoided in order to maintain the health of the ecosystem (See Figure 101, 102, 103, 104). In order to select species that would thrive within the treatment interventions, wetland plants were chosen that can withstand the influent water and support the treatment processes required. Supporting plants that can survive in wetland conditions were also selected to provide biodiversity and enhance the experience of the public within the zones that are not specifically designated for treatment processes. These plants fall into several categories and serve many benefits that have been explained earlier including biodiversity, shading, water treatment and compost recycling.

The dispersion of these plants is intended to take advantage of the characteristics of each plant group (See Figure 105). Specifically, water-borne and herbaceous plants are employed in the water treatment processes for their resilience and ability to be totally submerged. Used in the aqueduct bioswale, wetland canals and constructed wetlands, these plants serve as the main treatment media for stormwater. Herbaceous plants are also employed in the Living Machine to provide root zones for attached growth media while enhancing the spatial experience above the soil with their attractive presence. Throughout the adjacent landscaping of the project various conifer trees, broadleaf trees, shrubs, vines and groundcover are also employed to provide a dynamic and biodiverse environment that supports the wetland ecosystem.

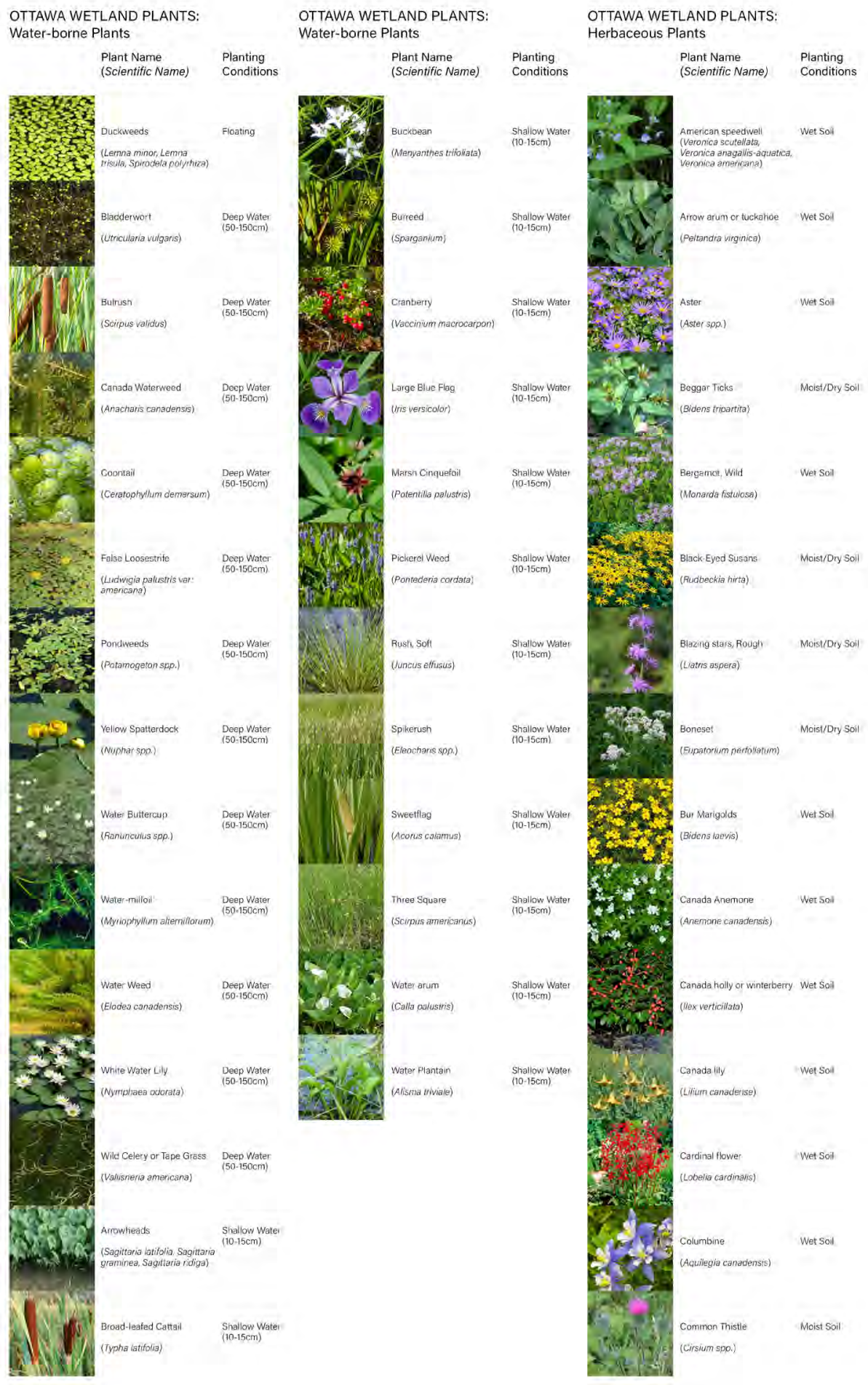

Figure 101: Table of Ontario wetland plants that can be used in the project. 


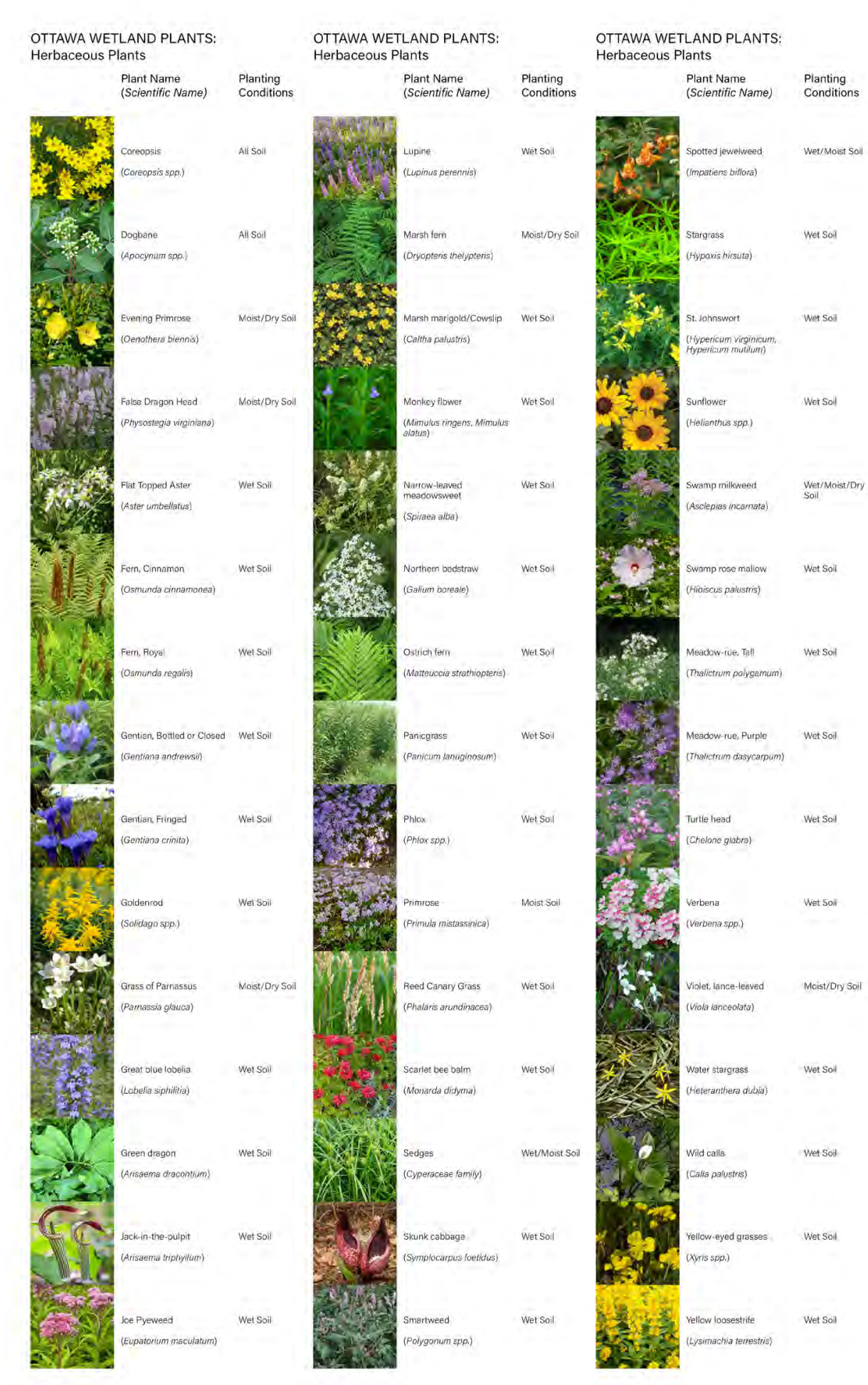

Figure 102: Table of Ontario wetland plants that can be used in the project.

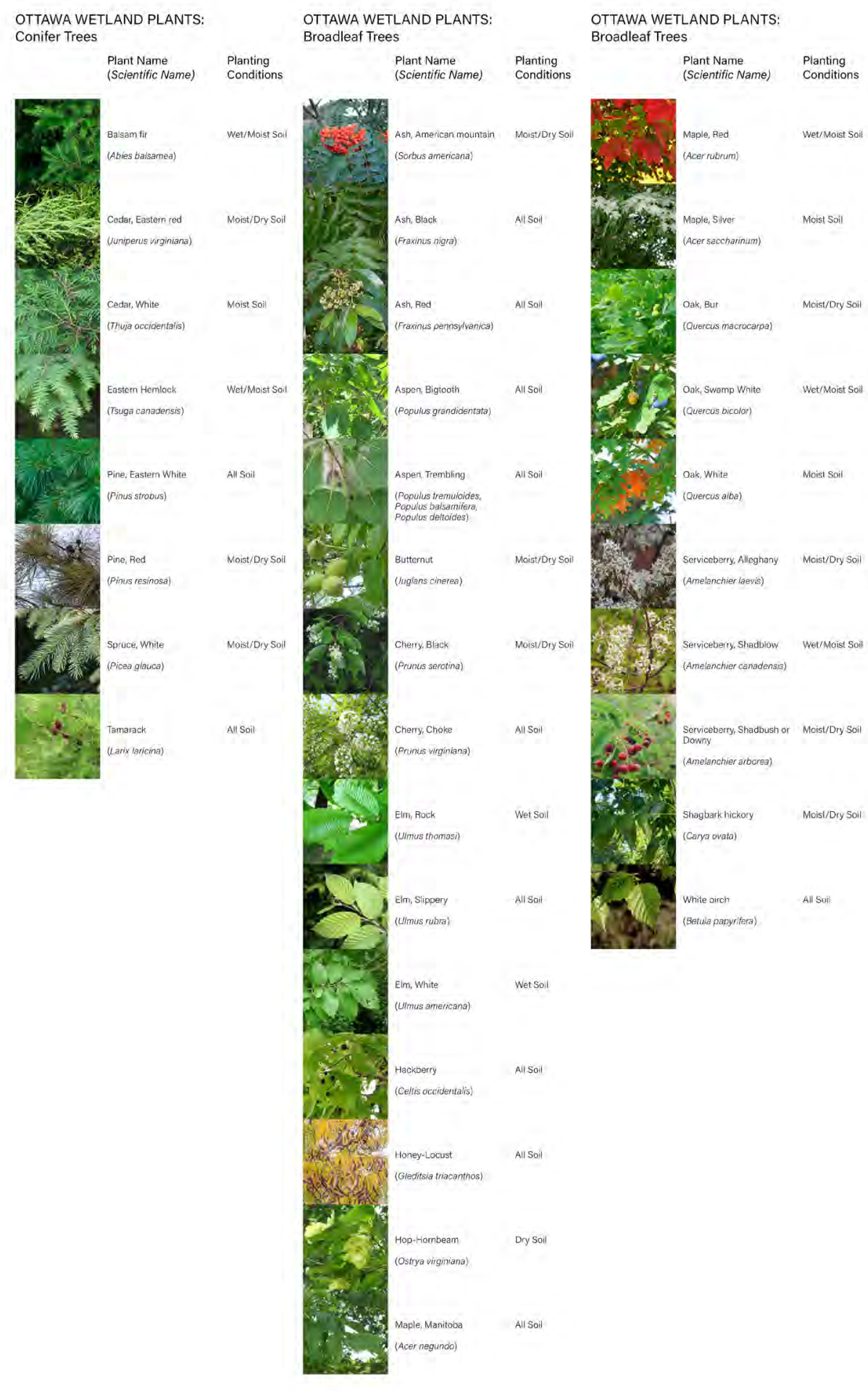

Figure 103: Table of Ontario wetland plants that can be used in the project. 


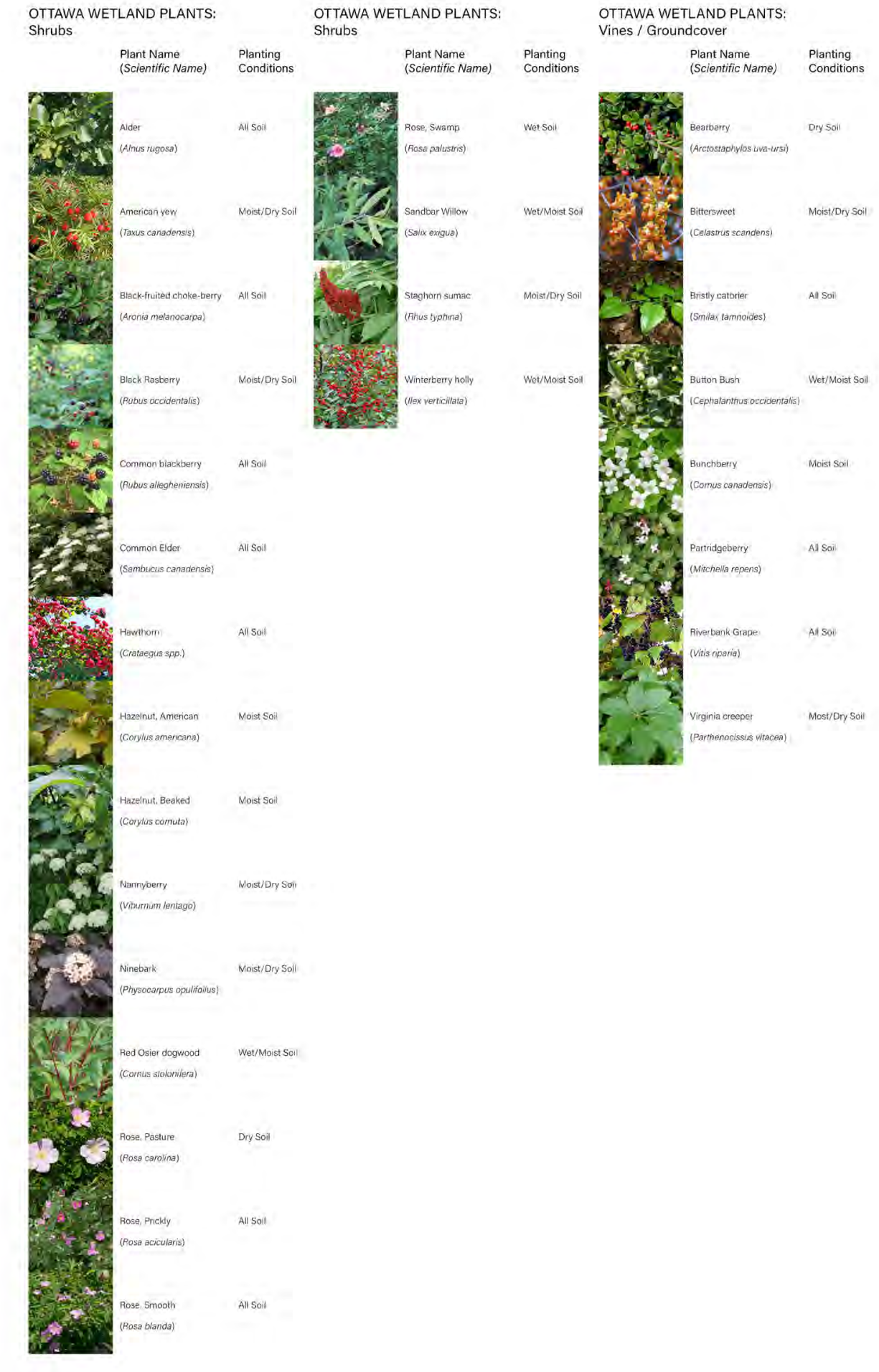

Figure 104: Table of Ontario wetland plants that can be used in the project.

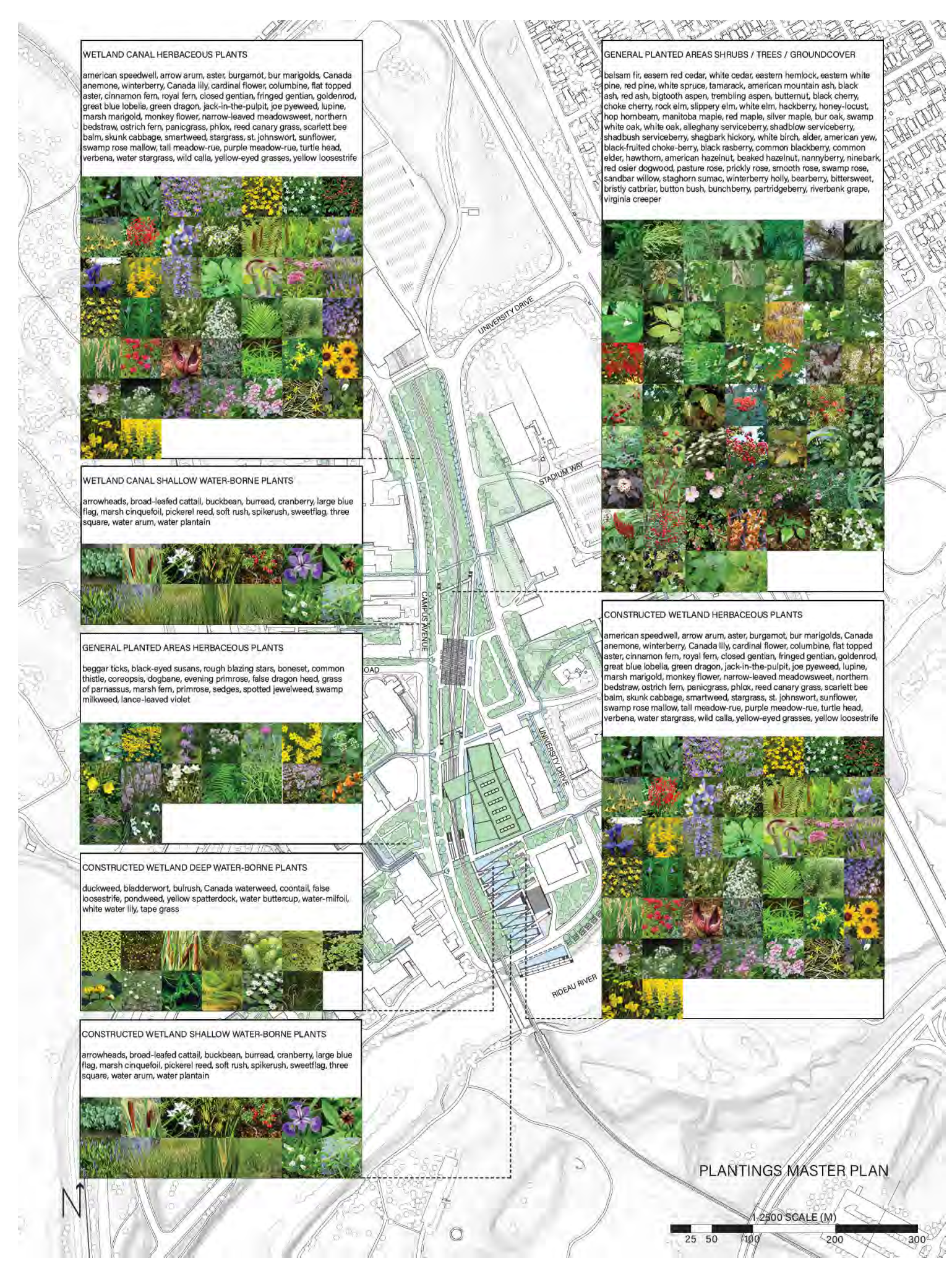

Figure 105: Map of planting distribution across campus. 
of the system in order to complement the interventions and a deeper exploration of

Considering the issues that have been outlined with regards to the current wate situation in Canada, Ottawa and, specifically, Carleton University, various water-based technologies and built examples have been explored and proposed to solve the campus problems through sustainable means. The hope for this project is that by implementing two distinct ecological water management networks on Carleton University's campus dealing with stormwater and wastewater respectively, their combined infrastructures and building mechanics can help to improve existing public zones while also shaping new ones through the formation of diverse spatial relationships.

These goals are achieved through a series of two water management networks, one dealing with wastewater and the other with stormwater. In order to deal with wastewater, a living machines in the central spine intercepts all wastewater from the main sewer lines on campus and employ a series of biological reactors using plants to achieve the primary, secondary and tertiary treatment of Carleton's wastewater for reuse in the campus mechanical heating and cooling system as well as other greywater applications. For stormwater management, the project employs a series of aqueduct networks consisting of sloped catchment planes to transport stormwater from building roofs towards the central spine. The wetland canals in the central spine collect water from the aqueducts and partially treat it ecologically using wetland plants as the filtering medium along their path to the constructed wetland park in the south. Once water reaches the constructed wetland park, the water is filtered and stored through a series of wetland cells using natural processes to achieve ecological stormwater runoff detention, infiltration, treatment and reuse for agricultural purposes. If this Master's Degree project could be developed further, major avenues of exploration would likely include more research as to the possible sustainable uses of the byproducts seasonal variations present on the site. But alas, the project chose instead to focus on developing the infrastructural aspects of the ecological water management networks and their associated improvements to the experiential qualities on campus while also understanding their technical processes to improve the campus relationship with water.

In summary, these technologies aim to achieve the ultimate spatial goals for the project. The living machine employ plants in order to treat the water and provide aesthetic improvement for new building experiences while further providing an infrastructural base for a new centralized University Centre that anticipates the growth of campus over time. The aqueducts that direct stormwater to the central spine from across campus act to improve and animate neglected green spaces along their path while also providing an architectural connection to the central spine. The wetland canals in the central spine that capture the water from the aqueducts create an organic north-south axis supporting walkways and a bike path following the train line while connecting both sides of campus. The constructed wetland park in the south offers new experiential and learning environments for leisure and study that support community gathering and maintain clear references to the Rideau River.

The presence of these water management networks aims to use water-based technologies to both treat water and improve the architectural experience of pedestrians throughout Carleton. These systems provide inter-disciplinary research opportunities while also granting the possibility to educate the public on natural resource life cycles and the possibilities of ecological technologies to offer solutions to everyday problems. Also, by making water management processes visible, further awareness and education can be generated in order to understand where water comes from and how it is returned to the earth through the natural water cycle. Lastly, the technologies for the capture 
treatment and reuse of both stormwater and wastewater will further help to generate campus and community support for the creation of sustainable resource management Ultimately, the proposed new physical and symbolic university centre is intended to be an agent showing a way forward regarding human relationships with water.
Constructed Wetlan

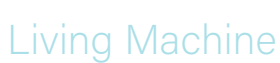

A constructed wetland is a landscape that mimics the natural processes of a wetland using natural media within a controlled series of infrastructural cells to treat water.

A Living Machine is a constructed and controlled system that employs natural media in a series of reactors in order to treat water using ecological processes.

Stormwater is water than is generated from precipitation events and can take the form of rain snow, hail, sleet or surface runoff.

Wastewater is water that is generated from residential, commercial, institutional or industrial waste and is typically transported in sewers. Water management is a complex discipline that deals with how to collect, transport and treat all types tof water that affect urban and suburban development including stormwater and wastewater.

Infrastructure is a type of construction that helps facilitate the transportation of products, materials, resources, people and animals in order to support a larger urban network. It can consist of roads,

pipes and wires among other things.

A bioswale is a stormwater management feature that consists of a naturalized raised earthen construction that is used to control and direct storwater along a permeable surface path to allow for infiltration.

Water is the essence of life. Fueling the water cycle., it is necessary for the function of all living things and their accompanying ecosystems directly influencing the health of the planet. A watershed is a group of waterways and bodies of water that feed into a specified waterway of body of water.

A river is a waterway that transports water with sloping current in a determined direction usually towards a larger body of water. It can be part of a larger watershed. 
A wetland is a natural landscape feature that holds water and supports a diverse ecosystem that acts as a filter

for a body of water. It can also be referred to as a bog or marsh

A lake is a land-locked body of water usually without currents. It can be part of a larger watershed and feed rivers, wetlands, and other tributaries.

cology refers to the study of natural processes,

organisms and phenomena.

Natural refers to anything that is ocurrs organically or is common to the environment and is biological in essence without any human interaction.

A weir is a stormwater management feature that consists of a built construction or wall that is used to direct water towards a desired area and to manage flow rates.

A reactor is a containment unit that can house a

variety of chemical and biological processes for

multiple purposes including ecological wastewater and stormwater treatment

A canal is a built construction that contains and transports water along a specific path.

Public refers to anything that is acessible by anyone

without any specific permissions.

A plant is a vegetative organisms that feeds on sunlight, nutrients, water and carbon dioxide to survive, producing oxygen and biomass as a by-product.

Biodiversity refers to a system that includes a large

variety of organisms in order to develop a complex and robust ecosystem.

An aqueduct is an elevated construction historically used to transport water from a far away location at a higher altitude to a desired location at a lower altitude using gravity. It is most well-known from Roman origins.

Infiltration is when water percolates and is absorbed

by the soil where permeable soils exist to replenish

groundwater and aquifer resources.
American Institute of Architects. "Sidwell Friends Middle School." American Institute of Architects. Accessed January 9, 2021. https://www.aiatopten.org/node/140.

City of Ottawa. January 9, 2021. https://ottawa.ca/en/living-ottawa/water/wastewaterand-sewers/wastewater-collection-and-treatment\#combined-

ity of Ottawa. "Characterization of Ottawa's Watersheds: An Environmental Foundation Document with Supporting Information Base." City of Ottaw citycouncil/ec/2012/01-17/05-Document\%201\%20EN\%20-\%20 watershed_report_en\%5b1\%5d.pdf.

Devabalane E "Strategies for Sustainable Development of Wetland Resources: Lake Ousteri, Puducherry." In Implementing Campus Greening Initiatives:

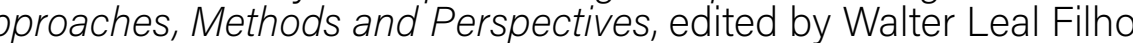
Nandhivarman Muthu, Golda Edwin, Mihaela Sima, 125137. Switzerland: Springer International Publishing, 2015. Accessed January 9 2021. https://doi-org.proxy.library.carleton.ca/10.1007/978-3-319-11961-8.

District of Sechelt. "Water Resource Centre Fast Facts." DIstrict of Sechelt. Accessed January 9, 2021. https://www.sechelt.ca/Portals/0/public\%20document\%20 ibrary/Public\%20Notices/2014-10-16\%20WRC\%20Fast\%20Facts.pdf.

Edwin, Golda A. and G. Poyyamoli, M. Nandhivarman, Ramaswamy Arun Prasath, Dwipen Boruah. "Constructed Wetlands for the Treatment of Grey Water in Campus Premises." In Implementing Campus Greening Initiatives: Approaches, Methods and Perspectives, edited by Walter Leal Filho, Nandhivarman Muthu, Golda Edwin, Mihaela Sima, 337349. Switzerland: Springer International Publishing, 2015. Accessed January 9 2021. https://doi-org.proxy.library.carleton.ca/10.1007/978-3-319-11961-8,

Environment and Climate Change Canada. Canadian Environmental Sustainabaility Indicators: Canada's Water Use in Global Context. Gatineau: Environment and Climate Change Canada, 2016

Environment and Climate Change Canada. Examination of Governance, Existing Data, Potential Indicators and Values in the Ottawa River Watershed. Ganuary 9 2021. http:/ publications gcca/Collections/collection_2019/ eccc/En4-373-2019-eng.pdf

Environment Canada. "Threats to Sources of Drinking Water and Aquatic Ecosystem Health in Canada." NWRI Scientific Assessment Report Series, no. 1 (Burlington Ontario: National Water Research Institute, 2001): 0-72 Accessed January 9, 2021. http://publications.gc.ca/collections/Collection/En40237-1-2001E.pdf

Exall, Kirsten, Jiri Marsalek and Karl Schaefer. "Water Reuse in Canada: Opportunities and Challenges." In Integrated Urban Water Resource Management, edited by Petr Hlavinek, Tamara Kukharchyk, Jiri Marsalek and Ivana Mahrikova, 253-262. Dortrecht, Netherlands: Springer, 2006. Accessed January 9 2021. https://books-scholarsportal-info.proxy.library.carleton.ca/ en/read?id=/ebooks/ebooks0/springer/2009-12-01/1/1402046855\#page $=7$ 
Felicity Ayut, Lucita and Newati Wid. "Anaerobic Digestion of Organic Waste in UMS Campus for Resource Recovery and Waste Reduction." In Green Engineering for Campus Sustainability, edited by Abu Zahrim Yaser, 133143. Singapore: Springer Nature Singapore Pte Ltd., 2020. Accessed January 9 2021. https://doi-org.proxy.library.carleton.ca/10.1007/978-981-13-7260-5.

Fenton, Kellie. "Innovative Waste Water Strategies in the Landscape: The Application of Green Infrastructure Principles in Cape Cod, Massachusetts." Landscape Architecture \& Regional Planning Masters Projects (2017) 0-88. Accessed January 9, 2021. https://scholarworks.umass.edu/cgi/

viewcontent.cgi? article=1091\&context=larp_ms_projects.

Gong, Shenying, Yanting Wang and Jie Fu, "Advanced Treatment of Campus Cempus Sustainability, edited by Abu Zahrim Yaser, 245-259 Singapore: Springer Nature Singapore Pte Ltd 2020 Accessed January 9, 2021 https:// doi-org.proxy.library.carleton.ca/10.1007/978-981-13-7260-5.

International Living Future Institute. "Certified Living: Omega Centre for Sustainable Living." International Living Future Institute Accessed January 9, 2021 https:// living-future.org/lbc/case-studies/omega-center-for-sustainable-living/

Jayaratne, Rajika, Roger Seyb, Mike Martindale and James Shuang Li. "Constructed Wetland Design Practices and Performances: An Overview." Sormwater Conference (2010): 1-17. Accessed January 9, 2021. https://www.waternz.org. nz/Attachment?Action=Download\&Attachment_id=1240,

Kirskey, Will. "Port of Portland Opts for Decentralized, Sustainable Water Architecture With the Living Machine Ecological Wastewater System. Journal AWWA 102, no. 2 (2010): 19-22. Accessed January 9, 2021. https://dol-org. proxy.library.carleton.ca/10.1002/j.1551-8833.2010.tb10038.x.

Kosmacker, Jeff. "Omega Center for Sustainable Living Marks 10th Anniversary of Environmental Innovation \& Commitment to Climate Action." Omega (2019). Accessed January 9, 2021. https://www.eomega.org/about-omega/ press-center/omega-center-for-sustainable-living-marks-10th-anniversary-ofenvironmental-innovation-commitment-to? nid $=17962$.

Landscape Performance Series. "Sidwell Friends Middle School." Landscape Architecture Foundation. Accessed January 9, 2021. https://www.

ing Water Accessed Juci Water. Accessed January 9, 2021. http://sustainablewater.com/wp-content/

Marsalek, Jiri. "Overview of Urban Drainage Impacts on Aquatic Habitat." In Integrated Urban Water Resource Manpacment, Adited by Petr Havinek, books-scholarsportal-info proxylibrarycarleton ca/en/read?id/// ebooks/ebookso/springer/2009-12-01/1/1402046855\#page=7.

Massachussets Clean Water Toolkit. "Constructed Stormwater Wetlands." Massachussets Stormwater Handbook. Accessed January 9, 2021. https:// megamanual.geosyntec.com/npsmanual/constructedstormwaterwetlands. aspx.

MD Wastesystems. "Wastesystem South Burlington Municipal Eco-Machine." Urbn Ecology (2015). Accessed January 9, 2021. https://urbanecologycmu. wordpress.com/2015/11/18/wastesystem_south-burlington-municipaleco-machine/.
Nasuha Safie, Nurliyana and Abu Zahrim Yaser. "Sewage Treatment in Campus for Recycling Purpose." In Green Engineering for Campus Sustainability, edited by Abu Zahim Yaser, $207-243$. Singapore: 2020. Accessed January 9, 2021. https://doi-org.proxy.library.carleton. $\mathrm{ca} / 10.1007 / 978-981-13-7260-5$.

National Round Table on the Environment and the Economy. Changing Currents. Water Sustainability and the Future of Canada's Natural Resource Sectors.

Ottawa: National Round Table on the Environment and the Economy, 2010. An Okan an Guad. Constructed Wetlands for Stornwater Manegement: An Okanagan Guidebook. Associated Environmental Consultants lnc., 2018 Accessed January 9, 2021. https://www.obwb.ca/

Organica. "Facility." Organica Water. Accessed January 9, 2021

Achesi. https:/www.

Organicawater.com/facility.
Ormeci, Banu. "An Overview of Water Supply, Use and Treatment in Canada." In Urban Water Challenges in the Americas: A Perspective from the Academies of Sciences, edited by Katherine Vammen and Adriana 2021. https:/ /wwwinteracademies.org/sites/default/files/publication/ianasurban_water_book_2015.pdf.

Ottawa Riverkeeper. "Ecology and Impacts." Ottawa Riverkeeper's River Report, no. 1 (May 2006): 0-81. Accessed January 9, 2021. https://www.ottawariverkeeper. ca/wp-content/uploads/2018/01/River-Report-English.pdf.pdf.

Palm Beach County. "Wakodahatchee Wetlands." Palm Beach County, Florida. Accessed January 9, 2021. https://discover.pbcgov.org/waterutilities/Pages/ Wetlands.aspx.

Pollution Probe. "A New Approach to Water Management in Canada." Published March 2008. Accessed January 9, 2021. https://books-scholarsportal-info. proxy.library.carleton.ca/en/read?id=/ebooks/ebooks0/gibson_cppc/2009-12

Pollution Probe. "Towards a Vision and Strategy for Water Management in Canada." Published April 2007. Accessed January 9, 2021. https://books-scholarsportalinfo.proxy.library.carleton.ca/en/read?id=/ebooks/ebooks0/

UBLI "SO

BLIC. S1 hech Janary 9 2021. https://www.archdaily.com/896286/sechelt-water-resource-centre-

Ryan, Zoe. Building with Water: Concepts, Typology, Design. Basel: Birkhauser

Saegrov, Sveinung, Leif Sigurd Hafskjold, Axel Konig, Jon Ronstum, Ingrid Selseth, Froydis Sjovold. "Wastewater Network Challenges and Solutions." In Integrated Urban Water Resource Management, edited by Petr Hlavinek, Netherlands: Springer, 2006. Accessed January 9, 2021. https:// books-scholarsportal-info.proxy.library.carleton.ca/en/read?id=/
ebooks/ebooks0/springer/2009-12-01/1/1402046855\#page=7.

Schneider, Daniel. Hybrid Nature: Sewage Treatments and the Contradictions of the Industrial Ecosystem. Cambridge, Massachussets: MIT Press, 2011.

Shelef, Oren, Amit Gross and Shimon Rachmilevitch. "Role of Plants in a Constructed Wetalnd: Current and New Perspective." Water 5 (2013): 405-419. Accessed January 9, 2021. doi:10.3390/w5020405. 
Sustainability Carleton University. Carleton University Energy Master Plan. Ottawa: Carleton University, 2018. Accessed January 9, 2021. https://carleton.ca/fmp/ wp-content/uploads/Sustainability-Energy-Master-Plan-2018-21-update.pd

Turenscape. "Shanghai Houtan Park/Turenscape." ArchDaily. Accessed January 9,

2021. https://www.archdaily.com/131747/shanghai-houtan-park-turenscape.

United States Environmental Protection Agency. Wastewater Technology Fact Sheet The Living Machine. Washington, DC: Municipal Technology Branch 2002. Accessed January 9,21
pubs/living_machine.pdf.

UN-HABITAT. Constructed Wetlands Manual. Kathmandu, Nepal: UN-HABITAT Water for Asian Cities Programme, 2008. Accessed January 9, 2021. https:// ssw $2008 \%$ Cons/ducted\%20Welands\% 20 Manualpdf

2008\%20Constructed\%20Wetlands\%20Manual.pdf.
Vaitkeviciute, Vaiva, and Kamile Jakubauskaite, Jurga Vitkuviene. "Ecological Cleaning and Reusing of Wastewater: Possibilities, Advantages and Proposals." Journ of Sustainable Architecture and Civil Engineering 1, no. 18 (2017): 57-64.
Accessed January 9, 2021. http://dx.doi.org/10.5755/j01.sace.181.17557.

Verbyla, Mathew E. Ponds, Lagoons and Wetlands for Wastewater Management. New York: Momentum Press, 2017.

Wintgens, Thomas, Thomas Melin, Davide Bixio and Chris Thoeye. "Integrated Concepts for Reuse of Upgraded Wastewater: Role of Membranes in Water Recycling." In Integrated Urban Water Resource Management, edited by Petr Hlavinek, Tamara Kukharchyk, Jiri Marsalek and Ivana
Mahrikova, 263-267. Dortrecht, Netherlands: Springer, 2006. Accessed January 9, 2021. https://books-scholarsportal-info.proxy.library. carleton.ca/en/read?id=/ebooks/ebookso/springer/2009-12$01 / 1 / 1402046855 \#$ page $=7$

Zheng, Dr. Youbin, Siobhan Dunets and Eric Rozema. Constructed Wetlands. Schoo of Environmental Sciences, University of Guelph: Greenhouse and Nursery Water Treatment Information System. Accessed January 9 2021. http://www.ces.uoguelph.ca/water/NCR/ConstructedWetlands.pdf.
APPENDIX 1: OTTAWA WATERSHED DATA

While studying the Ottawa River Watershed, the specific characteristics of the local ecosystem that are of special importance are suspended solids, dissolved oxygen, nutrients, trace metals, organic chemicals occurring at toxic levels, $\mathrm{pH}$ and water temperature and large changes of these characteristics can negatively impact the biological health of the ecosystem. 'Measurements of many of these water quality indicators within the Ottawa watershed have been documented in various reports conducted by the Clty of Ottawa that can be summarized succinctly. With regards to total suspended solids (TSS) in the watershed, urban creeks typically have TSS levels averaging $17 \mathrm{mg} / \mathrm{L}$ whereas the Ottawa and Rideau Rivers typically average $3-4 \mathrm{mg} / \mathrm{L} .{ }^{2}$ Measurements of Phosphorus levels in the watershed found an average of $0.08 \mathrm{mg} / \mathrm{L}$ or greater, making them mostly above the Provincial Water Quality Objectives (PWQO) except for low levels in the Ottawa River and exceptionally high levels in urban creeks leading to excessive weed growth and algae blooms in the late summer across the watershed. ${ }^{3}$ E. coli measurements throughout the watershed tended to meet the PWQO except in urban creeks and areas in the Ottawa and Rideau Rivers downstream of combined sewage overflows where counts were as high as 10000 counts per $100 \mathrm{~mL}^{4}$ Measurements of nitrogen, nitrates, nitrites, sulphates and zinc generally met PWQO requirements whereas levels of copper, iron and manganese were met within most watercourses except urban creeks. ${ }^{5}$ Overall, the PWQO levels for lead were exceeded 1 Jiri Marsalek, "Overview of Urban Drainage Impacts on Aquatic Habitat," in Integrated Urban Water Resource Management, eds. Petr Hlavinek, Tamara Kukharchyk, Jiri Marsalek and Ivana Mahrikova (Dortrecht, Netherlands: Springer, 2006) 182, accessed January 9, 2021, https://books-scholarsportal-info.proxy.library.carleton.ca/en/read?id=/ebooks/ebookso/springer/2009-12$001 / 1 / 1402046855$ \#page $=7$.

2City of Ottawa, 'Characterization of Ottawa's Watersheds: An Environmental Foundation Document with Supporting

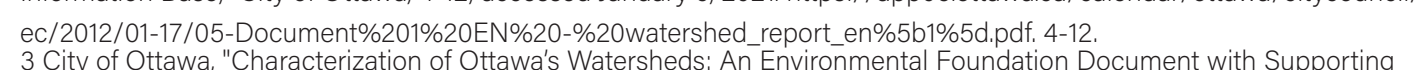

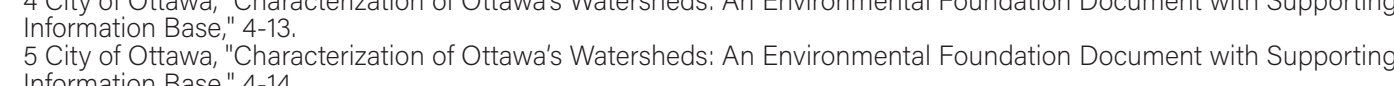


consistently and the levels of phosphorus, E. coli, copper and iron are generally rising over time in all major watercourses. ${ }^{6}$ These measurements indicate the contaimant levels present within the watershed that are in need of mitigation,

In addition to water quality measurements, Ottawa has established two water quality indicators, fish consumption advisories and beach closures, in order to monitor the various threats to drinking water present within the Ottawa River watershed including, but not limited to; nutrients, acidification, endocrine disrupting substances, genetically modified organisms, pathogens, algal toxins, pesticides, long-range atmospherically transported pollutants, municipal wastewater effluents, industrial wastewater discharges, urban runoff, solid waste management practices, and water quality changes affecting water quality due to climate change, diversions and extreme events. ${ }^{7}$ Fish consumption testing has found that, due to bioaccumulation of toxins, larger and older fish in the Ottawa river, especially downriver of the city of Ottawa, contain levels of contaminants that are harmful to humans indicating high levels of pollutants in this area. ${ }^{8}$ Likewise, Ottawa sees numerous beach closures every year due to $E$. coli contamination above 100 counts per $100 \mathrm{ml}$, a figure used as an indicator of other harmful water pathogens due to human and animal fecal pollution from stormwater runoff from heavy rain, combined sewer overflows and sewage spills or leaks. ${ }^{9}$ In 2005 the beach at Petrie Island in East Ottawa was closed 11 out of 71 days due to high E. col readings indicating the presence of large amounts of waterborne pathogens in Ottawa that threaten water quality and habitat health.10 These consequences indicate some of the ways in which water pollution can become more visible and tangible in everyday life 6 City of Ottawa, "Characterization of Ottawa's Watersheds: An Environmental Foundation Document with Supporting
Information Base", 4-14 7 Ottawa Riverkeeper, "Ecology and Impacts," 59-60. 8 Ottawa Riverkeeper, "Ecology and Impacts," 61.

9 Ottawa Riverkeeper, "Ecology and Impacts" 61

10 Ottawa Riverkeeper "Ecology and lmpacts" 61
APPENDIX 2: ECOLOGICAL WATER TREATMENT SCIENCE

Within contaminated waters, including both stormwater and wastewater collected pollutants can include various substances including pathogens, nutrients, and numerous toxins, among others, each posing their own threats to the environement Pathogens are disease causing organisms such as bacteria and viruses that tend to wash off the land from either wild animal, farm animal and/or pet waste or enter the watershed through leaky sewer lines and malfunctioning septic systems.' Of particular interest in these systems, Escherichia coli (E. coli) is a bacterium commonly found in human and animal waste that can enter surface waters through direct discharge from mammals and birds, from agricultural and stormwater runoff containing animal waste and from sewage leaked deliberately or accidentally into a watercourse. ${ }^{2}$

Nutrients, coming from agricultural fertilizers, septic systems, lawn care products and yard and animal wastes, are compounds that stimulate plant growth such as nitrogen and phosphorus but in levels can become detrimental to the ecosystem. ${ }^{3}$ Nitrogen and phosphorus are the two most important nutrients affecting the productivity of aquatic systems and both typically originate from natural sources but can also be introduced to the waterway by sewage effluents, industrial discharges, and agricultural and urban runoff. ${ }^{4}$ They can occur in various species and have different implications for toxicity or eutrophication where some forms of nitrogen are toxic to fish and other forms of nitrogen and phosphorus can contribute to eutrophication. ${ }^{5}$ Eutrophication of water from nutrient loading in stormwater may cause an increase in aquatic macrophytes and algal biomass towards blue-green algae as well as a reduction in food supplies, water

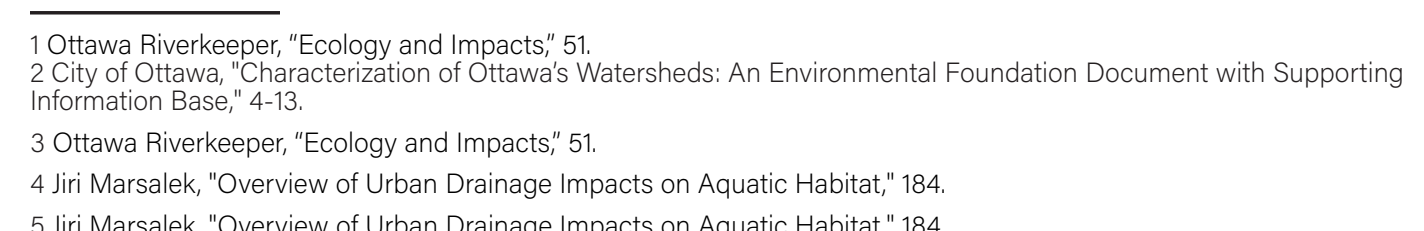


clarity and dissolved oxygen. ${ }^{6}$ Phosphorus in high quantities can lead to excessive growth of aquatic plants, the creation of unsightly mats of algae, and the depletion of oxygen which limits the ability of fish to survive.

Finally, other contaminants including toxins such as heavy metals, pesticides, oil and grease from roadways and organic compounds like PCBs are substances that can harm aquatic or human life and tend to bioaccumulate. ${ }^{8}$ Of particular note ${ }_{\text {" }}$ suspended solids comprise both inorganic and organic particulates kept in suspension by the turbidity of the water and achieve high concentrations in urban areas suffering from soil erosion. ${ }^{9}$ Suspended solids can cause numerous direct and indirect environmental impacts caused by large single precipitation events or long-term impacts including reduced sunlight penetration, physical abrasion of gills and other sensitive tissues, grinding or dislodgement of algae, damage of aquatic vertebrates and invertebrates, blanketing of waterbed substrates where fish spawn and food sources live, reduced access to microhabitats, reduced density of benthic vertebrates, and transport of various pollutants. ${ }^{10}$ Alternatively, dissolved oxygen (DO) is important for aquatic life and plants, the capacity for water to take in waste and the processes at the sediment/ water interface." Levels of DO are generally high unless there are large quantities of organic debris, discharges of sewage effluents or high ambient temperatures whereas low levels of DO typically occur in shallow streams or stormwater ponds in summer months when water temperature increases and organics are rapidly decomposed or in the winter months when the water is covered with ice.12

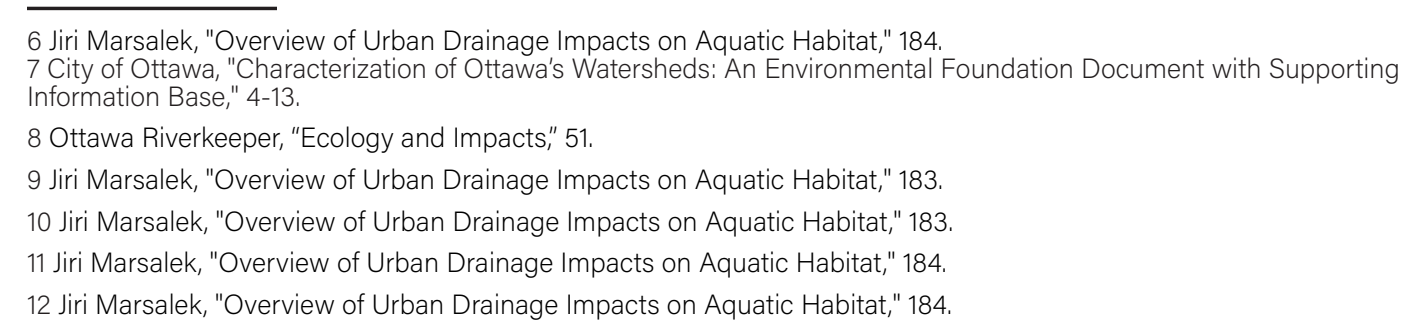

Urban areas can specifically cause issues related to elevated concentrations of ammonia, chlorides, heavy metals, and trace organic contaminants..$^{13}$ Acid rain is also common in urban areas with concrete structures contributing to rainwater buffering creating neutral $\mathrm{pH}$ runoff, whereas low $\mathrm{pH}$ from snowmelt and salt presence may increase the mobility of heavy metals and high $\mathrm{pH}$ levels, originating from pollution may also impact fish. ${ }^{14}$ Sources of waste heat such as impervious surfaces in urban areas can increase the temperature of surface runoff, particularly in the summer months, which can lead to reduced dissolved oxygen, increased rates of organic decomposition, and oxygen deficiency. ${ }^{15}$ This urban runoff, carrying POPs, pesticides, EDS, pathogens and microorganisms from various urban sources directly to the waterway, contributes to eutrophication and acidification of the receiving waters.$^{16}$ These examples all outline the various mechanisms in which waterways can become contaminated by both stormwater and wastewater

In order to treat contaminated water, several natural removal mechanisms can be employed. Within natural systems, attached and suspended growth work to remove soluble organic compounds which are then degraded biologically both aerobically with dissolved oxygen as well as anaerobically without dissolved oxygen.17 The key processes for heavy metal removal take place near plant roots in the surrounding sediment where particulate metals may be absorbed by hydrous and manganese oxides on the surface of soil particles and organic matter and dissolved metals can react to form hydrated compounds called metal complexes. ${ }^{18}$ Metals can also be removed through

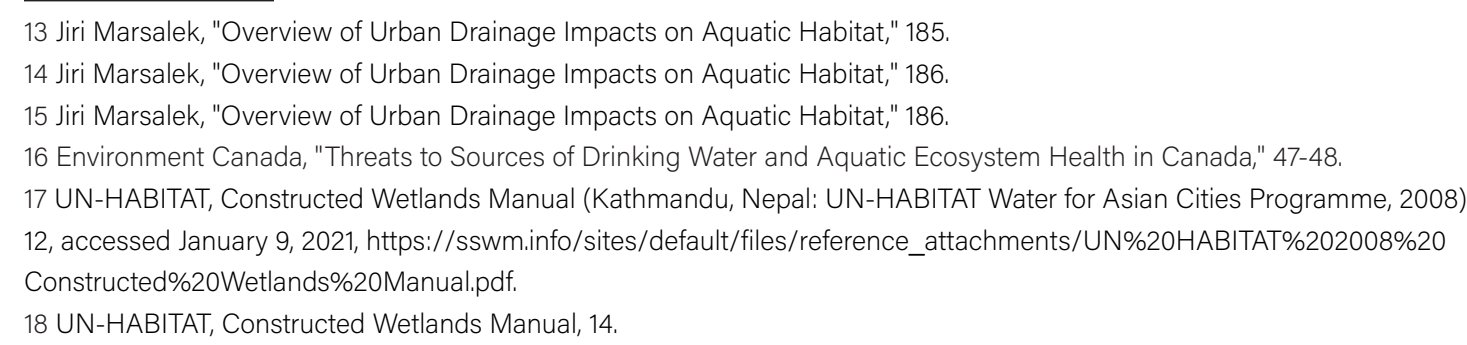


sedimentation, filtration, absorption, complexation, precipitation, cation exchange, plant uptake and microbially-mediated reactions such as oxidation..$^{19}$ Organic matter is broken down by microorganisms present in the wetland, fermentation and is settled by gravity and mineralized as a source of energy or assimilated into biomass. ${ }^{20}$ Nitrogen is removed through volatilization, ammonification, nitrification/denitrification, plant uptake and matrix absorption. ${ }^{21}$ Similarly to nitrogen, phosphorus is an essential nutrient for growth of plants and organisms and plants will store phosphorus during the growing season and release it later. ${ }^{22}$ The metabolism of xenobiotics in plants takes place in three phases that are transformation, conjugation and compartmentation. ${ }^{23}$ Pathogens and other microorganisms are trapped in the system by filtration, sedimentation and adsorption resulting in more than $90 \%$ of the coliforms and more than $80 \%$ of the fecal streptococci typically eliminated. ${ }^{24}$

In ecological water treatment systems, plants are employed to promote many of these removal mechanisms. Plants form an integral part of nutrient cycling which varies by season, location and other environmental and ecological factors. ${ }^{25}$ The roots of these plants perform many functions including plant uptake of nutrients, filtering, flow velocity reduction, improved sedimentation, decreased resuspension, and even the distribution of water and clogging prevention, but most importantly they provide

19 UN-HABITAT, Constructed Wetlands Manual, 13

20 Golda A. Edwin and G. Poyyamoli, M. Nandhivarman, Ramaswamy Arun Prasath, Dwipen Boruah, "Constructed Wettands for the Treatment of Grey Water in Campus Premises," 34

21 UN-HABTA, Constructed Wellands Manual, 3.

aswamy Arun Prasath, Dwipen Boruah, "Constructed Wetlands for

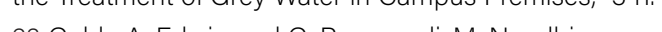

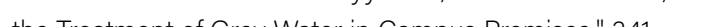

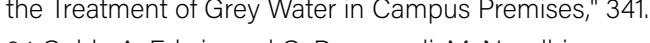

aswamy Arun Prasath, Dwipen Boruah, "Constructed Wetlands for

25 Golda A. Edwin and G. Poyyamoli. M. Nandhivarman . Ror The Treatment of Grey Water in Compus Premises" 340-34 surface area for the growth of microorganisms that process the water. ${ }^{26}$ The roots also function to release gases and exudates such as antibiotics, carbon, and oxygen, which enhance microbial activity, oxidize some phytotoxins, improve nutrient degradation and heavy metal sedimentation and increase denitrification. ${ }^{27}$ Plants themselves serve to help the treatment process by absorbing nutrients such as nitrogen and phosphorus or phytotoxins such as heavy metals through plant uptake. ${ }^{28}$ Additionally, plants affect the microclimatic conditions of the system by providing shading which protects against algal growth, insulation from radiation in the spring and frost in the winter, reduction in wind velocity and sediment stabilization. ${ }^{29}$ These outline only some of the positive functions that plants have in natural water treatment systems, whereas they can also provide other positive functions such as aesthetic appearance, elimination of pathogens, reduction of insects and offensive odors, salt phytoremediation, and bioindication as well as negative functions such as enhanced mosquito production and increased methane emission. ${ }^{30}$

Several organisms reside within these ecosystems and complement the treatment mechanisms promoted by the plants by creating a complete food chain The vegetative organisms have a shared relationship with heterotrophic bacteria in the system that metabolize bioavailable organic matter in the water using oxygen and carbon dioxide that is released by the plants through photosynthesis. ${ }^{31}$ The bacteria converts the organic matter in waste to carbon dioxide and methane and converts

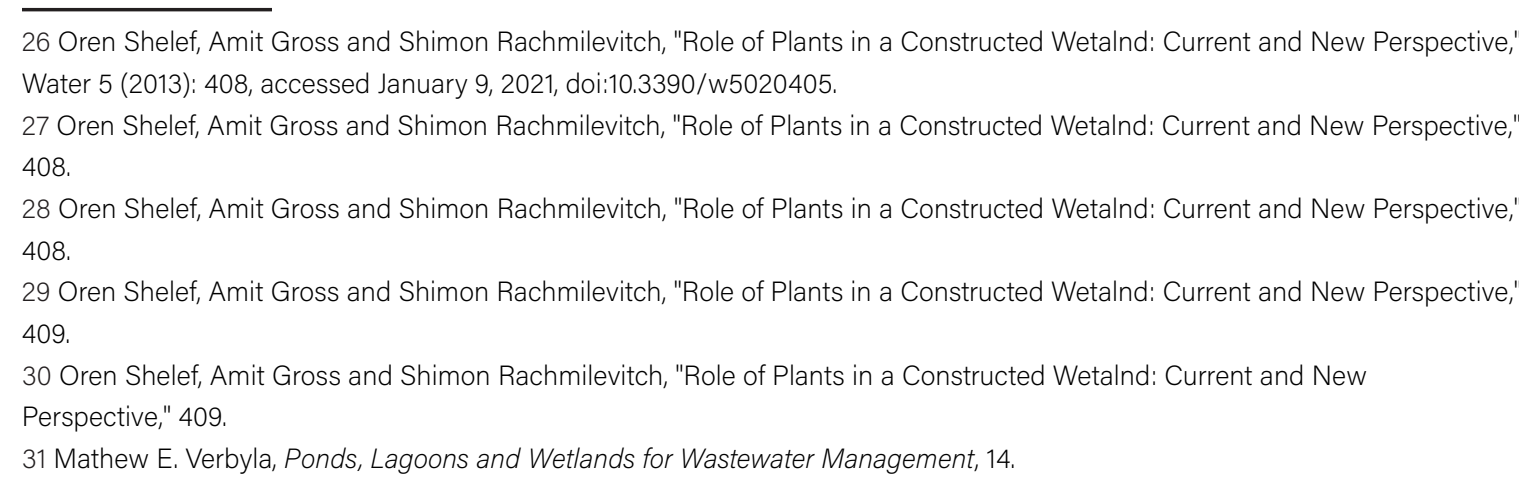


proteins and organic nitrogen to ammonia, nitrate, and nitrogen gas. ${ }^{32}$ Scrapers feed on algae attached to submerged objects while shredders feed on the remains of macrophytes and large organic matter, producing finer particles that become a food source for gatherers, collectors, and filterers. ${ }^{33}$ Predators are atop the food chain and feed on these organisms. ${ }^{34}$ Many fungi are also well-adapted to degrading biomass with complex organic compounds such as dead leaves or wood and typically grow at slower rates than bacteria but are able to withstand lower $\mathrm{pH}$ levels and can play an important role in cycling nitrogen and removing E. coli, ${ }^{35}$ Ciliated protozoa in the system feed on potentially harmful bacteria and can be used as bioindicators of treatment efficiency since their presence is associated with better treatment efficiency for coliforms, inorganic nitrogen and phosphorus. ${ }^{36}$ Lastly, free-living helminths (worms) originating from human or animal waste can also be found in natural water treatment systems and especially those used to treat domestic and agricultural wastewater.",3 Together with plants, this compex network of organisms outline the ways in which natural systems that can be employed to remove contaminants and produce cleaner water and healthier ecosystems.

32 Daniel Schneider, Hybrid Nature: Sewage Treatments and the Contradictions of the Industrial Ecosystem, XV 33 Mathew E. Verbyla, Ponds, Lagoons and Wettlands for Wastewater Management, 18. 35 Mathew E Verbyla Ponds, Lagoons and Wettands for Wastewater Management 17 36 Mathew E Verbyla, Ponds, Lagoons and Wettands for Wastewater Management 14 37 Mathew E Verbyla Ponds Lagoons and Wettands for Wastewater Management 78
APPENDIX 3: LIVING MACHINE TECHNOLOGY

Within the typical Living Machine, each component serves a specific purpose within the series. The anaerobic reactor acts as the initial step of the process and functions similarly to a septic tank, using an oxygen-absent atmosphere to decompose organic matter and reduce the biochemical oxygen demand (BOD) and suspended solids before further treatment? After preliminary treatment, raw influent enters the reactor and passes through an initial sludge blanket zone then to a second clarification zone with strips of mesh that help to trap and settle solids while also providing surface area for colonization of anaerobic bacteria that digests the solids. ${ }^{2}$ The settled sludge is periodically removed and sent for biosolids treatment while the gases produced are passed through an active carbon filter or biofilter for odor control. ${ }^{3}$ Next in the process is the anoxic reactor which is mixed and has controlled aeration to prevent anaerobic conditions and promote floc-forming and denitrifying microorganisms that reduce the $B O D{ }^{4}$ The reactor is covered with a planted biofilter for odor control and can contain an attached growth medium to promote the dense growth of bacteria and microorganisms. ${ }^{5}$ Additionally, settled biosolids from the clarifier and nitrified process water from the final open aerobic reactor are typically recycled back into the anoxic reactor to support denitrification without the use of additional chemicals such as methanol. ${ }^{6}$ The closed aerobic reactor uses aeration and mixing to continue to reduce the BOD, remove odorous gases, and stimulate nitrification. ${ }^{7}$ Odor is again controlled using a planted biofilter sitting atop the reactor. ${ }^{8}$ The open aerobic reactors are aerated 1 United States Environmental Protection Agency, Wastewater Technology Fact Sheet: The Living Machine, 2.
2 United States Environmental Protection Agency, Wastewater Technology Fact Sheet: The Living Machine, 2.
3 United States Environmental Protection Agency, Wastewater Technology Fact Sheet: The Living Machine, , 2.
4 United States Environmental Protection Agency, Wastewater Technology Fact Sheet: The Living Machine, 2-3.
5 United States Environmental Protection A Agency, Wastewater Technology Fact Sheet: The Living Machine, 2-3.
6 United States Environmental Protection Agenny, Wastewater Technology Fact Sheet: The Living Machine, 3.
7 United States Environmental Protection Agency, Wastewater Technology Fact Sheet: The Living Machine, 3.
8 United States Environmental Protection Agency, Wastewater Technology Fact Sheet: The Living Machine, 3. 
tanks that function similarly to closed aerobic reactor except that, instead of being covered with a biofilter, they are covered with vegetation in racks, which provide surface area for microbial growth, perform plant uptake and serve as a habitat for beneficial insects and microorganisms. ${ }^{9}$ The mechanical aeration provides mixing to reduce odor and a greater concentration of dissolved oxygen supporting the heterotrophic and ammonifying bacteria which improves efficiency. ${ }^{10} \mathrm{~A}$ number of these reactors are set in a series depending on the influent characteristics and effluent requirements and function to reduce the BOD to better than secondary treatment levels and complete the nitrification process." The clarifier is a settling tank that separates the remaining solids from the treated wastewater which are then recycled back to the closed aerobic reactor or collected for biosolid treatment.12 The ecological fluidized beds (EFBs) are polishing filters consisting of an aerated inner tank with attached growth medium and outer tank for sludge collection that are arranged in a series and perform the final treatment to reduce BOD, total suspended solids and nutrients to meet final effluent requirements. ${ }^{13}$ Using this arrangement, conventional Living Machines are typically constructed to accommodate 40,000-80,000 gallons of wastewater per day but can have a capacity up to 120,000 gallons per day or more.14 Therefore, the typical Living Machine principles offer a wide range of possibilities when considering effective ecological water treatment.

As an alternative, the Organica Food Chain Reactor system employs fixed-bed biofilm activated sludge using natural and engineered root structures to provide ample surface area for the growth of robust and diverse biomass that can handle highe 9 United States Environmental Protection Agency, Wastewater Technology Fact Sheet: The Living Machine, 3.

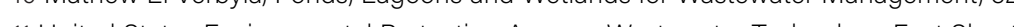

12

13 United States Environmental Protection Agency Wastewater Technology Fact Sheet: The Living Machine, 3

14 Fenton, Kellie, "Innovative Waste Water Strategies in the Landscape: The Application of Green Infrastructure Principles in Cape Cod, Massachusetts," 27. fluctuations in influent quality and quantity compared to conventional suspended or attached growth systems.15 In fact, the combined use of natural plant roots and engineered biofiber media generates 2-4 times greater volume of active biomass per cubic meter and 3-4 times greater species diversity when compared to conventional systems. ${ }^{16}$ All housed within an odorless facility, the lack of suspended biomass and use of biofilm that is attached to either the natural or engineered media allows for better space efficiency in treating higher quantities of influent and allows for effluent to be fed through a disc filtration rather than a secondary phase separation mechanism. ${ }^{17}$ As a result of the use of fixed-film biomass, the system contains very low amounts of suspended solids that, combined with the highly efficient oxygen transfer supply from loose biofilm on the plants, produces cleaner water throughout the system and requires less aeration than conventional systems. ${ }^{18}$ This outlines the possible advantages of adapting Living Machine principles to achieve more efficient treatment without sacrifising the ecosystem benefits of the system.

Should tertiary treatment be necessary for any Living Machine system, one option is to employ a microwave/electrodeless ultraviolet/ozone (MV/UV/O3) system to deeply treat bioreactor outflow to meet the requirements for campus water reclamation and even potable use..$^{19}$ Using this system with operating conditions of $450 \mathrm{~W}$ microwave power and two electrodeless UV lamps, the removal efficiency of bacteria, color, and odor in effluent water can reach over $99 \%$ and meet requirements for miscellaneous water reuse. ${ }^{20}$ Alternatively, the application of membrane bioreactors

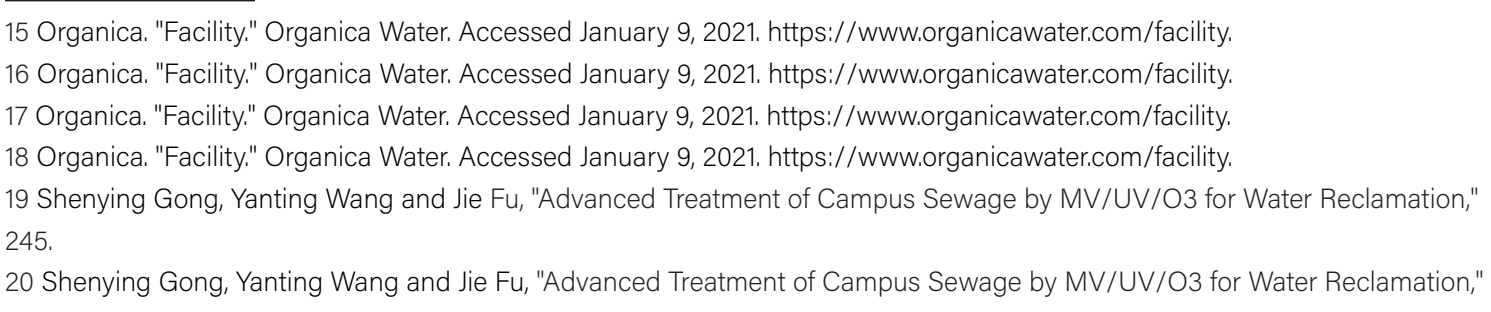


(MBRs) that combine biological treatment processes and biomass retention using microfiltration (MF) or ultrafiltration (UF) membranes can be used to remove suspended solids, organic matter, and disinfect the water to produce a high quality effluent with various possible uses. ${ }^{21}$ If tertiary treatment is employed, water can be used for higher standard applications and can even be made potable in certain instances systems.

21 Thomas Wintgens, Thomas Melin, Davide Bixio and Chris Thoeye, "Integrated Concepts for Reuse of Upgraded Wastewater: Role of Membranes in Water Recycling," "in Integrated Urban Water Resource Management, edited by Petr January 9,2021 . Wharchyk, Jiri Marsalek and Ivana Mahrikova (Dortrecht, Netherlands: Springer, 2006), 206-207, accessed $01 / 1 / 1402046855$ tpage $=7$.
Wetland plants have adapted to prolonged saturation by transferring oxygen from the atmosphere to the rooting zone which enables both aerobic and anaerobic microbial degradation processes in wetland sediment and promotes a rich diversity of bacteria.' Their submerged stems and plant matter provides significant surface area for microbial organisms to attach and form biofilms to improve microbial degradation. ${ }^{2}$ Although plants only contribute about $10 \%$ of nutrient removal, their roots provide oxygen and surface area for important water-treating bacteria to thrive. ${ }^{3}$ Also, the physical barriers formed by the plant stems promote filtration and sedimentation. Contaminants are taken up by plants while organic compounds expelled by living and decaying plants can be toxic to some microbes or bind with dissolved metals and nutrients and reduce their bioavailability. ${ }^{5}$ Additionally, the diversity of microbes in wetlands allows them to degrade a diverse range of contaminants and resist any sudden release of a large amount of a specific contaminant. ${ }^{6}$ These several functions that are supported by wetland plants can be optimized through various wetland configurations, each with their own advantages and disadvantages.

Free water (FW) systems are similar to stormwater treatment ponds and lagoons in that they contain large areas of open water but they employ larger numbers of plant life for treatment functions including submerged vegetation, emergent vegetation and floating macrophytes. ${ }^{7}$ Closely related to FW systems are Surface Flow (SF) wetlands, which closely mimic natural marshes, stormwater or wastewater flows horizontally

1 Okanagan Basin Water Board, Constructed Wetlands for Stormwater Manegement: An Okanagan Guidebook, 2-3,2-4. 20 kanagan Basin Water Board, Constructed Wetlands for Stormwater Manegement: An Okanagan Guidebook, 2-3,2-4. 3 Dr. Youbin Zheng, Siobhan Dunets and Eric Rozema, Constructed Wetlands, 5 .

40 Okanagan Basin Water Board Constructed Wetlands for Stormwater Manegement. An Okanagan Guidebook, 2-32-4 50 kanaga Basin Water Bord Constructed Wettands for Stormwater Manegement. An Okanagan Guidebook 232.4 6 Okanagan Basin Water Board, Constructed Wetlands for Stormwater Manegement: An Okanagan Guidebook 23,2-4 7 Mathew E. Verbyla, Ponds, Lagoons and Wetlands for Wastewater Management, 62. 
across the wetland surface with a low gradient at a depth typically between 0.3 and $0.7 \mathrm{~m} .{ }^{8} \mathrm{SF}$ wetlands are usually narrow in order to achieve a consistent flow velocity that maximizes contact with the plants and biofilms. ${ }^{9}$ Water can be discharged through an outlet device such as a simple weir or an engineered structure that controls water level and flow.10 Overall, these systems are effective at removing organic material through microbial degradation and settling, inorganic materials through settling, nitrogen through denitrification and ammonia volatilization, but are unable to effectively remove phosphorus."

In Subsurface Flow (SSF) wetlands, water flows beneath the surface through a growing media penetrated with plants growing on the surface and saturated to a depth of a few centimeters below the surface.12 Large numbers of microbes can attach to the porous growth media and the penetrating roots disperse oxygen through the subsurface but inlet and outlet engineering is required to ensure the desired flow rate through the growth media.13 Subsurface Flow systems are differentiated by the direction that water flows through them, being horizontal or vertical. In horizontal flow (HF) systems, water enters through an inlet and flows horizontally through the substrate exiting through an outlet on the other side of the cell. ${ }^{14}$ These systems effectively remove organic material and suspended solids through anaerobic microbial processes and sedimentation but are only partially effective at removing nitrogen via denitrification and phosphorus via ligand exchange reactions..$^{15}$ In vertical flow (VF) systems, water is dispersed over

8 Okanagan Basin Water Board, Constructed Wetlands for Stormwater Manegement: An Okanagan Guidebook, 2-4 9 Okanagan Basin Water Board, Constructed Wetlands for Stormwater Manegement: An Okanagan Guidebook, 2-4, 11 Dr. Youbin Zheng, Siobhan Dunets and Eric Rozema, Constructed Wetlands (School of Environmental Sciences, University of Guelph: Greenhouse and Nursery Water Treatment Information System), 2, accessed January 9, 2021, http://www.ces.uoguelph. ca/water/NCR/ConstructedWetlands.pdf.

12 Okanagan Basin Water Board, Constructed Wetlands for Stormwater Manegement: An Okanagan Guidebook, 2-4

13 Okanagan Basin Water Board Constructed Wettands for Stormwater Manegement: An Okanagan Guidebook, 24

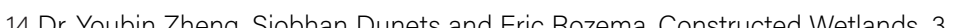

the surface of the wetland through piping and percolates downward through the substrate media where it is collected at the bottom of each cell and pumped to the next one.16 Even though phosphorus treatment is still low, vertical mechanics create more oxygen rich (aerobic) conditions that make them effective for the treatment of nitrogen (ammonia and nitrate), organic matter and suspended solids. ${ }^{17}$ The various configurations for constructed wetlands offer different possibilities when considering influent quality, desired effluent quality, cost, space and more.

When considering maintenance operations for constructed wetlands, both preventative and corrective measures should be undertaken. ${ }^{18}$ Preventative maintenance constitutes the general upkeep of the constructed wetland and its supporting infrastructure and includes inspections, organic clean-out and collection, sediment removal, monitoring, and record-keeping, whereas corrective maintenance constitutes tasks that arise from unforeseen events or equipment failure.19 Within the first 3 years of operation, bi-annual inspections should be performed to record the types and distribution of the dominant wetland species, the presence and distribution of planted wetland species, the presence and distribution of invasive wetland species, indications that other species are replacing the planted wetland species, percentage of standing water that is unvegetated, the maximum elevation and vegetative condition in this zone, if the design elevation of the normal pool is being maintained, the stability of the original depth zones and the micro-topographic features, the accumulation of sediment in the forebay and micropool, and the survival rate of plants. ${ }^{20}$ Based on these inspections, maintenance can include sediment removal, periodic mowing of embankments, removal of invasive species, replanting of native vegetation or seeding 16 Dr. Youbin Zheng, Siobhan Dunets and Eric Rozema, Constructed Wetlands, 3.

18 Okanabir Zneng, Siobhan Dun Contrected Wetands for Stormwater Manegement: An Okanagan Guidebook 8.50 19 Okanagan Basin Water Board Constructed Wetlands for Stormwater Manegement: An Okanagan Gurdebook 8.50 20 Massachussets Clean Water Toolkit. "Constructed Stormwater Wetlands" 
as required, removal of debris of debris from outlet structures. ${ }^{21}$ Wetland sediment and plants have a limited capacity to store contaminants that are not broken down into gaseous form or simple compounds like carbon dioxide or water and decomposing plants tend to partially release their stored phosphorus making the phosphorus treatment short-lived. ${ }^{22}$ Additionally, wetlands tend to act as a sink for metals and their metal levels may become toxic to the plants within the wetland or be released at undesirable levels, ${ }^{23}$ Reseeding and replanting annually in order to maintain a healthy plant community may be necessary in some instances and can help discourage weed development and invasive species. ${ }^{24}$ In some instances, should treatment be compromised by the accumulation of specific contaminants, constructed wetlands may require partial or total rejuvenation, involving the removal and replacement of wetland plants and sediment. ${ }^{25}$ After plants and sediments have been cleaned out of a constructed wetland cell, they can be processed on-site or exported to local disposing facilities for composting. ${ }^{26}$ The overall maintenance of a constructed wetland system is minimal, being that is is intended as a natural ecosystem that monitors itself. However, as has been shown, in some instancesmaintenance operations need to be employed to ensure the lasting health of the system.

21 Okanagan Basin Water Board, Constructed Wetlands for Stormwater Manegement: An Okanagan Guidebook, 6-46. 22 Okanagan Basin Water Board, Constructed Wetlands for Stormwater Manegement: An Okanagan Guidebook, 8-55. 24 Okanagan Basin Water Board, Constructed Wetlands for Stormwater Manegement: An Okanagan Guidebook, 8-55. 25 Okanagan Basin Water Board, Constructed Wetlands for Stormwater Manegement: An Okanagan Guidebook 8-54,8-55. 26 Okanagan Basin Water Board Constructed Wetlands for Stormwater Manegement: An Okanngan Guidebook 8.55

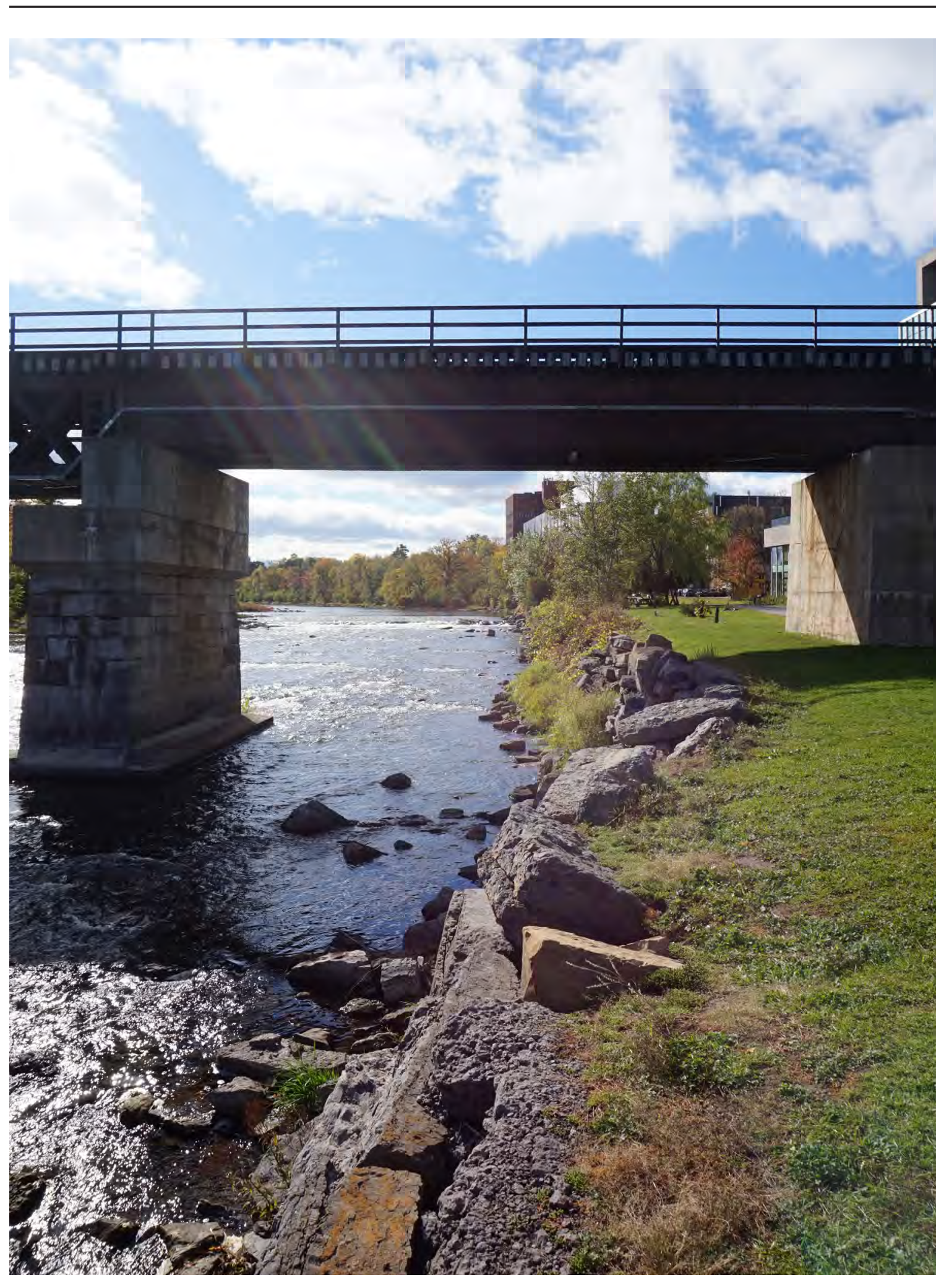



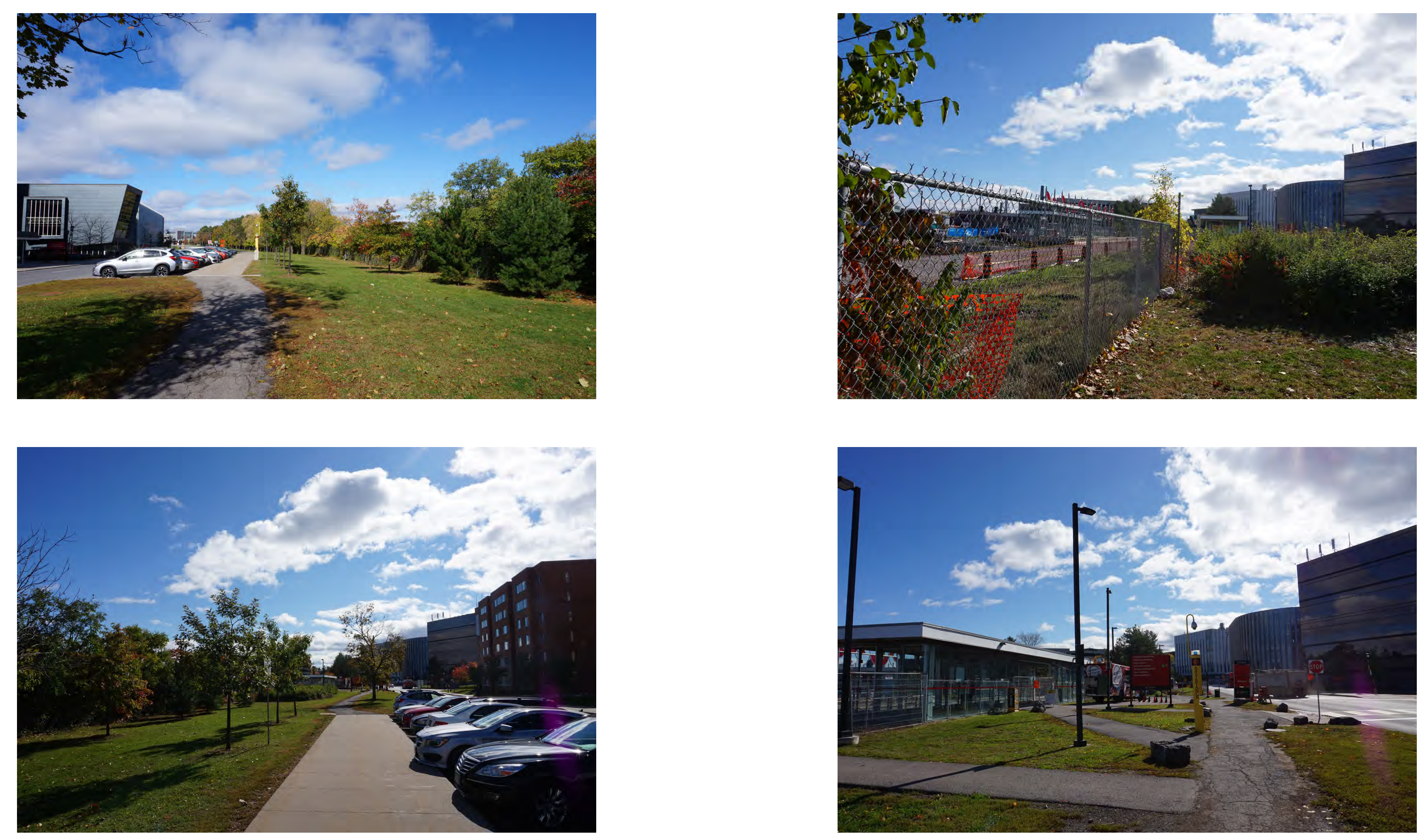

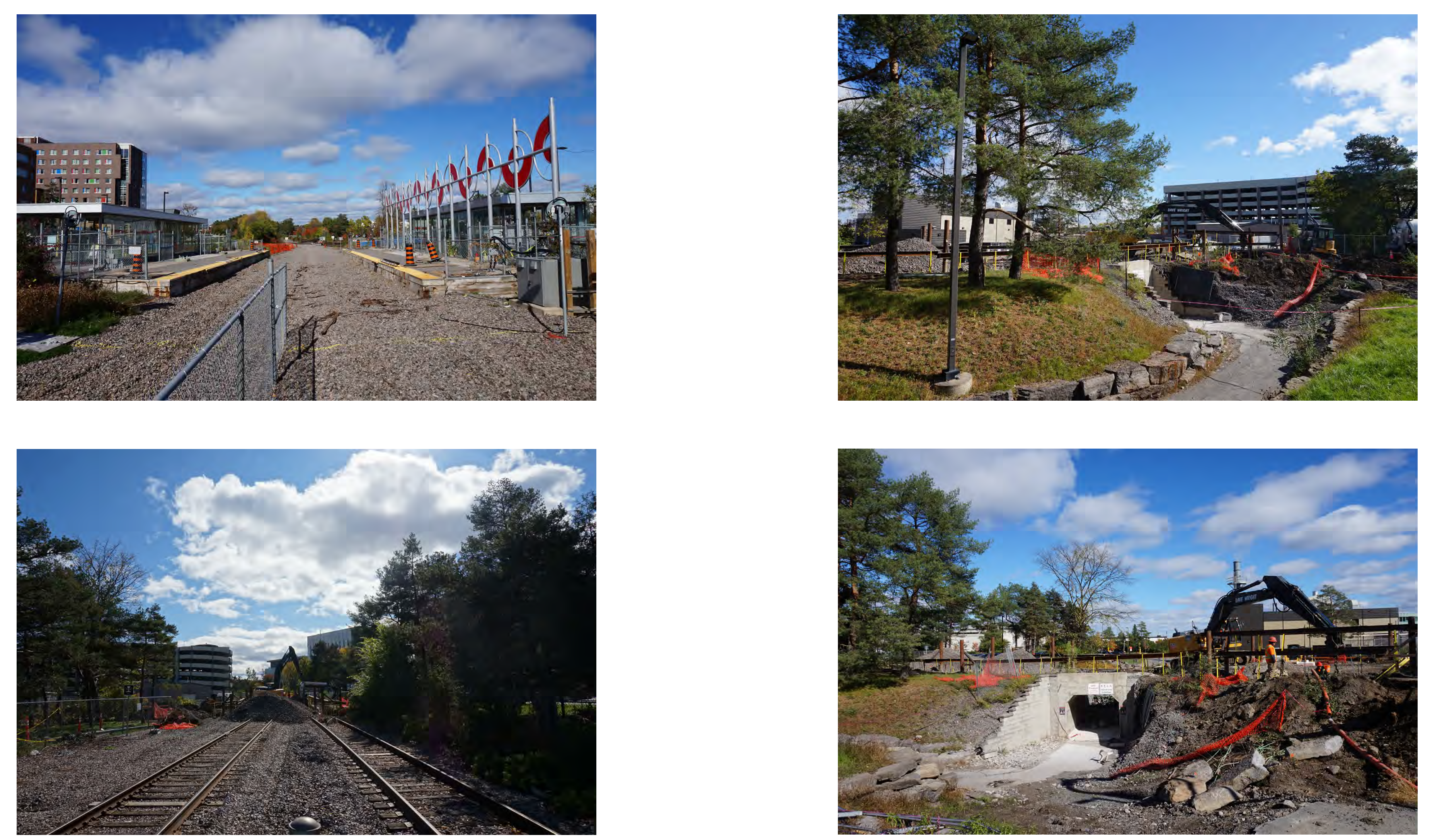

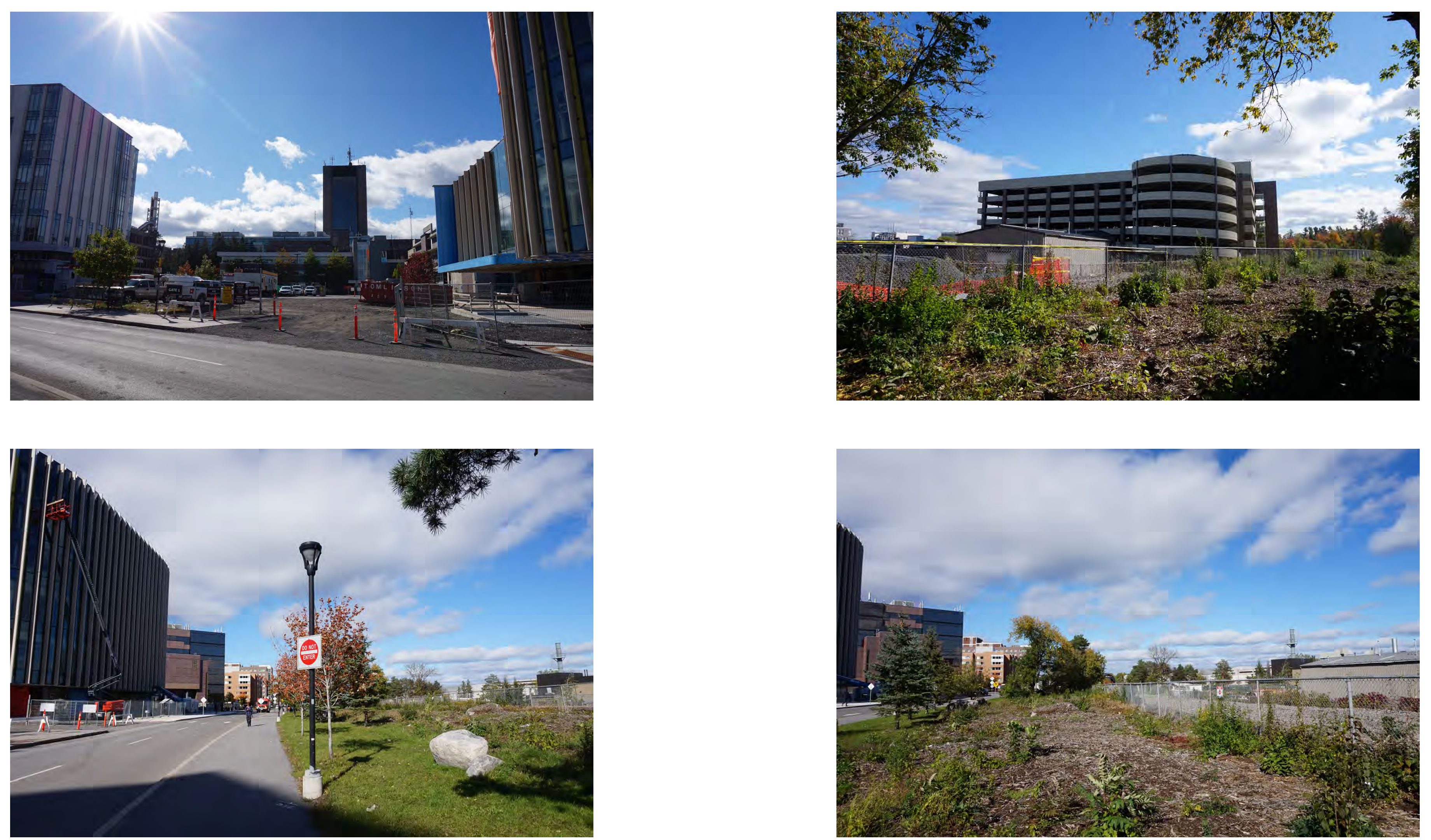

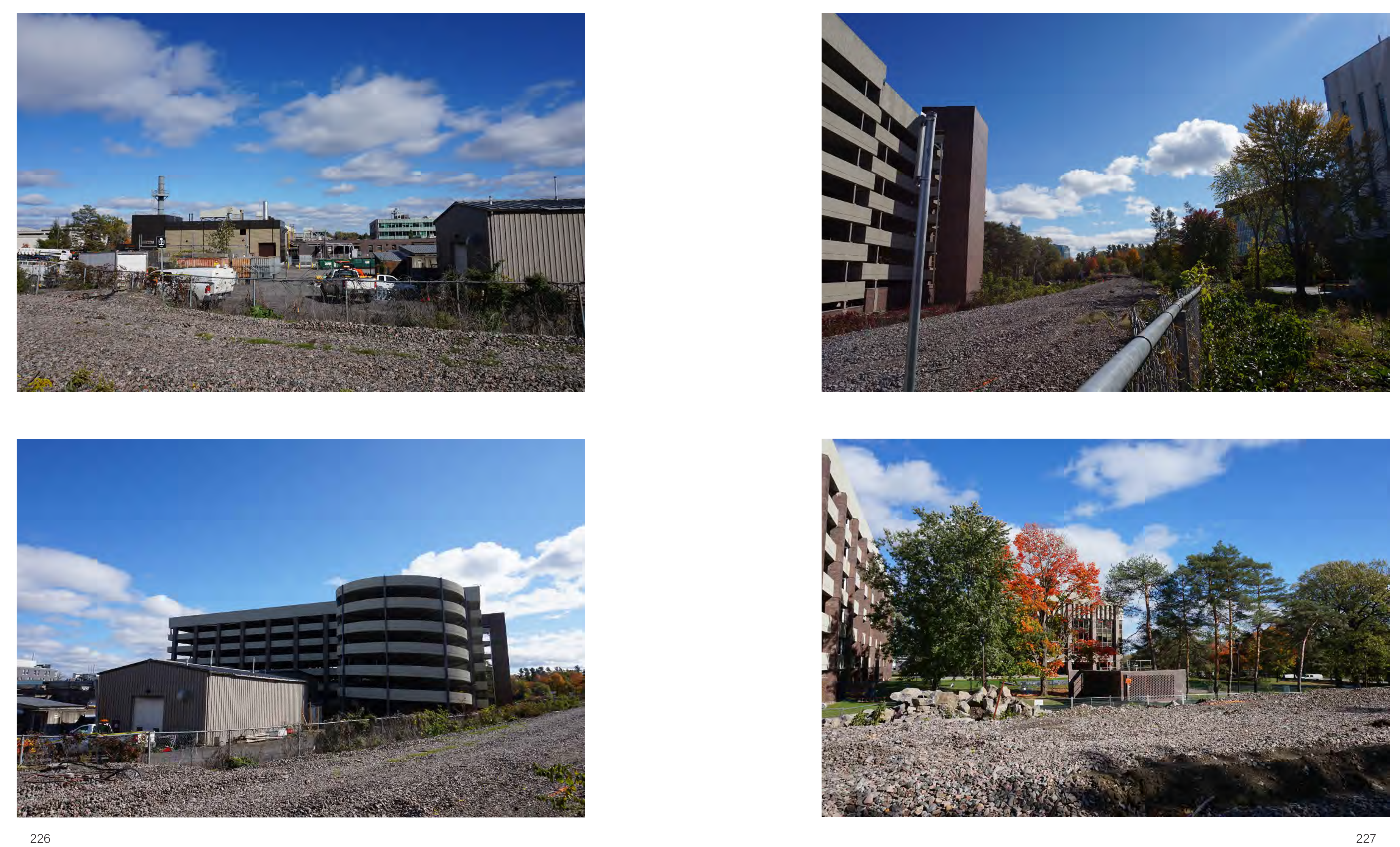

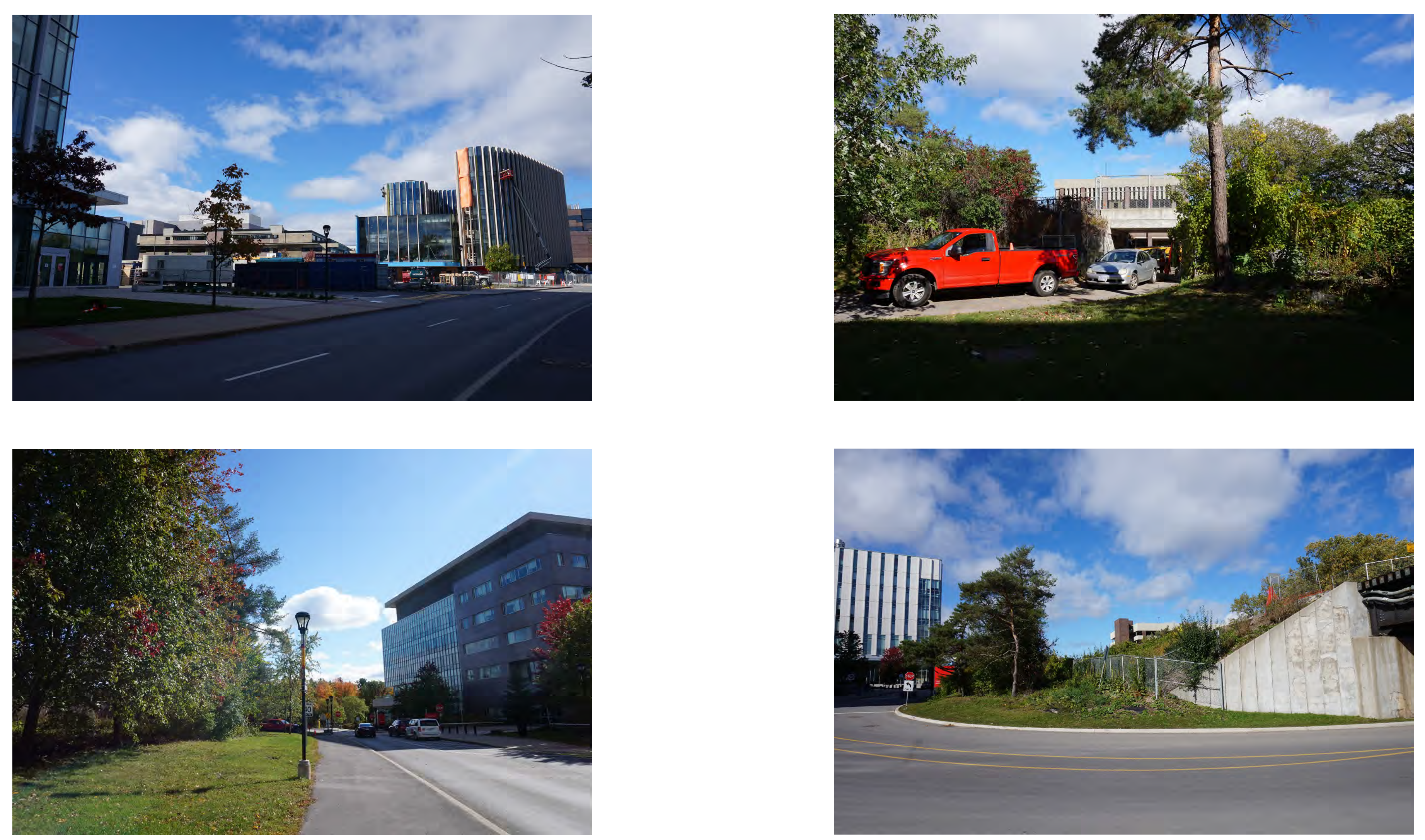

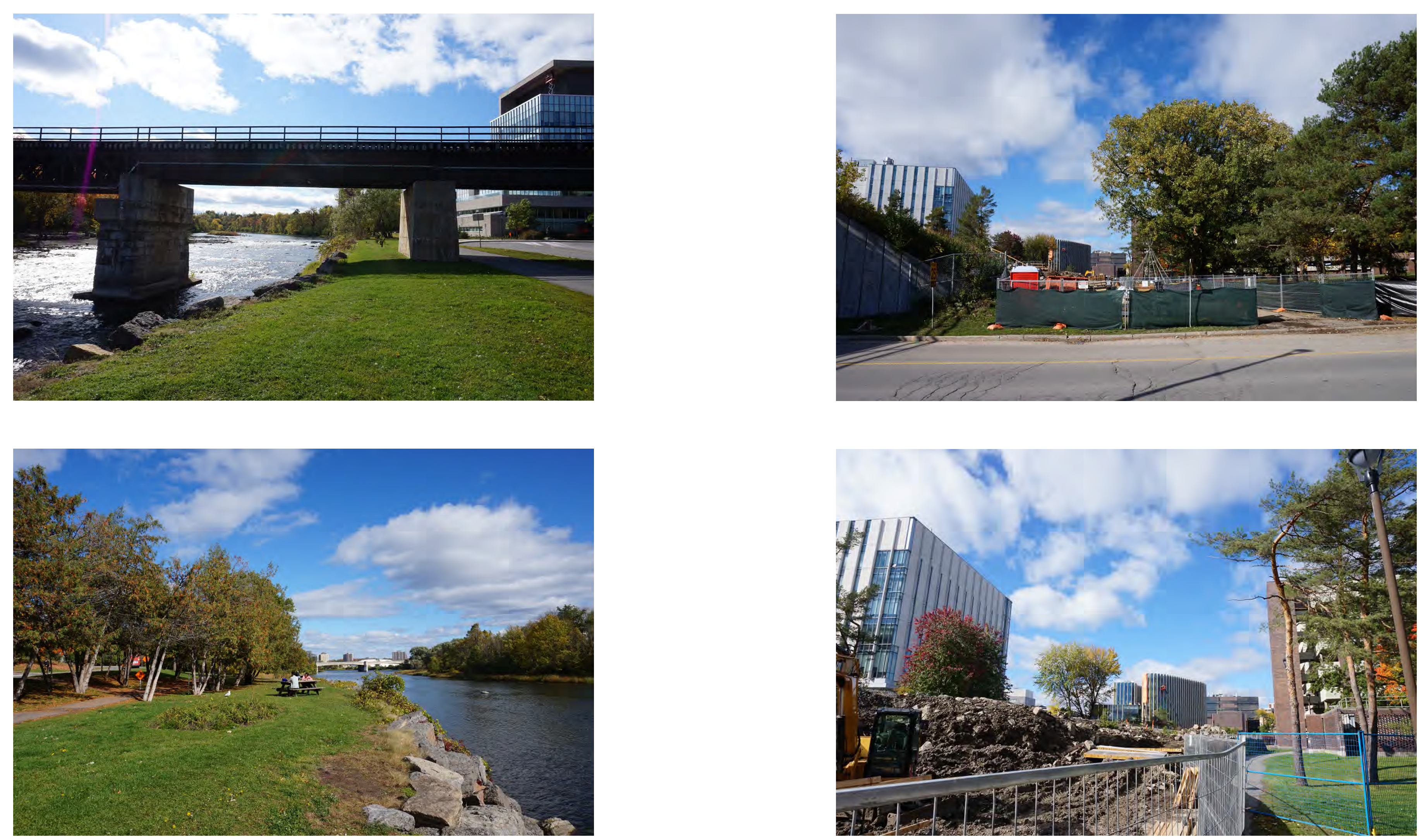

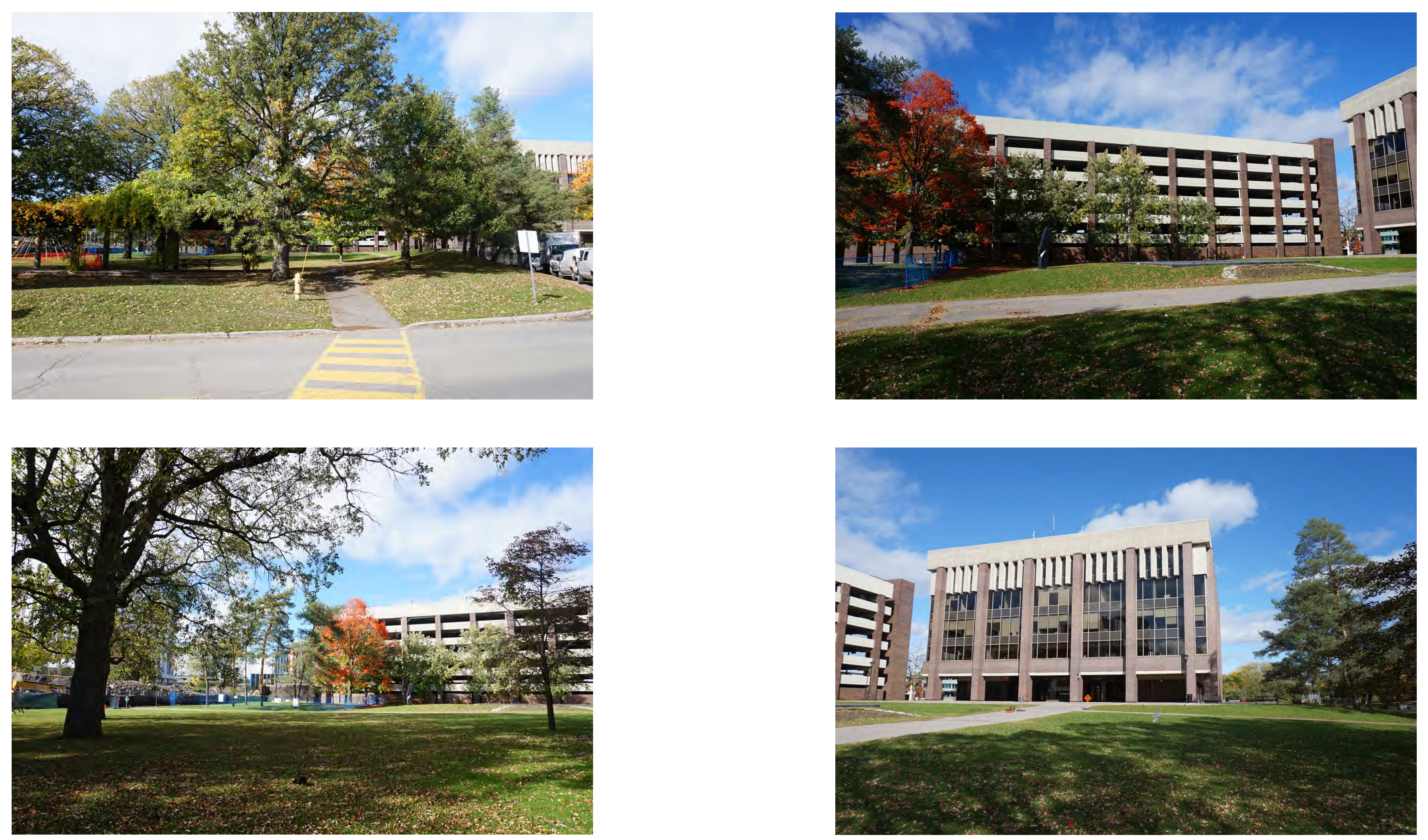

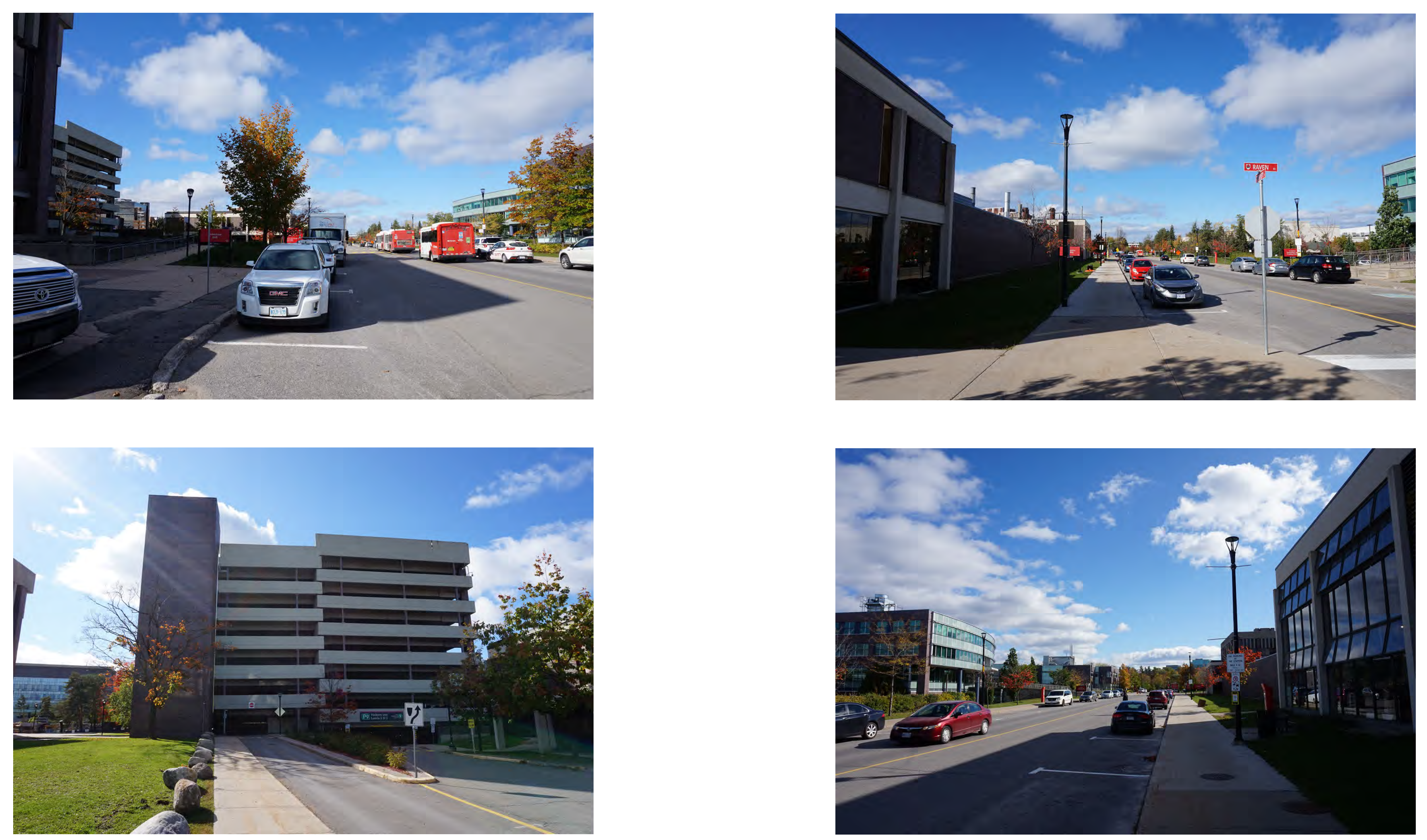

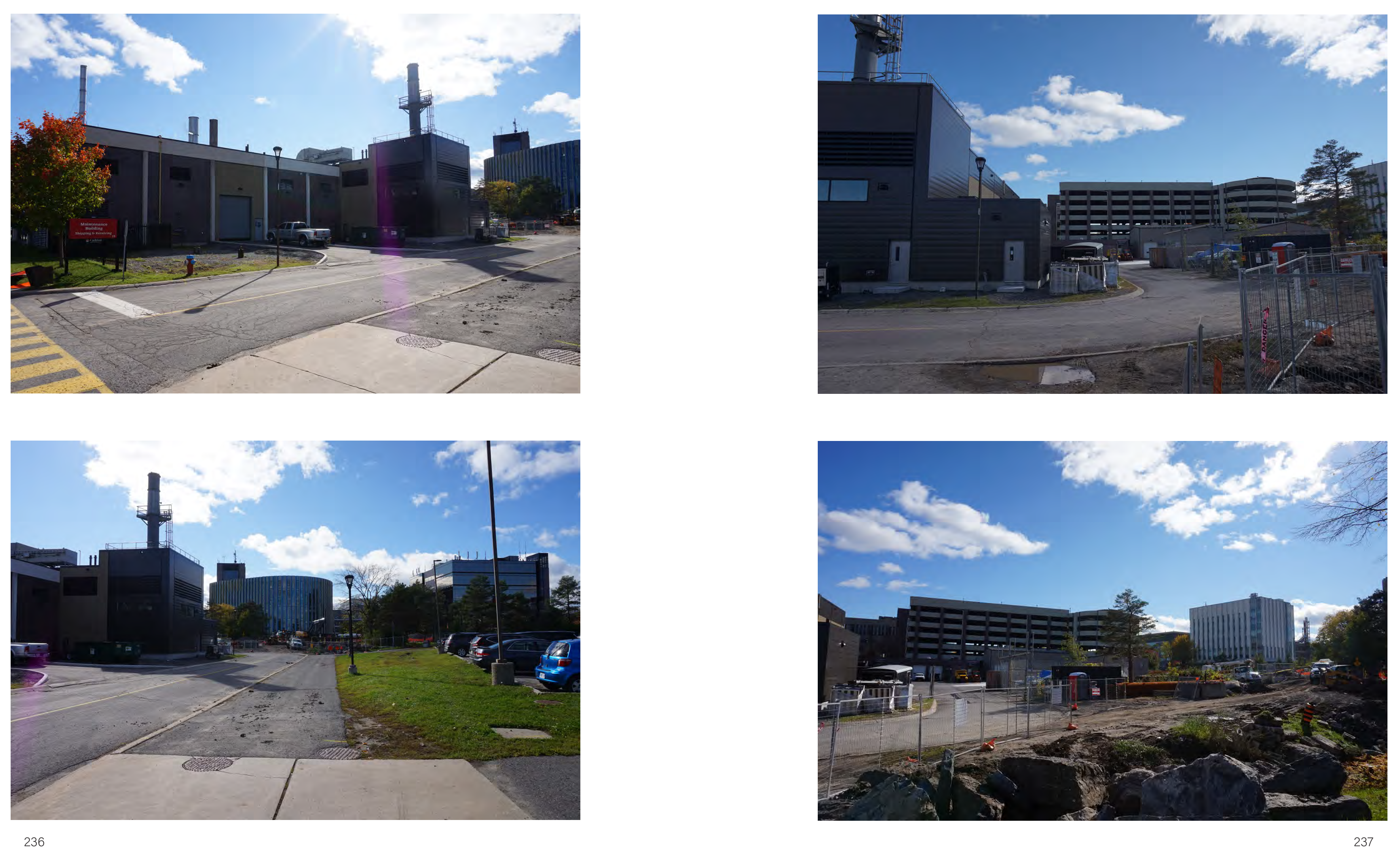

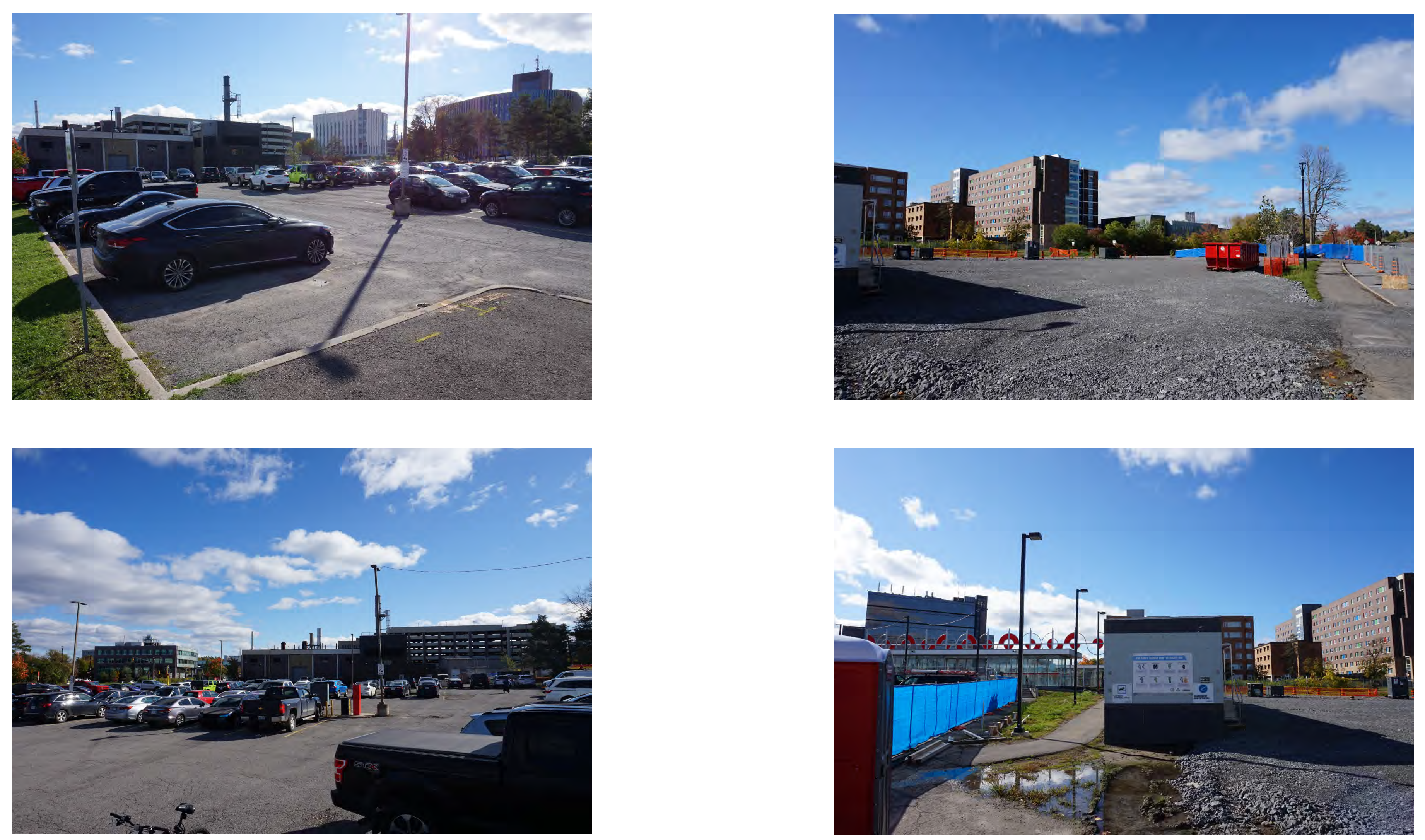

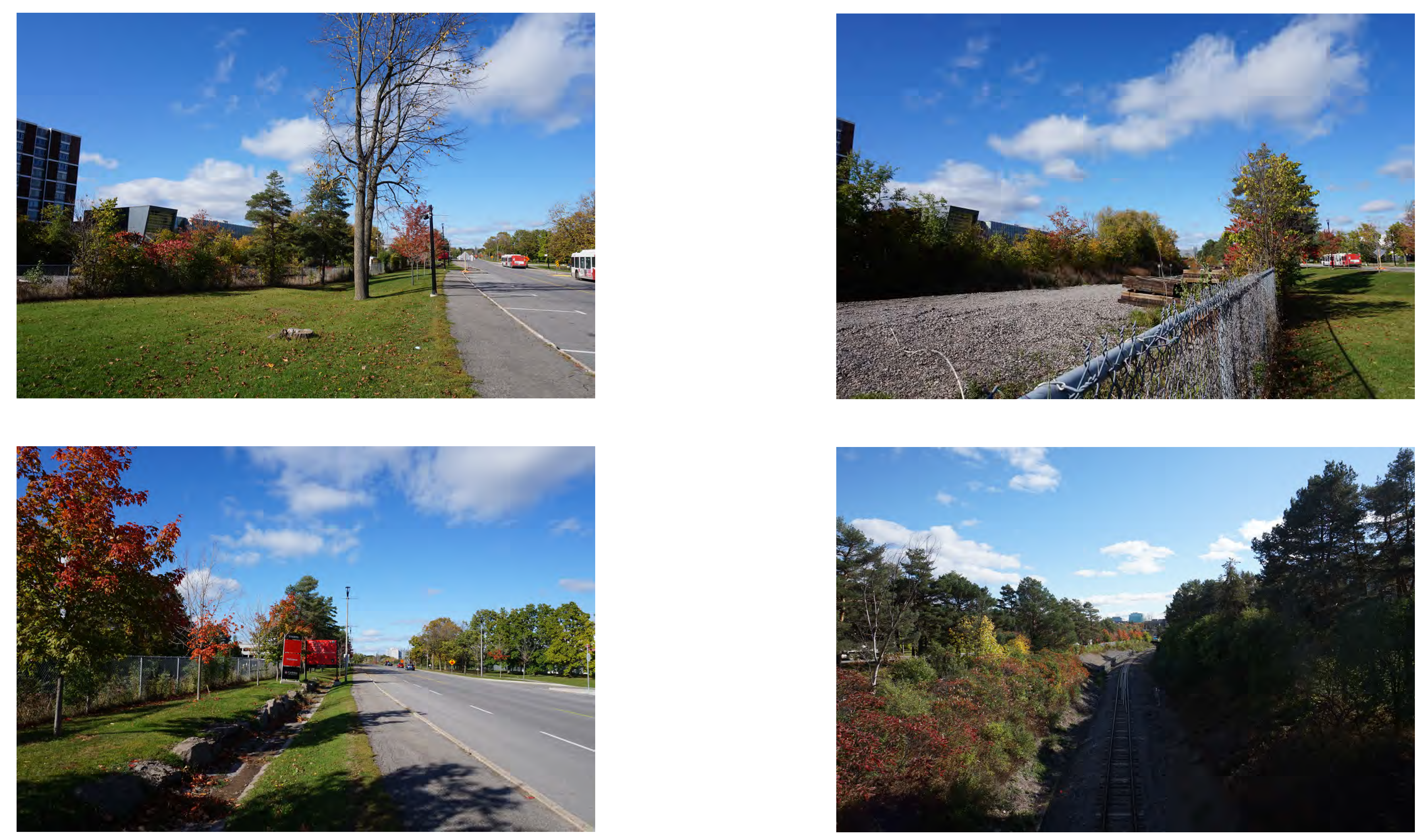


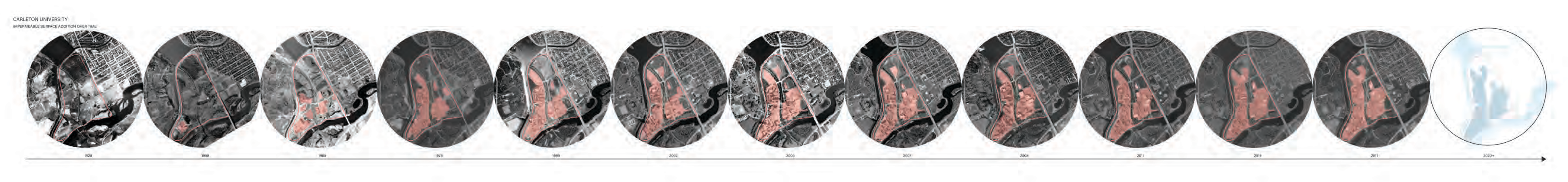




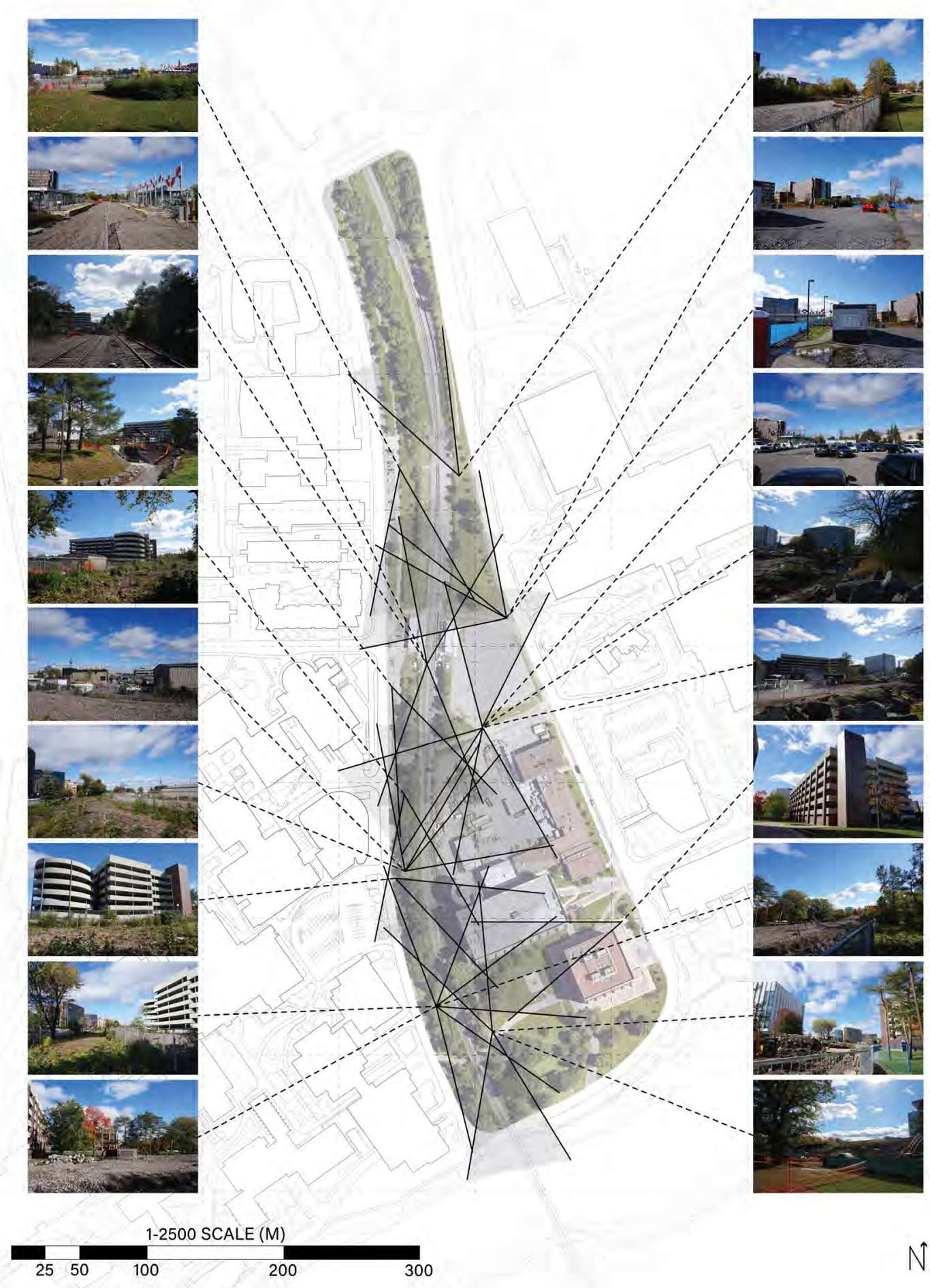

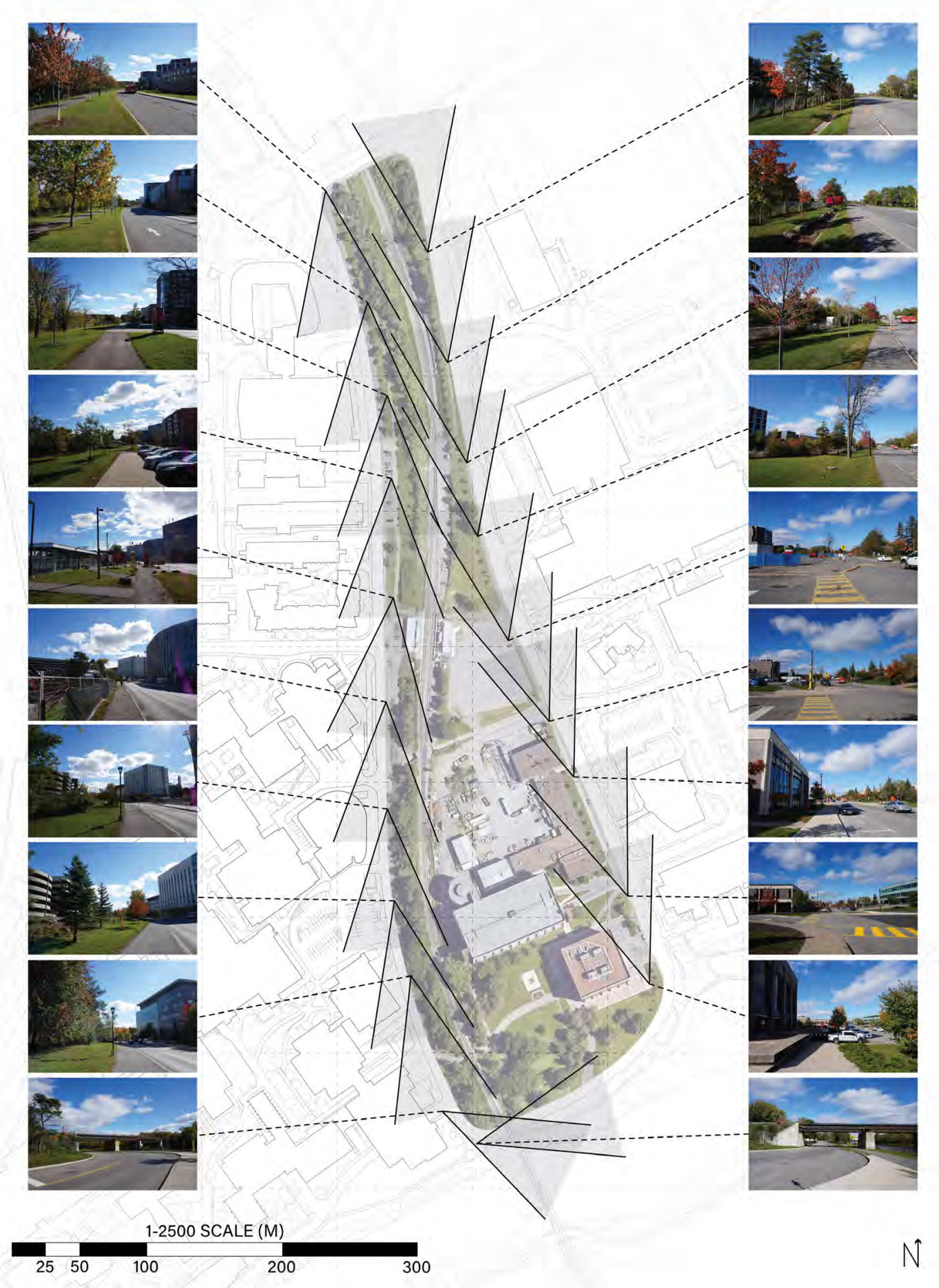

